\title{
INVESTIGATING THE DIELECTRIC PROFILING OF ICE CORES
}

\author{
D I S E R T A T I N \\ for the award of the degree \\ "Doctor rerum naturalium" (Dr.rer.nat.) \\ of the Georg-August-Universität Göttingen
}

within the doctoral programme Geosciences of the Georg-August University School of Science (GAUSS)

submitted by

Seyedhamidreza Mojtabavi

from Iran

Göttingen, 2020 


\section{Thesis Committee}

- Prof. Dr. Frank Wilhelms, Department of Crystallography, Geoscience Centre, University of Göttingen, 37073 Göttingen, Germany

- Prof. Dr. Andreas Pack, Department of Isotope Geology, University of Göttingen, 37077 Göttingen, Germany

- Dr. Daniela Jansen, Geosciences/Glaciology, Alfred-Wegener-Institut Helmholtz-Zentrum für Polar- und Meeresforschung, Bremerhaven, Germany

Members of the Examination Board:

- Reviewer: Prof. Dr. Frank Wilhelms, Department of Crystallography, Geoscience Centre, University of Göttingen, 37073 Göttingen, Germany

- Second Reviewer: Prof. Dr. Andreas Pack, Department of Isotope Geology, University of Göttingen, 37077 Göttingen, Germany

Further members of the Examination Board:

- Prof. Dr. Matthias Willbold, Department of Isotope Geology, University of Göttingen, 37077 Göttingen, Germany

- Prof. Dr. Daniela Sauer, Department of Physical Geography, Institute of Geography, University of Göttinge ,37077 Göttinge, Germany

- Prof. Dr. Martin Sauter, Department of Applied Geology, Geoscience Centre, University of Göttingen, Goldschmidtstr. 3, 37077 Göttingen, Germany 
- Dr. Daniela Jansen, Geosciences/Glaciology, Alfred-Wegener-Institut Helmholtz-Zentrum für Polar- und Meeresforschung, Bremerhaven, Germany

Day of the oral examination: November 20, 2020 


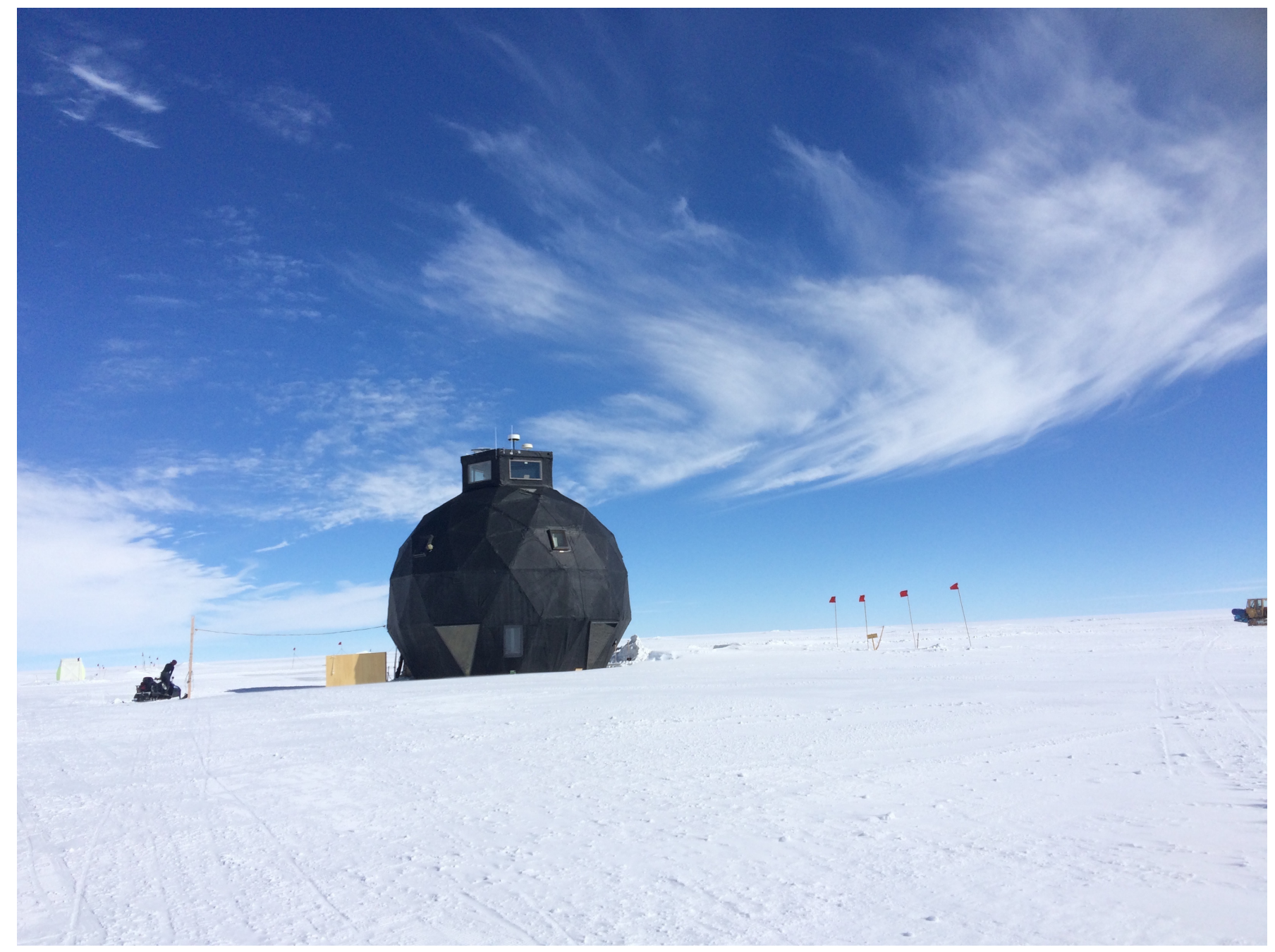




\section{ABSTRACT}

The polar regions are important components of the Earth's climate system, as these areas are the main sources of fresh water on Earth. Any conflicts in that system can affect people's lives in different ways. Numerous studies show that global air temperature has increased, and it can lead to a global sea level rise due to polar ice-sheet mass loss. An increase in sea level in polar regions not only provides evidence of climate change, but also acts as a complex feedback mechanism between the Earth system components. This feedback can be used to predict what can happen in the future at different spatial and temporal resolutions. The ice core is an important climate archive that can help us to understand past climate conditions and we can use this information to predict future climate change using Earth climate modelling. There are numerous methods to investigate information from the ice core, Dielectric Profiling (DEP) recoded along the ice core is one such methods. Dielectric Profiling (DEP) is related to the impurity content of the ice core, such as acidity, salt, and ammonia concentrations or impurities caused by a volcanic event.

In this dissertation, I focus on measuring and processing the recorded permittivity and conductivity of DEP data and then use the data in different aspects of glaciology and paleoclimatology. This study investigates different ice core data, including The East GReenland Ice-core Project (EGRIP) as a first ice core from the upper region of the North-East-Greenland Ice Stream (NEGIS), the North Greenland Eemian (NEEM) ice core with the oldest reconstructed record from a folded core, and the North Greenland Ice Core Project (NGRIP) with the oldest undisturbed record in Greenland.

This dissertation established a first chronology of the EGRIP ice core over the Holocene and late last glacial period. The depth-age relationship of an ice core plays a key role in assessing the past Earth climate system. After field measurement in Greenland and processing the data set, I rely on DEP data and electrical conductivity measurements (ECM) and tephra records for the synchronization between the EGRIP, NEEM, and NGRIP ice cores. The synchronization was mainly of volcanic events and common patterns of DEP and ECM peaks. The timescale was transferred to the EGRIP ice core from the annual-layercounted Greenland Ice Core Chronology 2005 (GICC05) timescale from the NGRIP core. This new timescale for the EGRIP is named GICC05-EGRIP-1.

Second, this dissertation investigates the internal architecture of the Greenland ice sheet by linking numerical forward modelling on the dielectric profile of ice cores and data derived from multi-channel ultra-wideband radar systems from the airborne survey. The modelling results have very good agreement with radio-echo sounding measurements. It was found that the internal reflections are mainly due to conductivity changes, and the across - flow concentrated fabric in the deeper part of drill site (e.g., EGRIP ). Also, this study provides the possibility to determine ages for the reflectors, which can be considered as isochrone, and extend the dating from the drill site regions along the radar lines over large parts of northern Greenland.

Third, this dissertation evaluates extreme climate after the massive eruption of 'Alaska's Okmok volcano and its effect on human lives. In this way, unpublished DEP data from NGRIP2 and NEEM ice have been processed for the synchronization between ice cores. This volcano was evaluated based on the DEP, ECM, volcanic tephra data, and climate proxy records in six Arctic ice cores. The Earth system model simulations indicate that temperatures in Mediterranean regions were $7^{\circ} \mathrm{C}$ below normal during the two-year period after this massive eruption. The global cooling due to that eruption affected the lives of people in the late Roman Republic in 43 and $42 \mathrm{BC}$. 



\section{Publications and Author Contributions}

This thesis is comprised of three independent studies. Individual studies are found in Chapters 2 to 4 .

Chapter 2 - A first chronology for the East GReenland Ice-core Project (EGRIP) over the Holocene and last glacial termination

Mojtabavi, S., Wilhelms, F., Cook, E., Davies, S., Sinnl, G., Skov Jensen, M., Dabl-Jensen, D., Svensson, A., Vinther, B., Kipfstubl, S., Jones, G., Karlsson, N. B., Faria, S. H., Gkinis, V., Kjer, H., Erhardt, T., Berben, S. M. P., Nisancioglu, K. H., Koldtoft, I., and Rasmussen, S.

A version of the chapter has been accepted in the peer-reviewed journal Climate of the Past (Mojtabavi et al., 2020b):

Mojtabavi, S., Wilhelms, F., Cook, E., Davies, S., Sinnl, G., Skov Jensen, M., Dabl-Jensen, D., Svensson, A., Vinther, B., Kipfstubl, S., Jones, G., Karlsson, N. B., Faria, S. H., Gkinis, V., Kjor, H., Erhardt, T., Berben, S. M. P., Nisancioglu, K. H., Koldtoft, I., and Rasmussen, S. O.: A first chronology for the East GReenland Ice-core Project (EGRIP) over the Holocene and last glacial termination, Clim. Past Discuss., https://doi.org/10.5194/cp-2019-143, accepted, 2020., https://www.clim-past-discuss.net/cp-2019-143/

Original draft preparation by SM with major contributions from FW, SOR, EC, MSJ; statistical analysis of the (depth,depth)-match and interpolation by FW and SOR; matching by SM, FW, SOR, GS, MSJ; DEP data processing by SM, FW; ECM data processing by SOR, GS, MSJ; tephra data processing by EC, SD, GJ; DEP measurements in the field by SM, SK, NAB, SHF, VG, HK; ECM measurements in the field by SM, SOR, HK, TE, KN, SMPB, SHF, IK; preparation, set-up and testing of DEP system by SM, FW; preparation, set-up and testing of ECM system by BV, DDJ, SOR; tephra selection and sampling in the field by EC, SM, SD, SMPB; All authors contributed to improving the final paper.

Chapter 3 - Deep insights to the Greenland ice sheet by linking multichannel ultra-wideband radar surveys to the latest deep ice cores by synthetic radar modelling Mojtabavi, S., Eisen, O., Franke, S., Jansen, D., Steinhage, D., Paden, J., Dabl-Jensen, D and Wilhelms, F.

This manuscript is in final step of preparation to be submitted at the peer-reviewed journal (Mojtabavi et al., 2020a):

Mojtabavi, S., Eisen, O., Franke, S., Jansen, D., Steinhage, D., Paden, J., Dabl-Jensen, D and Wilhelms, F: Deep insights to the Greenland ice sheet by linking multichannel ultra-wide-band radar surveys to the latest deep ice cores by synthetic radar modelling

Chapter 4 - Extreme climate after massive eruption of Alaska's Okmok volcano in 43 BCE and effects on the late Roman Republic and Ptolemaic Kingdom

McConnell, J. R., Sigl, M., Plunkett, G., Burke, A., Kim, W. M., Raible, C. C., Wilson, A. I., Manning, J. G., Ludlow, F., Chellman, N. J., Innes, H. M., Yang, Z., Larsen, J. F., Schaefer, J. R., Kipfstubl, S., 
Mojtabavi, S., Wilhelms, F., Opel, T., Meyer, H., and Stefensen, J. P.

A version of the chapter published at the peer-reviewed journal Proceedings of the National Academy of Sciences (McConnell et al., 2020):

McConnell, J. R., Sigl, M., Plunkett, G., Burke, A., Kim, W. M., Raible, C. C., Wilson, A. I., Manning, J. G., Ludlow, F., Chellman, N. J., Innes, H. M., Yang, Z., Larsen, J. F., Schaefer, J. R., Kipfstubl, S., Mojtabavi, S., Wilhelms, F., Opel, T., Meyer, H., and Stefensen, J. P.: Extreme climate after massive eruption of Alaska's Okmok volcano in 43 BCE and efects on the late Roman Republic and Ptolemaic Kingdom, Proceedings of the National Academy of Sciences, 117, 15 443-15 449, doi: 10.1073/pnas.2002722117, https://www.pnas.org/content/117/27/15443

J.R.M., M.S., and C.C.R. designed research; J.R.M., M.S., G.P., A.B., W.M.K., N.J.C., H.M.I., J.F.L., J.R.S., S.K., S.M., F.W., T.O., H.M., and J.P.S. performed research; J.R.M., M.S., N.J.C., and Z.Y. analyzed data; and J.R.M., G.P., W.M.K., C.C.R., A.I.W., J.G.M., F.L., and N.J.C. wrote the paper. 


\section{DATA SETS AT WWW.PANGAEA.DE}

With this PhD dissertation and articles I have published the following data sets at www.pangaea.de:

1. Interpolated time scale for the ice with GICC05 ages for each bag depth ( $0.55 \mathrm{~m}$ segments) of the EGRIP core in the 13.7 - $1383.8 \mathrm{~m}$ depth interval (Mojtabavi et al., 2020c, https://doi.pangaea.de/ 10.1594/PANGAEA.922393).

2. Match points between the EGRIP core and the NGRIP2 core and corresponding GICC05 ages (Mojtabavi et al., 2020d, https://doi.pangaea.de/10.1594/PANGAEA.922350).

3. Match points between the EGRIP core and the NGRIP1 core and corresponding GICC05 ages (Mojtabavi et al., 2020e, https://doi.pangaea.de/10.1594/PANGAEA.922348).

4. Permittivity measured with the dielectric profiling (DEP) technique on the Talos Dome ice core, Antarctica (Mojtabavi and Wilhelms, 2020i, https://doi.pangaea.de/10.1594/PANGAEA. 922322).

5. Specific conductivity measured with the dielectric profiling (DEP) technique on the Talos Dome ice core, Antarctica (Mojtabavi and Wilhelms, 2020h, https://doi.pangaea.de/10.1594/ PANGAEA.922320).

6. Specific conductivity and permittivity of the Greenland ice sheet (Mojtabavi and Wilhelms, 2020g, https://doi.pangaea.de/10.1594/PANGAEA.922310).

7. Permittivity measured with the dielectric profiling (DEP) technique on the NGRIP2 ice core (down to $1298.525 \mathrm{~m}$ depth) (Mojtabavi and Wilhelms, 2020f, https://doi.pangaea.de/10.1594/ PANGAEA.922308).

8. Specific conductivity measured with the dielectric profiling (DEP) technique on the NGRIP2 ice core (down to $1298.525 \mathrm{~m}$ depth) (Mojtabavi and Wilhelms, 2020e, https://doi.pangaea.de/10. 1594/PANGAEA.922306).

9. Permittivity measured with the dielectric profiling (DEP) technique on the NEEM ice core (1493.30-1757.310 m depth) (Mojtabavi and Wilhelms, 2020d, https://doi.pangaea.de/10.1594/ PANGAEA.922305).

10. Specific conductivity measured with the dielectric profiling (DEP) technique on the NEEM ice core (1493.30-1757.310 m depth) (Mojtabavi and Wilhelms, 2020c, https://doi.pangaea.de/10. 1594/PANGAEA.922303).

11. Permittivity measured with the dielectric profiling (DEP) technique on the EGRIP ice core, 1383.84-2122.445 m depth (Mojtabavi and Wilhelms, 2020b, https://doi.pangaea.de/10.1594/ PANGAEA.922299). 
12. Specific conductivity measured with the dielectric profiling (DEP) technique on the EGRIP ice core, 1383.84-2122.445 m depth (Mojtabavi and Wilhelms, 2020a, https://doi.pangaea.de/10. 1594/PANGAEA.922285).

13. Acidity measured with the Electrical Conductivity Method (ECM) on the EGRIP ice core (down to $1383.84 \mathrm{~m}$ depth), converted to hydrogen ion concentration (Mojtabavi et al., 2020f, https: //doi.pangaea.de/10.1594/PANGAEA.922199).

14. Permittivity measured with the dielectric profiling (DEP) technique on the NEEM ice core (down to $1493.295 \mathrm{~m}$ depth) (Mojtabavi et al., 2020g, https://doi.pangaea.de/10.1594/PANGAEA. 922195).

15. Specific conductivity measured with the dielectric profiling (DEP) technique on the NEEM ice core (down to $1493.295 \mathrm{~m}$ depth) (Mojtabavi et al., 2020h, https://doi.pangaea.de/10.1594/ PANGAEA.922193).

16. Permittivity measured with the dielectric profiling (DEP) technique on the NGRIP1 ice core (down to $1371.69 \mathrm{~m}$ depth) (Mojtabavi et al., 2020i, https://doi.pangaea.de/10.1594/PANGAEA. 922192).

17. Specific conductivity measured with the dielectric profiling (DEP) technique on the NGRIP1 ice core (down to $1371.69 \mathrm{~m}$ depth) (Mojtabavi et al., 2020j, https://doi.pangaea.de/10.1594/ PANGAEA.922191).

18. Chronology for the East GReenland Ice-core Project (EGRIP) (Mojtabavi et al., 2020k, https:// doi.pangaea.de/10.1594/PANGAEA.922139).

19. Permittivity measured with the dielectric profiling (DEP) technique on the EGRIP ice core, 13.77$1383.84 \mathrm{~m}$ depth (Mojtabavi et al., 20201, https://doi.pangaea.de/10.1594/PANGAEA.922138).

20. Specific conductivity measured with the dielectric profiling (DEP) technique on the EGRIP ice core, 13.77-1383.84 m depth (Mojtabavi et al., 2020m, https://doi.pangaea.de/10.1594/ PANGAEA.919313). 


\section{ACKNOWLEDGMENTS}

I would like to begin by thanking my PhD supervisor, Frank Wilhelms. A HUGE THANK for all your supports over the last three and half years. I have learned a lot from you! You have shown me how to be an outstanding scientist! I look forward to future collaborations.

I would also like to thank my PhD committee members, Daniela Jansen and Andreas Pack for helping me to organise my $\mathrm{PhD}$ project

I would also like to thank Sune Olander Rasmussen for his supports that really helped to improve my first paper.

I would also like to thank Olaf Eisen for his supports.

Thanks to AWI institute for providing all facilities for me during my $\mathrm{PhD}$ project and also thanks to my colleagues in the glaciology section. I will miss our coffee machine so much!!

A big thank to all great members of EGRIP project and university of Copenhagen, specially to the colleagues attending the expedition in Greenland in 2018 and 2019. Interesting time in science trench at the camp. Fantastic experience and great time in my research and life.

Thanks to my family. My mother, father and sibling that always encourage me throughout my academic journey.

And, an immense thank to my LOVE, my fiancée and my best friend, Maryam!! you lifted me up in difficult times through the last years. You and me will get through all hard times hand in hand, TOGETHER. Without your love and supports, I would not be the person I am today! 



\section{Contents}

List of Figures $\quad$ xiv

List of Tables $\quad$ xv

1 Introduction 1

1 Polar Regions and Climate Change . . . . . . . . . . . . . . . . 1

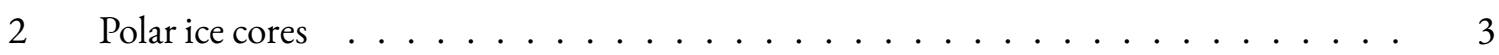

3 Internal reflections in polar ice sheets . . . . . . . . . . . . . . 5

4 Field measurements and data processing $\ldots \ldots \ldots \ldots$

5 Workflow of the $\mathrm{PhD}$ dissertation $\ldots \ldots \ldots \ldots \ldots . \ldots \ldots$

2 A first chronology for the East GReenland Ice-core Project (EGRIP) over the Holocene and last glacial termination $\quad 15$

$1 \quad$ Introduction . . . . . . . . . . . . . . . . . . . 16

2 Data and methods . . . . . . . . . . . . . . . . 17

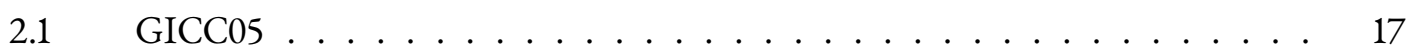

2.2 Ice-core data sets over the Holocene and last glacial termination $\ldots \ldots$. . . . 18

2.3 Field measurements and data processing . . . . . . . . . . . . . . . 19

2.4 Synchronization of dielectric profiling and electrical conductivity measurement records of EGRIP, NGRIP NEEM . . . . . . . . . . . . 24

2.5 Transfer of the GICC05 timescale to the EGRIP ice core . . . . . . . . . . 26

3 Results and discussion . . . . . . . . . . . . . . . . . . 27

3.1 Synchronization of the EGRIP, NEEM and NGRIP cores _ . . . . . . . . 27

3.2 Tephra horizons identified for the chronology . . . . . . . . . . . 28

3.3 GICC05-EGRIP-1 . . . . . . . . . . . . . . . . . . . 28

3.4 Error analysis for the timescale transfer $\ldots \ldots \ldots$

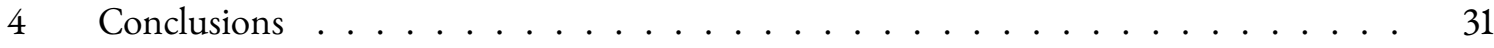

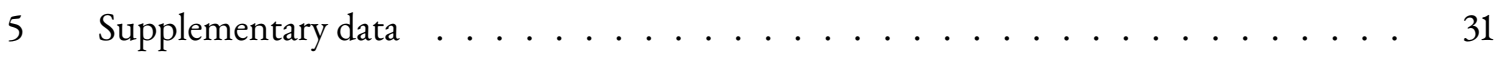

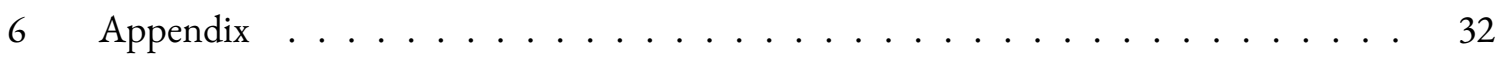

7 Quality index for the NGRIP and NEEM ice cores . . . . . . . . . . . . . . 32

8 Calibration and corrections to the DEP data . . . . . . . . . . . . . . 32

9 Details on the ECM procedures . . . . . . . . . . . . . . . . . 35

10 Statistical analysis of the (depth, depth)-match with linear interpolation . . . . . . . 35

11 Statistical analysis of the (depth, depth)-match with cubic spline interpolation . . . . . 37

12 Author contributions . . . . . . . . . . . . . . . . 40 
13 Acknowledgements . . . . . . . . . . . . . . . . . . 40

3 Deep insights to the Greenland ice sheet by linking multichannel ultra-wide-band radar surveys to the latest deep ice cores by synthetic radar modelling

1 Introduction . . . . . . . . . . . . . . . . . . . 44

2 Data and Method . . . . . . . . . . . . . . . . . 45

$2.1 \quad$ Airborne Radar Data . . . . . . . . . . . . . . . . . . 45

2.2 Dielectric profiling (DEP) and ice core data . . . . . . . . . . . . 47

2.3 Modelling of synthetic radar traces (SYN) and the depth of internal reflection horizons $(\mathrm{IRH}) \ldots \ldots \ldots \ldots \ldots$

3 Results . . . . . . . . . . . . . . . . . . . . 50

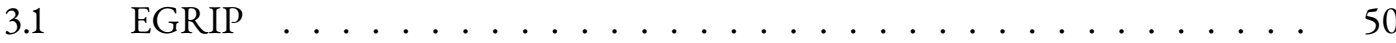

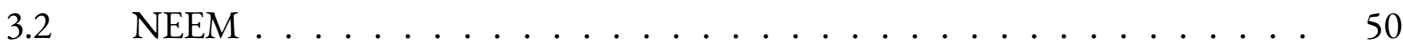

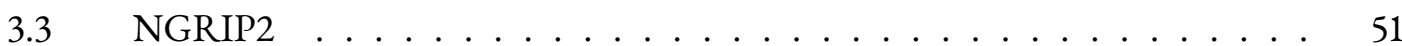

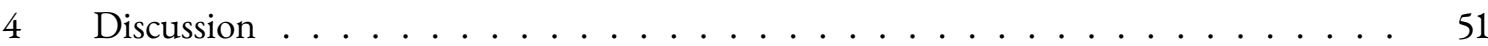

4.1 Origin of radar reflectors . . . . . . . . . . . . . 51

4.2 Age stratigraphy . . . . . . . . . . . . . . . . 57

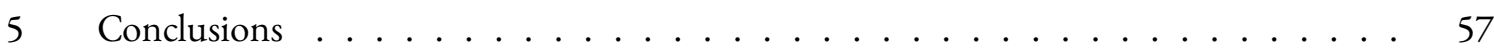

6 Supplementary data . . . . . . . . . . . . . . . . . 57

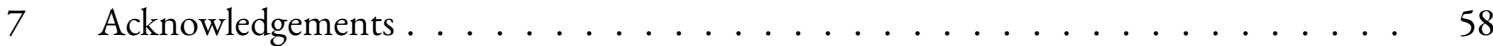

4 Extreme climate after massive eruption of Alaska's Okmok volcano in 43 BCE and effects on the late Roman Republic and Ptolemaic Kingdom 59

1 Significance . . . . . . . . . . . . . . . . . . . . 60

2 Ice Core Evidence of a Massive Eruption in Early 43 BCE . . . . . . . . . . . . 61

3 Volcanic Provenance . . . . . . . . . . . . . . . . . . . . . . . . . 64

4 Northern Hemisphere Climate Effects . . . . . . . . . . . . . . . . . . . . 64

5 Climate Effects and Historical Linkages in the Mediterranean Region . . . . . . . . 66

6 Materials and Methods . . . . . . . . . . . . . . . . . . . . 70

$6.1 \quad$ Measurements of Volcanic Fallout in Arctic Ice Cores. . . . . . . . . . . . . 70

6.2 DRI_NGRIP2 Ice Core Chronology. . . . . . . . . . . . . . . . . . . 71

6.3 Tephra Analyses. . . . . . . . . . . . . . . . . . 72

6.4 Sulfur Isotope Analyses. . . . . . . . . . . . . . . . . . 72

6.5 Earth System Model Simulations. . . . . . . . . . . . . . . . . . 72

$7 \quad$ Data Availability. . . . . . . . . . . . . . . . . . . . . . . . . . 73

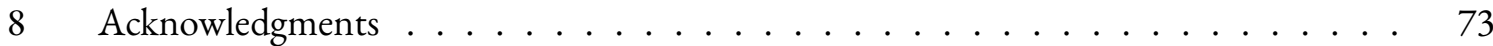




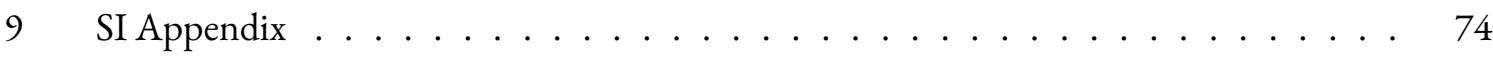

5 Conclusion and Summary $\quad 85$

$\begin{array}{ll}\text { References } & 98\end{array}$ 


\section{List of Figures}

1.1 Cryospheric Contributions to Sea-Level Rise . . . . . . . . . . . . . . . . 2

1.2 Schematic cross-section of an ice sheet, modified after (Oerter, 2009) . . . . . . . . 4

1.3 Locations of deep ice-core drill sites in Antartica and Greenland. . . . . . . . . . . 5

1.4 The multi-channel ultra-wideband (UWB) installed on the AWI Polar 6 Basler BT- 67 aircraftb that was recorded EGRIP radar data in Greenland 2018. Photo is taken by Sepp

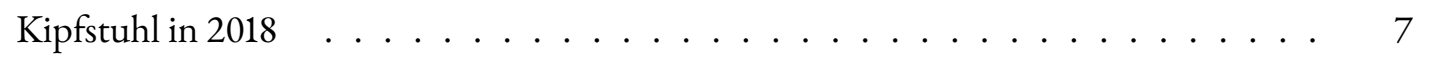

1.5 The DEP device (Wilhelms et al., 1998) at EGRIP, season 2019. Photo taken by Seyedhamidreza Mojtabavi . . . . . . . . . . . . . . . . . 9

1.6 The ice cores were stored inside a core storage before being processed at EGRIP, season 2019. Photo taken by Sepp Kipfstuhl . . . . . . . . . . . . . . . . . . . . 10

1.7 Cutting lines of a sample section from the EGRIP ice core. The ice core is split into the different aliquots with a horizontal band saw, or swiss saw (a vertical saw). . . . . . . . 11

1.8 Workflow of this $\mathrm{PhD}$ dissertation $\ldots \ldots \ldots \ldots \ldots$

2.1 Locations of deep ice-core drill sites: EGRIP, NEEM, NGRIP, GRIP, GISP2, DYE-3, and Camp Century in Greenland, and close-up of the EGRIP drill site inside the North East Greenland Ice Stream (NEGIS) . . . . . . . . . . . . . . . . .

2.2 Overview of dielectrical profiling (DEP) and electrical conductivity measurements (ECM) that we used for the synchronization between ice cores over the Holocene and late last glacial periods. . . . . . . . . . . . . . . . .

2.3 Match points between EGRIP, NEEM (blue) and NGRIP (yellow) ice cores based on the DEP and ECM data sets. The core quality index $Q$ as derived from the validated DEP (blue) and ECM (red) data, respectively. . . . . . . . . . . . . . . 20

2.4 Schematic of the DEP instrument. . . . . . . . . . . . . . . . 21

2.5 Example of DEP data processing . . . . . . . . . . . . . . 22

2.6 Example of the DEP data gap length and relative precision of ECM vs DEP depth assign-

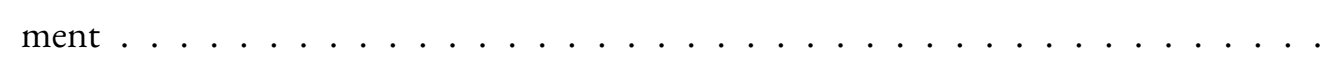

2.7 Element-element biplots showing geochemical matches between EGRIP and NGRIP samples . . . . . . . . . . . . . . . . . . .

2.8 Example of the ECM and DEP data match between the NGRIP2, NEEM and EGRIP

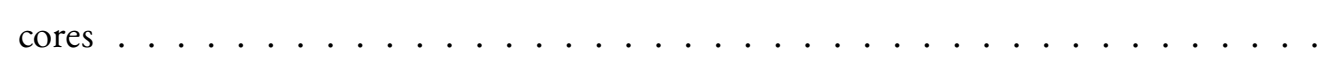

2.9 Average EGRIP annual layer thicknesses between the match points. The EGRIP depthage relationship with match points and the tephra horizons. . . . . . . . . . . .

2.10 The EGRIP/NGRIP and EGRIP/NEEM annual-layer thickness ratio calculated between neighbouring match points. . . . . . . . . . . . 
2.11 Quality indices for the EGRIP, NGRIP and NEEM ice cores. . . . . . . . . . . . . 32

2.12 Calibration curve of the measurements with artificial tubes and free-air measurement for DEP device. . . . . . . . . . . . . . . . . . . . 34

2.13 Histogram of the difference data with linear interpolation for the match points between EGRIP-NGRIP1/2. . . . . . . . . . . . . . . . . . . . . 36

2.14 Histogram of the difference data with cubic spline interpolation for the match points between EGRIP-NGRIP1/2 . . . . . . . . . . . . . . . . . . . . . . . 38

2.15 The (EGRIP, NGRIP) match points, (EGRIP-depth, GICC05-time)-scale, the(EGRIPdepth, GICC05-MCE)-curve ～. . . . . . . . . . . . . . . . . . 40

3.1 Locations of deep ice-core drill sites in Greenland Ice Sheet. Focus on ice core locations in the vicinity of NEGIS. NEEM drill site with the RES profile line from CReSIS flight 20110329-02-028. NGRIP2 drill site with the RES profile line of CReSIS flight 20120330-03-014. EGRIP drill site with the RES profiles line of AWI flights 2018050806-004 and 20180512-01-001. . . . . . . . . . . . . . 46

3.2 A-scopes for traces of the radar systems in NEEM, NGRIP2 and EGRIP (Parallel) synthetic traces . . . . . . . . . . . . . . . . . . . 52

3.3 Z-scopes for synthetic and RES data sets for the NEEM and NGRIP2 and EGRIP ice cores 53

3.4 Z-scopes for synthetic and RES data sets of the EGRIP ice core location . . . . . . . . 55

3.5 Example of the reflection for potential crystal orientation fabric (COF) at the NEEM

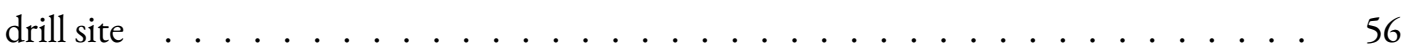

4.1 Location map. Shown are drilling sites for the six Arctic ice core records evaluated in this study (pluses), the Okmok and Mount Etna volcanoes, tree . . . . . . . . . . . . .

4.2 Ice core, tree ring, and speleothem evidence for the 45 and $43 \mathrm{BCE}$ eruptions and climate

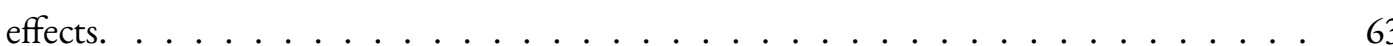

4.3 Total alkali $(\mathrm{Na} 2 \mathrm{O}+\mathrm{K} 2 \mathrm{O})$ and silica compositions of tephra from GISP2 ice during the $43 \mathrm{BCE}$ event compared with tephra from Okmok II and other potential source volcanoes 65

4.4 Volcanically forced temperature and precipitation anomalies in the Mediterranean region from 60 to $30 \mathrm{BCE} \ldots \ldots \ldots$. . . . . . . . . . . . . . 67

4.5 Selected new and previously published measurements of volcanic-fallout-related parameters in the six Arctic ice cores evaluated for this study . . . . . . . . . . . . . . 76

4.6 Selected continuous elemental measurements of NGRIP2 ice (388 to $391.5 \mathrm{~m}$ ) used for annual layer counting . . . . . . . . . . . . . . . . . . 77

4.7 Volcanic fallout surrounding the 43 BCE Okmok II eruption in the A. NGRIP2 and B. GISP2 ice cores. . . . . . . . . . . . . . . . . . . . . 78 
4.8 Images of selected tephra shards extracted from GISP2 ice ( 481.06 to $481.16 \mathrm{~m}$ ) and geochemically tied to the Okmok II eruption that started in early 43 BCE. . . . . . . . . 79

4.9 Tephra geochemistry comparisons . . . . . . . . . . . . . . . . . 80

4.10 Annual and seasonal 43 BCE CESM-modeled (Materials and Methods) temperature and precipitation anomalies relative to the 60 to $46 \mathrm{BCE}$ reference period with no volcanic

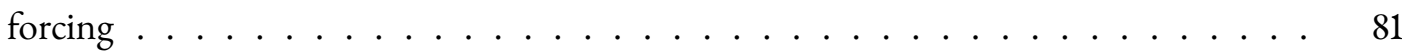

4.11 As in SI Appendix, Fig. 4.10 but for 42 BCE. . . . . . . . . . . . . . . . . . 82

4.12 Seasonal 43 BCE CESM-modeled (Materials and Methods) temperature and precipitation anomalies in response to radiative forcing from the early 43 BCE Okmok II erup-

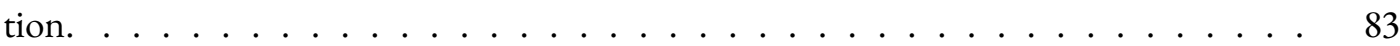

4.13 As in SI Appendix, Fig. 4.12 but for 42 BCE. . . . . . . . . . . . . . . . . 84 


\section{List OF TABLES}

2.1 Geochemical matches between EGRIP and NGRIP . . . . . . . . . . . . . . . 24

3.1 Information about each RES systems and modelled data. . . . . . . . . . . . . 46

3.2 Information about the DEP data sets. . . . . . . . . . . . . . . . . 47

3.3 The matched layers of synthetic and real radargrams. . . . . . . . . . . . . 54

4.1 DRI_NGRIP2 age scale in both year before 1950 (yb1950) and year (BCE/CE) . . . . 75 

Chapter 1

\section{Introduction}

\section{Polar Regions and Climate Change}

The polar regions play an important role in our planet as they are rapidly losing the ice, and it can affect people's lives in different ways (Meredith et al., 2019). The Arctic surface air temperature has increased by more than double the global average (Meredith et al., 2019; Notz and Stroeve, 2016; Richter-Menge et al., 2017) over the last two decades. Numerous studies show that greenhouse gases due to anthropogenic activities play a key role in the Arctic temperature changes (Meredith et al., 2019; Fyfe et al., 2013; Najafi et al., 2015). As the cryosphere has a very complex climate system, any conflict in that system can cause different consequences in the Earth's climate system. There are several feedback mechanism examples of Arctic temperature change, including: a lower summer albedo effect due to sea ice and snow cover loss, increase in total water vapors in the Arctic region, change in cloudiness in the summer season, heat generated due to newly formed sea ice in the autumn season, northward transport change in heat and moisture and the different rate of heat loss to space from the Arctic respective to the subtropics region (Meredith et al., 2019; Serreze et al., 2012; Pithan and Mauritsen, 2014; Goosse et al., 2018; Stuecker et al., 2018). The Northeast Greenland Ice Stream (NEGIS) is an important region with a significant dynamic change on the Greenland ice sheet. The NEGIS is presently draining more than $10 \%$ of the Greenland ice sheet and is an important region concerning the future rise in sea level. (Joughin et al., 2010, 2018; Smith-Johnsen et al., 2020; Rignot and Mouginot, 2012).

The Antarctic has displayed different behavior compared to the Arctic over the past 30-50 years (Meredith et al., 2019). Air temperature has increased over West Antarctica; in contrast, there is no significant change in temperature over East Antarctica (Meredith et al., 2019; Nicolas and Bromwich, 2014; Jones et al., 2016; Turner et al., 2016). This is due to deep ocean circulation and heat exchanges over the Southern Ocean (Collins et al., 2013). Thwaites Glacier is an important region in the west of Antarctica, because the bedrock is below sea level (Schoof, 2007). It has a huge potential for the future rise in sea level due to warm circumpolar deep water (CDW) (Meredith et al., 2019), with a melt rate up to $200 \mathrm{~m}$ yr-1 (Milillo et al., 2019). Antarctica and Greenland contain the most important source of fresh water on Earth, which is a potential for the change in global sea level (see Fig. 1.1) as these regions are very sensitive and respond 
rapidly to climate change (Meredith et al., 2019). Recently, the Greenland ice sheet has been losing a huge amount of ice, amounting to approximately 267 billion metric tons per year (Richter-Menge and M. Jeffries, 2019). This contributes a rate of $0.7 \mathrm{~mm}$ per year to the rise in global sea-level (Richter-Menge and M. Jeffries, 2019).

The Global mean sea level (GMSL) of the Last Interglacial was likely 6-9 m higher than today due to the Greenland and Antarctic ice sheets (Meredith et al., 2019). Therefore, it is essential to understand the past climate system in both Greenland and the Antarctic and its interaction with the rest of Earth's climate system components.
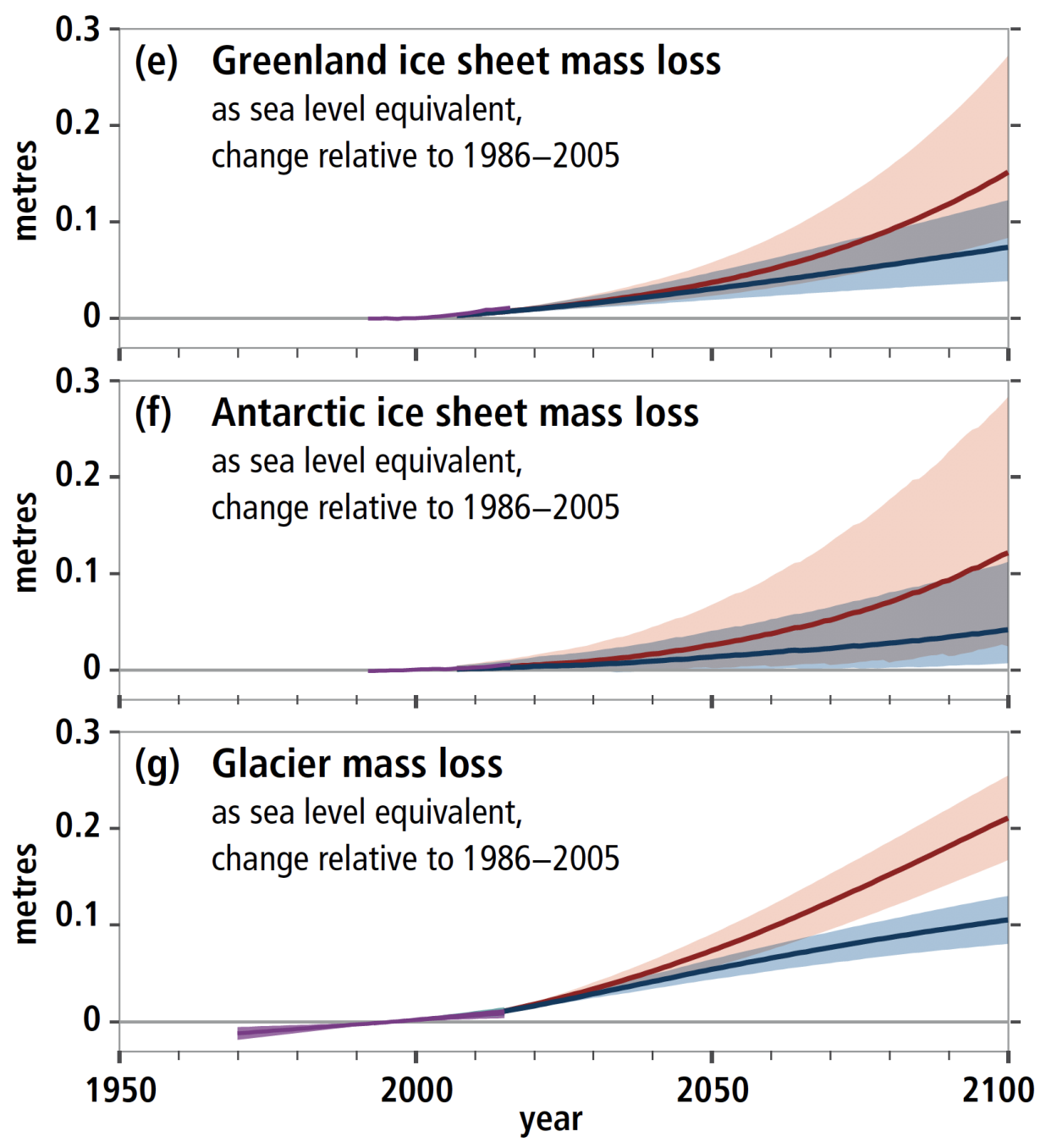

Figure 1.1 - Cryospheric Contributions to Sea-Level Rise, Projected RCP2.6 (blue) and Projected RCP8.5 (red) (Figure taken from Pörtner et al. (2019)). 


\section{Polar ice cores}

The ice cores from Antarctica and Greenland comprise one of the most important climate archives, and investigating these ice cores can help us to understand past climatic conditions. There are several open questions concerning past climate change, which are related to various factors. For example, a huge volcanic eruption that causes extreme climate changes such as global cooling, which in turn leads to an historical human crisis (McConnell et al., 2020). Scientists still do not have enough information about the physical processes that cause past climate change, for example, the effect of Earth's radiative equilibrium, sun insolation, volcanic eruptions, human activities ( greenhouse gas emissions), climate variabilities and feedback mechanisms between the cryosphere, atmosphere and ocean. Therefore, the study of the ice core as a climate archive can provide useful information for the Earth climate models to predict future climate change.

Figure 1.2 shows the schematic cross-section of an ice sheet (Antarctica and Greenland) (Oerter, 2009). Following the descriptions in Oerter (2009), annual layers become thinner on the way down through the ice column in an ice sheet with slow movements (Figure 1.2, flowlines) of the ice from the inland ice sheet to the ocean. Accumulation area (Figure 1.2, green area) is characterized by a positive mass balance at the surface and, snow precipitation is maintained on an annual average. The equilibrium line shows a dividing line between ablation and accumulation areas. The ideal region for deep drilling is at the highest area of the summit on the ice sheet (Figure 1.2). The changes in the ice flow path should be taken into account for the interpretation of ice core data.

There are numerous deep ice cores that are drilled from polar ice sheets over the past 50 years (Figure 1.3). The longest ice core is in Antarctica; it covers the last $800000 \mathrm{yr}$ (Augustin et al., 2004). Recently, the data from some deep ice core projects are continuing to improve our knowledge about the palaeoclimate in Greenland and Antarctica. Examples include, the East GReenland Ice-Core Project (EGRIP) to understand ice dynamics in Greenland (e.g., Mojtabavi et al., 2020b), and Beyond EPICA Oldest Ice Core (Rodriguez-Morales et al., 2020) in Antarctica where scientists are hoping to reach a 1.5 million yr long ice core. It can improve our understanding of the role of greenhouse gas cycles in the Quaternary period. To reach the longest possible ice core timescale, we need to drill an ice core at the summit of the ice sheet (Figure 1.2). In a region at the summit, the ice flow is vertically downward, which is a suitable place for a long record (such as Beyond EPICA Oldest Ice Core project). In contrast, the purpose of another project, EGRIP, with a long distance from summit region, is to understand ice dynamics due to the strong ice flow (Mojtabavi et al., 2020b). The differences in accumulation and ice flow conditions on the ice sheet are important factors for the dating age of interval layers (See Figure 1.2).

The establishment of the depth-age relationship of an ice core is the first key step to assessing past climate changes from proxy parameters of the ice core. Several approaches are available to establish the 


\section{typical for \\ Greenland $\longleftrightarrow$ Antarctica}

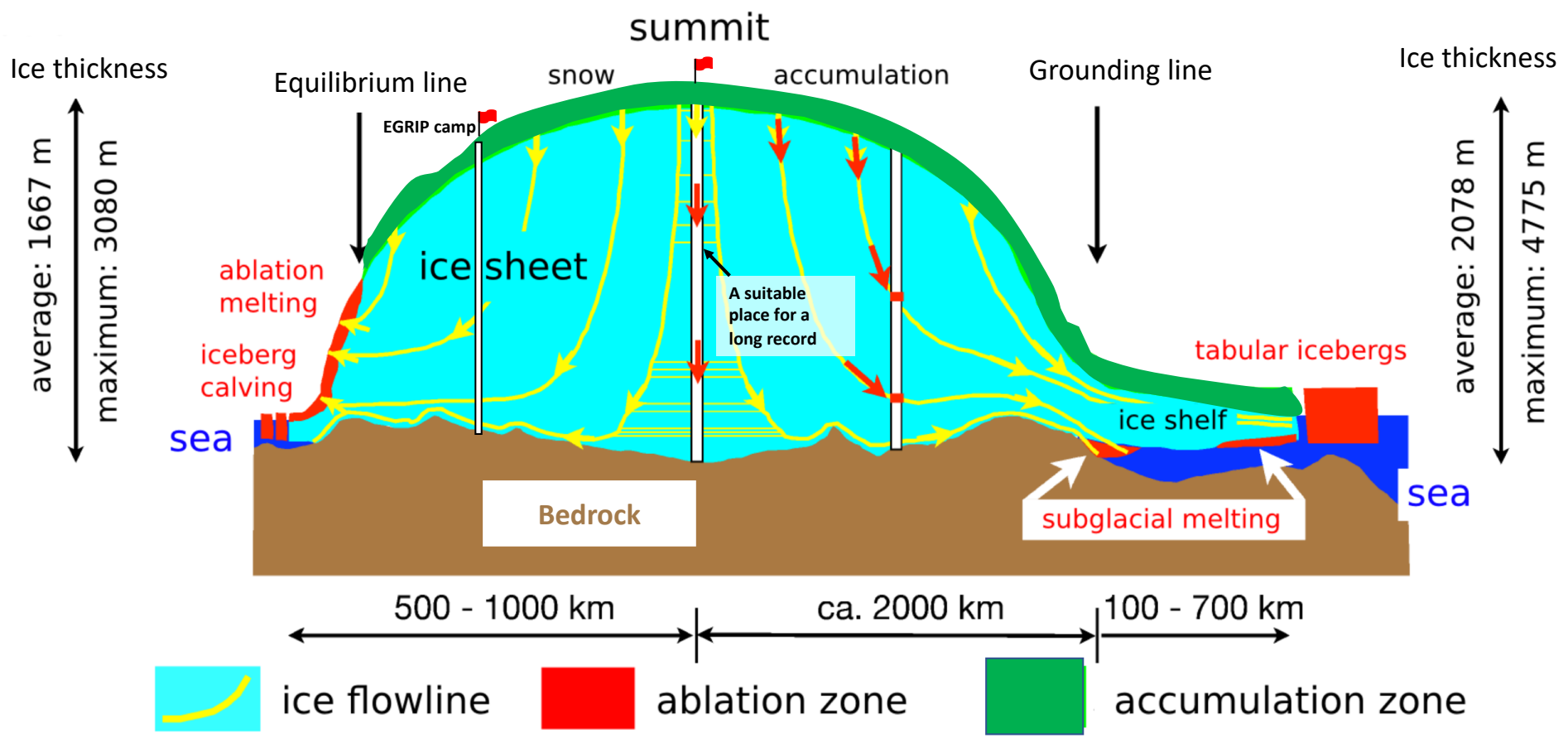

Figure 1.2 - Schematic cross-section of an ice sheet, modified after (Oerter, 2009)

depth-age relationship of an ice core. Three methods can be used for the ice core chronologies. These methods are often combined by scientists. (Rasmussen, 2006):

- Using annual layer counting of high-resolution chemical and physical of ice core properties (e.g., Andersen et al., 2006). In this respect, high resolution data sets are used to count as many annual layers of ice core as possible. It is very time consuming, and to reduce uncertainty in counting, is usually performed by several investigators.

- Ice core chronologies from ice flow pattern and accumulation rate models, which are most useable in deeper parts of the ice core. It is very difficult to detect the annual layer signal at deeper parts because of flow-induced thinning (e.g., Wolff et al., 2010).

- Synchronization between two ice cores and transfer timescale of well-dated reference horizons to another ice core (e.g., Mojtabavi et al., 2020b).

The Antarctic ice core chronology (AICC2012) (Veres et al., 2013) is the dating reference frame (0-120 $\mathrm{ka} \mathrm{BP}$ ) for the consistent common interpretation of several ice core records from Greenland and Antarc- 

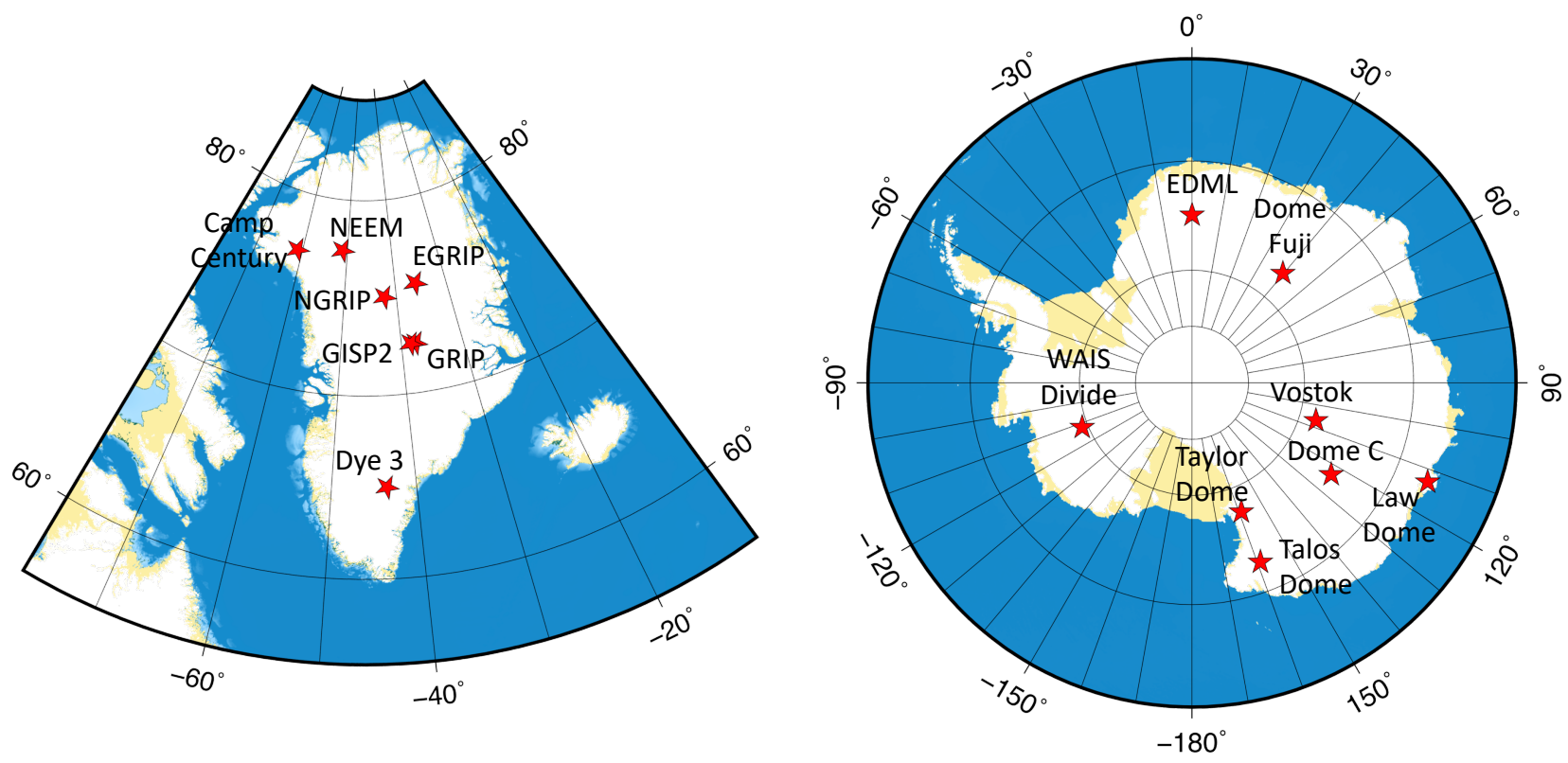

Figure 1.3 - Locations of deep ice-core drill sites in Antartica and Greenland.

tica. The four ice cores are used in AICC2012 (Veres et al., 2013) from Antarctica, namely Vostok, EPICA Dome C (EDC), EPICA Dronning Maud Land (EDML) and Talos Dome (TALDICE). The AICC2012 is also consistent with the Greenland Ice Core Chronology 2005 (GICC05) timescale for the last $60.2 \mathrm{ka}$ and is the recommended multi-core timescale for Greenland ice cores (Vinther et al., 2006; Rasmussen et al., 2006; Andersen et al., 2006; Svensson et al., 2006, 2008; Wolff et al., 2010; Seierstad et al., 2014).

\section{Internal reflections in polar ice sheets}

Radioglaciology was started in the 1970s (Robin, 1975) and, a review about the five decades of radioglaciology is given by Schroeder et al. (2020). New techniques have developed, and there is a wide range of information and useful data in this field. Recently, radar sounding methods have provided data about the subglacial water, the geometry of subglacial bedforms, and the subglacial and englacial thermal states of ice sheets (Schroeder et al., 2020). Also, planetary radar sounders are used, and are planned to characterize Mars, the Earth's moon, comets and the icy moons of Jupiter (Schroeder et al., 2020). Two orbital radar sounders have been used to collect information of water ice on Mars (Schroeder et al., 2020); MARSIS by European Space Agency (Mars Advanced Radar for Subsurface and Ionospheric Sounding), and SHARAD onboard the Mars Reconnaissance Orbiter launched by NASA (National Aeronautics and Space Administration, USA) (Seu et al., 2007; Jordan et al., 2009). Until now, satellite radar sounders (satellite-borne SAR) are only available to detect the surface of ice on the Earth (e.g., ice surface velocity) 
(Drews, 2011). The radar systems can detect a different data set of air-ice, ice-snow and ice-bedrock interfaces with differences in dielectric constants (Arnold et al., 2019). As described by Navarro and Eisen (2009), the propagation of electromagnetic waves for the radar system can be determined by Maxwell equations, and any behavior in waves is related to the dielectric properties. Airborne radar remote sensing is an effective method, which can provide considerable information in the field of geoscience (Arnold et al., 2019). This method has a large advantage compared to other radar measurement methods such as ground based and satellite-based methods. Airborne radar measurement can cover a large area compared to the radar-based measurement and it has better resolution than satellite-based methods (Arnold et al., 2019). Airborne radar sounding has been used to observe subsurface conditions, ice thickness changes, basal topography, and englacial layers over the past 50 years (Schroeder et al., 2020). Several studies show the past and present ice-stream from Antarctica and Greenland (Siegert et al., 2004; Bingham and Siegert, 2009; Rippin et al., 2014; Franke et al., 2020). Recently, a multi-channel VHF/UHF ultra-wideband airborne radar sounder and imager has been developed for improved measurement resolution over Greenland and Antarctica (Hale et al., 2016). The multi-channel ultra-wideband (UWB) is installed on the AWI Polar 6 Basler BT- 67 aircraft and has a 150-600 MHz frequency range with a large, cross-track array of 24 elements (Hale et al., 2016) (See Figure 1.4).

As described by Arnold et al. (2019), the internal layers reflection can be due to density changes over the bellow $200 \mathrm{~m}$ depths (Paren and Robin, 1975; Arcone et al., 2004) and conductivity changes over the upper $200 \mathrm{~m}$ of the ice sheet (Millar, 1982; Hempel et al., 2000; Eisen et al., 2006; Winter et al., 2017; Mojtabavi et al., 2020a). In addition, the crystal orientation change can influence the dielectric constant of the ice (Fujita et al., 2000; Eisen et al., 2007). Each radar system has a different frequency that is determined by the ice-snow properties to be measured, and specific frequency bands are due to radar system limitations and frequency allocation (Arnold et al., 2019).

Radar data has increased our ability to track isochrones layers over Greenland and Antarctica (Schroeder et al., 2020), which can provide useful information such as past accumulation rate and velocity patterns (Eisen, 2008). Isochrones layers have linked the several ice core sites in Antarctica (Cavitte et al., 2016; Winter et al., 2019), and this approach can help to identify a location for the Oldest Ice, which will be drilled ice in future (ice older than 1.5 million years) (Fischer et al., 2013; Rodriguez-Morales et al., 2020). There is another study by MacGregor et al. (2015) for the age stratigraphy in the Greenland ice sheet based on radio-echo sounding (RES) data and ice core data. Apart from radar measurements, numerical forward modelling is another method to study internal ice sheet layers. The synthetic model results by Eisen et al. $(2006,2007)$ show the conductivity changes cause radar reflection in the ice sheets, and a single reflector is related to a strong change of COF. Winter et al. $(2017,2019)$ used the same numerical model approach to compare measurements from different radio-echo sounding systems and age stratigraphy by linking isochrones layers in the East Antarctic. 


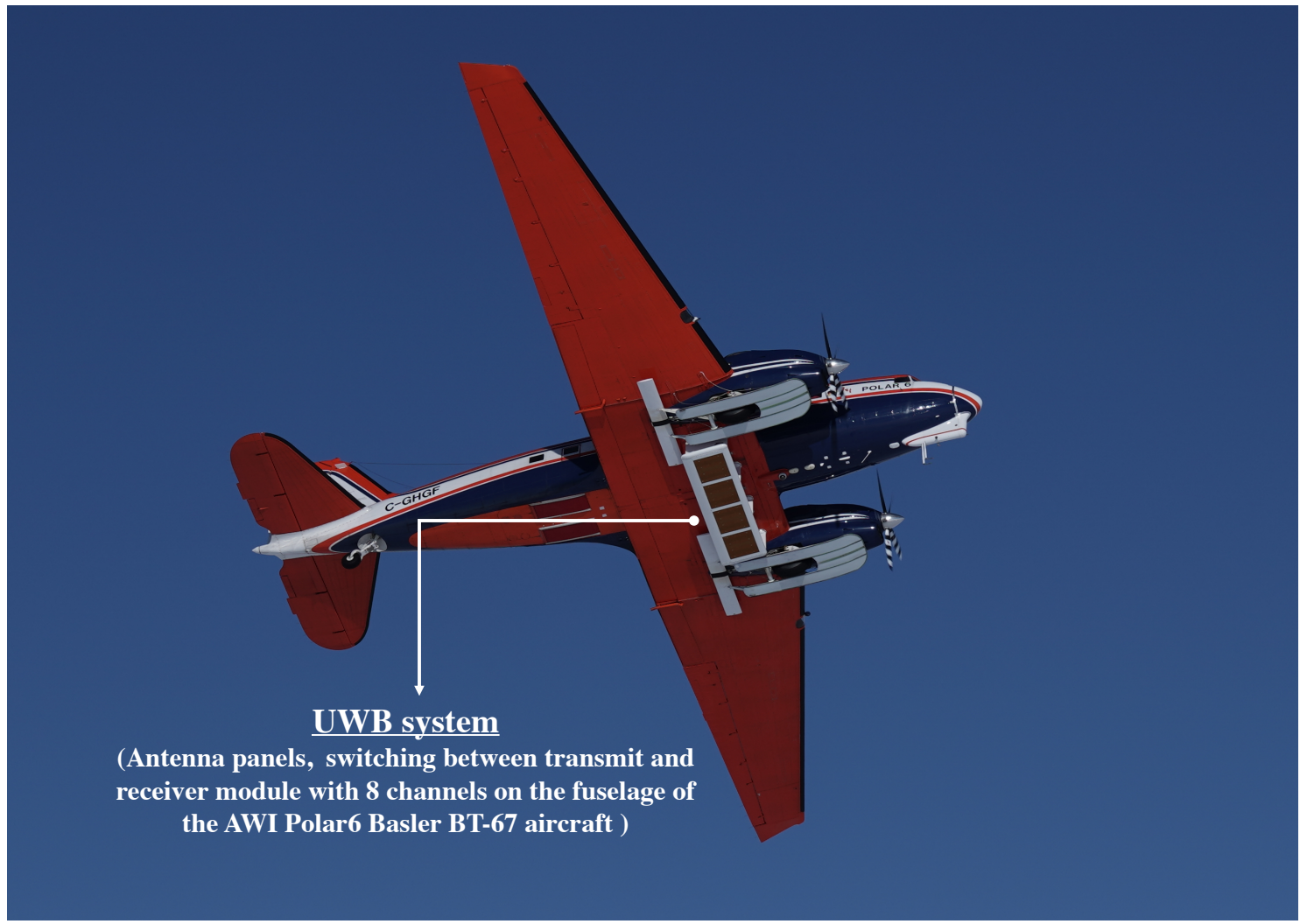

Figure 1.4 - The multi-channel ultra-wideband (UWB) installed on the AWI Polar 6 Basler BT- 67 aircraftb that was recorded EGRIP radar data in Greenland 2018. Photo taken by Sepp Kipfstuhl in 2018.

\section{Field measurements and data processing}

EGRIP ice core is one of the most recent deep ice core projects in Greenland. The drilling of the ice core started in 2016 (Dahl-Jensen et al., 2019; Mojtabavi et al., 2020b) and, it will be continued in the next years (The project was not finished at the time of submission of this thesis). The EGRIP site is located on the special region of the Greenland ice sheet in the upper region of the NEGIS, where the ice is moving very fast. This region is an interesting place to study and understand complex ice dynamics in Greenland. Fresh ice cores are logged after drilling in the season (Figure 1.6) during the summer in the northern hemisphere, when weather conditions are better than in winter. As the ice core should be kept at a minimum of $-20^{\circ} \mathrm{C}$, drilling and scientific processing of the ice core takes place under a snow surface in a cave.

Some ice cores processed in the same season and some of them are stored in the core buffer for the next season (Figure 1.6). The brittle ice cores are stored in the camp and, they will be processed next season. The poor quality of the brittle ice core section is due to rapid relaxation (decompression) (Neff, 2014). The ice core section is split into the different aliquots (Figure 1.7) for further analyses in the science trench or for the laboratory analyses in different universities in Europe (Dahl-Jensen et al., 2019). The first step 
of ice processing is Dielectric Profiling (DEP), which is a rapid dielectric profiling of ice cores (Moore and Paren, 1987). The DEP device described by Wilhelms et al. (1998) is used in the EGRIP camp and data has been processed as described Mojtabavi et al. (2020b). The conductivity changes in DEP profiles is mainly related to acidity, salt, and ammonia concentrations of ice cores (Moore et al., 1992; Moore et al., 1994). Figure 1.5 shows the DEP device Wilhelms et al. (1998), when the ice core section is placed (1.65 $\mathrm{m})$. Firstly, the DEP operator measures and documents the length of the ice core section, the position of any breaks or core cutter, and any information that is useful for data processing.

Some measurements were conducted in the science trench during the field camp (Dahl-Jensen et al., 2019). After DEP measurement, the ice core was spilt with a horizontal band saw (Swiss saw) to two main pieces (Figure 1.7). One piece was used for the physical properties measurements, the other piece was used to record ECM profiles with the technique described by Hammer (1980) with a Danish ECM setup directly in the science trench. The ECM conductivity pattern is related to acidity concentrations of ice cores (Moore et al., 1992). The visible volcanic eruption can be detected in the field, immediately after the conductivity records of ECM and DEP measurements. It will help to select specific ice core section samples forfurther tephra analyses. DEP and ECM peaks were investigated for tephra to the identification of tephra layers (e.g., McConnell et al., 2020). The section after ECM measurement was moved to the AWI line scanner. The line scanner recorded visual layers (cloudy bands) of the polished ice core that indicated visible layers along the glacier ice core section. In the last step of scientific ice core processing, the section was cutted for the tephra measurement and continuous measurements of stable water isotopes. Finally, ice core sections were shipped to universities for further analysis (Dahl-Jensen et al., 2019). 


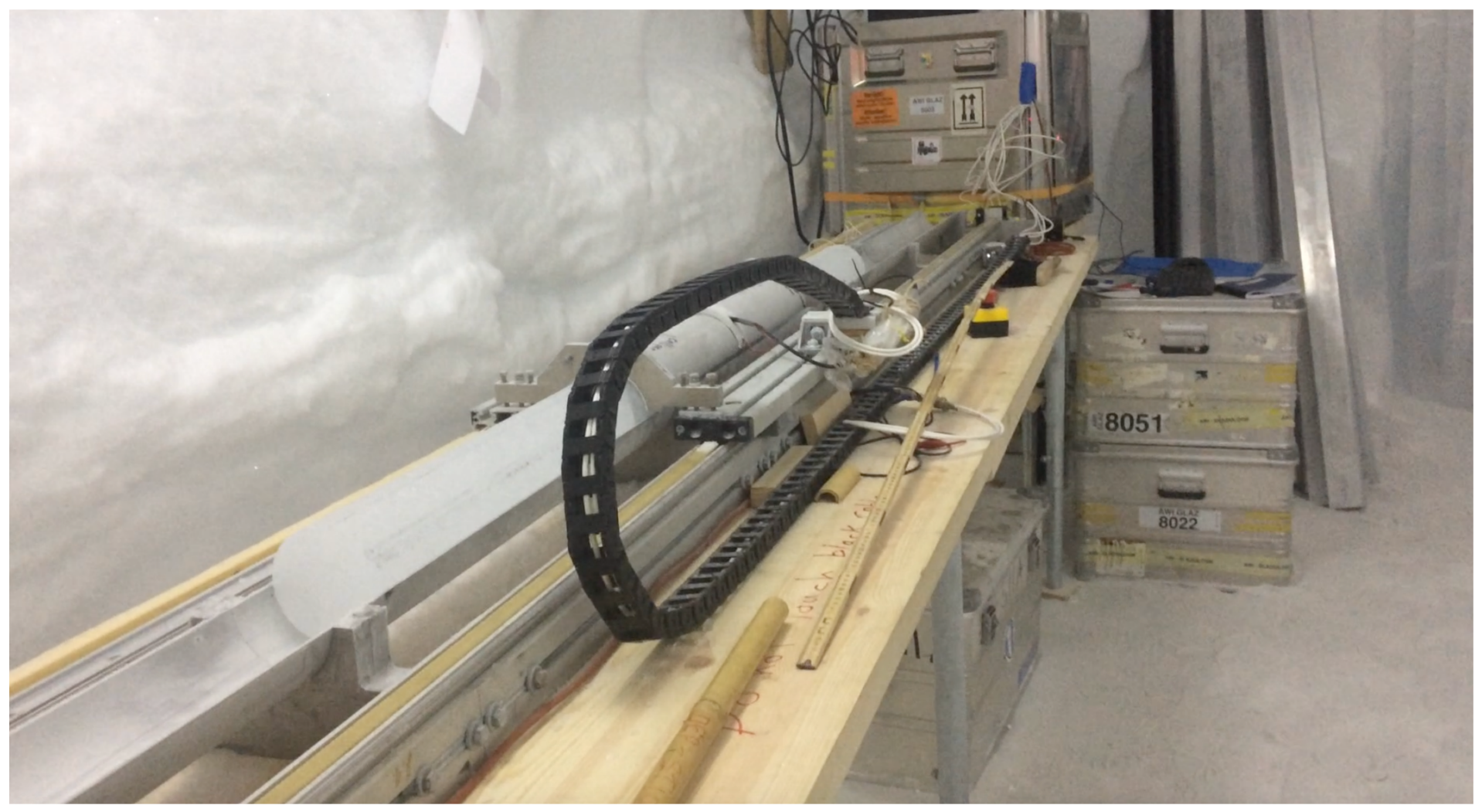

Figure 1.5 - The DEP device (Wilhelms et al., 1998) at EGRIP, season 2019. Photo taken by Seyedhamidreza Mojtabavi (for details of the DEP device see Figure 2.4). 


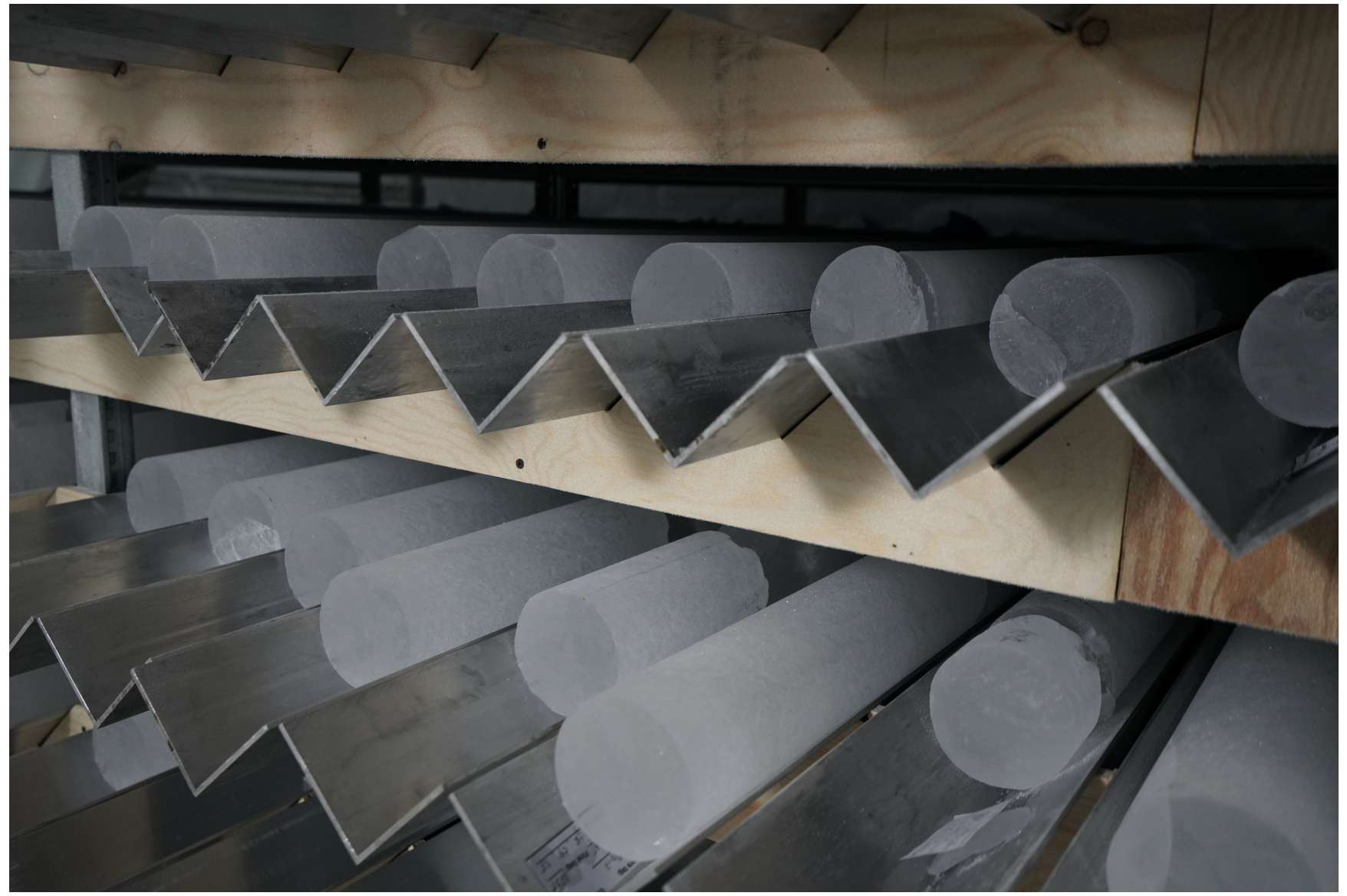

Figure 1.6 - The ice cores were stored inside a core storage before being processed at EGRIP, season 2019. Photo taken by Sepp Kipfstuhl. 


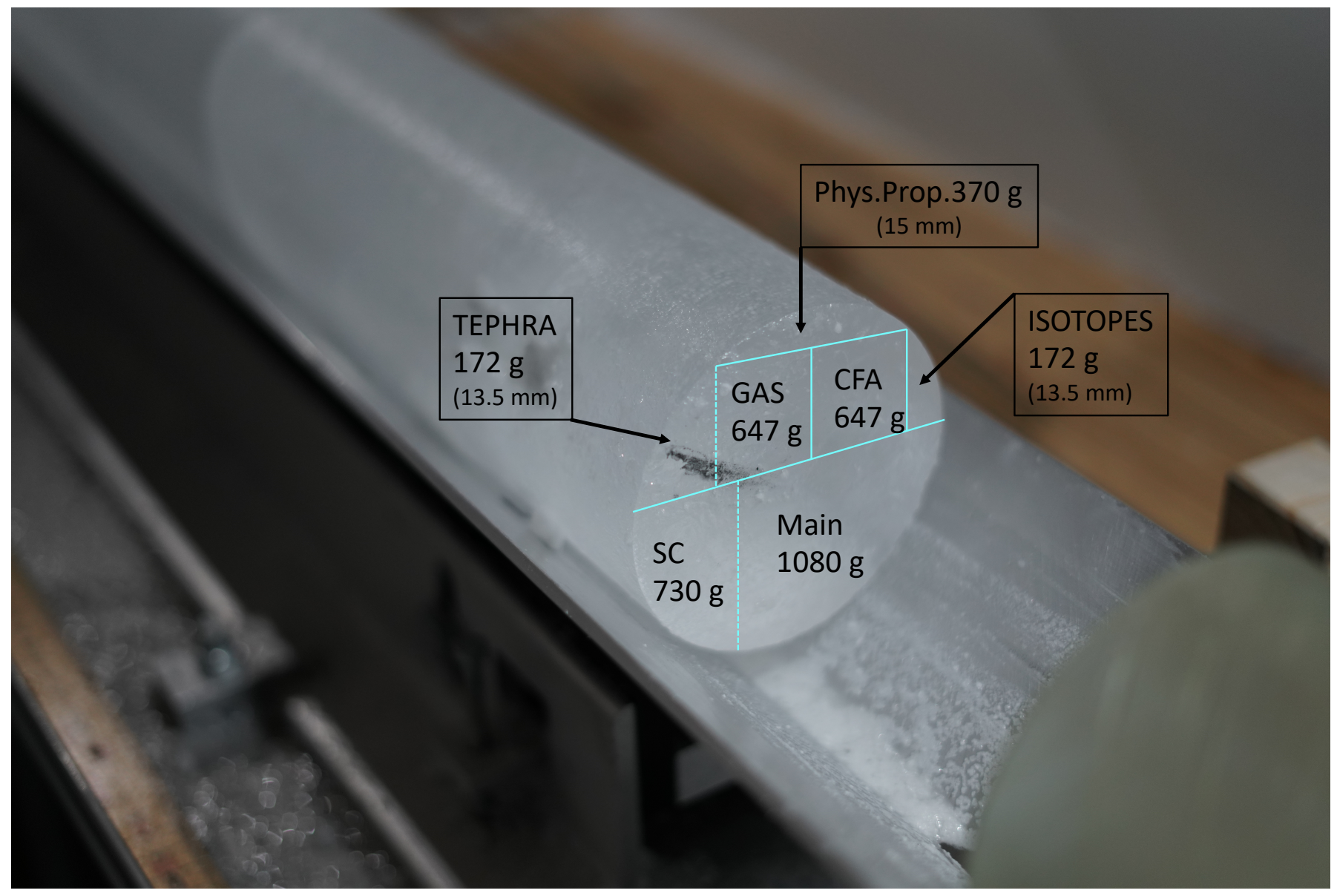

Figure 1.7-Cutting lines of a sample section from the EGRIP ice core. The ice core is split into the different aliquots with a horizontal band saw, or swiss saw (a vertical saw). Photo taken by Sepp Kipfstuhl. 


\section{Workflow of the PhD dissertation}

Figure 1.8 shows the simplified workflow of this $\mathrm{PhD}$ dissertation and the relationship between methods and data sets. Some data sets were measured and processed from the Greenland ice sheet for this $\mathrm{PhD}$ study (e.g. the EGRIP project), and some data sets were proceeded and investigated from previous Greenland ice core projects (e.g. NGRIP, NEEM). Figure 1.8a presents the measurement and calibration of DEP data and then combines these data with other data sets for different aspects of glaciology and paleoclimatology. Figure 1.8b illustrates the data sets (green arrows) and methods for a numerical forward radar modelling study with airborne radar measurements such as AWI and CReSIS data to investigate internal layers inside the Greenland Ice Sheet (Chapter 3). Figure 1.8c shows (yellow arrows) refers to the research conducted to establish the ice chronology for the EGRIP ice core project with GICC05 timescale (Chapter 2). Figure 1.8d illustrates (pink arrows) the study carried out in which the DEP, ECM and tephra ice core records with climate simulations and other climate proxy records were evaluated to identify massive volcanic eruptions (Chapter 4). Other future studies are in preparation. In these studies, I will investigate if the tephra layers along the ice cores have associated with ECM and DEP peaks along the NEEM, NGRIP and GRIP ice cores for the GS-1, GI-1 (a-c), GI-1 (d-e) and GS-2.1 periods (11.7 and $17.4 \mathrm{ka} \mathrm{b} 2 \mathrm{k})$. A further study is focused on the Holocene period along the NGRIP, EGRIP, Renland and NEEM ice cores. 


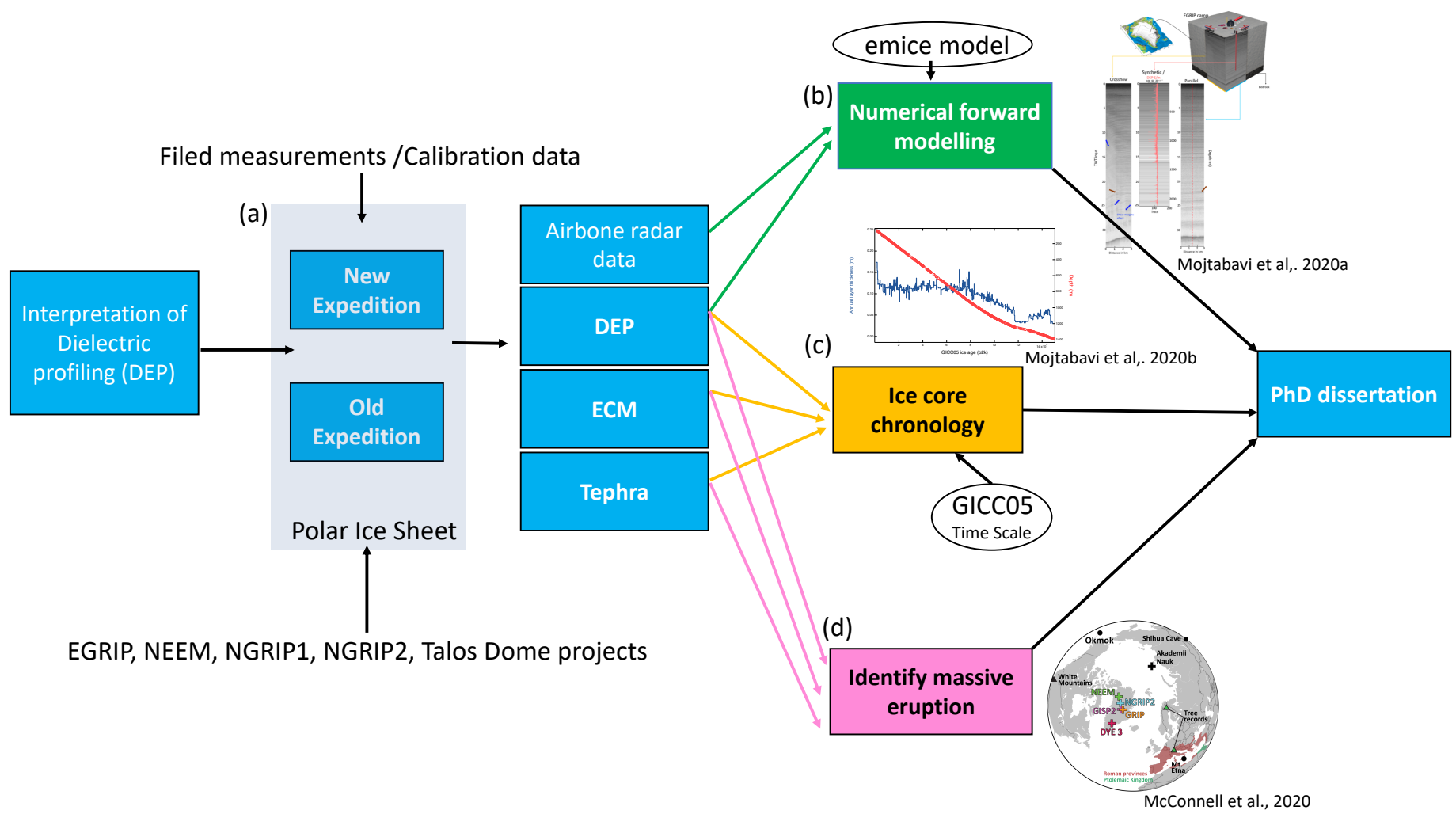

Figure 1.8 - Workflow of this $\mathrm{PhD}$ dissertation 

Chapter 2

\title{
A first chronology for the East GReenland Ice-core Project (EGRIP) over the Holocene and last glacial termination ${ }^{\dagger \ddagger}$
}

\author{
Seyedhamidreza Mojtabavi ${ }^{1,2}$, Frank Wilhelms ${ }^{1,2}$, Eliza Cook $^{3}$, Siwan Davies ${ }^{4}$, Giulia \\ Sinnl $^{3}$, Mathias Skov Jensen ${ }^{3}$, Dorthe Dahl-Jensen ${ }^{3,5}$, Anders Svensson ${ }^{3}$, Bo Vinther ${ }^{3}$, \\ Sepp Kipfstuhl ${ }^{1,3}$, Gwydion Jones ${ }^{4}$, Nanna B. Karlsson ${ }^{1,6}$, Sergio Henrique Faria ${ }^{7,8,9}$, \\ Vasileios Gkinis ${ }^{3}$, Helle KJer ${ }^{3}$, Tobias Erhardt ${ }^{10}$, Sarah M. P. Berben ${ }^{11}$, Kerim H. \\ Nisancioglu ${ }^{11,12}$, Iben Koldtoft ${ }^{3}$, Sune Olander Rasmussen ${ }^{3}$
}

\begin{abstract}
${ }^{1}$ Alfred-Wegener-Institut Helmboltz-Zentrum für Polar-und Meeresforschung, Bremerhaven, Germany ${ }^{2}$ Department of Crystallography, Geoscience Centre, University of Göttingen, 37073 Göttingen, Germany ${ }^{3}$ Physics of Ice, Climate and Earth, Niels Bohr Institute, University of Copenhagen, Denmark ${ }^{4}$ Department of Geography, College of Science, Swansea University, Swansea, Wales, UK ${ }^{5}$ Center for Earth Observation Science, University of Manitoba, Winnipeg, Canada ${ }^{6}$ Geological Survey of Denmark and Greenland, Copenhagen, Denmark ${ }^{7}$ Basque Centre for Climate Change (BC3), 48940 Leioa, Spain ${ }^{8}$ Nagaoka University of Technology, 940-2188 Nagaoka, Japan ${ }^{9}$ IKERB ASQUE, Basque Foundation for Science, 48011 Bilbao, Spain ${ }^{10}$ Climate and Environmental Physics, Physics Institute and Oeschger Center for Climate Change Research, University of Bern, Sidlerstrasse 5, 3012 Bern, Switzerland ${ }^{11}$ Department of Earth Science, University of Bergen, Bjerknes Centre for Climate Research, Allégaten 41, 5007, Bergen, Norway ${ }^{12}$ Centre for Earth Evolution and Dynamics, University of Oslo, Oslo, Norway
\end{abstract}

\section{Abstract}

This paper provides the first chronology for the deep ice core from the East GReenland Ice-core Project (EGRIP) over the Holocene and late last glacial period. We rely mainly on volcanic events and common patterns of peaks in dielectric profiling (DEP), electrical conductivity measurements (ECM) and tephra records for the synchronization between the EGRIP, NEEM and NGRIP ice cores in Greenland. We transfer the annual-layer-counted Greenland Ice Core Chronology 2005 (GICC05) timescale from the NGRIP core to the EGRIP ice core by means of 381 match points. The NEEM ice core is only used for supporting match-point identification. We name our EGRIP time scale GICC05-EGRIP-1. Over the uppermost $1383.84 \mathrm{~m}$, we establish a depth-age relationship dating back to 14,967

\footnotetext{
${ }^{\dagger}$ published as discussion paper Mojtabavi et al. (2020b). "A first chronology for the East GReenland Ice-core Project (EGRIP) over the Holocene and last glacial termination", Clmate of the Past, (2020) https://cp.copernicus.org/preprints/cp-2019-143/

${ }^{\ddagger}$ Note: the final version published as "A first chronology for the East Greenland Ice-core Project (EGRIP) over the Holocene and last glacial termination, Clim. Past, 16, 2359-2380, bttps://doi.org/10.5194/cp-16-2359-2020, 2020." bttps://cp.copernicus.org/articles/16/2359/2020/cp-16-2359-2020.btml
} 
a b2k (years before the year $2000 \mathrm{CE}$ ). Tephra horizons provide an independent validation of our match points. In addition, we compare the ratio of annual layer thicknesses between ice cores in-between the match points to assess our results in view of the different ice-flow patterns and accumulation regimes of the different periods and geographical regions. This initial timescale is the basis of interpretation and refinement of the presently derived EGRIP high-resolution data sets of chemical impurities.

\section{Introduction}

The dating of an ice core establishes the depth-age relationship to derive a chronology of past climatic conditions from the measured proxy parameters. The proxy parameters reflect past atmospheric conditions and biogeochemical events along the core. Concerning the ice sheet as a whole, the depth-age relation is needed to map the ice sheet's internal architecture to interpret and understand the climatic evolution and the behaviour of ice streams (MacGregor et al., 2015). This is a particular focus of the East GReenland Ice-core Project (EGRIP). The drill site has been chosen close to the onset of the North East Greenland Ice Stream (NEGIS) (see Fig. 2.1), which is the largest ice stream of the Greenland ice sheet (Joughin et al., 2010, 2018). A main objective of the EGRIP project is to study the dynamics of the ice flow in the NEGIS ice stream by analysing the ice core's rheology and its relation to the deformation of the ice.

The main objective of this work is to facilitate analysis of the data from the core by transferring the GICC05 timescale, which has already been transferred from NGRIP to the GRIP, GISP2, and NEEM deep ice cores (Seierstad et al., 2014; Rasmussen et al., 2013), to EGRIP by aligning features in the DEP and ECM data sets of the EGRIP, NGRIP and NEEM ice cores. We establish a timescale for the time period of the Holocene and the last glacial termination. We stop specifically at $15 \mathrm{ka} \mathrm{b} 2 \mathrm{k}$, as the density of the match points in the period of Holocene, GS-1 (often called the Younger Dryas) and GI-1 (or the Bølling-Allerød) is much higher than in the glacial (and especially in the Last Glacial Maximum, LGM). We present this timescale to enable climate studies while work on a revised layer-counted timescale is ongoing.

The GICC05modelext timescale was transferred from NGRIP to the North Greenland Eemian (NEEM) ice core by matching 787 match points of mainly volcanic origin identified in the electrical conductivity measurement (ECM) and dielectric profiling (DEP) records and - where available - verified by tephra horizons (Rasmussen et al., 2013). To apply this approach to the EGRIP core, we have profiled the upper $1383.84 \mathrm{~m}$ of the EGRIP core using ECM and DEP in the field during the 2017, 2018 and 2019 field seasons. We rely mainly on volcanic events as reflected in the common peak pattern in the DEP and ECM records for the synchronization between the EGRIP ice core and the NGRIP1 and NGRIP2 cores. The NEEM ice core is included in order to support match-point identification, while the GICC05 ages are transferred from NGRIP to EGRIP. Three identified tephra horizons independently verify the correct match of the ice cores. 

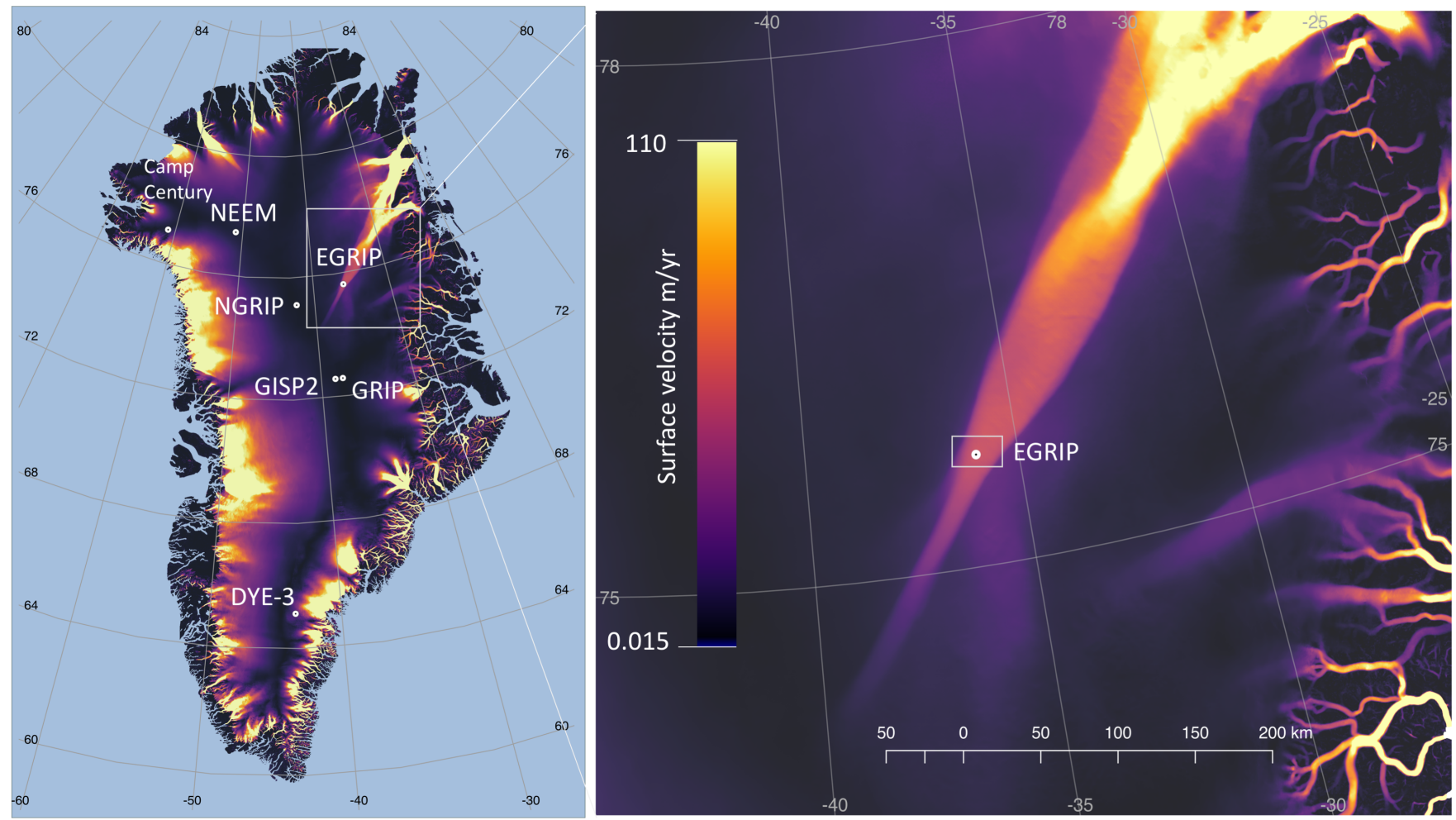

Figure 2.1 - Locations of deep ice-core drill sites: EGRIP, NEEM, NGRIP, GRIP, GISP2, DYE-3, and Camp Century in Greenland, and close-up of the EGRIP drill site inside the North East Greenland Ice Stream (NEGIS). Colours show surface flow velocities from satellite data (Joughin et al., 2018).

\section{Data and methods}

\section{GICC05}

The annual-layer-counted Greenland Ice Core Chronology 2005 (GICC05) is derived from measurements of stable water isotopes in the DYE-3, GRIP and NGRIP (see Fig. 2.1) ice cores for the period back to 7.9 ka b2k (Vinther et al., 2006) and high-resolution measurements of chemical impurities, conductivity of the ice, and visual stratigraphy from the GRIP and NGRIP ice cores for the period between $7.9 \mathrm{ka}$ and $14.7 \mathrm{ka} \mathrm{b2k}$ (Rasmussen et al., 2006). For the period from $14.7 \mathrm{ka}$ to $42 \mathrm{ka} \mathrm{b2k}$, the dating of the cores is based on annual layer counting in the visual stratigraphy, the electrical conductivity profiles, and a set of chemical impurities data (Andersen et al., 2006). The timescales are compared to time scales of different other climate archives at suitable tie points, like e.g. marine sediment cores (Svensson et al., 2006). For the NGRIP core, the GICC05 time scale has been extended even further into the glacial, back to $60 \mathrm{ka}$ b2k by annual layer counting (Svensson et al., 2008) and ice-flow modelling (Wolff et al., 2010). For the older parts (Wolff et al., 2010) the NGRIP ss09sea06bm model time scale, shifted to younger ages by 705 years, has been spliced onto the end of the GICC05 timescale, thereby forming the so-called GICC05modelext chronology. The GICC05modelext was also applied to the central Greenland GRIP and GISP2 
cores by more than 900 marker points and verification with 24 tephra horizons (Seierstad et al., 2014). In summary, the GICC05modelext timescale is the consistent reference frame for the entirety of Greenland deep cores.

Previous studies assessed the differences between independent timescales of Holocene paleoclimate records. Adolphi and Muscheler (2016) indicated that the GICC05 counting error underestimates the total uncertainty in some parts of the Holocene based on the comparison between the radiocarbon dating calibration curve (Reimer et al., 2013, IntCal13) and (Svensson et al., 2008, GICC05), and the work was extended in Adolphi et al. (2018). The objective of this work, however, is to extend GICC05 to the EGRIP core to allow parallel analysis of the records, and we thus refrain from a further discussion of the absolute accuracy of GICC05 here.

\section{Ice-core data sets over the Holocene and last glacial termination}

\subsubsection{EGRIP}

Here, we processed and analysed new DEP and ECM records and selected cryptotephra layers in the uppermost $1383.84 \mathrm{~m}$ of the EGRIP ice core. At the start of the drilling operation in 2016, the drilling site was located at $75^{\circ} 38^{\prime} \mathrm{N}$ and $35^{\circ} 60^{\prime} \mathrm{W}$ (see Fig. 2.1). The average annual accumulation rate is about $100 \mathrm{~kg} \mathrm{~m}^{-2} \mathrm{yr}^{-1}$ (equivalent to $0.11 \mathrm{~m} \mathrm{yr}^{-1}$ of ice) for the period 1607-2011 as determined from a firn core close to the main EGRIP drilling site (Vallelonga et al., 2014). Radar-soundings suggest the ice thickness to exceed $2550 \mathrm{~m}$ and traced radar layers from the NGRIP site suggest that the drill site preserves an undisturbed climatic record of at least $51 \mathrm{kyr}$ (Vallelonga et al., 2014). The camp currently moves about $51 \mathrm{~m}$ to the North-Northeast each year (Dahl-Jensen et al., 2019). Fig. 2.2 presents an overview of the ice-core sections we used in this study. The EGRIP brittle zone is of better quality than the brittle ice from previous Greenland ice core projects such as NEEM and NGRIP. For the EGRIP core, Fig. 2.3 presents a quality index on the basis of the ratio between validated and total measured DEP and ECM sample points. This quality index falls below 0.3 between $505 \mathrm{~m}$ ( $4220 \mathrm{a} \mathrm{b} 2 \mathrm{k})$ and $1210 \mathrm{~m}$ (11163 a b2k) depth, which is consistent with the brittle zone between $550 \mathrm{~m}$ and $1250 \mathrm{~m}$ according to the field season reports (Dahl-Jensen et al., 2019). The quality index calculated from the earlier released NGRIP and NEEM DEP data is presented in Appendix 7 "Quality index for the NGRIP and NEEM ice cores".

\subsubsection{NGRIP}

The GICC05modelext timescale, as discussed in detail in section 2.1 above, is well established for the NGRIP ice core. To fully exploit the potential of DEP records for matching, we processed unpublished DEP data from the NGRIP1 core for the upper part (down to $1298 \mathrm{~m}$ ), and we used the NGRIP2 (below $1298 \mathrm{~m}$ ) that was published with the NGRIP ECM data in Rasmussen et al. (2013). The NGRIP1 and NGRIP2 cores have a depth offset of around $0.43 \mathrm{~m}$ between corresponding events in the overlapping section (Rasmussen et al., 2013).

\subsubsection{NEEM}

The firn core NEEM-2008-S1 originates from the NEEM access hole of the main core, drilled during the 2008 field season to a depth of $103 \mathrm{~m}$ (Gfeller et al., 2014). We used only ECM data for the matching the upper $100 \mathrm{~m}$, as DEP was not measured on the access-hole core. Below this depth, both DEP and ECM were used to transfer the GICC05 timescale from the NGRIP to the NEEM core (Rasmussen et al., 2013). The shallow and deep cores overlap, forming a continuous record. 


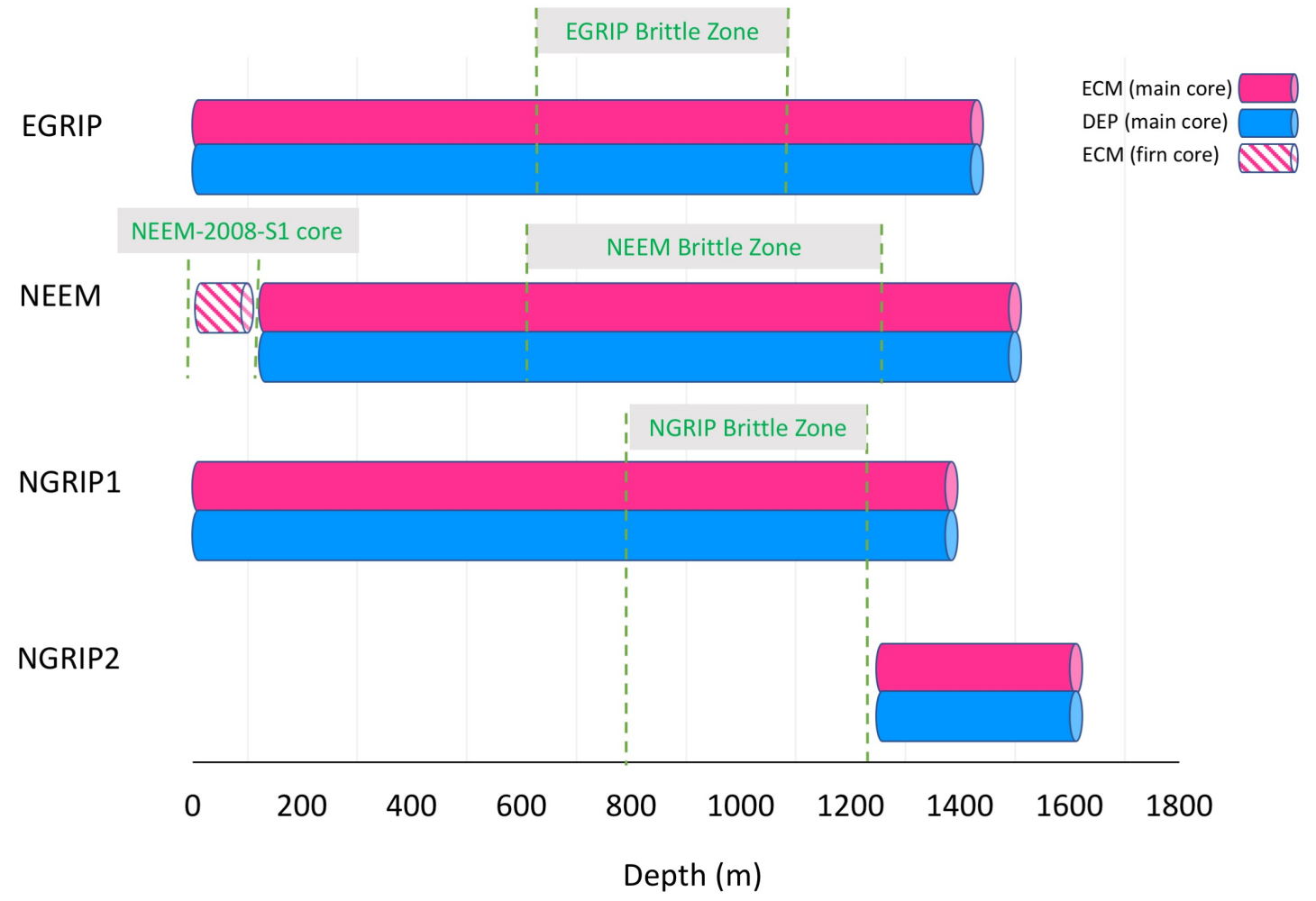

Figure 2.2- Overview of dielectrical profiling (DEP) and electrical conductivity measurements (ECM) that we used for the synchronization between ice cores over the Holocene and late last glacial periods.

\section{Field measurements and data processing}

\subsubsection{Dielectric profiling (DEP)}

Dielectric Profiling (DEP) has been introduced as a system for rapid scanning of ice cores' electric permittivity and conductivity shortly after drilling (Moore and Paren, 1987; Wilhelms et al., 1998). The permittivity and conductivity of ice and firn are determined by their respective densities and conductivities (Wilhelms, 2005). The conductivity is related mainly to acidity, salt and ammonia concentrations of ice cores (Moore et al., 1992; Moore et al., 1994). The dielectric stratigraphy of the EGRIP, NEEM and NGRIP cores were recorded directly during the field seasons with the DEP device described by Wilhelms et al. (1998) (Fig. 2.4), in the discussion below referred to as "deep-core DEP”. DEP is the first measurement within the processing line directly on site. A few minutes before scanning, the core is moved from the core storage to the DEP table. Further along the processing line, the ice core is split into the different aliquots. For all three ice cores, DEP measurements were carried out on $1.65 \mathrm{~m}$ long sections (Fig. 2.4d).

All cores were scanned with the deep-core DEP device as described in Wilhelms (1996) and Wilhelms et al. (1998) and the entire scan of a core's section was calibrated with average values of the calibration measurements. For the processing of the NGRIP and NEEM cores we have improved some features and adapted procedures that were 
Chapter 2. A first chronology for the East GReenland Ice-core Project (EGRIP) over the Holocene and

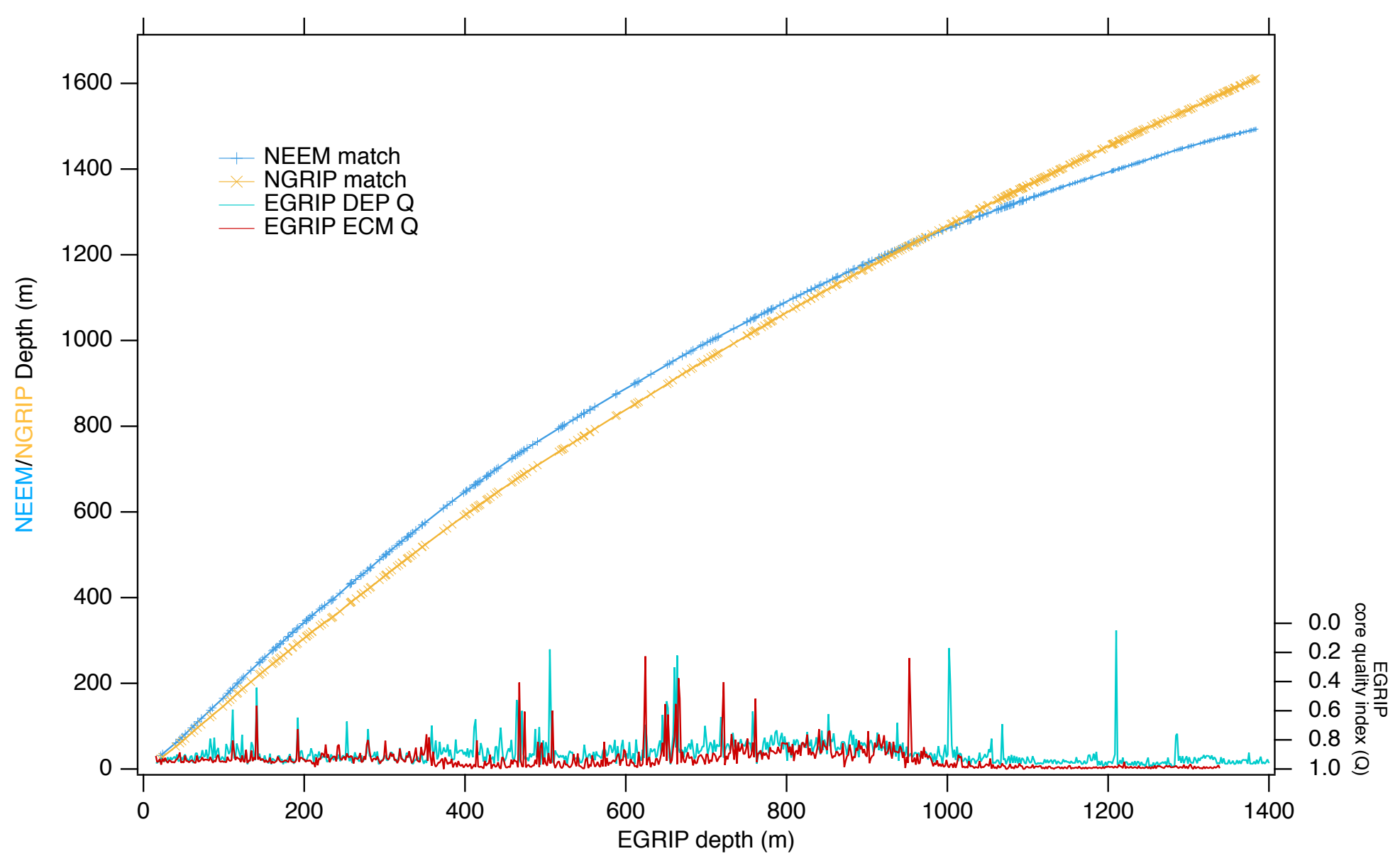

Figure 2.3 - Match points between EGRIP, NEEM (blue) and NGRIP (yellow) ice cores based on the DEP and ECM data sets. The core quality index $\mathrm{Q}$ as derived from the validated DEP (blue) and ECM (red) data, respectively.

developed for a different DEP device (Wilhelms, 2000), not yet described elsewhere in the application for the processing of data recorded with the deep-core DEP device. The identification of peaks is sufficient for the discussion in this paper. However, the data released with this paper will also be valuable for investigations relying on wellcalibrated material properties with absolute calibration, like e.g. modelling of synthetic radargrams. To provide a comprehensive presentation of the basis of the transfer of the timescale here, we outline the relevant discussion to operating the DEP system, while the related discussion on precision of the measured material properties, which are of more relevance for later use of the calibrated data, are presented in Appendix 8 "Calibration and corrections to the DEP data".

Due to the drilling procedure and properties of the ice, ice cores can exhibit breaks, broken-off slices or may in some instances (especially in the brittle zone) be fragmented (Fig. 2.4b). The missing pieces and free surfaces with possibly high conductivity have the potential to introduce artefacts into the DEP record. These are clearly identifiable in the permittivity record by dropping spikes. For the validation of the data, any drop in permittivity below a certain threshold (cf. the red line in Fig. 2.5) identifies a spike to be rejected, where the segment to be rejected is extended from the spike to where the signal approaches the average of the permittivity record. The automated 


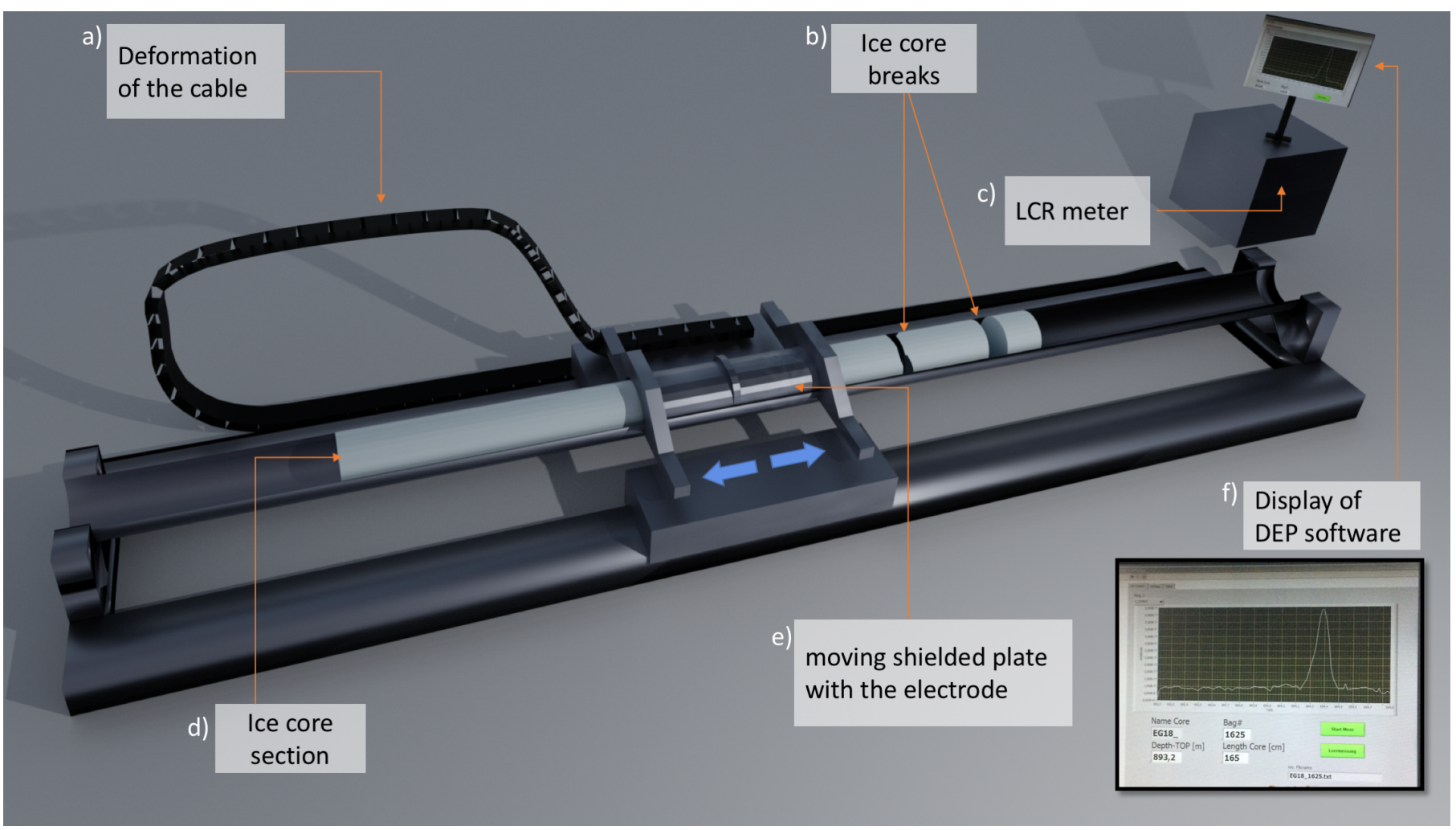

Figure 2.4-Schematic of the DEP instrument.

procedure as described in Rasmussen et al. (2013) (section 2.3) is much faster, more consistent in between the three different cores, and has proven to be superior to any approach based on a hand-written protocol, which depends on the judgement of the operator when identifying intervals of bad core. As the permittivity is very sensitive to bad core quality and the conductivity is much less prone to bad core quality, the outlined validation procedure leads to a robustly validated conductivity record.

The automated validation straight forwardly leads to a definition of a core quality index $Q \in[0,1]$ by calculating the total length of validated core sections divided by the standard DEP and ECM run lengths of $1.65 \mathrm{~m}$ for all three cores. For the EGRIP core, the core quality indices as derived from the DEP and ECM records, respectively, are presented in Fig. 2.3.

When processing the EGRIP core, over a certain period the operators erroneously did not reset the starting position of the scanning electrode of the DEP device. This is clearly identifiable in the records and resulted in recording already ahead of the core's top depth (blue arrows in Fig. 2.6), then taking measurements over the (correctly set) length of the section, but missing the corresponding length at the bottom end of the core section. The respective core sections have been shifted accordingly, but the missing end sections, which were not recorded, cannot be recovered. The reconstructed DEP record was compared and validated against the ECM record to assign the correct depths. The section about $1285-1385 \mathrm{~m}$ was corrected in this way, where in total about $8.5 \mathrm{~m}$ of the $100 \mathrm{~m}$ were not measured. Furthermore, we relied more heavily on the ECM record than on the DEP record when matching peaks within sections with known problems. Fig. 2.6 illustrates the corrections in the interval 1299.10-1302.05 m, where 


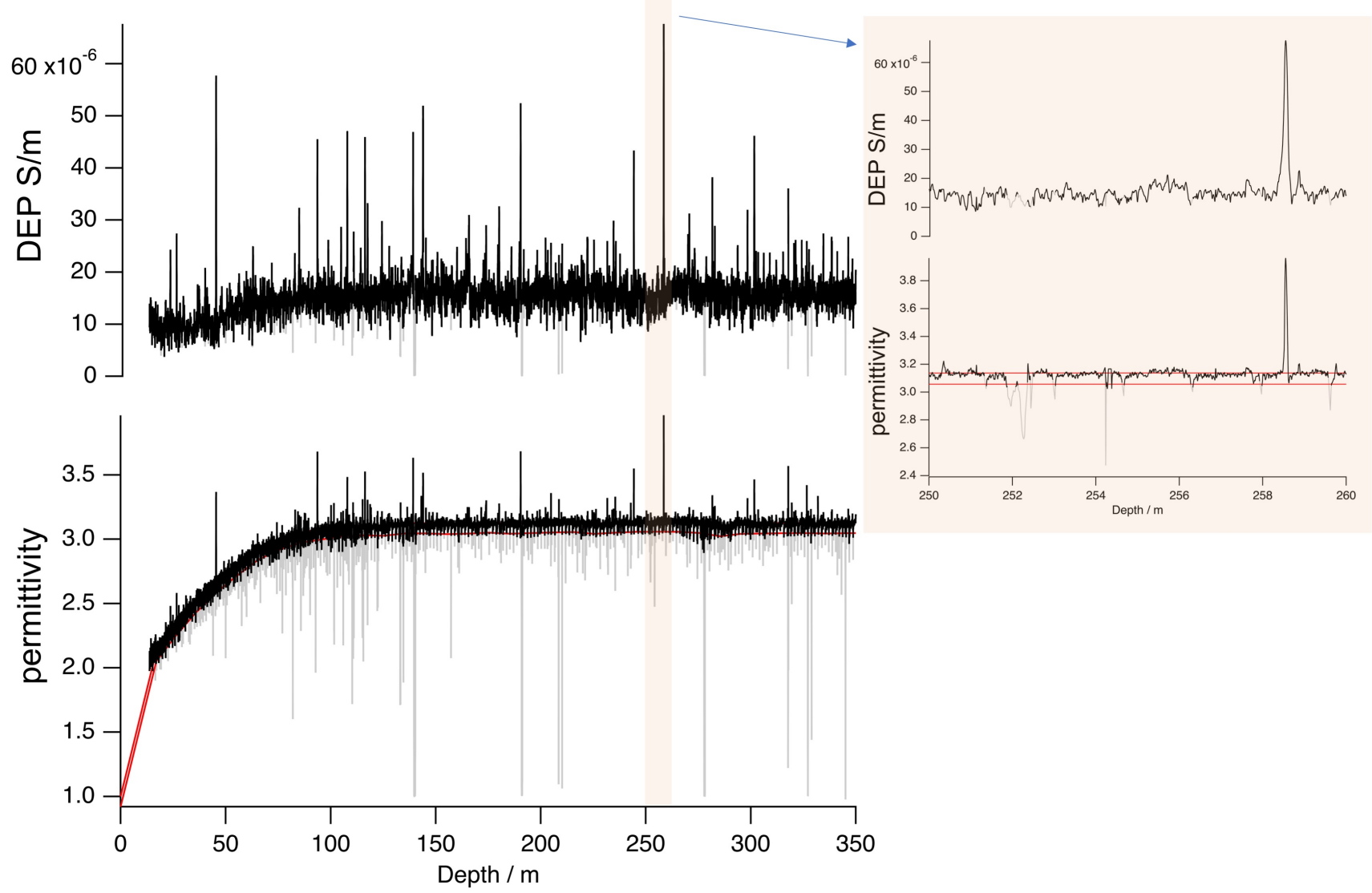

Figure 2.5 - Example of DEP data processing (removing core breaks from the raw data). Raw data is plotted in grey and validated data in black. We define insufficient data by permittivity drops below the threshold (indicated by the red line) and reject it during validation. Permittivity is presented in the top and conductivity in the bottom diagram. The insert shows the details for a short section $(250-260 \mathrm{~m})$.

a $35 \mathrm{~cm}$ data gap between two scanned sections cannot be reconstructed as it was not recorded due to the wrong positioning of the electrode.

\subsubsection{Electrical conductivity measurements (ECM)}

For the EGRIP core, we recorded ECM profiles with the technique described by Hammer (1980) directly in the field. The ECM signal is related to acidity concentrations of ice cores, even with high concentrations of neutral salt (Moore et al., 1992). NGRIP (Dahl-Jensen et al., 2002) and NEEM (Rasmussen et al., 2013) were measured using similar equipment during the respective processing campaigns in the field. For each measurement, the hand-dragged ECM instrument was moved along the depth axis of the ice-core sections' microtome-polished surface (three-bag sections, about $1.65 \mathrm{~m}$ long). In order to calibrate the ECM data, as described in Rasmussen et al. (2013), the ice temperature was measured for each run. In addition, to ensure the ECM quality, we repeated our measurement at least twice for each core section and checked the profiles for the best quality of the measurements. Also, the corebreak positions were registered along with measurement by moving the electrodes of the ECM instrument to the respective break position after the core scan, and registering the position in the data file. During the processing, 

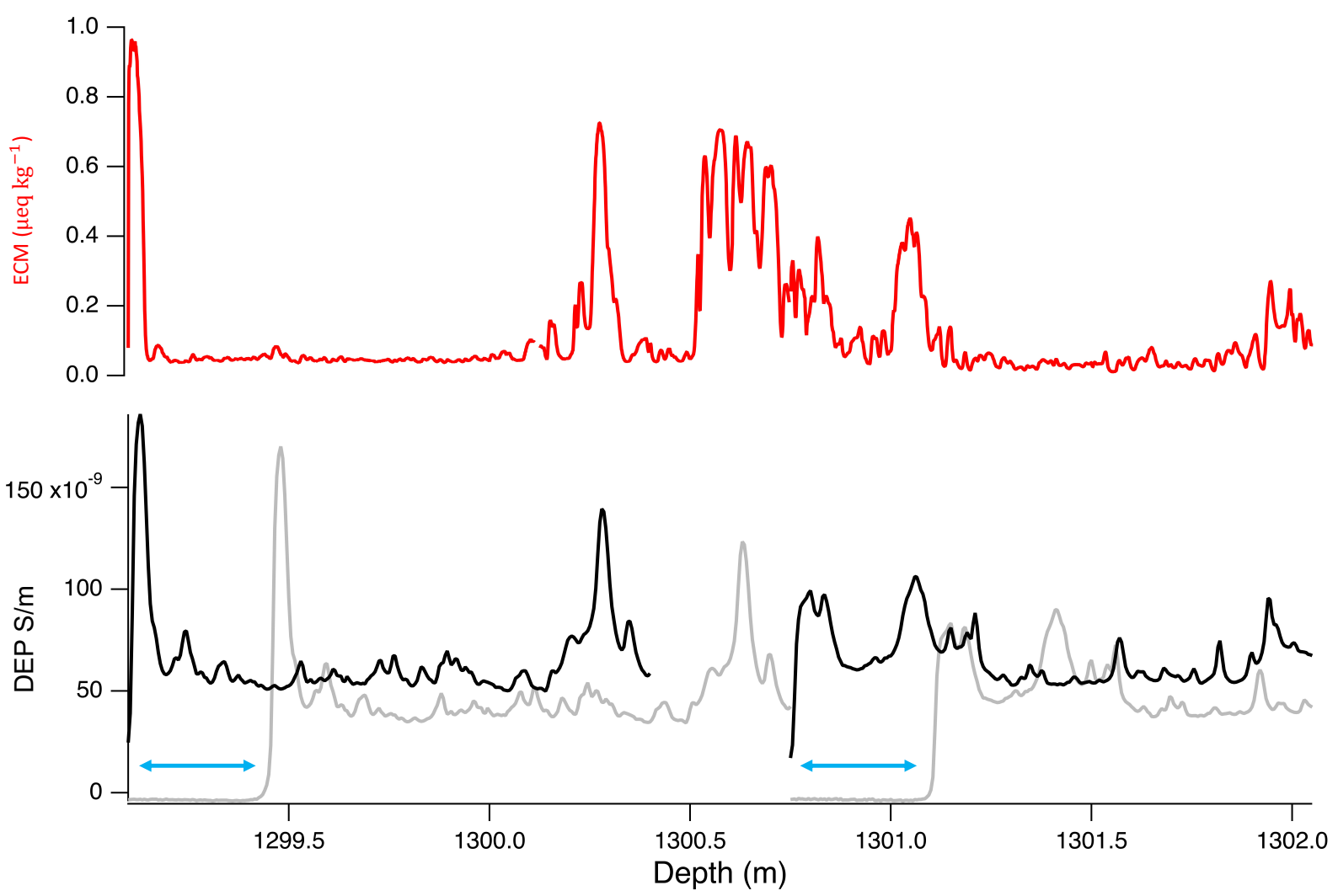

Figure 2.6 - Example of the DEP data gap length and relative precision of ECM vs DEP depth assignment. The DEP measurement with a wrong depth in grey and after shifting depth in black. There is a gap of $35 \mathrm{~cm}(1300.4-1300.75$ $\mathrm{m}$ ) between two DEP measurements. Blue arrows show the early measurements before the starting position of the core. Corresponding ECM data in red.

these recorded break marks were used to trim off artefacts and produce the final ECM data set. Data from each day were calibrated using independent measurements of the physical dimensions of the ECM measurement setup. The first and last few millimetres of recorded data are affected by the proximity to the end of the core and were removed. Areas with dips in the signal around logged core breaks were also muted during processing. Details on the acquisition and processing of the ECM record are laid out in Appendix 9 "Details on the ECM procedures".

The ECM current, $i$ (in $\mu A$ ), was converted to ice acidity (in $\mu$ equiv. $H^{+} \mathrm{kg}^{-1}$ ) by using the relationship $\left[H^{+}\right]=0.045 \times i^{1.73}$, as suggested by Hammer (1980). Even though conversion from current to acidity and calibration curves have been shown to be ice-core dependent, the matching and synchronization of the ice cores is independent of the absolute values of the calibrated ECM signal as it relies on recognition of similar patterns and peaks in the acidity records (Rasmussen et al., 2013).

The quality of the processed data were checked by comparing independently processed ECM data by three investigators. No major disagreements were found when comparing, and one set of data was agreed on for further use in matching. 


\subsubsection{Tephra horizons}

The EGRIP core was continuously sampled for tephra analysis in the field to maximize the probability for detection of volcanic ash deposits, particularly invisible deposits that exhibit low concentrations and/or small grain sizes, known as cryptotephra (Davies, 2015). An aliquot of ice was prepared from the outer curved edge of each $55 \mathrm{~cm}$ ice core section and subsampled at $11 \mathrm{~cm}$ resolution, providing approximately $30 \mathrm{ml}$ of meltwater per sample. Samples from sections with either significant peaks (Fig. 2.4f) in the DEP and ECM or visible layers were separated and prioritized for screening, whereby centrifuged samples were evaporated onto frosted glass microscope slides and covered in epoxy resin to enable scanning by high-magnification light microscopy, as described by Cook et al. (2018). Electron probe micro-analysis (EPMA) by wavelength dispersive spectrometry (WDS) was performed to determine the major element composition of individual grains in each deposit (Hayward, 2012) and EPMA measurements were performed using a Cameca SX100 electron probe microanalyzer at the Tephrochronology Analytical Unit, University of Edinburgh. This system has five wave dispersive (WD) spectrometers and was calibrated daily using internal calibration standards as described by Hayward (2012). With optimized instrument settings for the analysis of small cryptotephra grains ( $<20 \mu \mathrm{m}$ diameter), EGRIP samples were analysed with either a 5 or $3 \mu \mathrm{m}$ beam diameter. Secondary standards were analysed to capture instrument drift. The geochemical composition of each layer was compared to deposits in NGRIP and positive matches were used to establish the independent tie-points in between cores listed in Table 2.1. Major element biplots (Fig. 2.7) show graphical correlations for each NGRIPEGRIP tephra match point, and these are supported by similarity coefficient (Borchardt et al., 1972) and statistical distance $\left(\mathrm{D}^{2}\right)$ (Perkins et al., 1995, 1998) tests.

Table 2.1 - Geochemical matches between EGRIP and NGRIP were supported by the similarity coefficient test (SC) of Borchardt et al. (1972) and statistical distance (D2) test of Perkins et al. $(1995,1998)$. Here we provide SC and D2 values for major elements (normalized to 100\%) where 5 major elements (with $>\% 1 \mathrm{wt}$ ) were used for SC calculations for sample pairs with rhyolitic composition and 7 elements were used for sample pairs with basaltic composition. Values $>0.95$ suggest products are from the same volcanic source. For D2, seven major elements were used for the comparisons (with $>0.01 \% \mathrm{wt}$ ). The value for testing the statistical distance values at the $99 \%$ confidence interval is 18.48 (seven degrees of freedom).

\begin{tabular}{lllll}
\hline EGRIP Bag & Depth range & NGRIP /GRIP match & SC & $D^{2}$ \\
\hline 177 & $96.91-97.02 \mathrm{~m}$ & NGRIP 142.61-142.71 m & 0.985 & 1.65 \\
1627 & $894.41-894.52 \mathrm{~m}$ & NGRIP 1163.65-1163.80 m & 0.977 & 4.88 \\
2094 & $1151.59-1151.70 \mathrm{~m}$ & NGRIP 1408.88-1408.89 m (Mortensen et al., 2005) & 0.965 & 5.945 \\
\hline
\end{tabular}

\section{Synchronization of dielectric profiling and electrical conductivity mea- surement records of EGRIP, NGRIP NEEM}

Patterns in the DEP records of NGRIP, NEEM and EGRIP were initially matched by one investigator. The same cores' ECM data were matched separately and independently by three different investigators. Both matches are mainly based on clearly identifiable volcanic peaks and also synchronous patterns of other events (see Fig. 2.8), which not necessarily need to be of volcanic origin, but are assumed to reflect synchronous events. Based on these indepen- 

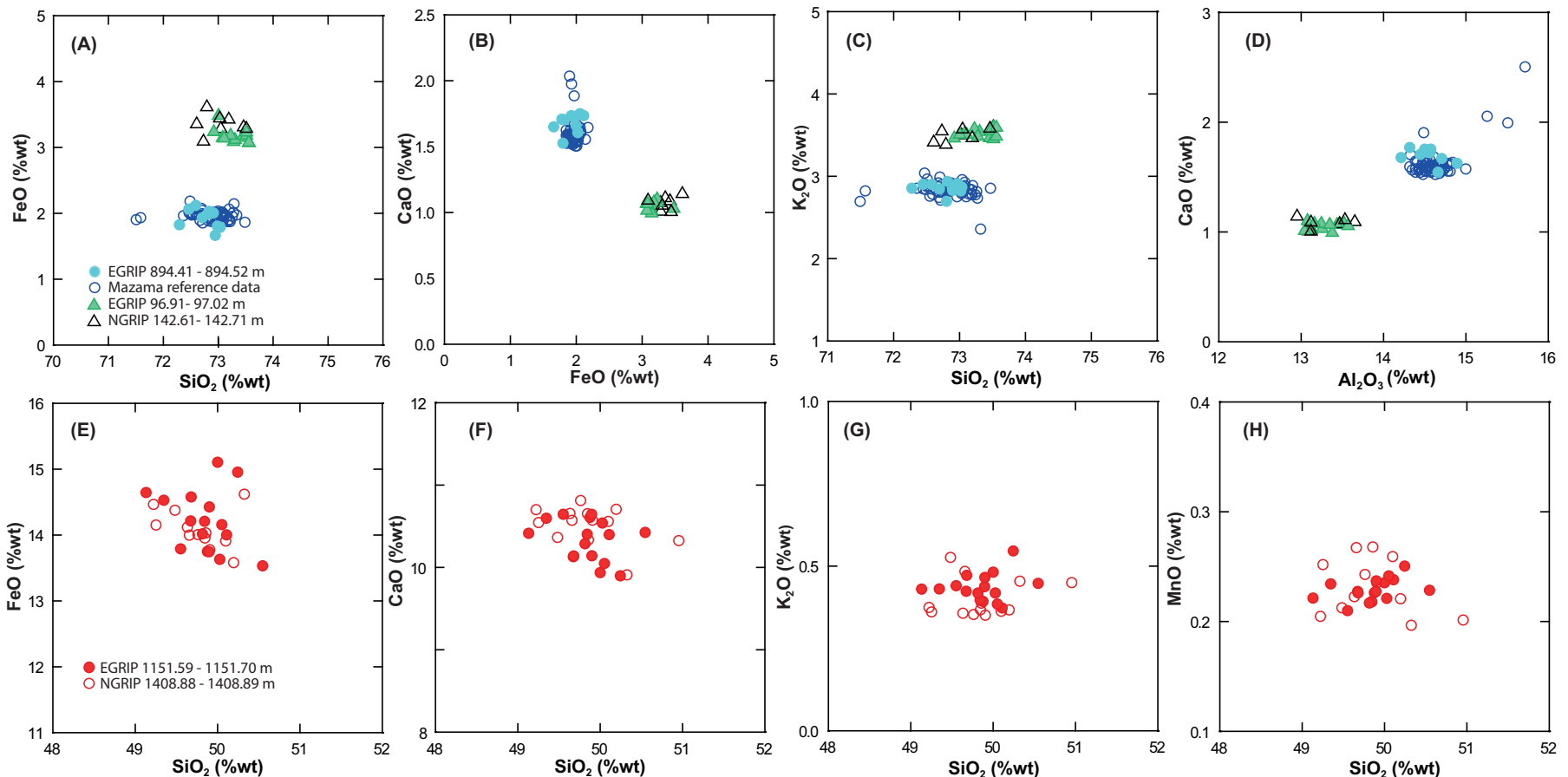

Figure 2.7 - Element-element biplots showing geochemical matches between EGRIP and NGRIP samples with the exception of EGRIP 894.41-894.52 m (EGRIP bag 1627), which is shown here with Mazama data from Jensen et al. (2019). Geochemical data are normalised to 100\% (anhydrous basis) and analyses with totals below $94 \%$ wt were excluded. Plates (A-D) for EGRIP bags 177 and 1627, Plates (E-H) for EGRIP bag 2094.

dent matches, the four investigators identified consistent and reliable common patterns, that are represented in the ECM and/or the DEP records from NGRIP and at least one of the other ice cores. For the confirmation of match points, all records of all three cores were loaded into the Matchmaker tool (Rasmussen et al., 2013) and assessed jointly by all four investigators in the different display options featured by the software. The Matchmaker tool allows easy identification of wrong match points via interactive plots and on-line evaluation of the match. To validate match points, we plot the depths of the common match points $D_{i}$ (in EGRIP or NEEM) against $d_{i}$ (NGRIP). The slope of each of these (depth, depth)-curves is the annual layer thickness ratio of the two cores, $r_{i}=\frac{D_{i+1}-D_{i}}{d_{i+1}-d_{i}}$. Points which deviate from the (depth, depth) curve or create jumps in $r$, are easily recognized and checked again. We only expect significant abrupt changes in $r$ at times where the climate (and thus the relative accumulation rates) shifts due to changes in climate conditions (Rasmussen et al., 2006, 2013; Seierstad et al., 2014; Winski et al., 2019), while the different ice-flow patterns at the cores' sites only lead to slow changes in $r$.

Short-term accumulation variability due to both climatic factors and wind-driven redistribution of snow on the surface can lead to relatively large variations in the ratio of layer thicknesses between different cores, especially when match points are only a few years apart. To reduce short-term accumulation-rate variability in the final timescale, we 
re-evaluated intervals with large variability in annual-layer-thickness ratios, and removed too closely spaced match points. The final minimum distance between match points is $0.22 \mathrm{~m}(1206.45 \mathrm{~m}-1206.67 \mathrm{~m})$, corresponding to around 3 years. Overall, the match points are reasonably evenly distributed throughout the entire ice core, and the maximum distance between neighbouring match points is $26.6 \mathrm{~m}$ ( $490.06 \mathrm{~m}-516.67 \mathrm{~m})$, corresponding to a time interval of 224 years.

\section{Transfer of the GICC05 timescale to the EGRIP ice core}

The procedure of transferring the timescale is similar to the approach described in (Rasmussen et al., 2013). Note that we hereby assume that the ratio of annual layer thicknesses is constant between the match points of EGRIP and NGRIP. For each $0.55 \mathrm{~m}$ EGRIP depth segment (the so-called $b a g$ ), we obtain the equivalent NGRIP depth by linear interpolation between the depths of the match points $D_{i}$ in EGRIP and $d_{i}$ in NGRIP. We then assign a GICC05 age from the annually resolved GICC05 time scale for NGRIP (Vinther et al., 2006; Rasmussen et al., 2006).

The EGRIP timescale inherits the maximum counting error (MCE) from the GICC05 timescale. Our match covers the time period back to 14,967 a b2k where the associated MCE is 196 a. The inaccuracies in the depth registration were estimated by (Rasmussen et al., 2013) to $10 \mathrm{~cm}(1 \sigma)$. For the joint assignment of DEP and ECM patterns, we repeat the assessment by (Rasmussen et al., 2013) for the (EGRIP depth, NGRIP depth) relation by computing the difference $\delta_{i}$ between each EGRIP match point and the linear interpolated depth derived from the neighbouring points $\delta_{i}=\left(D_{i+1}-D_{i-1}\right) /\left(d_{i+1}-d_{i-1}\right) *\left(d_{i}-d_{i-1}\right)+D_{i-1}-D_{i}$, thus merging all match points between EGRIP and NGRIP1 and EGRIP and NGRIP2 into one data set of 377 of the originally 381 match points for further statistical analysis. The difference in number occurs as $\delta$ is not defined for respective start and end points of both respective sequences. The statistical analysis of $\delta$ in Appendix 10 yields a standard deviation of $0.043 \mathrm{~m}$ for the depth assignment of a match point. As the annual layer thickness typically exceeds $0.04 \mathrm{~m}$ in the time period considered here, one expects an additional uncertainty for the peak assignment in the order of $1 \mathrm{yr}$.

Larger errors would occur in the case of erroneously matched sections as discussed in (Rasmussen et al., 2013), but wrong matches are even more unlikely here than in previous work, as three instead of two cores were matched and ibid. the authors also point out that erroneously matched sections are particularly relevant for the older part of the core, where the discussion here covers a section with comparably plentiful match points.

\subsubsection{Precision and accuracy of the time-scale transfer}

The central mode of the (depth, depth)-differences $\delta$ as defined above follows a Gaussian normal distribution with a standard deviation of $0.043 \mathrm{~m}$ (see Appendix 10). This demonstrates that the synchronization ties two cores together at the match points with high precision. Besides the central Gaussian normal distribution, the statistical analysis of $\delta$ identifies an overlaid second Gaussian normal distribution with a standard deviation of $0.19 \mathrm{~m}$. We interpret this distribution as stemming from curvature of the (depth, depth)-curve and as indicative of the average amount of detail, that each point contributes to the description of this curvature. As this difference between the actual match point and the linear interpolation between the neighbouring points depends on the variable curvature of the (depth, depth)-curve, which reflects both accumulation conditions and the evolution of glaciological conditions at both coring sites, the values of $\delta$ will generally be time correlated and cannot be expected to be randomly 
distributed with depth. We thus estimate that the EGRIP time scale may have time-correlated uncertainties relative to NGRIP of up to a handful of years related to changes in relative accumulation variability and ice-flow conditions not captured by the match points. This uncertainty will be largest in time periods far from the match points and near climatic shifts where the accumulation changed abruptly and not necessarily by the same ratio at different ice coring sites.

Now we assess the combined uncertainties. The GICC05 timescale $t(D)$ inherits the associated maximum counting error from GICC05, and given the analysis of $\delta$ above, we conclude that, at the match points, the time scale is precise relative to NGRIP within about one year $(1 \sigma)$. However, when we want to know the age at an arbitrary EGRIP depth, additional uncertainties apply due to the interpolation between the match points. There are two dominant sources: As discussed above, variations in relative accumulation rates and ice flow may add up to a handful of years of additional uncertainty relative to GICC05, but there is also a contribution from the choice of interpolation scheme in between the match points. The difference introduced by the choice between the most widely used linear and cubic spline interpolation schemes (Press et al., 1992) is about an order of magnitude larger than the above-mentioned random uncertainty associated with the identification of the match points (see Appendix 11).

We maintain linear interpolation for the time scale transfer despite the fact that the slope of the (depth, depth) curve changes instantaneously at the match points. While changes in this slope may in reality occur on many scales due to the intermittency of precipitation, wind-driven redistribution of snow, and relative changes in accumulation rates at the sites, the most significant of these changes are likely to happen at times of climate change rather than at the arbitrary depths of the match points. Considering this, one could consider an interpolation scheme where the change of curvature is distributed over the entire curve and/or concentrated at times of climate changes as derived from the proxies of the ice core. However, we believe that the advantage of obtaining a smoother (depth, depth)curve does not compare favourably to the additional assumptions needed and the added complexity of the time-scale transfer.

\section{Results and discussion}

\section{Synchronization of the EGRIP, NEEM and NGRIP cores}

A total of 257 match points between the EGRIP, NEEM and NGRIP1 ice cores and 124 match points between EGRIP, NEEM and NGRIP2 (total of 381 match points) with an additional three tephra horizons were identified. Fig. 2.8 shows an example section of ECM/DEP records matched between ice cores. The match points between the ice cores are shown on Fig. 2.3. In the process of combining match points from all investigators, some match points were removed due to differences in the peak shapes between DEP and ECM data or when there were too many match points very close to each other. There are fewer match points in the interval 600-1100 $\mathrm{m}$ due to the brittle zone, which in particular influences the NEEM and NGRIP1 cores. The ECM and DEP do not follow each other closely in the 1245-1283 m interval because of the alkaline nature of the ice associated with stadial conditions in EGRIP. This is due to high dust levels neutralizing the acidity of the ice (Ruth et al., 2003; Rasmussen et al., 2013). 
NGRIP2

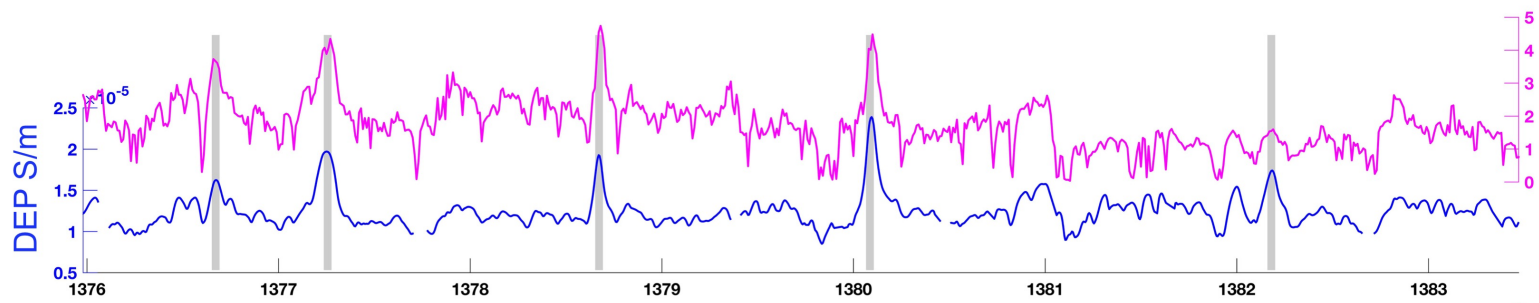

NEEM

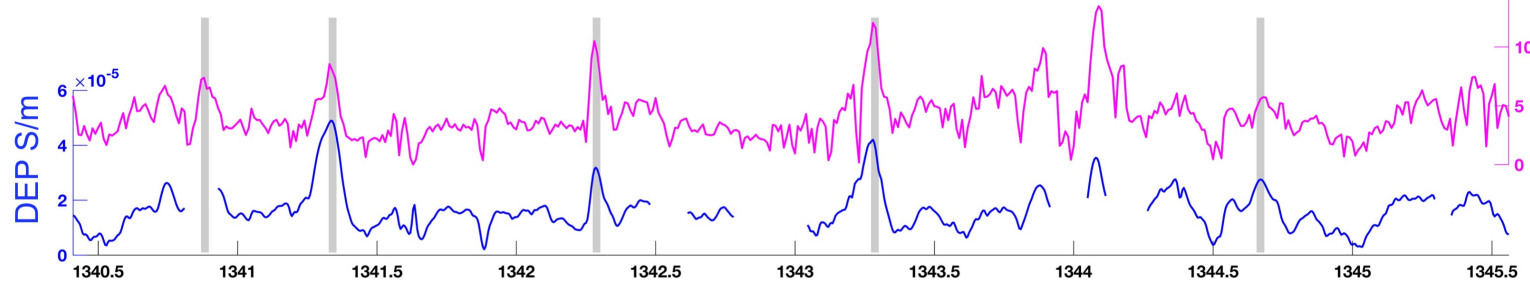

EastGRIP

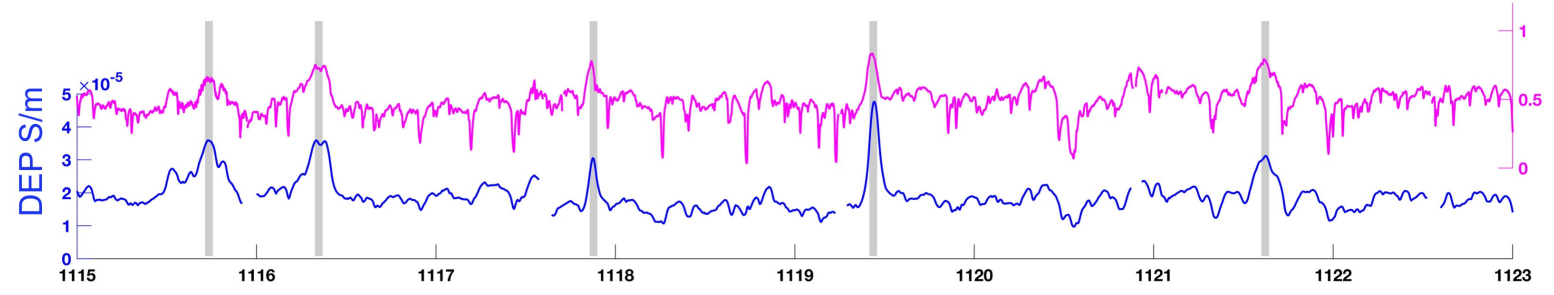

Depth (m)

Figure 2.8 - Example of the ECM and DEP data match between the NGRIP2 (top), NEEM (middle) and EGRIP (bottom) cores. The match points are marked by grey bands.

\section{Tephra horizons identified for the chronology}

Three tephra horizons have been located in EGRIP (Table 2.1). The locations of these horizons were consistent with the DEP and ECM based synchronization. The tephra horizons thus provide an independent validation for our match points. In addition, ongoing tephra investigations will likely provide additional points for synchronization between ice cores in intervals without DEP and ECM match points.

\section{GICC05-EGRIP-1}

As described in section 2.5, the GICC05 (depth, age) timescale was transferred from the NGRIP to the EGRIP ice core based on 381 match points. We name the relationship between depth and age for EGRIP over the Holocene and early last glacial periods GICC05-EGRIP-1 and present the average annual layer thickness between the match points in Fig. 2.9.

We synchronized the records of the ice cores back to $14.96 \mathrm{ka}$ b2k which corresponds to EGRIP depth 1383.84 $\mathrm{m}$, NEEM depth $1493.29 \mathrm{~m}$, and NGRIP2 depth $1611.98 \mathrm{~m}$. Along with this publication we release a time scale for each $0.55 \mathrm{~m}$ section ("bag"). For each EGRIP depth, the corresponding NGRIP depth was found by linear interpolation between the match points, and the GICC05 age was then determined from the published GICC05 time scale for NGRIP. The maximal uncertainty resulting from the choice of interpolation scheme is assessed in detail 
(see Appendix 2.14) and is about four years. The relatively smooth (depth, depth) relation of EGRIP-NGRIP and EGRIP-NEEM (see Fig. 2.3) shows that the ratios of annual layer thicknesses between cores do not vary noticeably between match points. Fig. 2.10 shows that EGRIP has thinner annual layers than both NEEM and NGRIP ice cores in the upper parts of the cores as also expected from the lower surface accumulation. Ice found in the EGRIP core originates from snow that was accumulating upstream, and accumulation rates increase upstream as the flow line approaches GRIP and NGRIP, where present-day accumulation is about twice of that at EGRIP (Vallelonga et al., 2014; Riverman et al., 2019; Karlsson et al., 2020). Surprisingly, annual layers in EGRIP remain almost constant back to $8 \mathrm{ka} \mathrm{b2k}$ (Fig. 2.9), while the layer thicknesses in large parts of the Holocene part of the NGRIP and NEEM cores thin linearly due to ice flow. We believe that it is a coincidence that the combined effects of the increasing upstream accumulation and ow-induced thinning at EGRIP balance out for the last $8 \mathrm{ka}$. Despite the lower accumulation at EGRIP, annual layers in EGRIP eventually get thicker than the annual layers in the NEEM and NGRIP ice cores. Below an EGRIP depth of around $700 \mathrm{~m}$, annual layers in EGRIP are thicker than the layers from the same period in the NEEM core, and similarly below $1000 \mathrm{~m}$, EGRIP annual layers are thicker than those in NGRIP (Fig. 2.10).

There are some gaps in the EGRIP ice-core record due to the brittle zone. However, the smoothness of the depth vs. depth plot in Fig. 2.3 and the annual layer thickness ratio in Fig. 2.10 robustly support our time scale based on the match points.

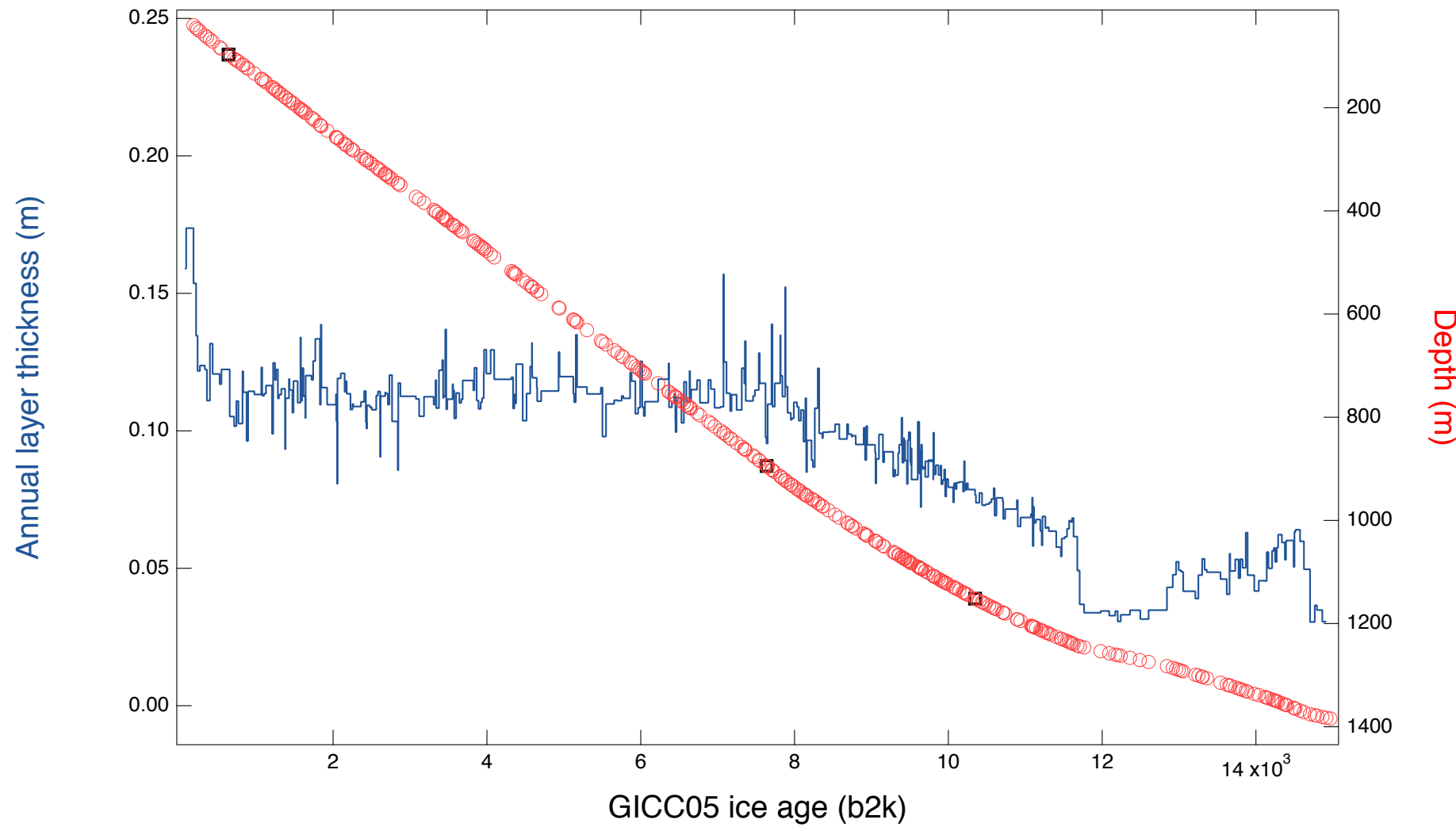

Figure 2.9 - Average EGRIP annual layer thicknesses (dark blue line, left y-axis) between the match points. The EGRIP depth-age relationship (right y-axis) with match points (red dots) and the tephra horizons (black squares). 


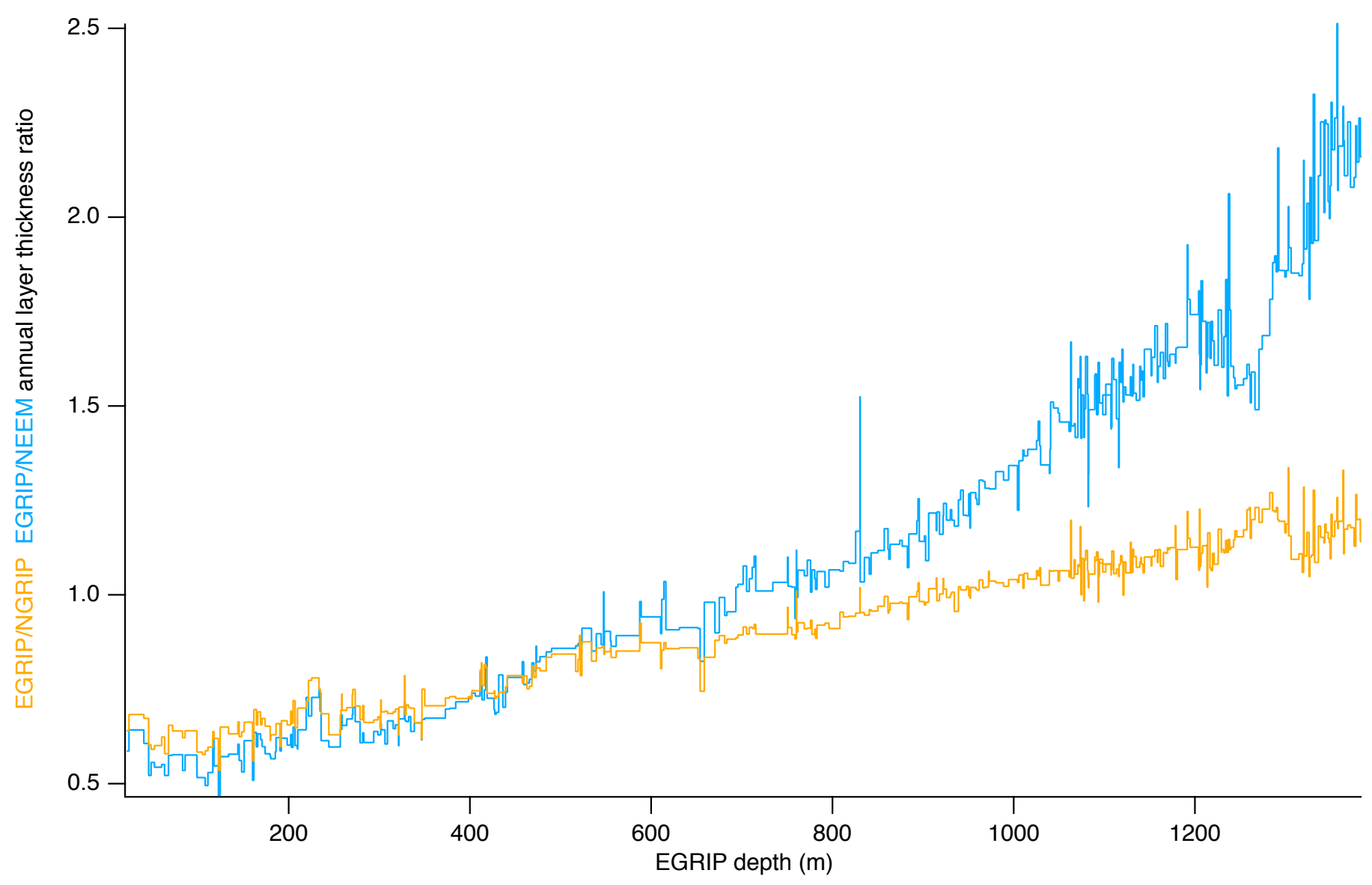

Figure 2.10 - The EGRIP/NGRIP (orange) and EGRIP/NEEM (blue) annual-layer thickness ratio (left axis) calculated between neighbouring match points.

\section{Error analysis for the timescale transfer}

We statistically treated the "leave-out analysis" $(\delta)$, which was already used in previous papers (Rasmussen et al., 2013) to estimate the uncertainty in match points. Binning the values revealed a robust mode that refers the statistical error of the match point assignment. The tails of the distribution relate to more curved intervals of the core. Cubic spline interpolation provides a similar estimate. However, when matching depths, we neither know the true curve nor how big the influence from the interpolation scheme is. We demonstrated that the two fundamentally different interpolation schemes of linear and cubic spline interpolation give a consistent result. The $\delta$ give qualitatively a similar pattern as the high-resolution difference of the interpolation schemes and has demonstrated its suitability to estimate the uncertainty of the interpolation scheme. They deviate more than the statistical uncertainty of the match-point assignment, but this is less than the tenfold of the statistical error for peak identification and for the timescale here it introduces an error of up to 4 years, while the inherited maximum counting error of the timescale increases from about 1 year to 2 centuries over the matched record. 


\section{Conclusions}

We have established the initial chronology for the EGRIP deep ice core in Greenland which encompasses the Holocene and late glacial periods. We have established the depth-age relation for the upper $\sim 1383.84 \mathrm{~m}$ of the core back to approximately $14.96 \mathrm{ka} \mathrm{b} 2 \mathrm{k}$ based on the GICC05 time scale and labelled it GICC05-EGRIP-1. After field measurements and processing of the ice-core data, we relied on the DEP and ECM records for the synchronization, using 381 match points between EGRIP, NEEM and NGRIP ice cores. The identification of tephra match points between the EGRIP and NGRIP core provide an independent tool for validating this synchronization. We used the ratio of annual layer thickness between ice cores as a tool to evaluate our match points. This first timescale can help to interpret, design sampling strategies and improve the understanding of the forthcoming EGRIP data sets.

\section{Supplementary data}

With the final version of this paper we will publish the following data sets at www.pangaea.de and www.iceandclimate.dk/data:

- GICC05-EGRIP-1 time scale for the EGRIP ice core (Mojtabavi et al., 2020k, https://doi.pangaea.de/10. 1594/PANGAEA.922139).

- Specific conductivity measured with the dielectric profiling (DEP) technique on the EGRIP ice core, 13.77$1383.84 \mathrm{~m}$ depth (Mojtabavi et al., 2020m, https://doi.pangaea.de/10.1594/PANGAEA.919313).

- Permittivity measured with the dielectric profiling (DEP) technique on the EGRIP ice core, 13.77-1383.84 m depth (Mojtabavi et al., 20201, https://doi.pangaea.de/10.1594/PANGAEA.922138).

- Acidity measured with the Electrical Conductivity Method (ECM) on the EGRIP ice core (down to 1383.84 $\mathrm{m}$ depth), converted to hydrogen ion concentration (Mojtabavi et al., 2020f, https://doi.pangaea.de/10. 1594/PANGAEA.922199).

- Specific conductivity measured with the dielectric profiling (DEP) technique on the NEEM ice core (down to $1493.297 \mathrm{~m}$ depth) (Mojtabavi et al., 2020h, https://doi.pangaea.de/10.1594/PANGAEA.922193).

- Permittivity measured with the dielectric profiling (DEP) technique on the NEEM ice core (down to 1493.297 m depth) (Mojtabavi et al., 2020g, https://doi.pangaea.de/10.1594/PANGAEA.922195).

- Specific conductivity measured with the dielectric profiling (DEP) technique on the NGRIP1 ice core (down to $1372 \mathrm{~m}$ depth) (Mojtabavi et al., 2020j, https://doi.pangaea.de/10.1594/PANGAEA.922191).

- Permittivity measured with the dielectric profiling (DEP) technique on the NGRIP1 ice core (down to 1372 m depth) (Mojtabavi et al., 2020i, https://doi.pangaea.de/10.1594/PANGAEA.922192). 


\section{Appendix}

\section{Quality index for the NGRIP and NEEM ice cores}

For the NEEM and NGRIP ice cores we calculated similar quality indices as provided for EGRIP above. They are presented together in Fig. 2.11.
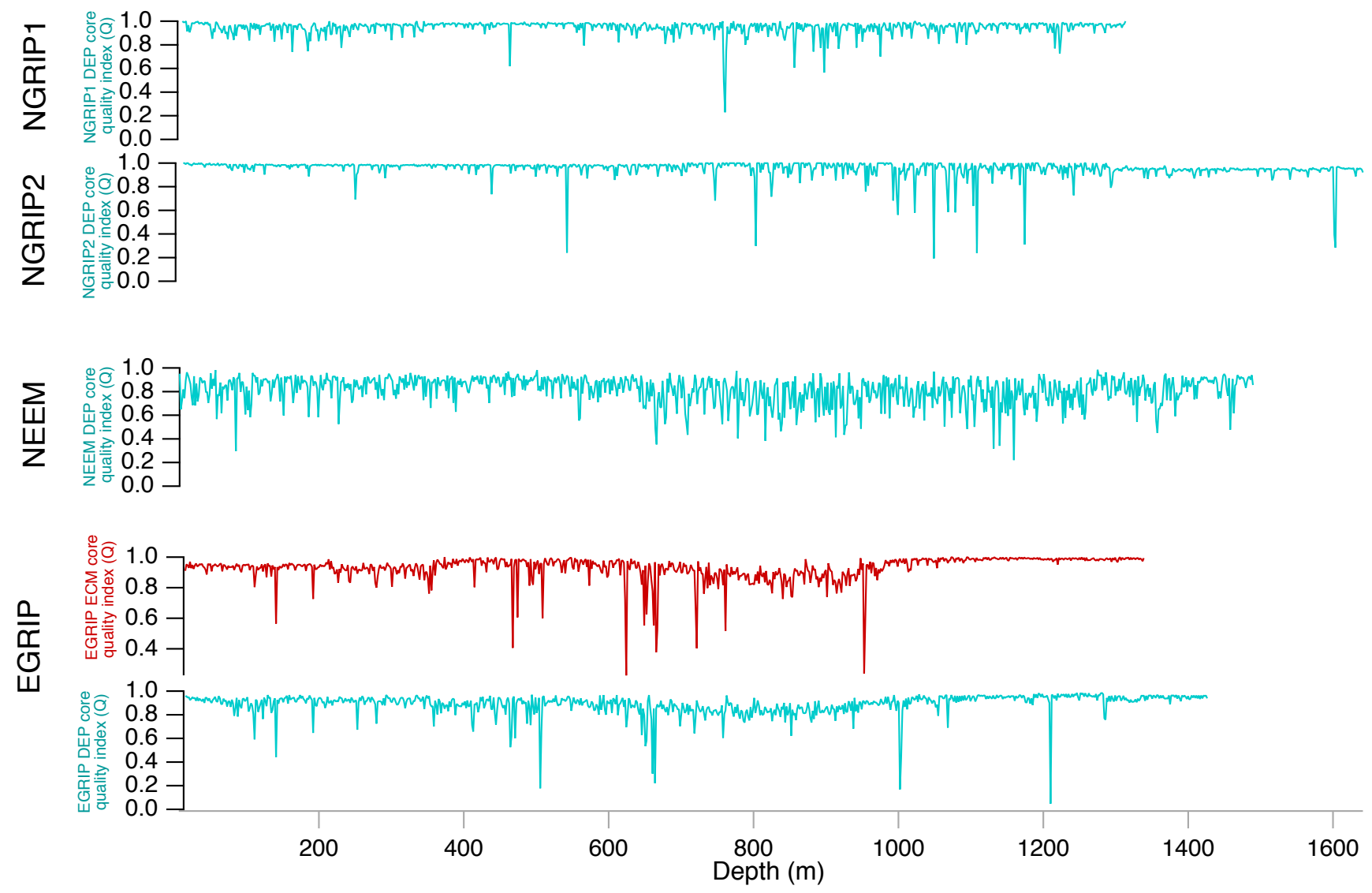

Figure 2.11 - Quality indices for the EGRIP, NGRIP and NEEM ice cores.

\section{Calibration and corrections to the DEP data}

As a correction in the few percent range we correct the offset, introduced by the changing stray admittance due to the varying cable geometry due to their movement during the measurement, by subtracting the course of free-air measurements from the respective measurement of a core section along the DEP device when processing the data. This is possible as the stray admittance is connected in electric series and is thus additive. This measure reduces coherent noise on the record, which is e.g. important when using the records for spectral analysis.

For the processing of the two NGRIP cores, reproducibility was ensured by laying the cables out to move freely in the same way for all measurements in between two recorded free-air measurements. This was improved for the NEEM and EGRIP processing by placing the cables into cable channels that enforce repeatable deformation. 
For the calibration of the DEP device, free-air measurements without ice were recorded frequently, usually at least twice daily before processing started and finished. The slight capacitance and conductance variation on the order of less than $4 \mathrm{fF}$ and $500 \mathrm{pS}$, thus corresponding to relative permittivity changes of $4 \mathrm{fF} / 63 \mathrm{fF}=0.06$ and conductivity changes of $(500 \mathrm{pS}) /(63 \mathrm{fF})^{*}(8.8542 \mathrm{pF})=70 \mathrm{nS}$, along the DEP device is due to the unavoidable deformation of the cables (Fig. 2.4a) when moving the scanning electrode along the device (Fig. 2.4e)." Compared to the properties of pure glacier ice (ref. to Fig. 2.5) these variations are in the order of $2 \%$ for the permittivity and $5 \%$ for the conductivity. Additionally, an offset of few $\mathrm{nS}$ residual conductance may remain even after performing the correction routines of the LCR meter (inductance L, capacitance C, resistance R) bridge (Fig. 2.4c).

As a further correction in the few percent range, we developed procedures to determine the true absolute free air-capacitance of the DEP capacitor. This is relevant when determining calibrated absolute values of the material properties: permittivity and conductivity. In the original publications (Wilhelms, 1996; Wilhelms et al., 1998) the proper calibration of the device is cross checked by comparison with the theoretical capacitance value of $63.4 \mathrm{fF}$, where for a precisely adjusted DEP bench, the free air capacitance coincides with in less than $2 \mathrm{fF}$. These small deviations from the theoretical value might well be due to mechanical tolerances like the electrode length in the range of a few tenths of a mm. However, for a slightly differently adjusted device (e.g. one with slightly more clearance to the core), the deviation from the ideal value of the free air capacitance might be a few $\mathrm{fF}$ more. Besides the calibration uncertainty of the LCR meter, it might also include a component of cable stray capacitance, which is not identifiable in the LCR meter's automated correction procedure.

To even proceed from the correction of cable stray admittance variation along the course of the device by simple subtraction towards absolute precision one needs to know the free-air-conductance, which is expected to vanish for the empty device, and the true free-air-capacitance of the capacitor, which needs a special approach as it cannot be measured directly and separately from other interfering capacitances.

In parallel to the NGRIP project, Wilhelms (2000) developed a calibration procedure for a custom DEP device with fixed electrodes, which was optimised for firn studies to establish the DECOMP model (Wilhelms, 2005). For the EGRIP core processing, we transferred the principle of introducing concentric metal tubes to the deepcore DEP bench and upgraded it with a rack to mount to move the tubes of different diameters along with DEP electrodes and record the capacitance along the DEP device. The tube in the electric field increases the capacitance of the arrangement and Wilhelms (2000) derives the theory to calculate the effective relative permittivity of the setup. For the calibration, tubes with radii in approximately $10 \mathrm{~mm}$ increments between 0 and $70 \mathrm{~mm}$ represented effective permittivity standards $(|\varepsilon|)$ between 1 to 4 (Fig. 2.12). The result is a calibration curve which holds for the calculation of a consistent free-air-capacitance for the correction of the DEP measurement of the EGRIP core. The free-air-capacitance is the proportionality factor of the measured capacitance and the effective permittivity, i.e. the slope of the graph in Fig. 2.12. From this analysis one derives the true free-air-capacitance of the deep-core DEP device as adjusted when it was assembled.

Now, we know the true free-air-capacitance (as determined from the just outlined calibration) together with the true (vanishing) conductance for an empty device. The free-air empty capacitor measurements thus determine the (additive) stray conductance and capacitance, which is the difference of the measurement and the reference values. 


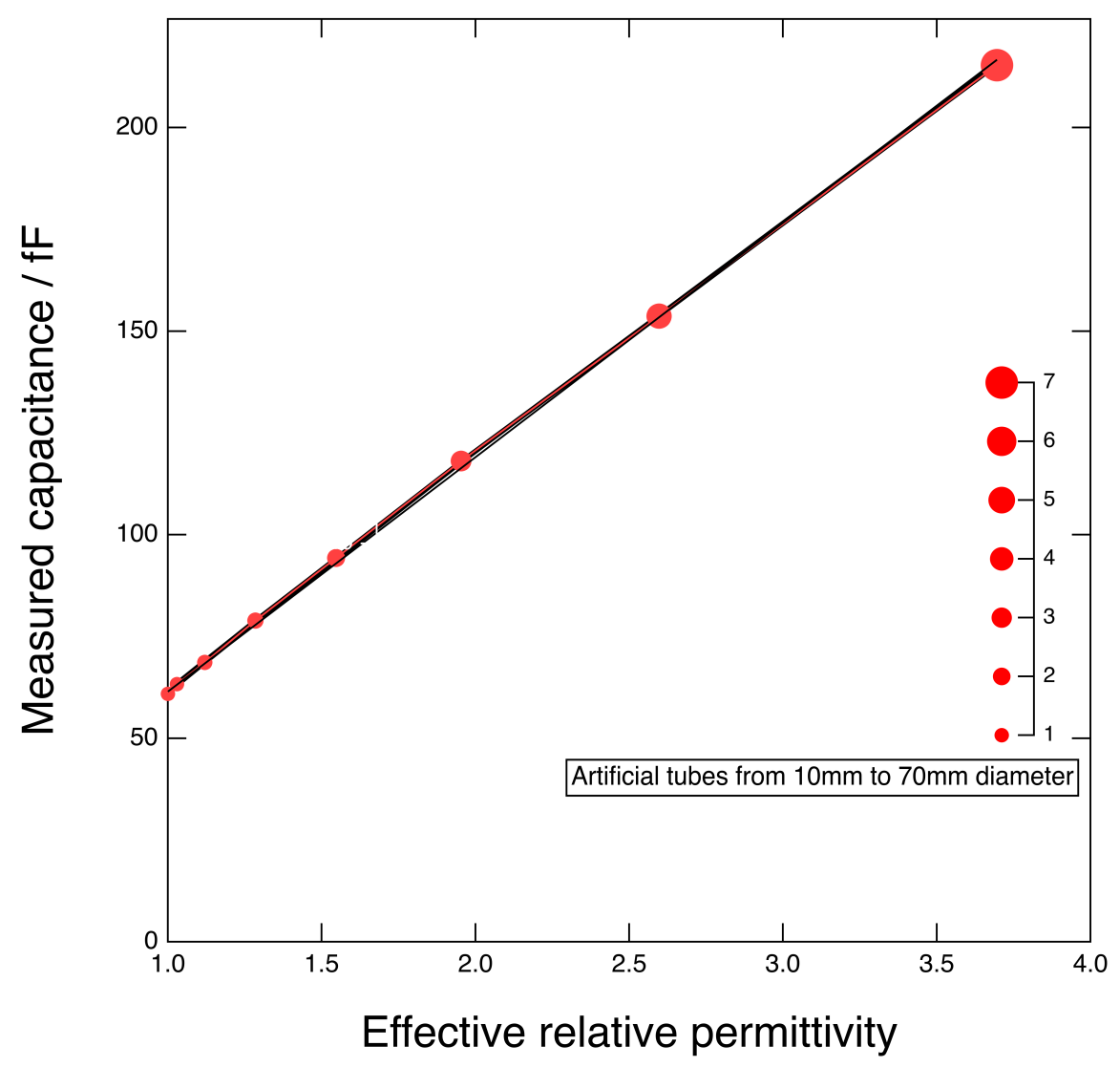

Figure 2.12 - Calibration curve of the measurements with artificial tubes and free-air measurement for DEP device.

The derived stray conductance and capacitance profile along the course of the DEP device are then subtracted from the actual ice-core measurements. The calculation of both material properties involves a division with the free air-capacitance, where introduction of further errors is minimised by using the precise value from the calibration procedure as outlined above.

Precise permittivity and resultingly precise free air capacitance values mainly make a difference when e.g. computing the wave propagation speed of radar waves while modelling synthetic radargrams (Eisen et al., 2006). For NGRIP and NEEM we did not yet perform the calibration procedure. From assigning the two-way travel time of prominent radar reflectors to volcanic spikes in the core, one can determine the radar wave propagation speed and calculate the ice's permittivity. As the NGRIP and NEEM datasets will also be used for comparison with radar surveys later, we determined the free air capacitance by averaging the measured capacitance over deep core sections and dividing with the expected permittivity of ice of $3.15 \pm 0.1$ which computes the free air capacitance with $3 \%$ relative error, which is only about $2 \mathrm{fF}$ absolute error for the free air capacitance.

To sum up, all material properties' datasets we derived here are only subjected to a few percent absolute error. While the EGRIP record is calibrated independently, for the NGRIP and the NEEM cores the permittivity, as 
determined from radar wave propagation, was used. The latter is a very minor restriction as this cannot be checked independently, but is not of practical relevance.

Due to the varying temperature in processing area throughout the field seasons, the core was not processed at a consistent temperature and we don't have the temperature readings avail to provide consistently harmonized conductivity data. The missing temperature correction does not affect the use of conductivity peaks for synchronization purposes in between ice cores, which is relevant for the discussion here. When e.g. deriving radar wave absorption coefficients from the presented conductivity record, one would have to be very cautious and have this limitation of the data in mind.

\section{Details on the ECM procedures}

The depth scale of the ECM profile was assigned based on the recorded movement of the electrodes interpolated between the logged top and bottom depth of individual ice-core sections. To investigate the quality of the depth assignment, a bag mark position analysis was carried out on the section below the brittle zone in EGRIP, 1160-1760 $\mathrm{m}$. Only ice core sections with an undamaged core of $1.65 \mathrm{~m}$ length were included in the analysis. Each $1.65 \mathrm{~m}$ section contains the equivalent of three $0.55 \mathrm{~m}$ bags, and the true depth of the bag interfaces ("bag marks") separating the first and second bags and the second and third bags, respectively, are known. During ECM measurements, these bag marks are logged (just as the break marks), but are not used for the processing. After processing of the ECM signal, the position of logged bag marks were interpolated onto the same depth scale as the processed ECM signal, making it possible to compare the true depth of these marks to their depths in the processed data. The distance in depth between logged and expected positions of individual bag marks were calculated for all sections included in the analysis. It was found that the depth assignment of the bag marks were almost always accurate within $20 \mathrm{~mm}$, with mean distance $\mu=8.3 \mathrm{~mm}$ and standard deviation $\sigma=7.9 \mathrm{~mm}$.

\section{Statistical analysis of the (depth, depth)-match with linear in- terpolation}

Each match point's depth assignment has an uncertainty due to the varying peak form, which is caused by regional deposition differences and short-term accumulation variations. This peak assignment uncertainty dominates the distribution of $\delta$ in sections where the EGRIP-NGRIP1/2 depth curve is straight. However, varying conditions at the time and place of the snow deposition or different ice flow pattern between the ice cores cause differently evolving annual layer thickness ratios $r_{i}=\frac{D_{i+1}-D_{i}}{d_{i+1}-d_{i}}$ and recognizable curvature of the (depth, depth)-curve. For the distribution function of $\delta$, we expect a normal distribution of the peak assignment overlaid by a distribution from the curvature of the (depth, depth) curve, in the following referred to as "the refinement".

For further statistical treatment, we bin the $\delta$ values. As $\delta \in[-0.42929 \mathrm{~m}, 0.385968 \mathrm{~m}]$, we counted the occurrence $N(i)$ of values for the $i=0 \ldots 20$ intervals $[-(0.525+i * 0.05) \mathrm{m},(-0.475+i * 0.05) \mathrm{m})$ in between $-0.525 \mathrm{~m}$ and $0.525 \mathrm{~m}$ and display the data in the following histogram (ref. Fig. 2.13). The standard deviation of the counts is $\sigma(N)=\sqrt{N} \cdot n=14$ bins are occupied. The distribution of $\delta$ is presented in Fig. 2.13. 


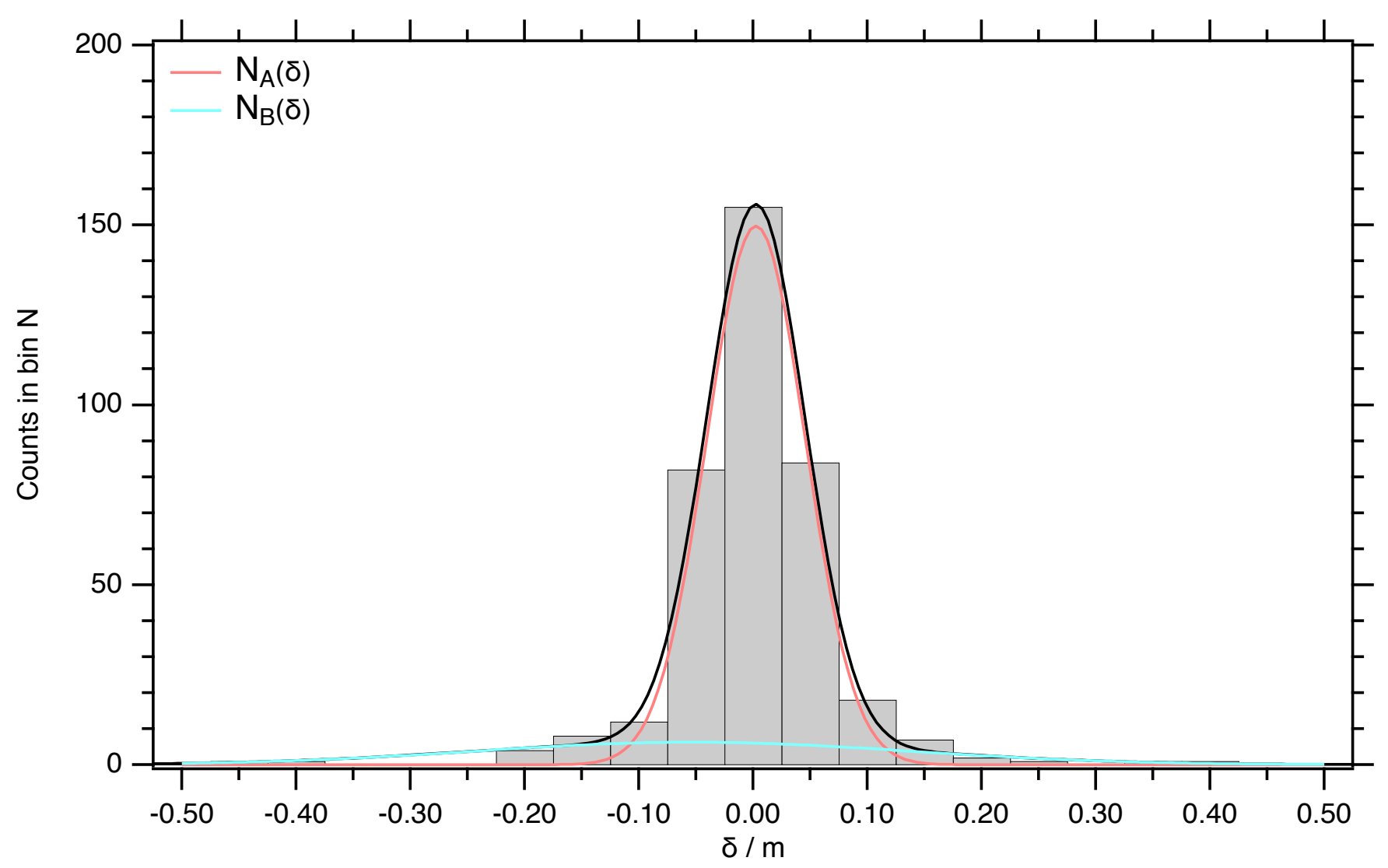

Figure 2.13- Histogram of the difference data with linear interpolation $\delta_{i}=\left(D_{i+1}-D_{i-1}\right) /\left(d_{i+1}-d_{i-1}\right)\left(d_{i}-\right.$ $\left.d_{i-1}\right)+D_{i-1}-D_{i}$ for the match points between EGRIP-NGRIP1/2.

The Gaussian normal distribution for the peak assignment in the centre seems to be overlaid by a second Gaussian normal distribution representing the refinement of the depth scale. This is indicated by the quite wide tails of the distribution. Following the just posed assumption, that the refinement distance is statistically normal-distributed $N_{B}(\delta)=B \exp \left(-\left(\delta-\mu_{B}\right)^{2} / \sigma_{B}^{2} / 2\right) / \sqrt{2 \pi} / \sigma_{B}$ and that the uncertainty of the peak assignment in smooth intervals is normal-distributed $N_{A}(\delta)=A \exp \left(-\left(\delta-\mu_{A}\right)^{2} / \sigma_{A}^{2} / 2\right) / \sqrt{2 \pi} / \sigma_{A}$, we $\chi^{2}$-fitted the sum $N(\delta)=$ $N_{A}(\delta)+N_{B}(\delta)$. The weight of the $\chi^{2}$ is the counting error $\sigma(N)=\sqrt{N}$. The fit of the $c=6$ independent parameters converged and yielded a $\chi^{2}=4.7$ for the $f=n-c=14-6=8$ degrees of freedom, indicating that the fitted distribution is supported by the data $\left(\int_{4.7}^{\infty} \chi^{2}(8)=0.79\right)$.

The $\chi^{2}$-fit computes for the peak assignment distribution $N_{A}(\delta)$ a scaling factor $A=(16 \pm 1) \mathrm{m}$, the shift from the centre $\mu_{A}=(0.003 \pm 0.003) \mathrm{m}$ and a standard deviation $\sigma_{A}=(0.043 \pm 0.002) \mathrm{m}$. Similarly for the refinement distance $N_{B}(\delta): B=(3 \pm 0.7) \mathrm{m}, \mu_{B}=(-0.05 \pm 0.04) \mathrm{m}$ and $\sigma_{B}=(0.19 \pm 0.04) \mathrm{m}$.

Solving $N_{A}\left(\delta_{j}\right)=N_{B}\left(\delta_{j}\right)$ for the roots $\delta_{1}=-0.11 m$ and $\delta_{2}=0.12 m$ defines the inner interval that is dominated by the peak assignment statistics. 349 points are in the interval $\left(\delta_{1}, \delta_{2}\right)$ and the direct statistical evaluation confirms $\sigma_{A}=0.043 \mathrm{~m}$ (in the main paragraphs of the paper we label this as statistical error for the peak assignment $\Delta D)$ and $\mu_{A}=0.003$, where the skew (0.06) and the kurtosis (-0.05) are small and support normal 
distribution $\delta \in(-0.11 \mathrm{~m}, 0.12 \mathrm{~m})$. A Shapiro Wilk test confirms normal distribution of the peak assignment errors, as $W=0.996$ and the corresponding $\mathrm{p}$-Value $p=0.54$.

As the refinement distance is overlaid by the peak assignment statistics in the centre of the distribution, none of the standard statistics is applicable, but the $\chi^{2}$-fitted $N_{B}\left(\delta_{i}\right)$, can be $\chi^{2}$-tested for the refinement-distance dominated bins. $\chi^{2}=4.0$ over the bins $i=1,2,6,7,13,14,15,17,18$ in the tail that at most are marginally influenced by $N_{A}\left(\delta_{i}\right)$. The $n=9$ bins together with initially $c=3$ fitted parameters computes $f=n-c=6$ degrees of freedom, which supports the refinement distance being normal distributed $\left(\int_{4.0}^{\infty} \chi^{2}(8)=0.68\right)$.

\section{Statistical analysis of the (depth, depth)-match with cubic spline interpolation}

Here, we quantify the difference between using linear interpolation and interpolation by cubic splines, which is a widely used scheme. The latter has the benefit of using smooth curves, such that the (depth, depth) curve and its derivatives are continuous, but as discussed above, several factors may cause the real (depth, depth) curve to be non-differentiable or even discontinuous, and we therefore maintain our practice of linear interpolation between the depths of the match points.

Analog to the definition of $\delta$ we define $\Sigma_{i}=S\left(D_{1}, \ldots, D_{i}, \ldots, D_{n}\right)-S\left(D_{1}, \ldots, D_{i}, \ldots, D_{n}\right)$, where $S\left(D_{1}, \ldots, D_{i}, \ldots, D_{n}\right)$ is a cubic spline calculated for all match points and $S\left(D_{1}, \ldots, D_{i}, \ldots, D_{n}\right)$ a cubic spline calculated for all but the i-th match point.

Analog to the above analysis with linear interpolation, we expect that each match point's depth assignment has an uncertainty due to the varying peak form, which is caused by regional deposition differences and short-term accumulation variations. This peak assignment uncertainty determines the distribution of $\Sigma$ in sections where the EGRIP-NGRIP1/2 depth curve is straight and no systematic glaciological differences occur. However, varying accumulation conditions at the time and position of snow deposition or different ice flow patterns influencing the ice cores cause differently evolving annual layer thickness ratios $r_{i}=\frac{D_{i+1}-D_{i}}{d_{i+1}-d_{i}}$ which leads to curvature of the (depth, depth) curve. This curvature may not be captured if there are no match points at the relevant depth, and different interpolation schemes will make different predictions across intervals without match points. For the distribution function of $\Sigma$ we thus expect two contributions: One from the uncertainty of peak assignment and the other one from the refinement.

For further statistical treatment, we bin the $\Sigma$ values. As $\Sigma \in[--0.674604 \mathrm{~m}, 0.364446 \mathrm{~m}]$, we counted the occurrence $N(i)$ of values for the $i=1 \ldots 21$ intervals $[-(0.725+i * 0.05) \mathrm{m},(-0.675+i * 0.05) \mathrm{m})$ in between $-0.675 \mathrm{~m}$ and $0.375 \mathrm{~m}$ and display the data in the following histogram (ref. Fig. 2.14). The standard deviation of the counts is $\sigma(N)=\sqrt{N} . n=17$ bins are occupied. The distribution of $\Sigma$ is presented in Fig. 2.14. The weight of the $\chi^{2}$ is the counting error $\sigma(N)=\sqrt{N}$.

Like for the (depth, depth) differences for the linear interpolation $\delta$, the distribution of $\Sigma$ appears having too wide tails to match a Gaussian distributions. We support this by trying to fit a single Gaussian normal distribution $N_{G}(\Sigma)=G \exp \left(-\left(\Sigma-\mu_{G}\right)^{2} / \sigma_{G}^{2} / 2\right) / \sqrt{2 \pi} / \sigma_{G}$. to the data. Even when treating the 3 values below $\Sigma<$ 0.325 as outliers and restricting the fit to the $n=14$ bins around 0 , we minimize $\chi^{2}=30.8$. For the $c=3$ 


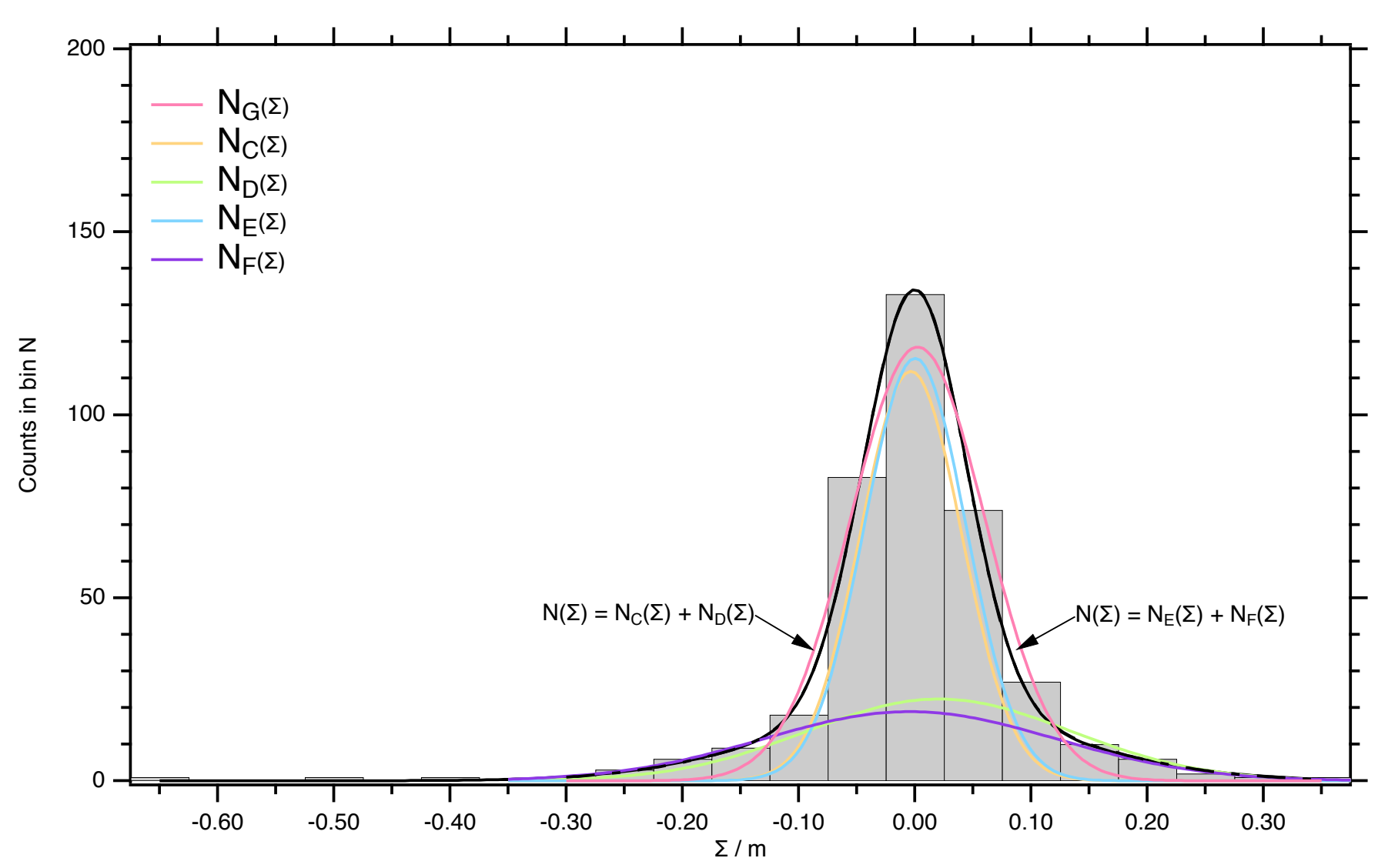

Figure 2.14- Histogram of the difference data with cubic spline interpolation $\Sigma_{i}=S\left(D_{1}, \ldots, D_{i}, \ldots, D_{n}\right)-$ $S\left(D_{1}, \ldots, D_{i}, \ldots, D_{n}\right)$ for the match points between EGRIP_NGRIP1/2.

fitted constants, the degree of freedom is $f=11$. This indicates that the fitted distribution is not supported by the data $\left(\int_{0}^{30.8} \chi^{2}(11)=0.99\right)$.

The Gaussian normal distribution for the peak assignment in the centre seems - as for the $\delta$ - to be overlaid by a second Gaussian normal distribution representing the refinement of the depth scale. Following the just posed assumption that the refinement distance is statistically normal-distributed $N_{D}(\Sigma)$ and that the uncertainty of the peak assignment in smooth intervals is normal-distributed $N_{C}(\Sigma)$, we tried to $\chi^{2}$-fit $N(\Sigma)=N_{C}(\Sigma)+N_{D}(\Sigma)$ to the entire dataset with $c=6$ fitting parameters. For the $n=17$ bins of the entire dataset $\Sigma$ we minimised $\chi^{2}=48.7$, which suggests the model does not describe the data (for details refer to Fig. 2.14, where the figures for a similar treatment as for rejecting $N_{G}(\Sigma)$ are provided).

By just treating the 3 values (out of 377 in total) below $\Sigma<0.325$ as outliers, which is justified, when we are mainly interested in assessing the central part of the distribution, which refers to the match-point assignment. Thus, repeating the fit for the bins $i=8, /$ ldots, $21(n=14)$ an labelling the fitted function $N(\Sigma)=N_{E}(\Sigma)+$ $N_{F}(\Sigma)$ to clearly distinguish the result from the fit to the entire dataset before, we are able to minimize $\chi^{2}=3.09$ for the $f=n-c=11$ degrees of freedom, indicating that the fitted distribution is supported by the data $\left(\int_{3.1}^{\infty} \chi^{2}(11)=0.93\right)$. 
The $\chi^{2}$-fit computes for the peak assignment distribution $N_{E}(\Sigma)$ a scaling factor $E=(12.6 \pm 1.6) \mathrm{m}$, the shift from the centre $\mu_{E}=(-0.0003 \pm 0.004) \mathrm{m}$ and a standard deviation $\sigma_{E}=(0.044 \pm 0.004) \mathrm{m}$. Similarly for the refinement distance $N_{F}(\Sigma): F=(6.0 \pm 1.5) \mathrm{m}, \mu_{F}=(0.004 \pm 0.013) \mathrm{m}$ and $\sigma_{F}=(0.13 \pm 0.02) \mathrm{m}$.

For the linear interpolation scheme (ref. to Appendix 10) the peak assignment contribution $\left(N_{A}(\delta)\right.$ dominates the central bins. Only $4 \%$ of the counts are attributed to the refinement $\left(N_{B}(\delta)\right)$ and we could define the interval where to perform a direct statistical analysis of the $\delta$ values for the peak assignment mode from the intersections of $N_{A}(\delta)$ and $N_{B}(\delta)$. For the cubic spline interpolation scheme $16 \%$ of the counts are contributing to the refinement $N_{F}(\Sigma)$ in the central bins. Thus the roots $\Sigma_{1}=-0.089 m$ and $\Sigma_{2}=0.087 m$ of $N_{E}\left(\Sigma_{k}\right)=N_{F}\left(\Sigma_{k}\right)$ do not define the complete inner interval, where the peak assignment contributes and it does not as clearly dominate the distribution of $\Sigma$. The peak assignment and the refinement modes do not separate as clearly as for the linear interpolation, and a Shapiro Wilk test for the $\left(\Sigma_{1}, \Sigma_{2}\right)$ interval fails. When extending the interval to $(-0.16 \mathrm{~m}, 0.16 \mathrm{~m})-$ which covers the contributions of the peak assignment mode well -, the direct statistical analysis for the 348 points estimates a standard deviation of $0.056 \mathrm{~m}$, skew of 0.06 and a kurtosis of 0.21 . This suggest a symmetrical distribution that is slightly higher with wider wings, which is consistent with the above observation of the refinement mode being recognizable in interval and the standard deviation is overestimated. A Shapiro Wilk test supports normal distribution in the interval $(-0.16 \mathrm{~m}, 0.16 \mathrm{~m})$, as $W=0.995$ and the corresponding $\mathrm{p}$-Value $\mathrm{p}=0.38$. As we already excluded outliers for the analysis, there is no meaning in the statistical analysis of the refinement distance and we assume $\Sigma$ as a measure for the systematic deviation when using cubic spline interpolation.

The cubic spline scheme confirms the above observed maximal error of the match points $\Delta D=0.043 \mathrm{~m}=$ $\sigma_{A} \approx \sigma_{E}=0.044$. When restricting $|\delta|,|\Sigma| \leq 0.375 \mathrm{~m}$, then both $\delta$ and $\Sigma$ have 3 match points exceeding this threshold and both distributions fit a profile with a standard deviation of $\sigma_{F}=\sigma_{B}$ (without 3 outliers) $=0.13 \mathrm{~m}$ for the refinement each match point contributes in average. This means that one of the interpolation schemes is not superior to the other, but comparing them illustrates the uncertainty associated with interpolation in between the match points.

Now, we calculate the systematic deviation between linear and cubic spline interpolation from datasets in 0.01 $\mathrm{m}$ resolution. $\zeta_{i}$ denotes the maximal absolute difference in the interval between the $\mathrm{i}$-th and $(\mathrm{i}+1)$-th match point, which is a direct measure of systematic differences due to the interpolation schemes.

$|\zeta|$ and $|\delta|$ are both less than $0.4 \mathrm{~m}$ and exhibit a similar pattern, while $|\Sigma|$ has less in common with both $\delta$ and $\zeta .|\zeta|$ is a good measure for the interpolation uncertainty along the record as it is the direct comparison of two fundamentally different interpolation approaches (see Fig. 2.15).

For linear interpolation, the statistical error for the computed depth in between two match points is limited by the maximal error of the match points $\Delta D=0.043 \mathrm{~m}$ and the error of the interpolated depth $\mathrm{D}$ is therefore $\sqrt{(\Delta D)^{2}+\zeta^{2}}$. To propagate the depth error and estimate the additional error of the time match, we start from the highest resolution published GICC05 dating of NGRIP with $2.5 \mathrm{~cm}$ and $5 \mathrm{~cm}$ depth resolution above and below $349.8 \mathrm{~m}$ respectively (Vinther et al., 2006; Rasmussen et al., 2006) and linearly interpolate the EGRIP depth $(D)$ onto the NGRIP depth $(d)$ to get the time scale $t(D)$ for EGRIP. We calculate $\frac{\partial t_{\text {GICC05 }}}{\partial D_{\text {EGRIP }}}$ in the high resolution dataset and sample it at the match points. 

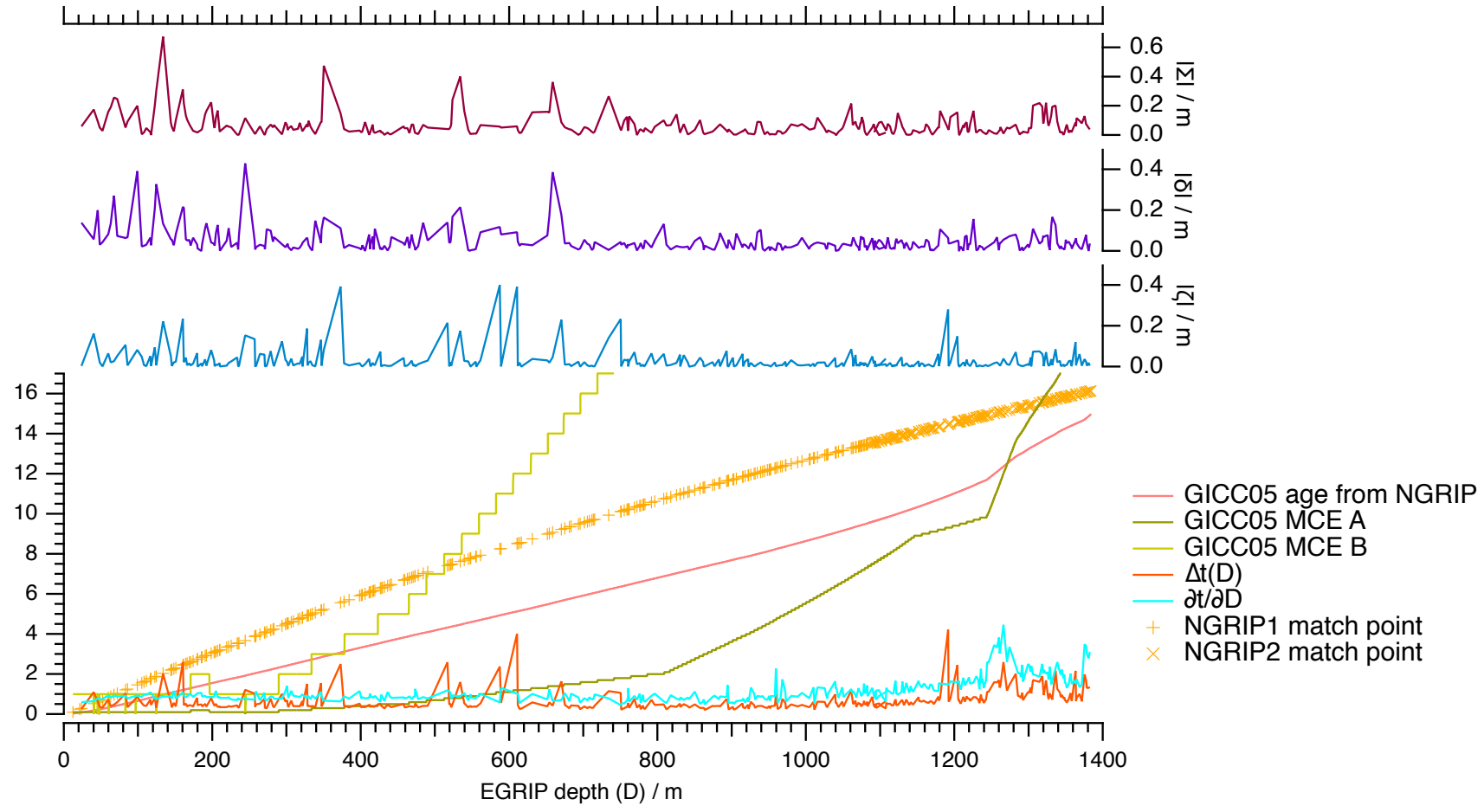

Figure 2.15 - The (EGRIP, NGRIP) match points, (EGRIP-depth, GICC05-time)-scale, the (EGRIP-depth, GICC05-MCE)-curve, $|\delta|,|\Sigma|,|\zeta|, \frac{\partial t_{\mathrm{GICC} 05}}{\partial D_{\mathrm{EGRIP}}}, \Delta t(D)=\left|\frac{\partial t}{\partial D}\right| \sqrt{(\Delta t)^{2}+\zeta^{2}}$

The matching error related to the timescale transfer $\Delta t(D)=\left|\frac{\partial t}{\partial D}\right| \sqrt{(\Delta t)^{2}+\zeta^{2}}$ is maximally about 4 years, exceeds the MCE on two occasions in the uppermost $200 \mathrm{~m}$ by 1 year, and becomes increasingly smaller compared to the MCE for increasingly deeper parts of the record (see Fig. 2.15).

\section{Author contributions}

Original draft preparation by SM with major contributions from FW, SOR, EC, MSJ; statistical analysis of the (depth,depth)-match and interpolation by FW and SOR; matching by SM, FW, SOR, GS, MSJ; DEP data processing by SM, FW; ECM data processing by SOR, GS, MSJ; tephra data processing by EC, SD, GJ; DEP measurements in the field by SM, SK, NAB, SHF, VG, HK; ECM measurements in the field by SM, SOR, HK, TE, KN, SMPB, SHF, IK; preparation, set-up and testing of DEP system by SM, FW; preparation, set-up and testing of ECM system by BV, DDJ, SOR; tephra selection and sampling in the field by EC, SM, SD, SMPB; All authors contributed to improving the final paper.

\section{Acknowledgements}

We thank Frédéric Parrenin and 2 anonymous reviewers for fruitful comments that improved the paper a lot. We thank all people involved in logistics, drilling and ice-core processing in the field. EGRIP is directed and organized by the Centre for Ice and Climate at the Niels Bohr Institute, University of Copenhagen. It is supported by funding agencies and institutions in Denmark (A. P. Møller Foundation, University of Copenhagen), USA (US 
National Science Foundation, Office of Polar Programs), Germany (Alfred Wegener Institute, Helmholtz Centre for Polar and Marine Research), Japan (National Institute of Polar Research and Arctic Challenge for Sustainability), Norway (University of Bergen and Bergen Research Foundation), Switzerland (Swiss National Science Foundation), France (French Polar Institute Paul-Emile Victor, Institute for Geosciences and Environmental research) and China (Chinese Academy of Sciences and Beijing Normal University). Sune Olander Rasmussen and Giulia Sinnl gratefully acknowledge the Carlsberg Foundation for support to the project ChronoClimate. Sergio Henrique Faria acknowledges support from the project iMechPro (RTI2018-100696-B-I00) from the Spanish Ministry of Science, Innovation, the Spanish Government through the María de Maeztu excellence accreditation 2018-2022 (Ref. MDM-2017-0714) and the Basque Government through the BERC 2018-2021 programme. Tobias Erhardt acknowledges the long-term support of ice-core research by the Swiss National Science foundation (SNFS) and the Oeschger Center for Climate Change Research. 

Chapter 3

\title{
Deep insights to the Greenland ice sheet by linking
} multichannel ultra-wide-band radar surveys to the latest deep ice cores by synthetic radar modelling ${ }^{\dagger}$

\author{
Seyedhamidreza Mojtabayi ${ }^{1,2}$, Olaf Eisen ${ }^{1,3}$, STeven Franke $^{1},{ }^{1}$, Daniela Jansen ${ }^{1}$, Daniel \\ Steinhage ${ }^{1}$, John Paden ${ }^{4}$, Dorthe Dahl-Jensen ${ }^{5,6}$, Frank Wilhelms ${ }^{1,2}$
}

${ }^{1}$ Alfred-Wegener-Institut Helmboltz-Zentrum für Polar-und Meeresforschung, Bremerhaven, Germany ${ }^{2}$ Department of Crystallography, Geoscience Centre, University of Göttingen, 37073 Göttingen, Germany ${ }^{3}$ Department of Geosciences, University of Bremen, Bremen, Germany ${ }^{4}$ Center for Remote Sensing of Ice Sheets (CReSIS), University of Kansas, Lawrence, KS, USA 5 Physics of Ice, Climate and Earth, Niels Bobr Institute, University of Copenhagen, Denmark ${ }^{6}$ Center for Earth Observation Science, University of Manitoba, Winnipeg, Canada

\section{Abstract}

For the past decade, multi-channel ultra-wide band radar systems are the key tool for deciphering the internal architecture of ice sheets, as they for the first time, record traceable layers from the echo free zone. These data enabled high resolution tectonic studies of folding, especially in relation to drainage glaciers, and establishing the internal architecture of isochrones all over Greenland. To interpret radar reflections in terms of age horizons and connect them over large areas in the ice sheet, the layer genesis has to be understood on a microphysical scale. Synthetic radar trace modelling based on the dielectric profile of ice cores exploit the full potential of assigning observed physical properties' variations on the decimetre scale to radar reflectors extending from the coring site to a regional scale or - in favourable cases - even the entire ice sheet. In this paper we compile the available dielectric profiling (DEP) data of the latest Northern Greenland deep ice cores of NGRIP - with the oldest undisturbed record in Greenland back to $122 \mathrm{ka} \mathrm{b2k}$ (years before the year $2000 \mathrm{CE}$ ), NEEM -- with the oldest reconstructed record from a folded core - and EGRIP -- the first ice core from the upper region of the NEGIS ice stream, which is presently draining about $12 \%$ of the Greenland ice sheet. Data from these cores are the best and exhaustive basis for assigning an age model to the Northern Greenland stratigraphic layers mapped by radar, and linking up the reflector properties to observations in the core. By linking observed physical properties on the millimetre and sub-millimetre scale

\footnotetext{
${ }^{\dagger}$ This manuscript is in final step of preparation to be submitted at the peer-reviewed journal. "Deep insights to the Greenland ice sheet by linking multichannel ultra-wide-band radar surveys to the latest deep ice cores by synthetic radar modelling."
} 
Chapter 3. Deep insights to the Greenland ice sheet by linking multichannel ultra-wide-band radar 44 surveys to the latest deep ice cores by synthetic radar modelling

to regional extend of radar reflectors in Northern-Greenland, we provide the basis for a deeper understanding of the deformation history and accumulation patterns of the Northern part of the Greenland ice sheet. Overall, the modelling results show that the internal reflections are mainly due to conductivity changes, and in deeper parts of the ice column the across-flow concentrated fabric at EGRIP.

\section{Introduction}

The ice sheets are the biggest freshwater reservoirs in the earth system and thus are a significant factor for the future behaviour of sea level (Shepherd et al., 2019; Tapley et al., 2019; Stocker et al., 2013). Thus, understanding the behaviour of the ice sheets in response to changes in climate is essential for improving predictions for the future evolution of sea level. Radio-echo sounding (RES) of ice sheets and the mapping of internal reflections can provide valuable insights into the history of ice streams, change of ice thickness from short to the long time scale, past accumulation patterns, and the physical properties of ice layers in Greenland and Antarctica (Kjær et al., 2018; Schroeder et al., 2019; Winter et al., 2017; MacGregor et al., 2015; Rodriguez-Morales et al., 2014; Urbini et al., 2008; Fujita and Mae, 1994; Fujita et al., 1999).

The Greenland Ice Sheet is a complex system. To understand the interplay between the catchment areas and its temporal evolution, we need to study regions of complex ice flow. The Northeast Greenland Ice Stream (NEGIS) is the largest ice stream in Greenland, draining about 12\% of the Greenland ice sheet (Fahnestock et al., 1993, 2001; Vallelonga et al., 2014; MacGregor et al., 2015; Joughin et al., 2018; Larsen et al., 2018). The drill site of the East GReenland deep Ice-core Project (EGRIP) is located in the upper region of the NEGIS, where the ice is currently moves about $\sim 51 \mathrm{~m}$ to the North-Northeast (NNE) in each year (Dahl-Jensen et al., 2019; Mojtabavi et al., 2020b). The drill site of the North Greenland Eemian (NEEM) core, which provided the oldest reconstructed record from a folded core (Dahl-Jensen et al., 2013) is located on the north eastern ice divide. Here the flow regime is less dynamic, with a flow velocity of about $5 \mathrm{~m}$ per year along the ridge, which is comparable to a flank flow regime. The North Greenland Ice Core Project (NGRIP) yielded an ice core with the oldest undisturbed record in Greenland back to $122 \mathrm{ka} \mathrm{b} 2 \mathrm{k}$ (Wolff et al., 2010). It is located on the central divide, about $200 \mathrm{~km}$ away from the EGRIP drill site, where flow velocities are about $1.3 \mathrm{~m} / \mathrm{a}$. Thus, the three locations comprise the three main dynamic flow regimes in Northern Greenland: Divide flow, flank flow, and in an ice stream.

Synthetic radar modelling has previously been applied to Antarctic records from the EPICA Dome C (EDC) and the EPICA Dronning Maud Land (EDML) ice cores (Winter et al., 2017; Eisen et al., 2006, 2004). Winter et al. (2017) used such a model for a comparison study of data from the vicinity of EDC, where they investigated how different radar systems image changes in physical properties in their internal reflection horizons (IRHs). Applying comparable approaches to Greenland data will help to understand the physical properties and thus inform models as well as contribute to process understanding. Combining the local results from modelled radargrams, on the basis of ice core data from different regimes, with the internal reflections in regionally distributed profiles of airborne radioecho sounding provide the opportunity to upscale local measurements of physical property data. This is eventually feeding into the dating of radar reflections in Northern Greenland. In this study we apply a numerical model for electromagnetic wave propagation, which was developed by Eisen et al. (2004), to calculate synthetic radargrams. For the first time, we force this model with records of dielectric properties from the latest Northern Greenland 
deep ice cores: the EGRIP ice core, the North Greenland Eemian ice core (NEEM) and the North Greenland ice core (NGRIP). We compare numerically modelled radargrams and data derived from multi-channel ultra-wide band radar systems in order to match radar reflections and physical processes that causes the reflections, as well as to determine ages for the reflectors which can be considered as isochrones.

\section{Data and Method}

\section{Airborne Radar Data}

Figure 3.1 gives an overview of the location of the ice core sites in relation to the dynamic setting. The EGRIP drill site $\left(75.38^{\circ}, \mathrm{N}, 35.60^{\circ}, \mathrm{W}\right)$ and the location of selected RES profiles that are located along the upstream part of the North East Greenland Ice Stream (NEGIS) are shown in panel (e) of Figure 3.1. In May 2018, AWI performed an extensive airborne radar survey on the NEGIS in the vicinity of the EGRIP drill site with a multichannel ultra-wideband radar system mounted on AWI's Polar6 aircraft. The radar sounder was developed at the Centre for Remote Sensing of Ice Sheets (CReSIS) at the University of Kansas and is designed for sounding ice thickness, internal layering and the basal interface of ice sheets. A detailed description of the radar system is given by Franke et al. (2020); Hale et al. (2016); Rodriguez-Morales et al. (2014); Wang et al. (2014). The radar system uses different transmit pulse durations as well as different receiver gains for different parts of the ice column to increase the dynamic range of the system. The recording parameters for the survey are shown in the Table 3.1. For details of the radar processing see Rodriguez-Morales et al. (2014); Franke et al. (2020). For the comparison with the synthetic radargrams we use a single trace from the SAR processed data product of the EGRIP-NOR-2018 AWI UWB radar campaign (for details of the survey see Franke et al. (2020)), which is located closest to the drill site. A single trace from SAR processed UWB data includes presumming during radar data acquisition as well as along-track stacking during the processing (for more details see Franke et al. (2020)). For the EGRIP drill site, we selected the closest traces from one profile oriented parallel to ice-flow direction (Frame 20180512_01_001) and a second profile oriented across to ice-flow direction (Frame 20180508_06_004) (Figure 3.1). The respective distance of the profiles parallel and across ice-flow to the EGRIP drill sites is $\sim 30 \mathrm{~m}$ and $\sim 6 \mathrm{~m}$ respectively.

The NEEM $\left(77.45^{\circ}, \mathrm{N}, 51.06^{\circ}, \mathrm{W}\right)$ and NGRIP $\left(75.10^{\circ}, \mathrm{N}, 42.32^{\circ}, \mathrm{W}\right)$ drill sites are shown in Figure 3.1, panels (c) and (d). For comparison of the synthetic radargrams at the location of the two ice cores, we used two radarprofiles (profile 20110329_02_028 for NEEM and profile 20120330_03_014 for NGRIP) from the operation ice bridge (OIB). We used the csarp_standard data product, which represents SAR processed radar data and the data were downloaded from the CReSIS website (www.cresis.ku.edu). The recording parameters for the survey around the NEEM and NGRIP with the Multi-Channel Coherent Radar Depth Sounder (MCoRDS2) mounted on NASA's P-3 aircraft are shown in the Table 3.1. A detailed description of the CReSIS data product and processing parameters is available on the CReSIS website. The closest trace's distance to the NEEM drill sites is $\sim 34 \mathrm{~m}$, while the closest trace distance to the drill site of the NGRIP core is $\sim 2.75 \mathrm{~km}$ (Figure 3.1). To compare the measured airborne radar data with the modelled synthetic data, we shifted the zero time of the airborne radar data to the surface reflection (air-ice interface). 
Chapter 3. Deep insights to the Greenland ice sheet by linking multichannel ultra-wide-band radar surveys to the latest deep ice cores by synthetic radar modelling

(a)

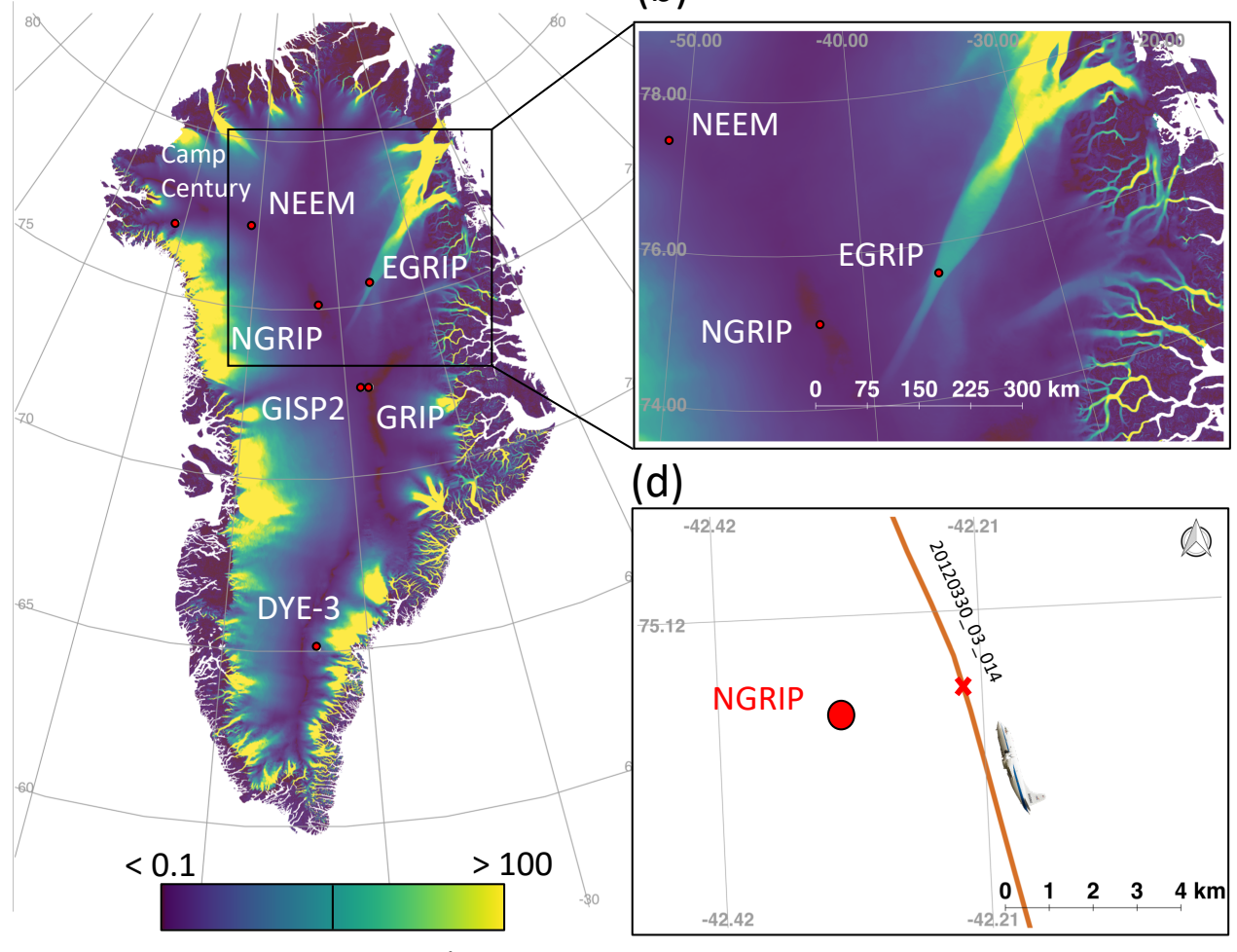

(c)

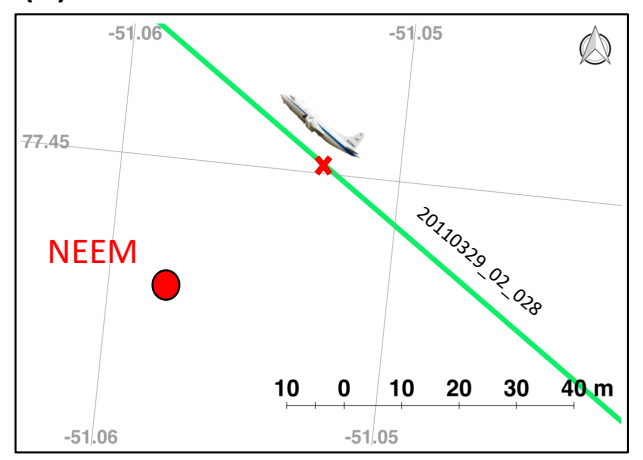

(e)

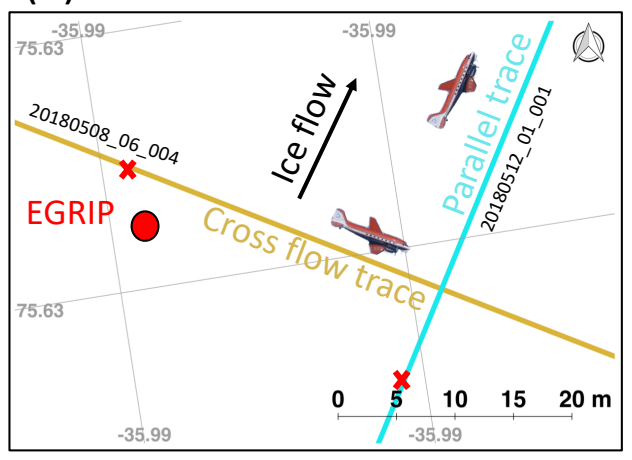

Surface velocity $(\mathrm{m} / \mathrm{yr})$

Figure 3.1 - (a) Locations of deep ice-core drill sites in Greenland Ice Sheet. (b) Focus on ice core locations in the vicinity of NEGIS. (c) NEEM drill site with the RES profile line from CReSIS flight 20110329-02-028. (d) NGRIP drill site with the RES profile line of CReSIS flight 20120330-03-014. (e) EGRIP drill site with the RES profiles line of AWI flights 20180508-06-004 and 20180512-01-001. The red cross marks show closest trace to the drill sites. Colours show surface flow velocities from satellite data (Joughin et al., 2018). Projection: WGS 84/NSIDC Sea Ice Polar Stereographic North (EPSG:3413).

Table 3.1 - Information about each RES systems and modelled data.

\begin{tabular}{lclllll}
\hline Dataset & Numerical model & $\begin{array}{l}\text { Waveform- } \\
\text { signal }\end{array}$ & $\begin{array}{l}\text { Pulse- } \\
\text { Repetition- } \\
\text { Frequency }\end{array}$ & $\begin{array}{l}\text { Sampling- } \\
\text { Frequency }\end{array}$ & $\begin{array}{l}\text { Sampling- } \\
\text { resolution }\end{array}$ & Frequency-range \\
\hline AWI (Polar6 aircraft) & MCoRDS5 & $\begin{array}{l}1 \mu \mathrm{s}-3 \mu \mathrm{s}-10 \mu \mathrm{s}- \\
\text { Chirp }\end{array}$ & $10 \mathrm{kHz}$ & $1600 \mathrm{MHz}$ & $0.45 \mathrm{~m}$ & $180-210 \mathrm{MHz}$ \\
CReSIS (NASA's P-3 aircraft) & MCoRDS2 & $\begin{array}{l}1 \mu s-3 \mu s-10 \mu \mathrm{s}- \\
\text { Chirp }\end{array}$ & $10 \mathrm{kHz}$ & $111 \mathrm{MHz}$ & $0.45 \mathrm{~m}$ & $180-210 \mathrm{MHz}$ \\
Modelled & emice & Ricker & & $0.02 \mathrm{~ns}$ & $0.02 \mathrm{~m}$ & $100-150 \mathrm{MHz}$ \\
\hline
\end{tabular}


Table 3.2 - Information about the DEP data sets.

\begin{tabular}{llllr}
\hline Dataset & $\begin{array}{l}\text { Sampling res- } \\
\text { olution }\end{array}$ & Frequency & Drill depth & New data in this study \\
\hline EGRIP & $5 \mathrm{~mm}$ & $250 \mathrm{kHz}$ & $2122.445 \mathrm{~m}$ & 1383.84 to $2122.445 \mathrm{~m}$ \\
NEEM & $5 \mathrm{~mm}$ & $250 \mathrm{kHz}$ & $2537.065 \mathrm{~m}$ & 1493.297 to $1757.310 \mathrm{~m}$ \\
NEEM-2011-S1 & $5 \mathrm{~mm}$ & $250 \mathrm{kHz}$ & $100 \mathrm{~m}$ & (Mojtabavi et al., 2020b) \\
NGRIP2 & $5 \mathrm{~mm}$ & $250 \mathrm{kHz}$ & $2930.32 \mathrm{~m}$ & 11.02 to $1298.705 \mathrm{~m}$ \\
\hline
\end{tabular}

\section{Dielectric profiling (DEP) and ice core data}

The dielectric properties (Moore and Paren, 1987) of the EGRIP, NEEM, and NGRIP ice cores were measured with a DEP (Dielectrical Profiling) bench with a frequency of $250 \mathrm{kHz}$ and $5 \mathrm{~mm}$ vertical resolution as described by Wilhelms et al. (1998); Wilhelms (1996, 2005); Mojtabavi et al. (2020b). To yield the best possible interpretation of the DEP data ice core breaks, missing pieces and differing all over quality of ice core sections were logged during processing, and slight capacitance/conductance variations due to the deformation of the cables of DEP device could be corrected by calibration data. A detailed description of DEP data processing of the EGRIP, NEEM, and NGRIP ice cores is given by Mojtabavi et al. (2020b). At the time of this study, the EGRIP drilling campaign did not reach bedrock, here we present and analyse new DEP data of the upper $\sim 2122 \mathrm{~m}$ of the ice core that were recorded during the 2017-19 field seasons (the DEP data down to 1383.849 was published by Mojtabavi et al. (2020b)). For the analysis of the NEEM region we used data measured on $100 \mathrm{~m}$ firn core (NEEM-2011-S1) (Karlsson et al., 2016) as a supplement to the main core data. The DEP data of the deeper core sections of the main ice core reach down to a depth of $\sim 2537 \mathrm{~m}$, which is about $20 \mathrm{~m}$ above the bed, and were recorded over a time span of several field seasons between 2008 and 2012.

As the first NGRIP coring (here referred as "NGRIP1") terminated in $1372 \mathrm{~m}$ depth due to a jammed drill, a second hole was restarted a few metres away, here referred as "NGRIP2". The DEP data from the NGRIP2 ice core reach down to $2930 \mathrm{~m}$ and were measured during the 1998-2004 field seasons. The data from the upper part of NGRIP2 down to $1298.705 \mathrm{~m}$ is published in this study for the first time, while data from the deeper part was presented in a previous study by Rasmussen et al. (2013). In table 3.2 the we list the so far unpublished and published DEP data sources we used in study.

It should be noted, that the DEP data is not yet corrected for the temperature difference between the deep ice insitu and during the measurements in the field. However, according to Winter et al. (2017) the effect of temperature should not affect the signature of conductivity and permittivity reflector patterns, as the amplitudes or decline of amplitudes of the reflections do not affect the depth of reflectors, which is the main parameter of comparison. Even when correcting the temperature effect, it is not to be expected to exactly reproduce the observed amplitudes with the synthetic radar trace modelling. A study by Wolff et al. (2005) illustrates that for the low-accumulation study area only $45 \%$ of the conductivity peaks reproduce in both of the paralleled topmost $788 \mathrm{~m}$ EPICA Dome C(EDC) cores, which were drilled $10 \mathrm{~m}$ apart, after the drill jammed in the first hole. As the ice cores are not reaching up to the snow surface due to setting up the deep drilling equipment in a trench, the DEP records start at $13.77 \mathrm{~m}, 6.55$ 
Chapter 3. Deep insights to the Greenland ice sheet by linking multichannel ultra-wide-band radar 48 surveys to the latest deep ice cores by synthetic radar modelling

$m$ and $11.02 \mathrm{~m}$ depth for the EGRIP, NEEM, and NGRIP2 ice cores, respectively. To simplify the comparison of modelled and observed results, we extended the DEP data up to the surface, where we used a relative permittivity of 1.55 and a conductivity of $4 \mu \mathrm{S} \mathrm{m}-1$ as surface values (Winter et al., 2017). The values are a DECOMP mixture (Wilhelms, 2005) of the measured pure ice conductivity (20 $\mu \mathrm{S} \mathrm{m}-1)$, the assumed surface firn density (300 kg m-3) and the relative pure ice permittivity (3.15), as determined below. However, the interpolated section only extends to a few meters, which cannot cause any significant shift in synthetic radar traces' reflector positions.

\section{Modelling of synthetic radar traces (SYN) and the depth of internal re- flection horizons (IRH)}

Following the approach in Winter et al. (2017), we used the conductivity and permittivity records, measured by means of DEP as described in the section above as input for the 1D-FD numerical model (One-Dimensional Finite Difference) “emice" Eisen et al. (2004) to calculate synthetic radar traces based on Maxwell's curl equations. In order to convert the depth of DEP data to the two-way travel time (TWT) domain of the RES data, we need to calculate electromagnetic wave speed in firn and ice $c_{z}$ from the vacuum speed of light $c_{0}$ and the real component $\varepsilon^{\prime}$ of the complex relative dielectric permittivity, $\varepsilon^{*}$,

$$
c_{z}=\frac{c_{0}}{\sqrt{\varepsilon^{*}}} \approx \frac{c_{0}}{\sqrt{\varepsilon^{\prime}}},
$$

where

$$
\varepsilon^{*}=\varepsilon^{\prime}-\mathrm{i} \varepsilon^{\prime \prime},
$$

and

$$
\varepsilon^{\prime \prime}=\frac{\sigma}{\omega \varepsilon_{0}} .
$$

In these equations, $\varepsilon^{\prime \prime}$ is the imaginary component of the complex relative dielectric permittivity, $\sigma$ is the conductivity, $\varepsilon_{0}$ the permittivity of the vacuum and $\omega$ the angular frequency.

Firn in the uppermost fraction of the core is a two-phase system, thus being composed from ice and air. Air has a relative permittivity of 1 and vanishing conductivity, while the ice phase of pure glacier ice exhibits the relative permittivity $\varepsilon_{\text {ice }}^{\prime}$ and the conductivity $\sigma_{\text {ice, }}$, which is determined by the chemical impurity load and the temperature of the ice. The complex relative dielectric permittivity $\varepsilon^{*}$ of the mixture further depends on the volume fraction of the ice phase, here being expressed as the fraction of firn density $\rho$ and pure ice density $\rho_{\text {ice }}$. The dielectric property of the firn is well described by the density and conductivity mixed permittivity (DECOMP) equation (Wilhelms, 2005):

$$
\varepsilon^{*}=\varepsilon^{\prime}-\mathrm{i} \varepsilon^{\prime \prime}=\left(\frac{\rho}{\rho_{\text {ice }}}\left(\sqrt[3]{\varepsilon_{\text {ice }}^{\prime}-\mathrm{i} \frac{\sigma_{\text {ice }}}{\omega \varepsilon_{0}}}-1\right)+1\right)^{3} .
$$


Thus, we determine density and conductivity, which are frequency independent, from the DEP measurements and calculate the input to our model at the central frequency of the radar system by means of the DECOMP formula(Eisen et al., 2006).

The imaginary and real parts of the complex dielectric permittivity were measured directly in the field with a DEP bench at a frequency of $250 \mathrm{kHz}$ for all ice cores. The "emice" model translates their variability with depths into reflection signatures of the impulse response of the subsurface. In the next step, the impulse response is convoluted with the source wavelet to also consider the effect of interferences. However, general amplitude decay with depth is not reproduced by the model.

We used $0.02 \mathrm{~m}$ as model depth resolution and $0.02 \mathrm{~ns}$ for the time increment. These values are based on the stability of the numerical calculations (Eisen et al., 2006). The maximum depth varies for each ice core. We used 35 and $36 \mu$ s TWT for the NEEM and NGRIP2 ice cores, respectively, to cover reflection in our model domain. At this point, we do not reach the bedrock of EGRIP ice core. The final logging depth for EGRIP is $2122.445 \mathrm{~m}$ which was drilled in field season 2019. Therefore, we used $30 \mu$ s TWT to cover reflection in our synthetic model domain for the EGRIP ice core. The time ranges were selected sufficiently large to cover reflections from the model boundaries based on the ice core depths.

Due to the integration over kilometres, the average dielectric permittivity for a depth interval may be determined even more precise than the estimated 1-2\% error of the DEP measurement (Wilhelms, 2005; Wilhelms et al., 1998; Mojtabavi et al., 2020b). For consolidated sections, below about $100 \mathrm{~m}$, we compared the "emice" model-output for the varied real part of permittivity $(3.15,3.16,3.17,3.18$ and 3.19) with observational radar traces' TWT, to find the best electromagnetic wave speed $c_{z}$ match for the radar reflections, where $c_{z}$ and $\varepsilon^{\prime}$ are closely related through equation 3.1. The real permittivity of the DEP record varies within the estimated 1-2\% error. Apart from this methodological limitation of DEP, the permittivity offset along the symmetry axis of an ice crystal and perpendicular to it is close to $1 \%$ as well (Fujita et al., 1993). Site-dependent evolution of the crystal orientation fabric (COF) together with the impossibleness to orient the cores, may also explain the observed variation on the permittivity records' real part. The correspondence of modelled and measured radar-traces is more prominent, when replacing the measured dielectric permittivity's real part with a fixed average value, that produces the conductivity-variation induced reflections at the accurate TWT and avoids interference from reflections due to noise in the real part's record. Winter et al. (2017) used a dielectric permittivity constant of 3.17 for the modelling of EDC ice core in Antarctica. In this study, we used a value of 3.15 value for all ice cores which represents the best correspondence between model and measured traces for the consolidated sections below $100 \mathrm{~m}$. A detailed description of the calculation and calibration to the DEP data is given by Mojtabavi et al. (2020b).

Following Eisen et al. (2006), we tested different wavelets and chose a Ricker wavelet for this study, which is short and thus favourable to determine the depth of the reflectors' origin at high resolution. The envelope of the synthetic traces, which is related to the reflected energy, is obtained by applying a Hilbert magnitude transformation (e.g., mimic rectification) (Eisen et al., 2006). Finally, the model outputs are smoothed with a Gaussian running mean of 100 ns (Eisen et al., 2006; Winter et al., 2017). That way the resolution of the filtered model output is in the range of the observed data, and the response to certain reflectors can be compared to events recorded in the measurements. 

surveys to the latest deep ice cores by synthetic radar modelling

To assign conductivity variations in the DEP record to internal reflection horizons (IRH), we mute selected conductivity peaks (Eisen et al., 2006; Winter et al., 2017) in our DEP data (green peaks highlighted by grey bands in Figure 3.2). By comparison of the recorded radar trace with the synthetic trace, we can proof the origin of a certain reflector if it changes in the synthetic trace, when being muted in the DEP record. Ultimately, the established dating for the DEP records (Mojtabavi et al., 2020b) is transferred to the identified internal reflexion horizons (IRH).

\section{Results}

Figures 3.2 and 3.3 accentuate the excellent agreement between the modelled synthetic radargrams (SYN) and the radar-observed internal reflection horizons (IRH). Figure 3.2 presents the peaks (grey bands) of internal reflection horizons as observed in A-scope representation we use for synchronization between radar measurements and synthetic traces, which are computed based on the DEP record of the ice core and the short (Ricker) wavelet. As discussed to more detail in section, the synthetic traces have a higher temporal (vertical) resolution compared to the radar measurements. For better graphical representation we split each trace into three time (depth) segments (synthetic in blue and RES in red), to have better magnitude resolution of the reflections, as the amplitude is decaying over time.

Figure 3.3 compares the measured radargrams close to the drill sites and synthetic radargrams (z-scope) from modelled traces (Figure 3.2), which are derived by plotting the trace 200 times with amplitudes in grey scale shades. The coloured circles in Figure 3.3 indicate some of the reflectors in the radargrams that correspond to a reported match point by Mojtabavi et al. (2020b). The timescale was transferred from ice cores to several key isochrones by synchronization of the synthetic and RES radargrams, following the procedures of Winter et al. (2019, 2017). After the depth-to-TWT conversion for the DEP data, we mute certain conductivity and permittivity peaks to identify their precise depth in RES and synthetic radargrams. We then use the depth-age relation to transfer age to the isochrone depths from the annual-layer-counted Greenland Ice Core Chronology 2005 (GICC05) timescale which was provided by Mojtabavi et al. (2020b); Rasmussen et al. (2013) for the EGRIP, NEEM, and NGRIP2 ice cores. The matched layers of synthetic and real radargrams that are sensitivive to muting conductivity peaks in the DEP record are listed in Table 3.3.

\section{EGRIP}

The two deepest peaks in the RES data at about 22.5 and $24 \mu \mathrm{s}$ TWT, just at the bottom of the already drilled ice core and about $8 \mu$ sWT above the bedrock reflection at the EGRIP drill site are highlighted in figure 3.2 and can be unambiguously matched between data and model. In the interval between about 4 and $16 \mu$ s TWT, more reflectors can be matched. The reflectors at 5, 10 and $15 \mu$ sWT are other examples of the upper part of EGRIP drill site, which appear to have their representation in the model data. The climatic transition from Holocene to the last glacial is characterized by a change from darker to lighter shades of grey ( $\sim 15 \mu$ s TWT in EGRIP). This is a widespread signal in radar section all over Greenland (e.g., MacGregor et al., 2015).

\section{NEEM}

At NEEM, the ice core has been drilled to the bed and the DEP record terminates a few meters above the bedrock. In the first and second panel of the Figure 3.2, a number of distinct reflectors match between RES and synthetic data 
(SYN). In some sections, the synthetic peaks are very close to each other (brown arrows in Figure 3.2), for example, around 0.7 and $2.7 \mu \mathrm{s}$ TWT. Due to the different time resolution of modelled ad recorded data it is difficult to unambiguously assign conductivity peaks to the corresponding RES reflections. Eisen et al. (2006); Winter et al. (2017) show that sometimes several peaks should be removed from DEP data in order to remove a reflection peak in model results. We highlight several distinct reflections from the NEEM drill site with orange double arrow indicators (Figure 3.3). At $17 \mu$ s TWT, we can detect the climatic transition in both synthetic and RES data.

\section{NGRIP2}

We observe three strong reflectors around $0.7 \mu \mathrm{s}$ TWT in the model results based on NGRIP2 DEP data (brown arrows in Figure 3.2), which can be matched with high confidence with reflections in RES data, comparable to the results from NEEM. We highlight 21 reflectors in NGRIP2 which can be matched between the synthetic trace and RES dataset. The events match very well below $18 \mu \mathrm{s}$ TWT (Figure 3.2 and Figure 3.3), not only in depth, but also in the characteristic shape of the signal. We also have clearly matched reflections (green double arrow indicators) within the top part of the ice column, as seen in Figure 3.3.

\section{Discussion}

\section{Origin of radar reflectors}

We find that conductivity can explain reflections in the radar signals in Greenland ice sheet. Previous studies (Eisen et al., 2006; Miners et al., 2002) have shown that conductivity can explain the majority of reflections in the radar signals in ice sheet. The Crystal orientation Fabric (COF) of the ice, which is stronger at the base of the ice sheets, also has an influence on the radar wave propagation in ice (Eisen et al., 2007). In general, it can be stated that for the upper $100 \mathrm{~m}$ of ice sheet, the reflections are based on permittivity and density contrasts. In general, below 100 $\mathrm{m}$ depth, the variability of the permittivity decreases and reflections are in few cases related to the change of crystal orientation fabric (COF) and in most occasions related to changes of the ice's impurity content, like e.g. volcanic layers and fundamental changes of the climate system (e.g. glacial transitions and DO events), which is closely related to the conductivity changes (Hempel et al., 2000; Fujita et al., 1999; Fujita and Mae, 1994; Eisen et al., 2006).

Figure 3.4 shows a modelled trace based on EGRIP DEP data, and RES profiles oriented parallel as well as across to ice-flow direction (see flight lines in Figure 3.1). Conductivity changes can explain most of the reflections in EGRIP drill site. . Figure 3.4 shows an effect of the flow velocity changes in the shear margins of NEGIS, which causes folding (Franke et al., 2020) (blue arrows in Figure 3.4) in the profile oriented across ice-flow. The folding is apparent in the stratigraphy by strongly inclined reflections, which results in weak signals (see RES crossflow profile in Figure 3.4).

Previous studies (Dahl-Jensen et al., 2013; Montagnat et al., 2014; Eichler et al., 2013; Li et al., 2018) showed that the NEEM core is a folded core with strong change of crystal orientation fabric (COF) at $2200 \mathrm{~m}$ depth (Figure 3.5). Figure 3.5 shows a strong reflector $\sim 22.2 \mu$ s around $1889 \mathrm{~m}$ that is reproduced with a small signal in our model result. The faint signals in the synthetic trace indicates that there is a small signal linked to the conductivity in the DEP data. The observed really large peak at $22.2 \mu$ s in the RES could indicate that the source of the reflection is 
Chapter 3. Deep insights to the Greenland ice sheet by linking multichannel ultra-wide-band radar surveys to the latest deep ice cores by synthetic radar modelling

(a)

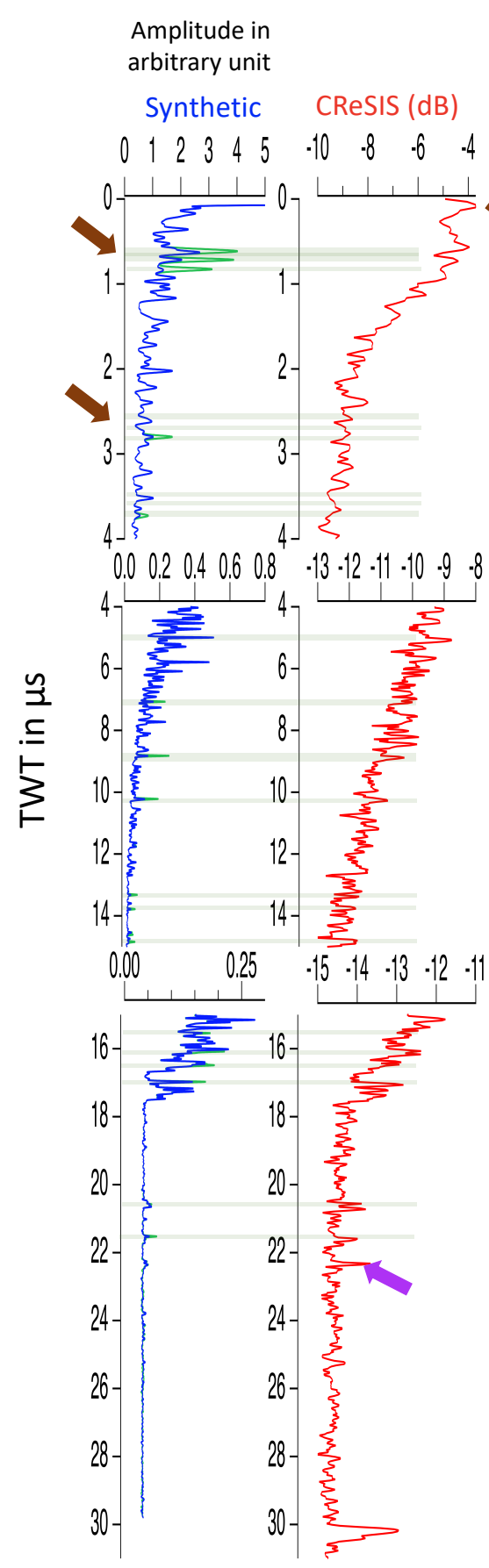

(b) NGRIP2

Amplitude in

arbitrary unit

Synthetic

CReSIS $(\mathrm{dB})$ $\begin{array}{llllll}0 & 4 & 6 & \cdot 11 \cdot 10 \cdot 9 \cdot 8 \cdot 7 \cdot 6\end{array}$

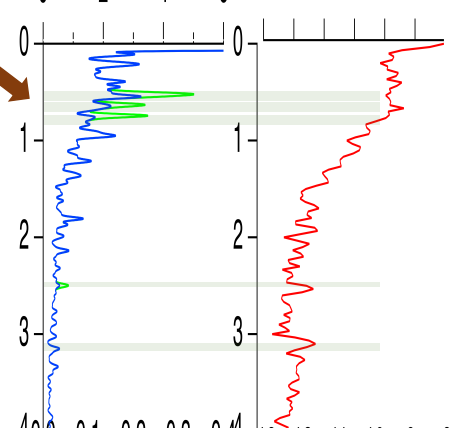

$40.0 \quad 0.10 .2 \quad 0.3 \quad 0.44 \cdot 13 \cdot 12 \cdot 11 \cdot 10 \cdot 9 \cdot 8$
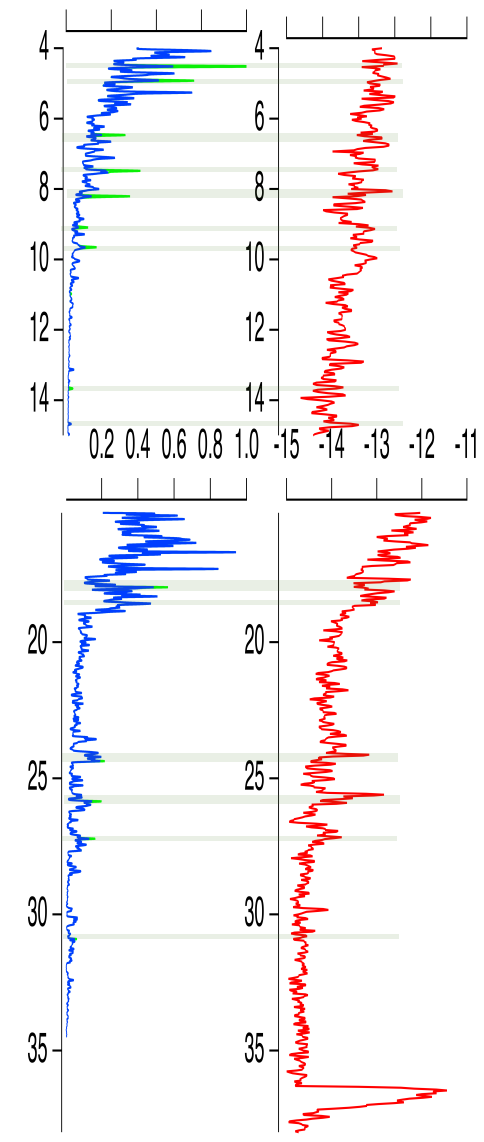

(c)

EGRIP

Amplitude in arbitrary unit

AWI (dB)

Synthetic along/cross flow

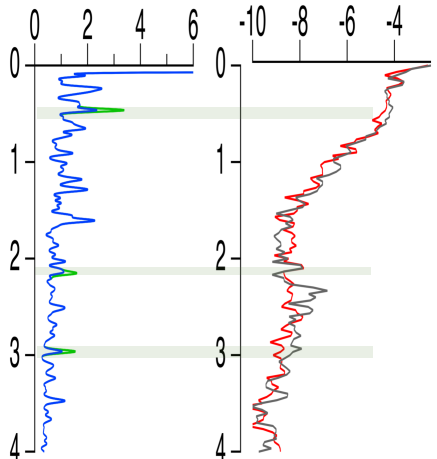

$0.00 .51 .01 .52 .0 \quad \cdot 13 \cdot 12 \cdot 11 \cdot 10 \cdot 9 \cdot 8$

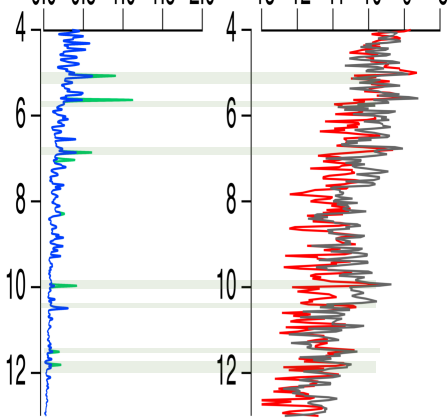

$0.0 \quad 0.5 \quad 1.0 \times 10^{-1} \cdot 15 \cdot 14 \cdot 13 \cdot 12 \cdot 11$

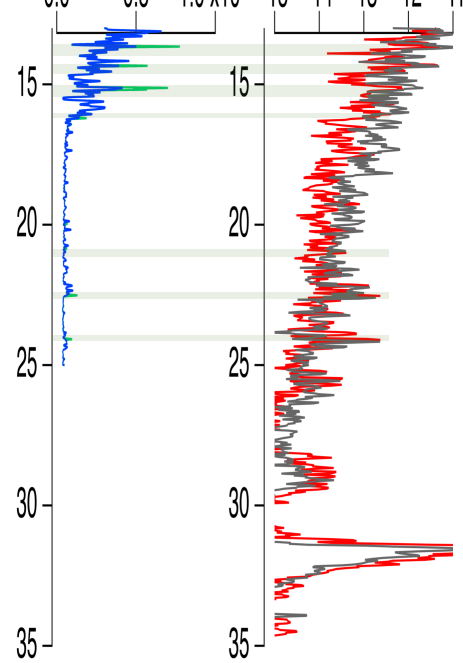

Figure 3.2 - A-scopes for traces of the radar systems (red) in (a) NEEM, (b) NGRIP2 and (c) EGRIP (along and across flow) synthetic traces (blue). The surface reflection of each trace is shifted to time zero. The used reflections for synchronization are marked by grey bands. The peaks highlighted in green cause the identified dated reflections (Table 3.3) which are observed both in the synthetic and RES traces. The coloured arrows highlight reflections that are described in detail in the results section. 


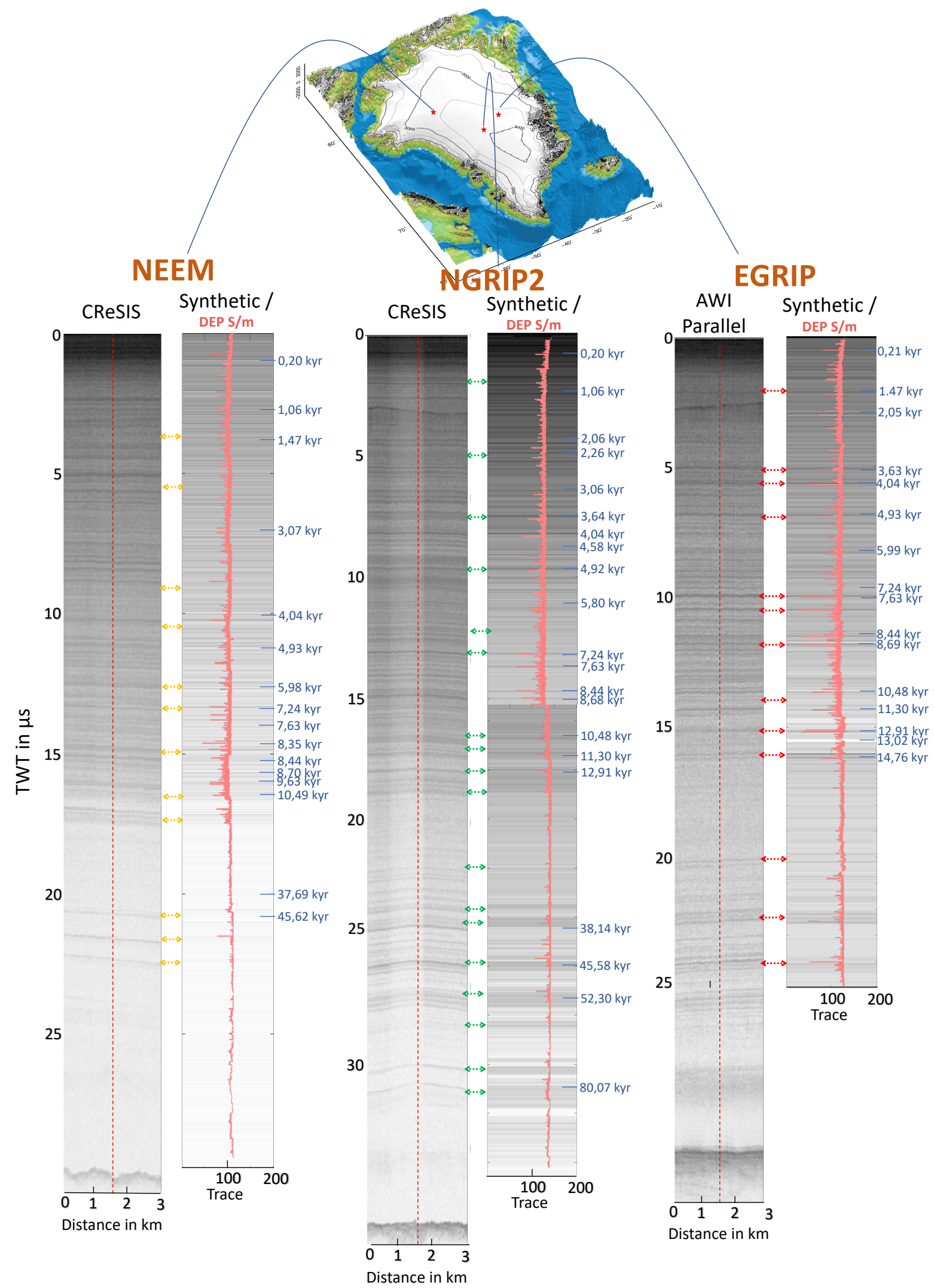

Figure 3.3-Z-scopes for synthetic and RES data sets for the NEEM and NGRIP2 and EGRIP ice cores. The surface reflection of each RES radargram is shifted to time zero. The coloured double arrows indicate the synchronous reflections between synthetic and RES radargrams. The coloured circles show selected dated reflectors observed in the SYN and RES radargrams. The vertical red dashed lines mark the positions of the traces of Figure 3.2, which correspond to the location of the traces closest to the the drill locations. The age-depth scale is based on the table 3.3. The Greenland map is based on the GEBCO (2014) data. 
Chapter 3. Deep insights to the Greenland ice sheet by linking multichannel ultra-wide-band radar 54 surveys to the latest deep ice cores by synthetic radar modelling

Table 3.3 - The matched layers of synthetic and real radargrams with approximate TWTs, depth ranges of their inducing conductivity/permittivity sections of DEP and corresponding ages from the GICC05 (depth, age) timescale which was provided by Mojtabavi et al. (2020b); Rasmussen et al. (2013). The wave propagation speeds and $\varepsilon^{\prime}$ calculated between $2.1 \mu$ s peak (red box) and other peaks at EGRIP. In this way, we calculated difference $\varepsilon^{\prime}$ between along and across flow direction.

\begin{tabular}{|c|c|c|c|c|c|c|c|c|c|c|c|c|c|c|c|}
\hline \multicolumn{3}{|c|}{ NEEM } & \multicolumn{3}{|c|}{ NGRIP2 } & \multicolumn{10}{|c|}{ EGRIP } \\
\hline TWT $\mu \mathrm{s}$ & Depth $(\mathrm{m})$ & Age (b2k) & TWT $\boldsymbol{\mu} \mathrm{s}$ & Depth (m) & Age (b2k) & $\begin{array}{c}\text { TWT } \mu \mathrm{s} \\
\text { along }\end{array}$ & $\begin{array}{l}\text { TWT } \mu \mathrm{s} \\
\text { across }\end{array}$ & Depth $(\mathrm{m})$ & Age (b2k) & $\begin{array}{l}\text { speed } \\
\text { along }\end{array}$ & $\begin{array}{l}\text { speed } \\
\text { across }\end{array}$ & $\varepsilon$ along & $\varepsilon$ across & $\Delta \varepsilon^{\prime}$ & Ave $\boldsymbol{\varepsilon}^{\prime}$ \\
\hline 0.71 & 70.34 & 220 & 0.63 & 60.4 & 220 & 0.4 & 0.4 & 45.45 & 216.6 & 170.547 & 170.547 & 3.090 & 3.090 & 0 & 3.090 \\
\hline 2.71 & 247.97 & 1062 & 2.5 & 220 & 1060 & 2.1 & 2.1 & 190.415 & 1470 & & & & & & \\
\hline 3.6 & 326.67 & 1470 & 4.49 & 390 & 2060 & 2.9333 & 2.9333 & 258.55 & 2050 & 163.531 & 163.531 & 3.361 & 3.361 & 0 & 3.361 \\
\hline 6.78 & 608.84 & 3076 & 4.9 & 424 & 2260 & 5 & 5 & 436.37 & 3639 & 169.624 & 169.624 & 3.124 & 3.124 & 0 & 3.124 \\
\hline 9.78 & 756 & 4045 & 6.44 & 554 & 3060 & 5.6 & 5.6 & 484.1 & 4048 & 167.820 & 167.820 & 3.191 & 3.191 & 0 & 3.191 \\
\hline 11.22 & 874 & 4931 & 7.45 & 640 & 3640 & 6.8 & 6.8 & 587.39 & 4931 & 168.926 & 168.926 & 3.150 & 3.150 & 0 & 3.150 \\
\hline 12.75 & 1001.8 & 5984 & 8.17 & 701 & 4040 & 8.233 & 8.233 & 708.21 & 5991 & 168.847 & 168.847 & 3.152 & 3.152 & 0 & 3.152 \\
\hline 13.18 & 1136.9 & 7247 & 9.06 & 777 & 4580 & 9.933 & 9.933 & 849.98 & 7245 & 168.400 & 168.400 & 3.169 & 3.169 & 0 & 3.169 \\
\hline 13.97 & 1175.93 & 7637 & 9.61 & 823.9 & 4920 & 11.467 & 11.5 & 980.17 & 8440 & 168.625 & 168.033 & 3.161 & 3.183 & 0.022 & 3.172 \\
\hline 14.19 & 1239.5 & 8359 & 11.26 & 941 & 5800 & 11.8 & 11.8333 & 1005.7 & 8697 & 168.100 & 167.525 & 3.181 & 3.202 & 0.022 & 3.192 \\
\hline 15.38 & 1246 & 8443 & 13.07 & 1117.5 & 7240 & 13.65 & 13.68335 & 1161.8 & 10483 & 168.205 & 167.721 & 3.177 & 3.195 & 0.018 & 3.186 \\
\hline 15.5 & 1265.5 & 8700 & 13.61 & 1163.5 & 7639 & 14.3333 & 14.3667 & 1219.4 & 11305 & 168.227 & 167.769 & 3.176 & 3.193 & 0.017 & 3.184 \\
\hline 15.78 & 1325.11 & 9630 & 14.63 & 1248.5 & 8440 & 22.533 & 22.6 & 1910.15 & & 168.327 & 167.779 & 3.172 & 3.193 & 0.021 & 3.182 \\
\hline 16.12 & 1370.14 & 10496 & 14.92 & 1272.5 & 8680 & 23.9 & 23.9667 & 2027.265 & & 168.518 & 168.004 & 3.165 & 3.184 & 0.019 & 3.175 \\
\hline 19.67 & 1749 & 37696 & 16.64 & 1419 & 10484 & 24.08335 & 24.15 & 2041.89 & & 168.443 & 167.934 & 3.168 & 3.187 & 0.019 & 3.177 \\
\hline 20.57 & 1830 & 45622 & 17.13 & 1470.5 & 11305 & & & & & & & & & & \\
\hline & & & 18 & 1527 & 12918 & & & & & & & & & & \\
\hline & & & 24.4 & 2067.3 & 38140 & & & & & & & & & & \\
\hline & & & 25.9 & 2192.2 & 45580 & & & & & & & & & & \\
\hline & & & 27.2 & 2308.5 & 52301 & & & & & & & & & & \\
\hline & & & 30.9 & 2619.3 & 80077 & & & & & & & & & & \\
\hline
\end{tabular}




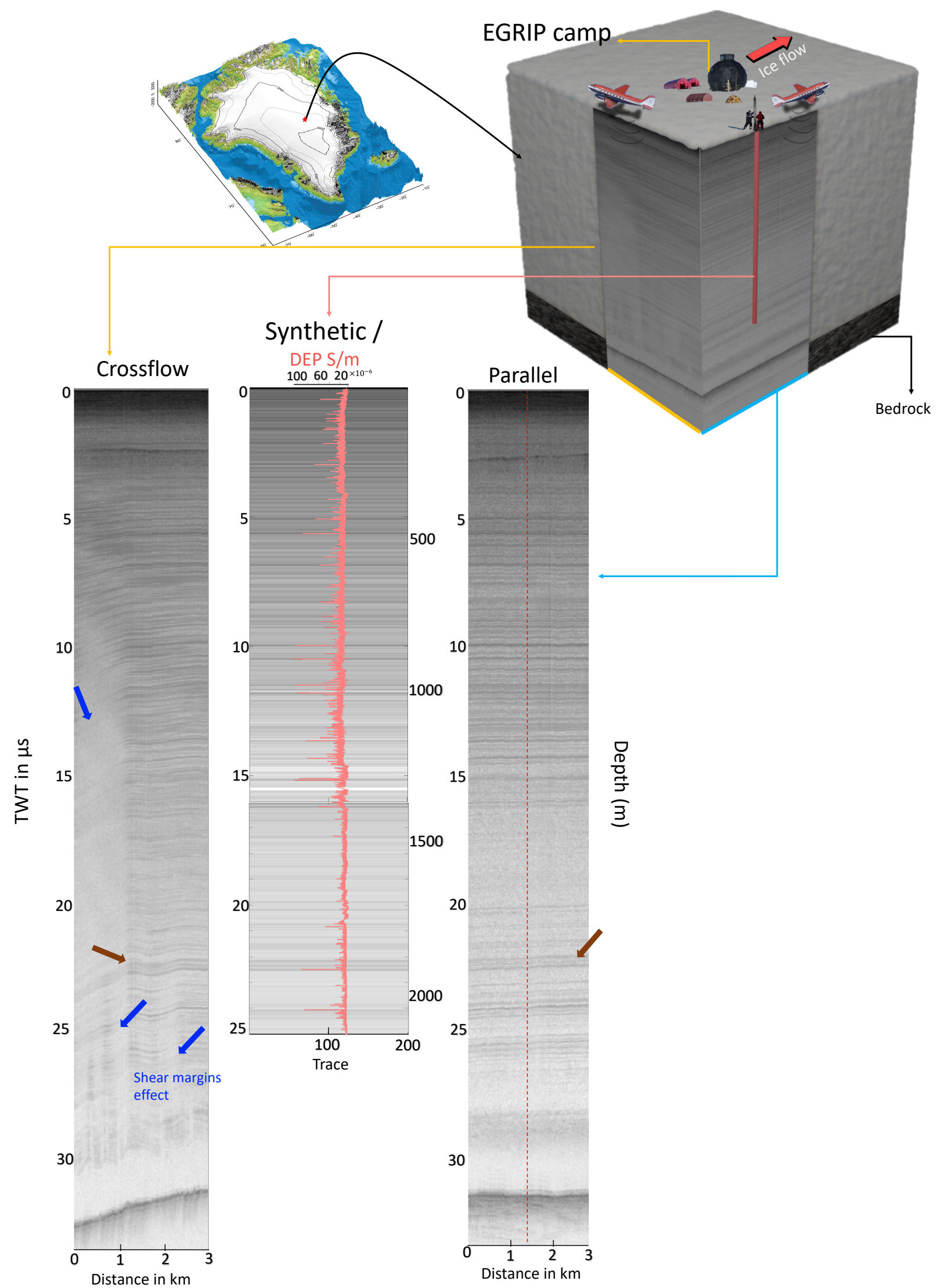

Figure 3.4 - Z-scopes for synthetic and RES data sets of the EGRIP ice core location. The vertical red dashed line shows the position of the trace of Figure 3.2. The blue arrows indicate an effect of the shear margin in the profile oriented across ice-flow. The coloured arrows show reflections that are described in detail in the discussion section. The Greenland map is based on the GEBCO (2014) data. 
Chapter 3. Deep insights to the Greenland ice sheet by linking multichannel ultra-wide-band radar surveys to the latest deep ice cores by synthetic radar modelling

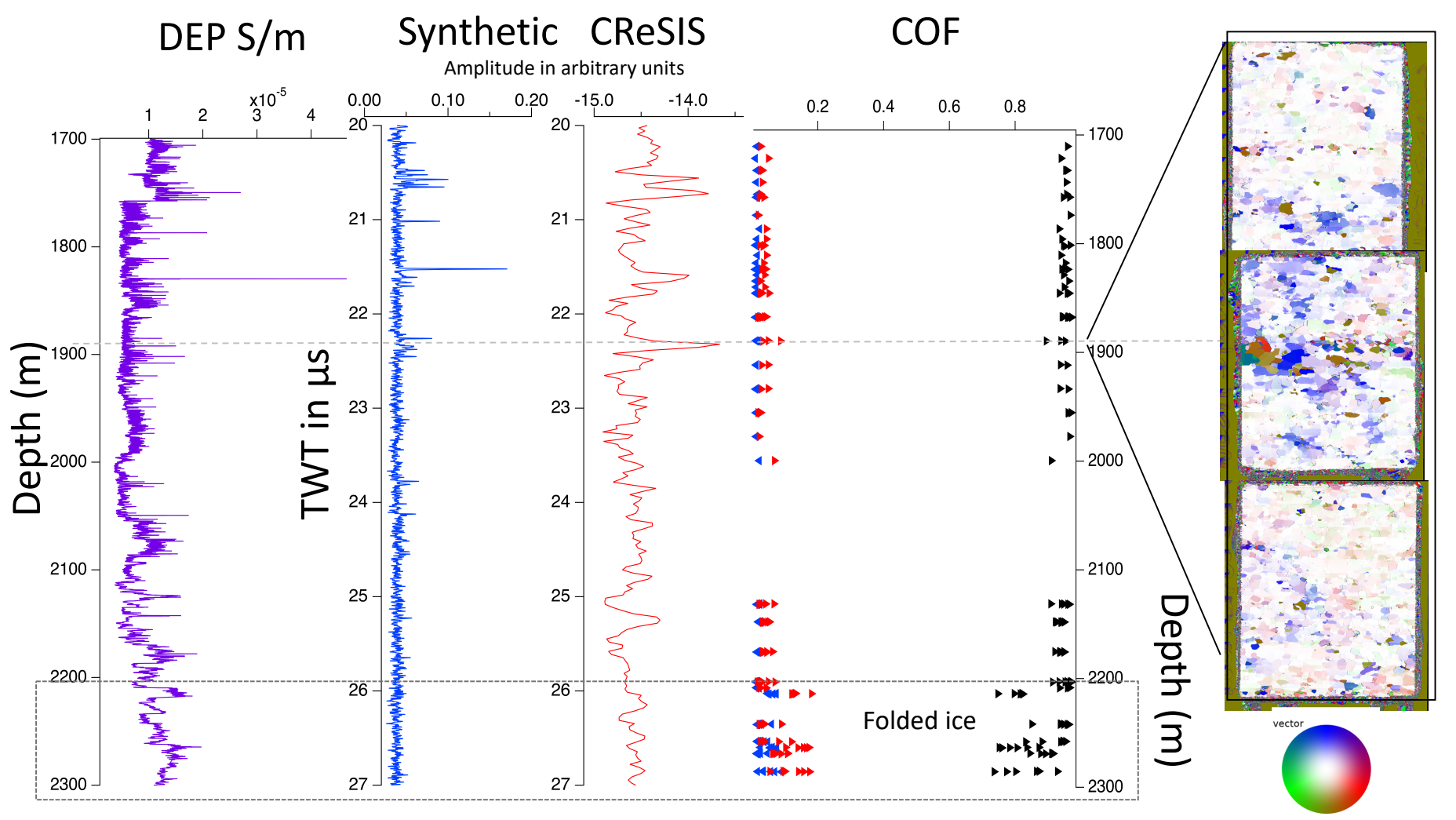

Figure 3.5- Example of the reflection for potential crystal orientation fabric(COF) at the NEEM drill site. From left to right: DEP data recorded (conductivity); A-scopes for traces of the radar system and synthetic traces in NEEM of Figure 3.2; Fabric data along the NEEM ice core (Eichler et al., 2013), orientation-tensor eigenvalues ( $\lambda_{1}$ : black triangle, $\lambda_{2}$ : red triangle, $\lambda_{3}$ : blue triangle); Segmentation of the fabric image (Eichler et al., 2013) with colorcoded c-axes orientations of the reflection section; dashed horizontal line connect to the RES reflector with depth of changes in COF $(\sim 1900$ mdepth $)$. 
not only due to a conductivity change in the DEP data. In the same depth, another possibility for the sources of the RES reflection is the sudden change of COF. The change of eigenvalues and fabric images (c-axes) Eichler et al. (2013) correspond to the reflector at $22.2 \mu \mathrm{s}$ in Figure 3.5. Previous research, Eisen et al. (2007) also indicated that radar reflections from below $\sim 2000 \mathrm{~m}$ depth resulted from changes in crystal-orientation fabric at the EDML drill site in Antarctica.

At the location of the NGRIP2 drill site, there is a deep section without any significant reflections (after $30 \mu \mathrm{s}$ TWT in Figure 3.2), and section after $25 \mu$ s TWT in NEEM drill site. This part of ice sheet is described as an echofree zone (EFZ) by Fujita et al. (1999); Drews et al. (2009); Winter et al. (2017) which is characterized by a sudden drop of returned power in the radar data. A study by Drews et al. (2009) shows disappearance of continuous layers in deeper sections of EDML drill site in Antarctica.

\section{Age stratigraphy}

By linking the dated events from DEP records at the locations of three deep ice cores to reflections in airborne RES data, we provide the possibility to extend the dating from the core locations along the radar lines over large parts of northern Greenland. The depths uncertainties of our modelling results are reduced compared to the TWTto-depth conversion with a constant electromagnetic wave speed (Winter et al., 2017, 2019) and a firn correction of $\sim 10-15 \mathrm{~m}$ due to higher velocities in firn section. In this way, the depth uncertainties are related to the DEP measurements and the width of the reflection-causing conductivity peaks (Winter et al., 2019). Our age stratigraphy with a direct connection of different deep ice cores can be used to better understand internal processes in the Greenland Ice Sheet. It is also a better assessment of age accuracy, which was provided by MacGregor et al. (2015) for the Greenland Ice Sheet. Quasi-Nye dating (MacGregor et al., 2015) can reasonably date reflections away from ice cores, however, the isochrones layers and unexplained layer can be proved by our study that would be given priority for COF analysis.

\section{Conclusions}

We have characterized internal layers inside the Greenland Ice Sheet. In order to understand physical processes that cause the reflection and identify ages for the layer's reflectors, we rely on the airborne radar measurements (radio-echo sounding) and modelling of synthetic radar traces that were fed by conductivity and permittivity data from EGRIP, NEEM, and NGRIP2 ice cores in Greenland. Our results show excellent agreement between the synthetic model and the radar measurements. From the comparison between the measured and modelled data it could be concluded that conductivity peaks are responsible for individual radar peaks. Overall, the modelling results demonstrate that the internal reflections in most part of sections in the ice sheet are due to conductivity changes. Reflectors in the observed radargrams have been dated by means of the presented sensitivity studies with the DEP record using the GICC05 time scale. For EGRIP our comparison of along and across flow wave propagation speeds suggests the concentration of the c-axis in a cone perpendicular to the flow direction and therefore we are able to orient the observed fabric in the ice core in the ice sheet and support the discussed flow regime of uniaxial extension.

\section{Supplementary data}

With the final version of this paper we will publish the following data sets at www.pangaea.de. 
Chapter 3. Deep insights to the Greenland ice sheet by linking multichannel ultra-wide-band radar surveys to the latest deep ice cores by synthetic radar modelling

- Specific conductivity measured with the dielectric profiling (DEP) technique on the EGRIP ice core, 1383.842122.445 m depth (Mojtabavi and Wilhelms, 2020a, https://doi.pangaea.de/10.1594/PANGAEA.922285).

- Permittivity measured with the dielectric profiling (DEP) technique on the EGRIP ice core, 1383.84-2122.445 m depth (Mojtabavi and Wilhelms, 2020b, https://doi.pangaea.de/10.1594/PANGAEA.922299).

- Specific conductivity measured with the dielectric profiling (DEP) technique on the NEEM ice core (1493.2971757.310 m depth) (Mojtabavi and Wilhelms, 2020c, https://doi.pangaea.de/10.1594/PANGAEA.922303).

- Permittivity measured with the dielectric profiling (DEP) technique on the NEEM ice core (1493.297-1757.310 m depth) (Mojtabavi and Wilhelms, 2020d, https://doi.pangaea.de/10.1594/PANGAEA.922305).

- Specific conductivity measured with the dielectric profiling (DEP) technique on the NGRIP2 ice core (down to $1298.555 \mathrm{~m}$ depth) (Mojtabavi and Wilhelms, 2020e, https://doi.pangaea.de/10.1594/PANGAEA.922306).

- Permittivity measured with the dielectric profiling (DEP) technique on the NGRIP2 ice core (down to 1298.555 m depth) (Mojtabavi and Wilhelms, 2020f, https://doi.pangaea.de/10.1594/PANGAEA.922308).

- AWI UWB radar data along of the EGRIP drill site at the onset region of the Northeast Greenland Ice Stream, camp 2018

\section{Acknowledgements}

EGRIP is directed and organized by the Centre of Ice and Climate at the Niels Bohr Institute. It is supported by funding agencies and institutions in Denmark (A. P. Møller Foundation, University of Copenhagen), USA (US National Science Foundation, Office of Polar Programs), Germany (Alfred Wegener Institute, Helmholtz Centre for Polar and Marine Research), Japan (National Institute of Polar Research and Artic Challenge for Sustainability), Norway (University of Bergen and Bergen Research Foundation), Switzerland (Swiss National Science Foundation), France (French Polar Institute Paul-Emile Victor, Institute for Geosciences and Environmental research) and China (Chinese Academy of Sciences and Beijing Normal University). We acknowledge the use of data from CReSIS generated with support from the University of Kansas, NASA Operation IceBridge grant NNX16AH54G, NSF grants ACI-1443054, OPP-1739003, and IIS-1838230, Lilly Endowment Incorporated, and Indiana METACyt Initiative. 
Chapter 4

\title{
Extreme climate after massive eruption of Alaska's Okmok
} volcano in $43 \mathrm{BCE}$ and effects on the late Roman Republic and Ptolemaic Kingdom ${ }^{\dagger}$

\author{
Joseph R. McConnell ${ }^{1,2}$, Michael Sigl ${ }^{3}$, Gill Plunkett ${ }^{4}$, Andrea Burke ${ }^{5}$, Woon Mi Kim ${ }^{3}$, \\ Christoph Raible ${ }^{3,4}$, Andrew I. Wilson ${ }^{6,7}$, Joseph G. Manning ${ }^{8}$, Francis M. Ludlow ${ }^{9}$, Nathan J. \\ Chellman $^{1}$, Helen M. Innes ${ }^{5}$, Zhen Yang ${ }^{9}$, Jessica F. Larsen ${ }^{10}$,Janet R. Schaefer ${ }^{11}$, SepP \\ Kipfstuhl $^{12}$, Seyedhamidreza Mojtabavi ${ }^{12,13}$, Frank Whilhelms ${ }^{12,13}$, Thomas Opel ${ }^{12}$, Hanno \\ Meyer $^{12}$, Jørgen Peder Steffensen ${ }^{14}$
}

${ }^{1}$ Division of Hydrologic Sciences, Desert Research Institute, 89512, USA ${ }^{2}$ Sir Nicholas Shackleton Visiting Fellow, Clare Hall, University of Cambridge, CB3 9AL, UK ${ }^{3}$ Climate and Environmental Physics, Physics Institute, and Oeschger Centre for Climate Change Research, University of Bern, CH-3012, Switzerland ${ }^{4}$ School of Natural and Built Environment, Queen's University Belfast, BT7 1NN, UK ${ }^{5}$ School of Earth and Environmental Sciences, University of St Andrews, UK ${ }^{6}$ Faculty of Classics, University of Oxford, OX1 3LU, UK ${ }^{7}$ School of Archaeology, University of Oxford, OX1 3TG, UK ${ }^{8}$ Department of History Classics and School of Forestry Environmental Studies, Yale University, 06520-8266, USA ${ }^{9}$ Department of History, School of Histories Humanities, Trinity College, Dublin 2 Ireland. ${ }^{10}$ Department of Geosciences, University of Alaska Fairbanks, 99775, USA ${ }^{11}$ State of Alaska Division of Geological and Geophysical Surveys, 99709, USA ${ }^{12}$ Alfred-Wegener-Institut Helmboltz-Zentrum fur Polar- und Meeresforschung, 27570 Bremerhaven and 14473 Potsdam, Germany ${ }^{13}$ Department of Crystallography, Geoscience Centre, University of Göttingen, 37073, Germany ${ }^{14}$ Physics of Ice, Climate, and Earth, University of Copenhagen, DK-1017, Denmark

\section{Abstract}

The assassination of Julius Caesar in $44 \mathrm{BCE}$ triggered a power struggle that ultimately ended the Roman Republic and, eventually, the Ptolemaic Kingdom, leading to the rise of the Roman Empire. Climate proxies and written documents indicate that this struggle occurred during a period of unusually inclement weather, famine, and disease in the Mediterranean region; historians have previously speculated that a large volcanic eruption of unknown origin was the most likely cause. Here we show using well-dated volcanic fallout records in six Arctic ice cores that one of the largest volcanic eruptions of the past 2,500 y occurred in early $43 \mathrm{BCE}$, with distinct geochemistry of tephra

†published as McConnell et al. (2020). "Extreme climate after massive eruption of Alaska's Okmok volcano in 43 BCE and effects on the late Roman Republic and Ptolemaic Kingdom" Proceedings of the National Academy of Sciences, 117, 15 443-15 449, doi: 10.1073/pnas.2002722117 https://www.pnas.org/content/117/27/15443 
deposited during the event identifying the Okmok volcano in Alaska as the source. Climate proxy records show that 43 and 42 BCE were among the coldest years of recent millennia in the Northern Hemisphere at the start of one of the coldest decades. Earth system modeling suggests that radiative forcing from this massive, high-latitude eruption led to pronounced changes in hydroclimate, including seasonal temperatures in specific Mediterranean regions as much as $7^{\circ} \mathrm{C}$ below normal during the $2 \mathrm{y}$ period following the eruption and unusually wet conditions. While it is difficult to establish direct causal linkages to thinly documented historical events, the wet and very cold conditions from this massive eruption on the opposite side of Earth probably resulted in crop failures, famine, and disease, exacerbating social unrest and contributing to political realignments throughout the Mediterranean region at this critical juncture of Western civilization.

\section{Significance}

The first century BCE fall of the Roman Republic and Ptolemaic Kingdom and subsequent rise of the Roman Empire were among the most important political transitions in the history of Western civilization. Volcanic fallout in well-dated Arctic ice core records, climate proxies, and Earth system modeling show that this transition occurred during an extreme cold period resulting from a massive eruption of Alaska's Okmok volcano early in 43 BCE. Written sources describe unusual climate, crop failures, famine, disease, and unrest in the Mediterranean immediately following the eruption—suggesting significant vulnerability to hydroclimatic shocks in otherwise sophisticated and powerful ancient states. Such shocks must be seen as having played a role in the historical developments for which the period is famed.

The assassination of Julius Caesar on the Ides of March in 44 BCE marked the beginning of a $17 \mathrm{y}$ struggle for the future of the greater Mediterranean region - including the Roman Republic and Egyptian Ptolemaic Kingdom-that culminated in the rise of the Roman Empire. Although it is sometimes difficult to separate fact from myth associated with these transformative events, the thin surviving historical accounts credibly describe unusual atmospheric phenomena in the Mediterranean region from $44 \mathrm{BCE}$ and China from $43 \mathrm{BCE}$ (Ramsey and Licht, 1997), as well as anomalously inclement weather (Stothers and Rampino, 1983) and widespread famine (Forsyth, 1988) that provide a notable environmental background important to understanding the period's reorganization of political power that ultimately changed the course of history (Thompson, 2018). Northern Hemisphere (NH) climate proxies show that 43 and $42 \mathrm{BCE}$ were among the coldest of the past 2,500 y, coincident with the start of one of the coldest decades (Sigl et al., 2015; Luterbacher et al., 2016), although no annually resolved climate proxy records exist for the Mediterranean region specifically. Moreover, ice core records of lead pollution in northcentral Greenland-a proxy of European lead/silver mining and smelting during antiquity and already low during the Crisis of the Roman Republic McConnell et al. (2018, 2019) — declined during this decade, suggesting further deterioration of the Roman economy. Historians and scientists who study these ancient times have speculated that a large volcanic eruption most likely was the cause of these unusual atmospheric and climate events, although uncertain chronologies and low resolution in the available ice core and other records have to date limited understanding of the magnitude and extent of the climate anomaly and therefore its potential effects on ancient societies. Speculation based primarily on the approximate timing and magnitude of known $\mathrm{NH}$ eruptions during this period suggested 
the most likely source volcano was Mount Etna (Stothers and Rampino, 1983)in Sicily or Shiveluch (Zielinski et al., 1994) in Kamchatka, with more recent speculation focused on Nicaragua's Apoyeque (Sigl et al., 2015; Harper, 2019).

\section{Ice Core Evidence of a Massive Eruption in Early 43 BCE}

We used records of volcanic fallout in six Arctic ice cores (Fig. 4.1 and SI Appendix, Fig. 4.5) -all synchronized to the same annual-layer-counted and verified timescale (McConnell et al., 2018) - as well as climate proxies and Earth system modeling to develop a more complete understanding of the timing and magnitude of volcanism during this period and its effects on climate and history. We focused our interpretation on high-resolution measurements of volcanic fallout (Materials and Methods) in the North Greenland Ice Core Project 2 (NGRIP2) core on the recently developed and verified Desert Research Institute (DRI) NGRIP2 age scale that provides the most detailed and well-dated records of volcanic fallout for this period (Fig. 4.2) McConnell et al. (2018). Age uncertainties for this age scale previously were shown to be less than \pm 2 y during antiquity (McConnell et al., 2018), although the exact coincidence between the massive fallout of radiatively important non-sea-salt sulfur (nssS) measured in NGRIP2 and the pronounced temperature anomaly in absolutely dated tree ring records (Sigl et al., 2015) implies no dating uncertainty in the ice chronology at 43 BCE (Fig. 4.2). Throughout this study, 43 BCE corresponds to the period between 1,991 and 1,992 y before 1950 (ybp) (SI Appendix, Table 4.1).

The NGRIP2 measurements clearly delineate volcanic fallout from two distinct eruptions: the first starting in early (i.e., January or February) 45 BCE and the second in early 43 BCE. The nssS fallout from the first eruption suggests it was a powerful but short-lived event, with fallout returning to background levels by late $45 \mathrm{BCE}$. Comparisons to the array of four other Greenland ice core records (SI Appendix, Fig. 4.5) show that fallout from the $45 \mathrm{BCE}$ event was confined largely to northern Greenland, suggesting a nearby high-latitude source volcano (e.g., Iceland). In addition, proxy records (Luterbacher et al., 2016) indicate no large-scale climate effects, so it is unlikely that this eruption had a significant influence on the midlatitude regions. The nssS fallout from the second event suggests that it was a massive eruption that started in early $43 \mathrm{BCE}$, with elevated volcanic fallout lasting more than $2 \mathrm{y}$. Increased nssS concentrations started in the NGRIP2 record in early winter and reached a temporary peak in spring and an overall maximum in late autumn of $43 \mathrm{BCE}$, before returning to background concentrations by spring $41 \mathrm{BCE}$ (Fig. 4.2). Sulfur isotope ratios measured in fallout from the beginning of the $43 \mathrm{BCE}$ event in Greenland Ice Sheet Project 2 (GISP2) ice (Materials and Methods) showed nonzero $\Delta^{33}$ S values (SI Appendix, Fig. 4.7) that result from oxidation in a high-ultraviolet environment consistent with plume ejection above the ozone layer in the lower stratosphere (Burke et al., 2019). Injection into the stratosphere is consistent with persistent, widespread climate effects.

Comparisons of volcanic acid deposition recorded in the five Greenland cores indicate moderately greater fallout in central Greenland during the $43 \mathrm{BCE}$ event, contrasting with the $45 \mathrm{BCE}$ event. Fallout deposition during the 2 y period was $\sim 123$ and $\sim 110 \mathrm{~kg} / \mathrm{km} 2$ as sulfuric acid in the northern NGRIP2 and North Greenland Eemian Ice Drilling (NEEM) cores and $\sim 131, \sim 135$, and $\sim 128 \mathrm{~kg} / \mathrm{km} 2$ in the GISP2 (Zielinski and Mershon, 1997), GRIP (Clausen et al., 1997), and Dye3 (Clausen et al., 1997) cores to the south, respectively (Materials and Methods). In 
Chapter 4. Extreme climate after massive eruption of Alaska's Okmok volcano in 43 BCE and effects on 62 the late Roman Republic and Ptolemaic Kingdom

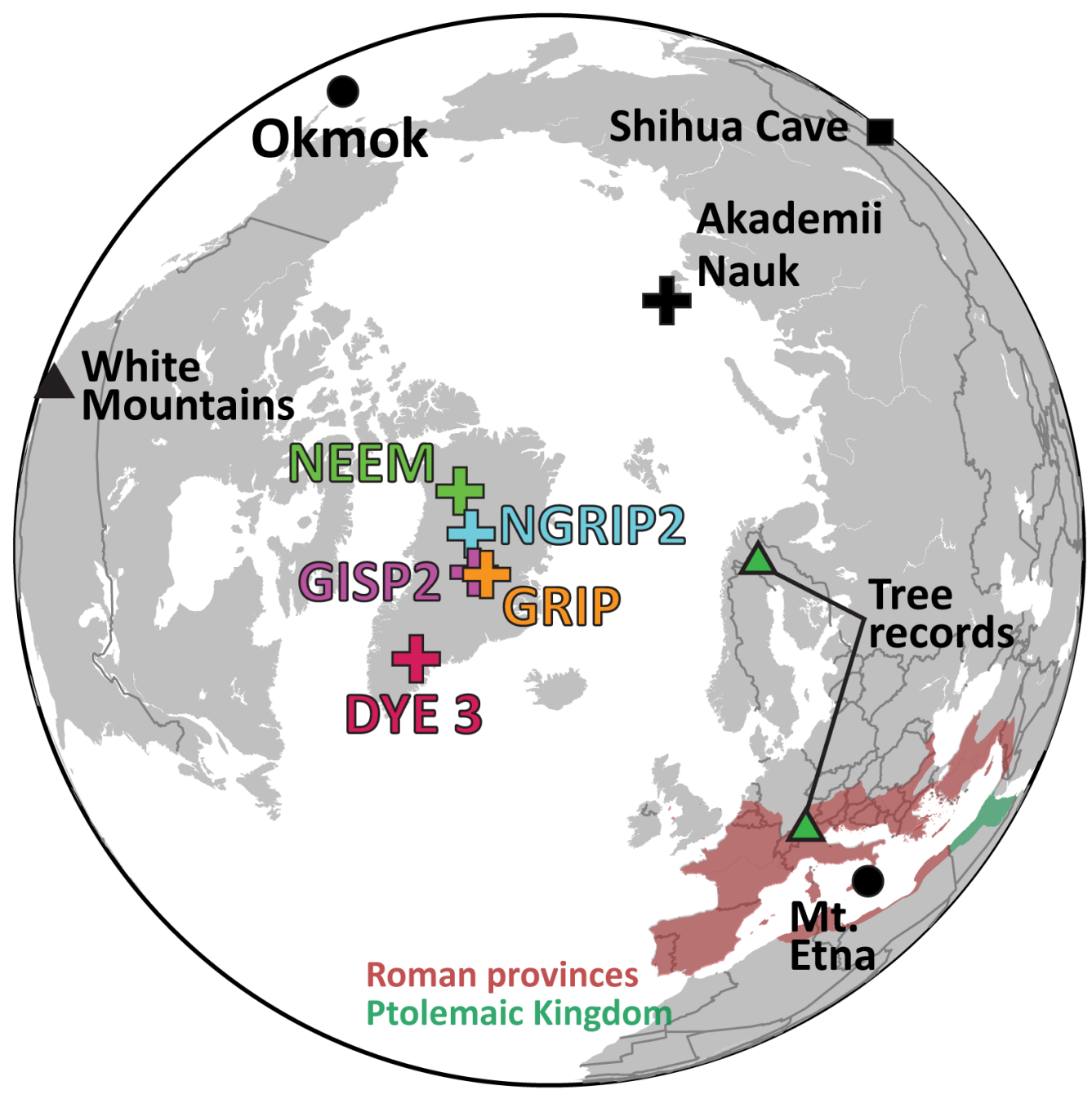

Figure 4.1- Location map. Shown are drilling sites for the six Arctic ice core records evaluated in this study (pluses), the Okmok and Mount Etna volcanoes, tree (Luterbacher et al., 2016; LaMarche and Hirschboeck, 1984) and Shihua Cave (Tan et al., 2003) speleothem-based climate proxy records, and the extent of the Roman provinces and Ptolemaic Kingdom in 44 BCE. 


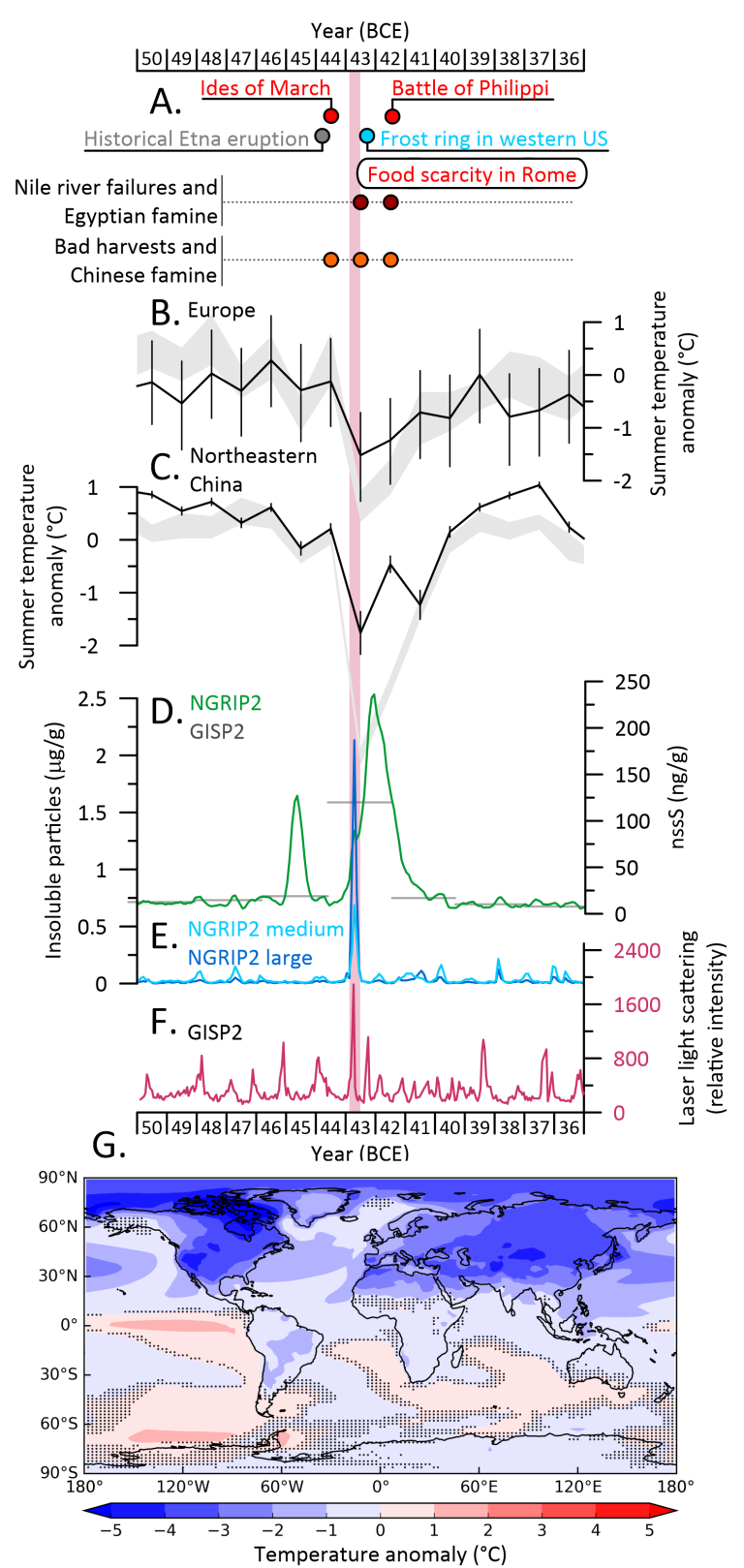

Figure 4.2 - Ice core, tree ring, and speleothem evidence for the 45 and 43 BCE eruptions and climate effects. (A) Selected historical and other events (see text). (B) Model-simulated (gray) and observed (black) summer temperature anomalies from European tree ring records with original $2 \sigma$ uncertainties (Luterbacher et al., 2016). (C) Modelsimulated (gray) and observed (black) summer temperature anomalies from the Chinese Shihua Cave speleothem record with original maximum temperature uncertainties (Tan et al., 2003). Shading in B and C shows annual CESM ensemble SEs. (D) Continuous NGRIP2 and discrete (2y) GISP2 nssS (Zielinski et al., 1994) concentrations. (E) NGRIP2 mass-equivalent insoluble particle concentrations for medium (2.5 to $5 \mu \mathrm{m})$ and large (5 to $10 \mu \mathrm{m})$ particles. (F) GISP2 LLS measurements (Ram and Koenig, 1997). (G) Simulated 43 and 42 BCE average air temperature anomalies (hashing shows anomalies that are not significant $[2 \sigma]$ ). Annual and seasonal simulations for each year are shown in SI Appendix, Figs. 4.10 and 4.11. All records were aligned at the start of the $43 \mathrm{BCE}$ volcanic event to be consistent with the DRI_NGRIP2 chronology. The vertical shaded bar shows the extent of the insoluble particle (i.e., tephra) spike at the start of volcanic fallout in the NGRIP2 record. 
all six Arctic ice core records (Fig. 4.1), the $43 \mathrm{BCE}$ event ranked among the largest observed during the past 2,500 y for acid-equivalent deposition. For example, it ranked second in NEEM (Sigl et al., 2015), third in GRIP (Clausen et al., 1997), second in GISP2 (Zielinski and Mershon, 1997), fourth in Dye3 (Clausen et al., 1997), and first in the combined NGRIP (Plummer et al., 2012) and NGRIP2 (this study) nssS record for the past 2,500 y. Similarly, average nssS for the 2 y period of 43 and 42 BCE ranked fourth highest in the Russian Arctic (Akademii Nauk) ice core record (this study) from $500 \mathrm{BCE}$ up to the Industrial Revolution and the start of widespread industrial sulfur pollution.

\section{Volcanic Provenance}

A sharp spike in 2.5 to $10 \mu \mathrm{m}$ insoluble particle concentrations in NGRIP2 and in laser light-scattering measurements in GISP2 (Ram and Koenig, 1997) coincided with the early stages of the 43 BCE volcanic nssS peak, suggesting deposition of volcanic tephra (Dunbar et al., 2017; McConnell et al., 2017) near the start of the eruption (Fig. 4.2 and SI Appendix, Fig. 4.5). Microprobe analyses (Materials and Methods) of 35 volcanic shards (SI Appendix, Fig. 4.8) filtered from corresponding GISP2 ice revealed geochemical characteristics (Fig. 4.3 and SI Appendix, Fig. 4.9) matching reference tephra from the andesite fall and pyroclastic density current units from the caldera-forming, volcanic explosivity index (VEI) 6, Okmok II $\left(53.4^{\circ} \mathrm{N}, 168.1^{\circ} \mathrm{W}\right)$ eruption in Alaska (Fig. 4.1).

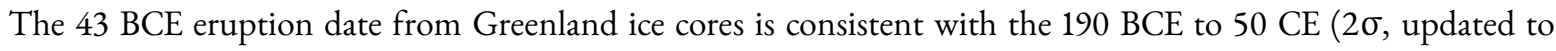
international working group on radicarbon calibration curves IntCal13) (Larsen et al., 2007) calibrated age range indicated by radiocarbon dates for organic material in the layers just below the initial proximal deposits of Okmok II. The geochemistry of the GISP2 shards and Okmok II reference tephra clearly is distinct from reference tephra from other potential volcanic eruptions in the first century BCE (Fig. 4.3 and SI Appendix, Fig. 4.9), providing nearly unambiguous evidence that the Okmok II eruption was the source of the $43 \mathrm{BCE}$ event. The precise identification of the source location now provides a key input in efforts to better model and understand the event's effects on climate.

\section{Northern Hemisphere Climate Effects}

The $2 \mathrm{y}$ cooling associated with the Okmok II eruption (Fig. 4.2) was among the most significant recorded in $\mathrm{NH}$ summer temperature proxies for the past 2,500 y. For example, 43 and $42 \mathrm{BCE}$ ranked as the second and eighth coldest years in a recent tree ring-based assessment (Sigl et al., 2015), respectively, while the decade from 43 to $34 \mathrm{BCE}$ was the fourth coldest. Central and northern European climate reconstructions based on measurements in temperature-sensitive trees from Scandinavia and Austria (Luterbacher et al., 2016) indicate marked regional summertime cooling of $>3{ }^{\circ} \mathrm{C}$ and $>2.5^{\circ} \mathrm{C}$ in 43 and $42 \mathrm{BCE}$ (Fig. 4.2), respectively. Similarly, an annually dated speleothem record of summer temperatures from Shihua Cave in northeastern China shows a pronounced $3 \mathrm{y}$ reduction in summertime temperature of $>2.0^{\circ} \mathrm{C}$ starting in $45 \mathrm{BCE}$, coeval with $43 \mathrm{BCE}$ within the $5 \mathrm{y}$ dating uncertainty of the speleothem record (Fig. 4.2). A rare frost ring recorded in bristlecone pine trees from California's White Mountains indicates anomalous, below-freezing temperatures in early September 43 BCE (Fig. 4.2) during the late NH summer growing season (LaMarche and Hirschboeck, 1984). 


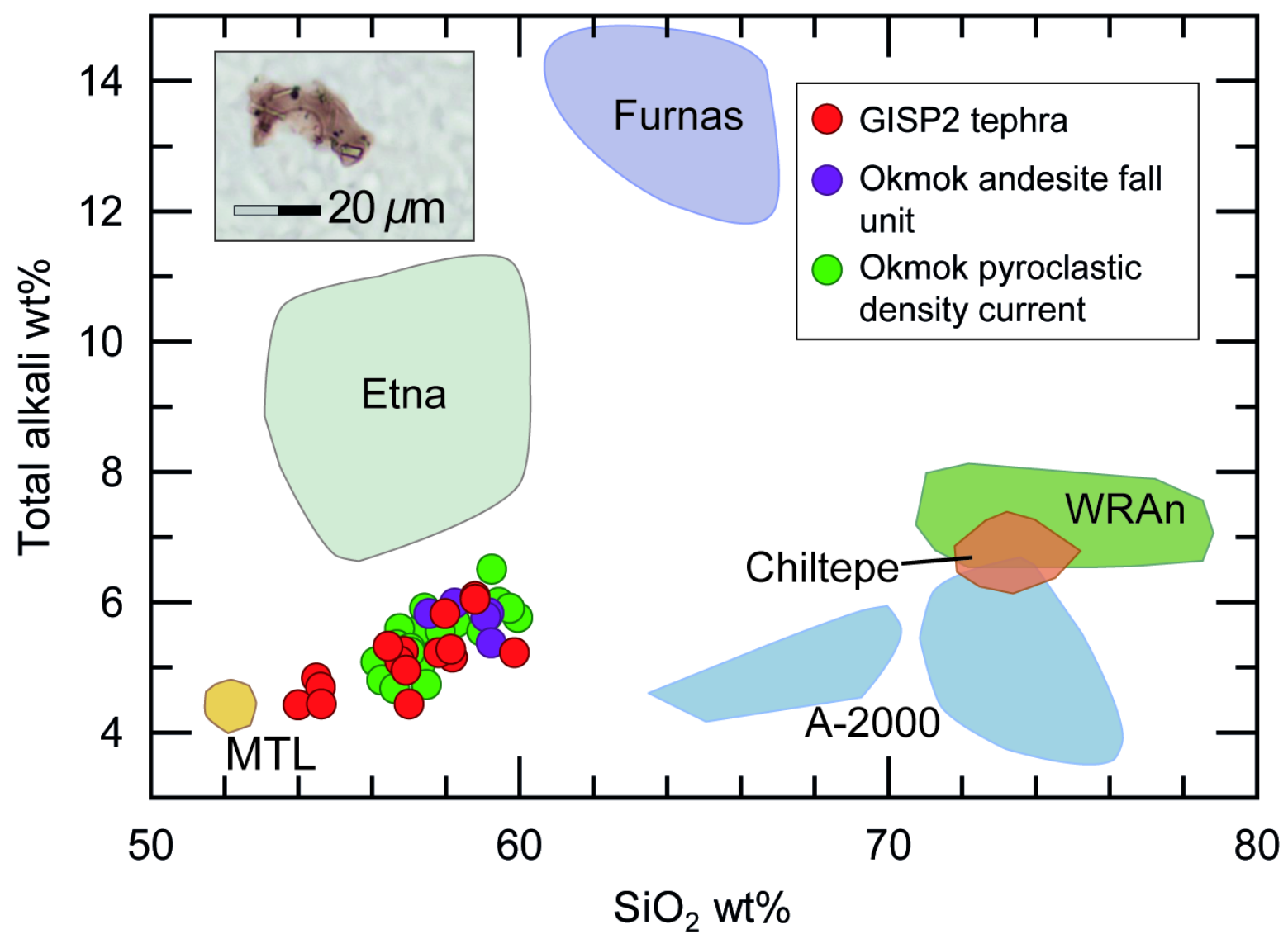

Figure 4.3 - Total alkali $(\mathrm{Na} 2 \mathrm{O}+\mathrm{K} 2 \mathrm{O})$ and silica compositions of tephra from GISP2 ice during the 43 BCE event compared with tephra from Okmok II and other potential source volcanoes. Filled circles show measurements (this study) of GISP2 and Okmok reference tephra. Shaded regions show tephra measurements from other potential first century BCE source volcanoes: Etna, Italy (Sadori and Narcisi, 2001; Vogel et al., 2010); Chiltepe from Apoyeque, Nicaragua (Kutterolf et al., 2008, 2011); Masaya Triple Tuff (MTL), Nicaragua (Kutterolf et al., 2008); A-2000, Askja, Iceland (Barber et al., 2008); White River Ash northern lobe (WRAn), Churchill, Canada (Preece et al., 2014); Furnas, Azores (Wastegård et al., 2020). Inset shows a tephra shard from the GISP2 sample. See SI Appendix, Fig. 4.9 for additional comparisons and analytical precision. 
Using the exact location and the estimated eruption timing and sulfur yield of the Okmok II eruption, we used the Community Earth System Model (CESM, version 1.2.2) (Hurrell et al., 2013) to simulate the severity, extent, and persistence of the climate response (Fig. 4.2 and Materials and Methods). The simulations indicate pronounced, widespread NH cooling in 43 and $42 \mathrm{BCE}$, with simulated summer air temperature anomalies similar in magnitude and duration to the European tree ring (Esper et al., 2014) and Chinese (Shihua Cave) speleothem (Tan et al., 2003) climate proxy records that show 2 to $3{ }^{\circ} \mathrm{C}$ declines in summer air temperatures (Fig. 4.2). Chinese written records also document unusually cold weather in 43 and $42 \mathrm{BCE}$, including late spring and early autumn frosts (De'er, 2004). The CESM simulations suggest that cooling may have persisted into the early 30 s $B C E$, as well as significant changes in global precipitation from the Okmok II eruption, including increases over the Mediterranean region and strong decreases over Asia and the high NH latitudes (SI Appendix, Figs. 4.10 and 4.11).

\section{Climate Effects and Historical Linkages in the Mediterranean Region}

Agreement between the few available annually resolved NH proxy records of summertime temperatures and the CESM-simulated temperature anomalies suggest that the model largely captures the temperature effects of radiative forcing associated with the early $43 \mathrm{BCE}$ Okmok II eruption. Therefore, we used the simulated temperature and precipitation anomalies in the Roman provinces and Ptolemaic Kingdom (Fig. 4.4 and SI Appendix, Figs. 4.12 and 4.13), where no annually resolved climate proxies are available to investigate possible effects on ancient societies, though recognizing that accurately modeling precipitation is often particularly challenging. The effect of climate shocks on ancient societies most usually and directly occurred through diminished agricultural yields, with crop failures occurring because of insufficient or excessive rainfall at critical periods for plant growth (Garnsey, 1989) or because of unusual growing season temperatures. The environmental perception of anomalous weather and other volcanically induced phenomena (e.g., visually spectacular dimming or discoloration of the solar disk) as portents also endowed these events with a significance that made their appearance politically influential in ancient societies.

The ice core and climate proxy record evidence, as well as the Earth system model simulations, suggests that the atmospheric and climate phenomena described by ancient Mediterranean sources and recently evaluated by historians (Ramsey and Licht, 1997; Forsyth, 1988) can be separated into two groups. The first clusters around March and April $44 \mathrm{BCE}$ and consists of atmospheric phenomena (solar dimming, halos, and parhelia) interpreted by ancient writers as signs and portents. Virgil, in his poem Georgics (1.466-73), said that the sun was darkened after Caesar's assassination, and the ancient commentator Servius added that "it is said, after Caesar had been killed in the Senate on the day before, the sun's light failed from the sixth hour until nightfall." Plutarch (Life of Julius Caesar 69.3-4) said not only that the sun was veiled and pale but also that it gave forth so little heat that fruits shriveled rather than ripened. Several authors mentioned seeing three suns in the sky (Dio Cassius, 45.17.5; Julius Obsequens, 68; Eusebius, Chronicle, Olympiad 184), a well-known phenomenon called "sun dogs" or parhelia caused by refraction of sunlight through ice crystals in the upper atmosphere in particularly cold weather. Dio and Obsequens added that there was a radiant colored halo around the sun, probably a "bishop's ring," a diffuse bluish-brown halo around the sun caused by sulfur-based aerosols from large volcanic eruptions. Other writers mentioned a solar halo that 

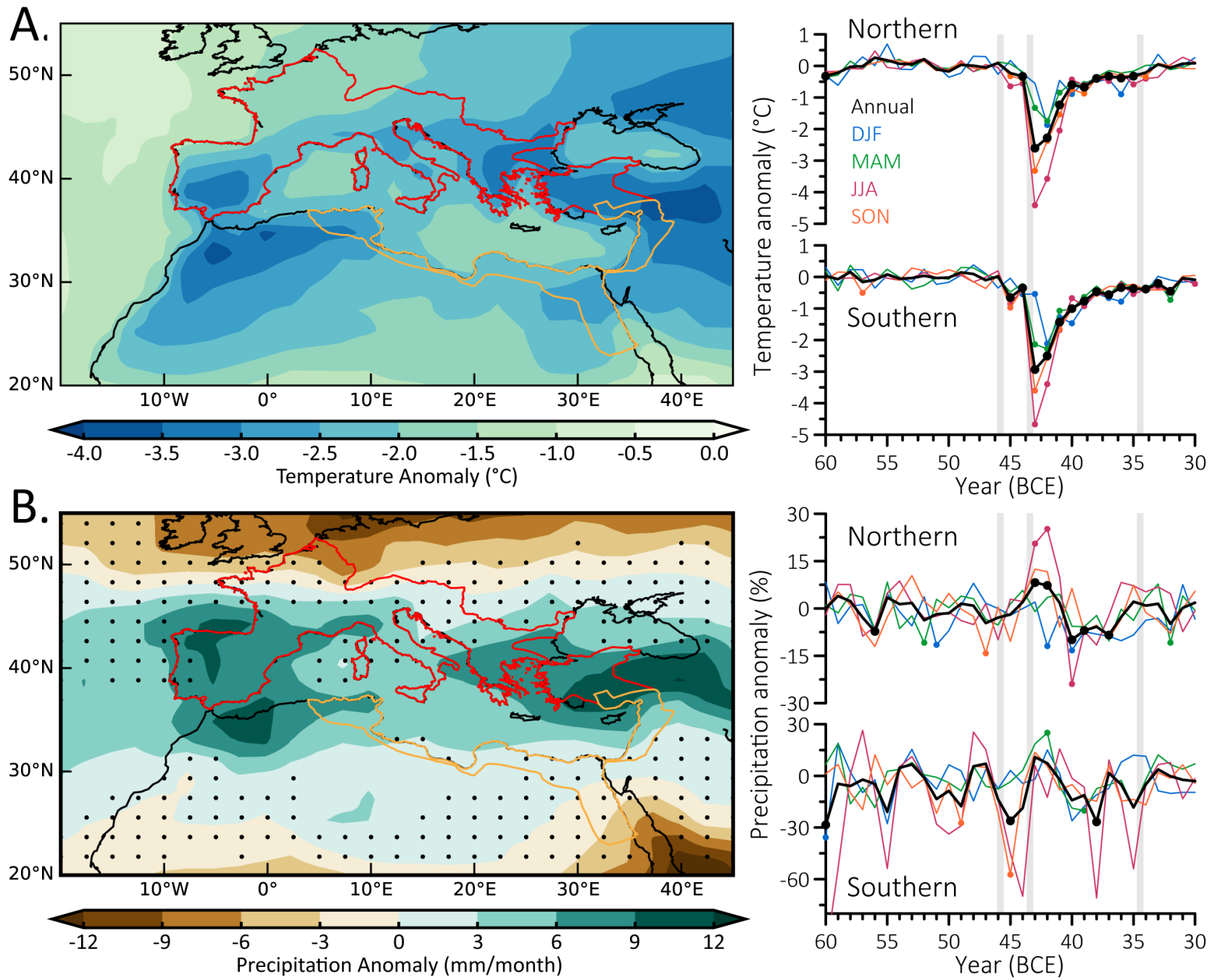

Figure 4.4 - Volcanically forced temperature and precipitation anomalies in the Mediterranean region from 60 to 30 BCE. (A) CESM-simulated average annual temperature and (B) precipitation anomalies for 43 and $42 \mathrm{BCE}$, with outlines of Roman provinces north (red) and south (orange) of the Mediterranean. Dots show areas where annual anomalies are not significant $(2 \sigma)$ relative to the 60 to $46 \mathrm{BCE}$ background variability with no volcanic forcing. Also shown are time series of simulated annual and seasonal temperature and precipitation anomalies for northern and southern Roman provinces. Years with symbols are significant $(2 \sigma)$ relative to the background variability. Gray bars show dates of ice core-based volcanic sulfur injections (Toohey and Sigl, 2017) in the simulations, including the early 43 BCE Okmok II eruption. 
marked Octavian's arrival in Rome in early April 44 BCE (e.g., Seneca, NQ 1.2.1; Suetonius, Augustus 95; Velleius Paterculus, 2.59.6; Pliny, NH 2.98; Dio Cassius, 45.4.4; Obsequens, 68; Orosius, 6.20.5) and which was seized upon by Octavian and his supporters to suggest divine favor for his cause (Ramsey and Licht, 1997; Forsyth, 1988). All these phenomena are consistent with the atmospheric effects of volcanic eruptions. However, given that they are reported as occurring before the probable date of the Okmok II eruption in $43 \mathrm{BCE}$, that all of the sources referring to them originate in Italy or the central Mediterranean, and that $\mathrm{NH}$ proxies show no large-scale climate effects, the comparatively minor, historically well documented eruption of Etna in $44 \mathrm{BCE}$ is a plausible candidate for their cause.

The second group of ancient sources relates more directly to unusually cold weather and famine (Forsyth, 1988). These sources group from early $43 \mathrm{BCE}$ to late $42 \mathrm{BCE}$ and are consistent with the extreme climate effects (Fig. 4.4) of the massive, early 43 BCE Okmok II eruption indicated by volcanic fallout in the Arctic ice cores (Fig. 4.2). Although some sources suggest harsh winter weather in late $44 \mathrm{BCE}$, it is uncertain whether these passages reflect especially unusual winters in the southern Balkans or are more simply a commentary on the conditions that traditionally led armies to avoid movements in winter. Whether they also reflect the continuing aftereffects of the relatively minor eruption of Etna in 44 BCE 7 or 8 mo earlier is therefore similarly uncertain. Plutarch's Life of Brutus (25.2-4) mentioned that on his way to Epidamnus (modern Durrës, Albania), Brutus marched in late 44 BCE through snowstorms and that he and his army suffered from boulimia, a disease brought on by fatigue, damp, and cold weather. Cicero, writing to Atticus in November 44 BCE, referred to stormy weather (Att. 16.11). Two additional letters of Cicero in February 43 BCE (Ad Fam. 9.24.3 and 12.5.2) refer to winter and cold (after the early $43 \mathrm{BCE}$ Okmok II eruption indicated in the ice core records), and in a less precisely dated passage, Josephus (Jewish Antiquities 14.310) wrote of Antonius in the winter of 43/42 BCE, telling Hyrcanus about the severely cold climate of Macedonia (Forsyth, 1988).

More significant in registering the onset of major societal stress is a group of sources referring to famine in northern Italy in April 43 BCE and northern Greece in October 42 BCE, as well as additional reports of famine, food shortages, endemic disease, and civil unrest in Rome and other parts of Italy starting in $43 \mathrm{BCE}$ and extending through 36 BCE (Garnsey, 1989). Plutarch in his Life of Antony (17.3) wrote that the greatest of the various hardships faced by Antony and his army in flight after their defeat at Mutina in April 43 BCE was famine, the army being reduced to eating wild fruit, roots, bark, and animals "never tasted before by men.” Julius Obsequens (69) said that in $43 \mathrm{BCE}$ a voice was heard at the oracle of Apollo (in Delphi, presumably), crying "madness of wolves in the winter; in the summer the grain is not harvested." The historian Appian said that there was also famine around the time of the Battle of Philippi, in October 42 BCE, as "Thessaly was no longer able to furnish enough supplies" (Bellum Civile 4.122), and later he said that Rome was "devastated by famine" (Bellum Civile 5.25) (Forsyth, 1988). While such hardships probably spring in part from conflict and political turmoil, our evidence now suggests an additional strong environmental context.

The CESM simulations suggest that the Okmok II eruption in early $43 \mathrm{BCE}$ resulted in 0.7 to $7.4^{\circ} \mathrm{C}$ seasonal cooling in specific regions of southern Europe and northern Africa, with cooling especially pronounced during summer and autumn (SI Appendix, Figs. 4.12 and 4.13). Although precipitation is often difficult to simulate ac- 
curately, model results also suggest that summer precipitation was 50 to $120 \%$ above normal throughout southern Europe and autumn precipitation was up to $400 \%$ percent of normal for specific regions, where normal is the average precipitation during the 60 to $46 \mathrm{BCE}$ period with no volcanic forcing.

Other evidence for famine during this period comes from Egypt (Forsyth, 1988). Linkages between the agriculturally critical annual Nile River floods and political instability are well established (Oman et al., 2006; Chaney, 2013), and particularly severe shocks to the Nile flood in the late 40s BCE are documented. The Okmok II eruption probably compounded the natural interannual variability of the Nile flood. Concomitant food shocks and the outbreak of disease are suggested in historical sources for the same years. Modern authorities agree that there were two famines in Egypt during the reign of Cleopatra, one of them occurring ca. 43 to 42 BCE. Seneca (NQ 4A.2.16) wrote that for two successive years, the 10th and 11th of Cleopatra's reign ( 43 and $42 \mathrm{BCE}$ ), the Nile did not flood. Appian seemed to confirm this, saying that in $43 \mathrm{BCE}$, Cleopatra declined to provide aid to Cassius on the grounds that Egypt was wracked by famine and pestilence (Bellum Civile 4.61), again (4.63) that Egypt was devastated by famine, and that around the time of the Battle of Philippi in October 42 BCE, Octavian and Antony could not obtain grain supplies from Egypt because "the country was exhausted by famine" (4.108). Although Seneca and Appian were writing one and two centuries after the events, respectively, their testimony is corroborated by a contemporary inscription from Thebes in southern Egypt (OGIS 194; TM 6325). This honors the local governor Kallimachos for his assistance in a time of dearth that clearly lasted more than a year. The text probably dates to $39 \mathrm{BCE}$ (year 13 of Cleopatra's reign) but referred to the continuing famine and social distress of the late 40s BCE.

The CESM simulations suggest sharp cooling from the Okmok II eruption in the lower reaches of the Nile River basin in spring, summer, and autumn, with little or no temperature change in the upper reaches (SI Appendix, Figs. 4.12 and 4.13). The headwaters of the Blue Nile (and Atbara River) in the Ethiopian Highlands are the source of over 85\% (Melesse et al., 2011) of the annual Nile River floodwater, and connections are well described between explosive volcanism and the East African monsoon (Oman et al., 2006; Colose et al., 2016) that is responsible for much of the summer precipitation in the Highlands. The CESM simulations presented here suggest generally wetter winter conditions in the lower reaches of the Nile and substantially drier winter, spring, and especially autumn conditions in the upper reaches, including the Blue Nile headwaters. Simulated summer precipitation in the Blue Nile headwaters, however, is unchanged or slightly higher as a result of the eruption.

The unusual atmospheric phenomena reported in Roman historical accounts in 44 BCE provide reasonable evidence for the presence of an aerosol veil in that year. We suggest that this probably was the result of the comparatively minor but local Mediterranean VEI 3 eruption of Mount Etna that year (Stothers and Rampino, 1983). Well-dated Arctic ice core records of volcanic fallout provide clear evidence suggesting a massive eruption of Alaska's Okmok volcano in early $43 \mathrm{BCE}$, thereby disassociating this eruption with the preceding aerosol veil based upon the best available documentary and ice core chronologies. This fallout coincided with a pronounced $2 \mathrm{y}$ or longer period of much colder $\mathrm{NH}$ temperatures documented by climate proxy records and supported by Earth system climate modeling, with simulations also suggesting substantial changes in precipitation. In the Mediterranean region, these wet and extremely cold conditions during the agriculturally important spring through autumn seasons probably reduced crop yields starting in early $43 \mathrm{BCE}$ and extending at least to early $41 \mathrm{BCE}$, compounding supply 
problems wrought by the ongoing political upheavals of the period. That this, indeed, occurred is known from reporting of widespread food shortages and famine in the Roman provinces and Ptolemaic Kingdom.

Natural disasters are known historically to create a "state of exception" in which business as usual becomes unfeasible and political and cultural norms are suspended, thereby providing room for rapid social and political change (Dove, 2014). While it is difficult to establish direct causal linkages, we thus postulate that this extreme climate shock-among the most severe of the past 2,500 y-contributed to reported social unrest and facilitated political change at this important juncture of Western civilization. For example, Sextus Pompeius's naval blockade of Italy from late 43 to $36 \mathrm{BCE}$ cutting off grain supplies from important grain-growing regions in Sicily, Africa, and elsewhere (Appian, Bellum Civile 5.15, 18; Dio Cassius, 48.7.4) undoubtedly contributed to reported food shortages in Rome and throughout Roman Italy. Critical local food supplies (Erdkamp, 2005), however, probably were already severely restricted by the extreme weather, and Sextus Pompeius can be seen as opportunistically using these circumstances to enhance political leverage arising from his blockade with constriction of much needed relief supplies. It is similarly challenging to establish direct links between Okmok II and the demise of the long-lasting Ptolemaic dynasty in Egypt, nominally accredited to the death of Cleopatra in 30 BC, following her naval defeat to Rome at the Battle of Actium in 31 BC. There can be little doubt, however, that Rome's interest in Egypt as its famed "breadbasket" was further magnified by the trials of the 40s BCE and that Egypt's own capacity to defend against Rome was diminished by the famine, disease, land abandonment, and reduced state income that followed the Okmok II eruption.

\section{Materials and Methods}

\section{Measurements of Volcanic Fallout in Arctic Ice Cores.}

Detailed elemental, chemical, and other (e.g., dielectric profiling $[\mathrm{DEP}]$ and electrical conductivity $[\mathrm{ECM}]$ reflecting acidity, laser light scattering [LLS] reflecting volcanic tephra) ice core records reflecting volcanic fallout were evaluated for this study, with particular focus on the period from 50 to $30 \mathrm{BCE}$. Included were five Greenland ice cores [NGRIP2 (McConnell et al., 2018): $75.1^{\circ} \mathrm{N}, 42.3^{\circ} \mathrm{W}$; NEEM (Sigl et al., 2013): $77.5^{\circ} \mathrm{N}, 51.1^{\circ} \mathrm{W}$; GISP2 (Zielinski et al., 1994): $72.6^{\circ} \mathrm{N}, 38.5^{\circ} \mathrm{W}$; GRIP (Wolff et al., 1997): $72.6^{\circ} \mathrm{N}, 37.6^{\circ} \mathrm{W}$; Dye3 (Clausen et al., 1997): $65.18^{\circ} \mathrm{N}$, $43.49^{\circ} \mathrm{W}$ ] and one Russian Arctic [Akademii Nauk (AN) (Opel et al., 2013): $80.5^{\circ} \mathrm{N}, 94.8^{\circ} \mathrm{E}$ ] core. Note that because of uncertainties in ice core chronologies between polar regions, an $\sim 47( \pm 5)$ BCE volcanic fallout (nssS) event in Antarctica (Sigl et al., 2015) cannot be attributed conclusively to Okmok II.

Ice core records of volcanic fallout included high depth resolution measurements of nssS and liquid conductivity in NGRIP2 (this study), NEEM (Sigl et al., 2015, 2013), and AN (this study), as well as size-resolved insoluble particle counts in NGRIP2 (this study) (SI Appendix, Fig. 4.5). Measurements were made with the unique continuous ice core analytical system at DRI using methods described elsewhere (McConnell et al., 2017, 2002). Additional ice core records included previously published, high depth resolution measurements of 1) DEP in NGRIP2 (Mojtabavi et al., 2020b), NEEM (Mojtabavi et al., 2020b), and GRIP (Wolff et al., 1997); 2) ECM in GISP2 (Taylor et al., 1997) and Dye3 (Clausen et al., 1997); and 3) LLS in GISP2 (Ram and Koenig, 1997). Note that the independently measured DEP records in NGRIP2 and NEEM were consistent with the continuous nssS and liquid 
conductivity measurements at DRI (SI Appendix, Fig. 4.5). We also evaluated discrete, 2 y sulfate concentration measurements in GISP2 (Zielinski et al., 1994). Measurement techniques used to develop these previously published records were described elsewhere (Ram and Koenig, 1997; Clausen et al., 1997; Wolff et al., 1997; Mojtabavi et al., 2020b; Taylor et al., 1997).

\section{DRI_NGRIP2 Ice Core Chronology.}

To enable comparisons between ice core volcanic fallout records, climate proxy information, and historical events, we used the precise DRI_NGRIP2 ice core chronology and synchronized all of the ice core records to that chronology. Development of the NGRIP2 chronology was described previously (McConnell et al., 2018). Briefly, we used high depth resolution DRI measurements on the NGRIP2 core for multiparameter annual layer counting (SI Appendix, Fig. 4.6). Because the continuous DRI measurements began at $159.56 \mathrm{~m}$, corresponding to $\sim 1270 \mathrm{CE}$, annual layer counting started at unambiguous nssS fallout from the eruption of Samalas in $1257 \mathrm{CE}$ (McConnell et al., 2018). Evaluation of this independent chronology against well-established tree ring-based chronologies using multiannual (Adolphi and Muscheler, 2016) variations in cosmogenic nuclides $\left({ }^{10} \mathrm{Be}\right.$ in ice, ${ }^{14} \mathrm{C}$ in wood) suggested uncertainty of less than $\pm 2 \mathrm{y}$ during antiquity. In addition, pronounced, short-lived cosmogenic nuclide increases in $994 \mathrm{CE}$ and $775 \mathrm{CE}$ recorded in both tree and ice core records (Sigl et al., 2015) showed no offsets, indicating exact synchronization with the tree-based climate proxies at these specific dates (McConnell et al., 2018). Moreover, recent evaluation of the DRI_NGRIP2 chronology using a newly discovered, short-lived cosmogenic nuclide event in the first millennium BCE (O'hare et al., 2019) also showed no offset at 661 BCE (2,610 ybp). Comparisons to the published NS1-2011 chronology (Sigl et al., 2015) based largely on similar continuous DRI measurements in the $411 \mathrm{~m}$ NEEM-2011-S1 intermediate core and 390.5 to $573.65 \mathrm{~m}$ in the NEEM bedrock core showed only minor differences (typically, \pm 2 y), well within the uncertainties of the published NS1-2011 chronology. For example, fallout from the massive 43 BCE eruption using the DRI_NGRIP2 chronology occurred 1 y earlier in 44 BCE using the NS1-2011 chronology.

Fallout measurements in all six Arctic ice cores (Fig. 4.1 and SI Appendix, Fig. 4.5) were synchronized at 43 BCE to allow comparisons. For NEEM, measurements on the NS1-2011 chronology were shifted by $1 \mathrm{y}$ to align the 43 BCE event and an annual layer between 44 and 46 BCE on the original NS1-2011 deleted to align the 45 BCE event. Note that because of missing measurements, this annual layer was interpolated during development of the NS12011 chronology. For AN, pervasive surface melting and high marine biogenic inputs from the surrounding ocean made identification of volcanic sulfur spikes difficult. Acidity and nssS measurements were mapped to an existing chronology based primarily on tie points between heavy-metal concentrations in AN and the well-dated NGRIP2 record as previously described (McConnell et al., 2019) and then shifted by $\sim 2 \mathrm{y}$ in this study to align the records at the start of the 43 BCE volcanic event. For GISP2, GRIP, and Dye3, measurements were mapped to the GICC05 timescale (Seierstad et al., 2014) and then compared to the NGRIP2 fallout record. Consistent with previous studies (Sigl et al., 2015; Adolphi and Muscheler, 2016), records on the GICC05 timescale (Seierstad et al., 2014) required a shift of $\sim 10$ y to align with the DRI_NGRIP2 chronology at the start of the 43 BCE event.

The speleothem-based summer temperature reconstruction from Shihua Cave (Tan et al., 2003), China, was shifted by 2.5 y to synchronize at $43 \mathrm{BCE}$ to be consistent with $\mathrm{NH}$ tree ring-based climate proxies and the ice core 
fallout records on the DRI_NGRIP2 chronology (Fig. 4.2). This shift was well within the 5 y maximum counting error for the original speleothem chronology (Tan et al., 2003).

\section{Tephra Analyses.}

To determine the provenance of the fallout, we obtained a sample of archived GISP2 ice (481.06 to $481.16 \mathrm{~m}$ ) from the National Science Foundation Ice Core Facility (NSF-ICF) corresponding to the LLS spike at the start of the 43 BCE event (Fig. 4.2 and SI Appendix, Fig. 4.7). The sample (QUB-1991) was melted and analyzed for tephra at Queen's University Belfast. The sample was centrifuged to concentrate particulates and decanted, and the residue was transferred using plastic pipettes to a preground, labeled glass slide on a hot plate within a laminar flow bench and, when dry, covered in Buehler EpoxiCure 2 resin. The sample was scanned on a polarizing light microscope, and tephra shards were counted and recorded. A total of 35 shards was identified (SI Appendix, Fig. 4.8), consisting of small (long axis mean of $23 \mu \mathrm{m}$ [ranging from 12 to $46 \mu \mathrm{m}$ ]), pale brown to brown, angular to subrounded glass (Fig. 4.3 and SI Appendix, Fig. 4.9), with variable microlite content. The slide was then ground and polished to expose the surfaces of the tephra shards for geochemical analyses. Major element geochemistry was determined using combined electron and wavelength dispersive spectrometry on a JEOL FEGSEM 6500F, with secondary glass standards analyzed in the same sessions to ensure acceptable operating conditions. Eleven major and minor elements were analyzed, following parameters previously outlined (Coulter et al., 2012). Geochemical similarity to glass from the Okmok II caldera-forming eruption prompted analysis of reference glass from this event (SI Appendix, Fig. 4.9). Samples of lapilli (16JFLOK001F) and scoria (16JFLOK006A) from the eastern flank of Okmok corresponding to the second and third phases of the Okmok II event were ground, sieved, and prepared as thin sections on a glass slide for geochemical analysis on the JEOL FEGSEM 6500F under the same conditions as QUB-1991. All measurements were normalized to $100 \%$ to allow for water content.

\section{Sulfur Isotope Analyses.}

GISP2 meltwater samples from 481.0 to $481.24 \mathrm{~m}$ were dried down, and the sulfate was isolated by column chemistry following established procedures (Burke et al., 2019). Sample sizes were small, with total sulfate ranging from 5 to $20 \mathrm{nmol}$. After purification, triple sulfur isotope $\left({ }^{32} S,{ }^{33} S,{ }^{34} S\right)$ measurements were made by multicollector inductively coupled plasma mass spectrometry at the St Andrews Isotope Geochemistry laboratory at the University of St Andrews (Burke et al., 2019). $\Delta^{33} S$ values were calculated relative to the standard Vienna-Canyon Diablo Troilite (VCDT) as $\Delta^{33} \mathrm{~S}=\delta^{33} \mathrm{~S}+1-\left(\delta^{34} \mathrm{~S}+1\right)^{0.515}$, where $\delta^{x} \mathrm{~S}=\left({ }^{x} S /{ }^{32} S\right)_{\text {sample }} /\left({ }^{x} S /{ }^{32} S\right)_{V C D T}-1$, with $\mathrm{x}$ being either 33 or 34 . Because of the small samples sizes, $1 \sigma$ uncertainties on $\Delta^{33}$ S ranged from 0.06 to $0.15 \%$ (SI Appendix, Fig. 4.7), slightly larger than previously reported uncertainties of $0.05 \%$ (Burke et al., 2019).

\section{Earth System Model Simulations.}

We used CESM (version 1.2.2) (Hurrell et al., 2013) to evaluate the impact of the volcanic eruptions on NH climate. The model consists of coupled components for the atmosphere, ocean, land, and sea ice and is run in $2^{\circ} \times$ $2^{\circ}$ horizontal resolution in the atmosphere/land and $1^{\circ} \times 1^{\circ}$ horizontal resolution in the ocean/sea ice. The vertical resolution of the atmosphere and ocean are 31 and 61 levels, respectively. A transient simulation started in year 1501 BCE was driven by orbital, solar (Schmidt et al., 2012), and greenhouse gas (Joos and Spahni, 2008) forcing, as well 
as volcanic forcing. In $60 \mathrm{BCE}$, the transient simulation was branched to perform an ensemble of 10 CESM1.2.2 simulations. Small disturbances were introduced in the atmosphere at the first time step and run until 30 BCE with the prescribed volcanic forcing that included three NH eruptions in 45 BCE, 43 BCE (Okmok II), and 34 BCE.

Stratospheric volcanic sulfur injection estimates for the three eruptions between 60 and 30 BCE were taken from the eVolv2k database (Toohey and Sigl, 2017), which is based on quantification of Antarctic and Greenland sulfate depositional fluxes using bipolar ice core arrays. The eruption years were shifted by $1 \mathrm{y}$ to align with the DRI_NGRIP2 chronology, and the default source locations from the eVolv2k database were adjusted to $64^{\circ} \mathrm{N}$ (i.e., Iceland) for the $45 \mathrm{BCE}$ eruption and to $54.4^{\circ} \mathrm{N}$ for the Okmok eruption in $43 \mathrm{BCE}$. We also used an eruption date of January 1 based on a short time lag between the Okmok eruption and initial volcanic fallout in Greenland that started in early 43 BCE. Using the Easy Volcanic Aerosol (EVA) forcing generator (Gao et al., 2008) and volcanic sulfur injection from eVolv2k, we generated global aerosol distributions and the evolution of extratropical stratospheric aerosol optical depth at $550 \mathrm{~nm}$. The space-time distribution of sulfate generated by EVA was converted to volcanic aerosol mass to be readable by CESM. Modifications to the prescribed aerosol distribution included 1) shifting peak sulfate injection in the stratosphere following (Gao et al., 2008) so that the atmospheric sulfate burden increased linearly until the fourth month after the eruption and then decreased exponentially according to the EVA model and 2) increasing the volcanic aerosol mass by $45 \%$ to reconcile CESM and EVA optical depths following (Zhong et al., 2018) but using the 1991 Pinatubo eruption as a reference.

The model output consisted of monthly means that were combined to form a 10-ensemble average for evaluation of the volcanic climate effects. We calculated annual and seasonal (December to February [DJF], March to May [MAM], June to August [JJA], and September to November [SON]) anomalies from the monthly ensemble means after removing the seasonal variability, with the anomalies relative to the 60 through 46 BCE background period with no volcanic forcing. We used a Student's t test ( $5 \%$ significance level or $2 \sigma$ ) to determine the significance of the anomalies relative to background variability during the reference period.

\section{Data Availability.}

All high-resolution ice core measurements presented in this study are provided in Dataset S1. Tephra geochemistry measurements are provided in Dataset S2.

\section{Acknowledgments}

National Science Foundation Grants 1925417, 1023672, and 0909541 to J.R.M. and 1824770 to J.G.M. and F.L. funded this research, in addition to support to A.I.W. and J.R.M. from the John Fell Oxford University Press (OUP) Research Fund and All Souls College, Oxford. Clare Hall, Cambridge, provided additional support to J.R.M. through the Sir Nicholas Shackleton Fellowship. F.L. also acknowledges support from an Irish Research Council Laureate Award (Climates of Conflict in Ancient Babylonia project, Award IRCLA/2017/303). Swiss National Science Foundation Grant 18001 funded C.C.R. and W.M.K. European Research Council Grant 820047 under the European Union's Horizon 2020 research and innovation program supported M.S. Marie Curie Career Integration Grant CIG14-631752 supported A.B. This work also benefitted from participation by some authors in the Past Global Changes Volcanic Impacts on Climate and Society working group. We thank the NGRIP and 
NEEM communities, M. Twickler, and the NSF-ICF for providing access to GISP2 samples, as well as students and staff in the DRI ice core group for assistance in the laboratory. R. Kreidberg provided editorial advice.

\section{SI Appendix}


Table 4.1 - DRI_NGRIP2 age scale in both year before 1950 (yb1950) and year (BCE/CE). Shading identifies approximate periods in the NGRIP2 and NEEM cores of high ( $>3 \sigma$ above background) non-sea-salt sulfur concentration indicating elevated volcanic fallout.

\begin{tabular}{|c|c|c|}
\hline yb1950 (ybp) & BCE(-)/CE(+) & Approximate Date \\
\hline 1948 & +2 & Jan-01 \\
\hline 1948.25 & +1 & Oct-01 \\
\hline 1948.5 & +1 & Jul-01 \\
\hline 1948.75 & +1 & Apr-01 \\
\hline 1949 & +1 & Jan-01 \\
\hline 1949.25 & -1 & Oct-01 \\
\hline 1949.5 & -1 & Jul-01 \\
\hline 1949.75 & -1 & Apr-01 \\
\hline 1950 & -1 & Jan-01 \\
\hline 1950.25 & -2 & Oct-01 \\
\hline 1989 & -40 & Jan-01 \\
\hline 1989.25 & -41 & Oct-01 \\
\hline 1989.5 & -41 & Jul-01 \\
\hline 1989.75 & -41 & Apr-01 \\
\hline 1990 & -41 & Jan-01 \\
\hline 1990.25 & -42 & Oct-01 \\
\hline 1990.5 & -42 & Jul-01 \\
\hline 1990.75 & -42 & Apr-01 \\
\hline 1991 & -42 & Jan-01 \\
\hline 1991.25 & -43 & Oct-01 \\
\hline 1991.5 & -43 & Jul-01 \\
\hline 1991.75 & -43 & Apr-01 \\
\hline 1992 & -43 & Jan-01 \\
\hline 1992.25 & -44 & Oct-01 \\
\hline 1992.5 & -44 & Jul-01 \\
\hline 1992.75 & -44 & Apr-01 \\
\hline 1993 & -44 & Jan-01 \\
\hline 1993.25 & -45 & Oct-01 \\
\hline 1993.5 & -45 & Jul-01 \\
\hline 1993.75 & -45 & Apr-01 \\
\hline 1994 & -45 & Jan-01 \\
\hline 1994.25 & -46 & Oct-01 \\
\hline
\end{tabular}


Chapter 4. Extreme climate after massive eruption of Alaska's Okmok volcano in 43 BCE and effects on

\section{A. NGRIP2}

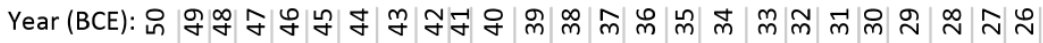
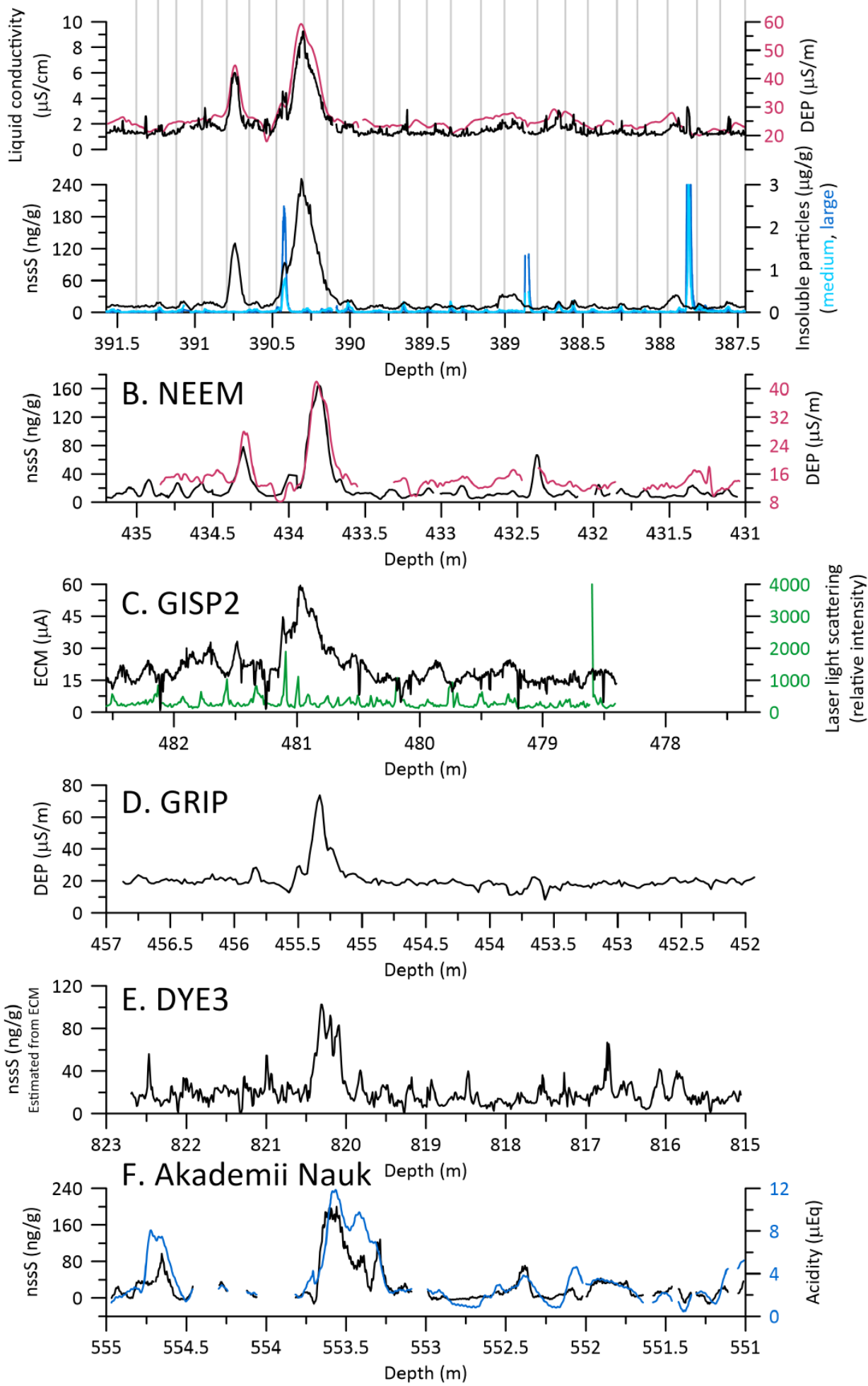

Figure 4.5 - Selected new and previously published measurements of volcanic-fallout-related parameters in the six Arctic ice cores (Fig. 4.1) evaluated for this study: A. NGRIP2 (this study and (Mojtabavi et al., 2020b)), B. NEEM (Mojtabavi et al., 2020b; Sigl et al., 2015), C. GISP2 (Taylor et al., 1997; Zielinski and Mershon, 1997), D. GRIP (Clausen et al., 1997; Wolff et al., 1997), E. DYE3 (Clausen et al., 1997), and F. Akademii Nauk (this study). Depth ranges correspond approximately to 25 to $50 \mathrm{BCE}$ after synchronization at $43 \mathrm{BCE}$ to the DRI-NGRIP2 age scale (McConnell et al., 2018). 

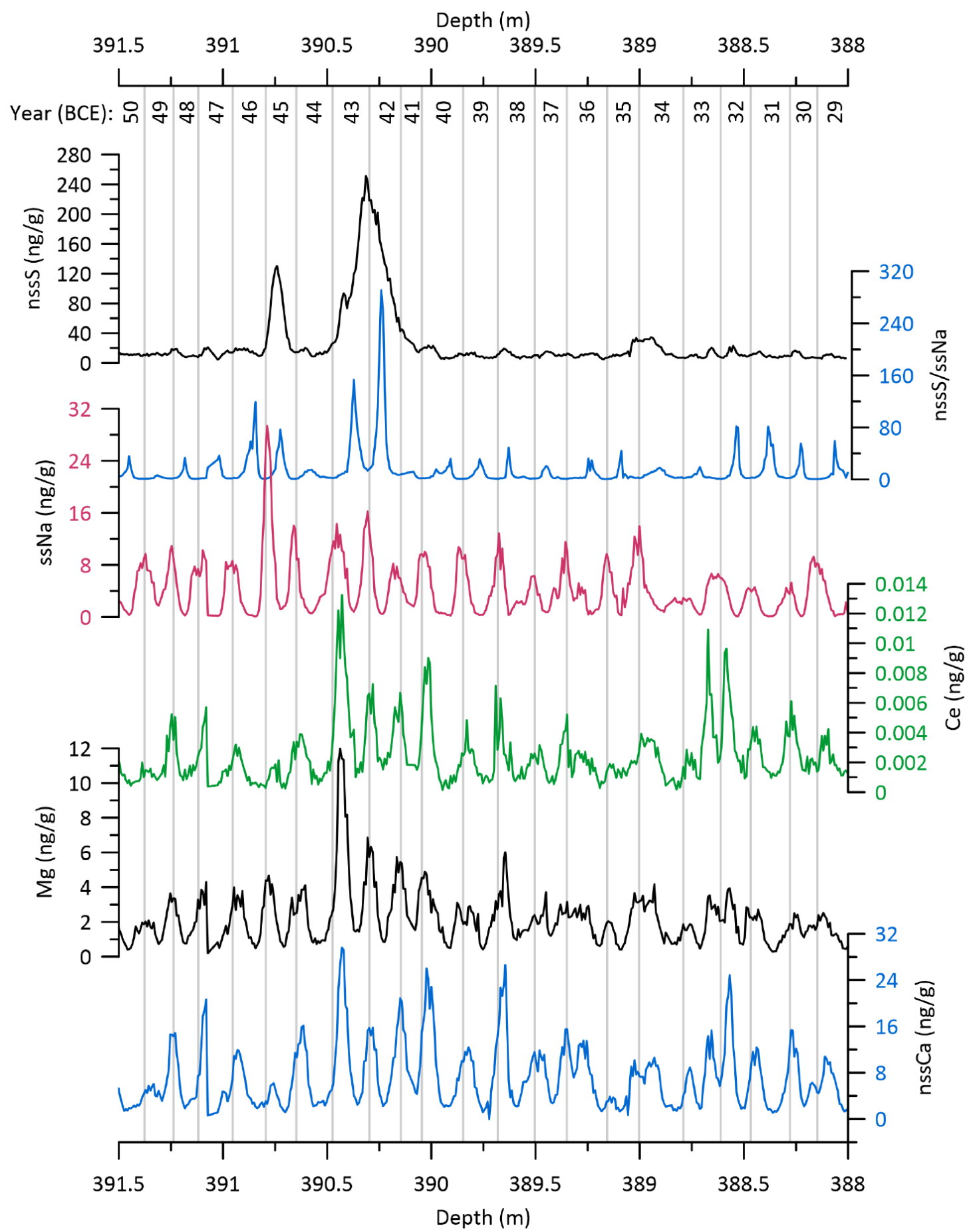

Figure 4.6 - Selected continuous elemental measurements of NGRIP2 ice (388 to $391.5 \mathrm{~m}$ ) used for annual layer counting. Shown are nssS, the ratio of nssS/ssNa, ss Na, cerium (Ce), magnesium $(\mathrm{Mg})$, and nssCa, where nssS is non-sea-salt sulfur, ssNa is sea-salt sodium, and nssCa is non-sea-salt calcium. Also shown are mid-winter (ostensibly January 1) annual layer picks corresponding to 29 BC to 49 BCE on the DRI_NGRIP2 age scale (McConnell et al., 2018). Ce and nssCa are primarily continental dust indicators while $\mathrm{Mg}$ includes both sea-salt and dust components. nssS reflects both volcanic fallout and background marine and terrestrial biogenic emissions. 

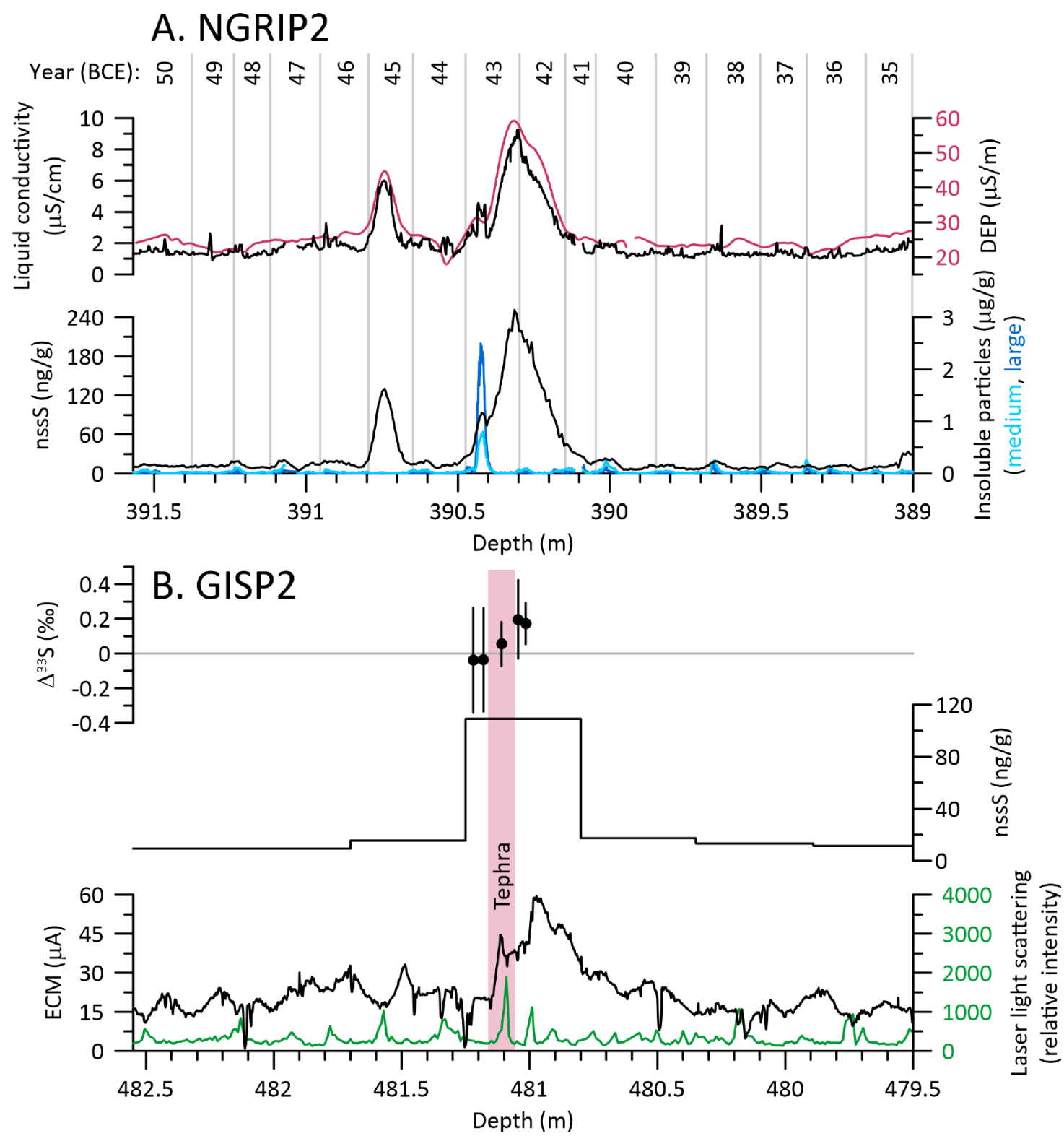

Figure 4.7 - Volcanic fallout surrounding the 43 BCE Okmok II eruption in the A. NGRIP2 and B. GISP2 ice cores. Shown for NGRIP2 are continuous measurements of liquid conductivity (this study), field DEP (Mojtabavi et al., 2020b), nssS (this study) and medium (2.5 to $5 \mu \mathrm{m}$ ) and large (5 to $10 \mu \mathrm{m}$ ) insoluble particle counts (this study). Shown for GISP2 are discrete measurements of $\Delta^{33} S( \pm 2 \sigma)$ (this study), discrete sulfate (Zielinski et al., 1994), ECM (Taylor et al., 1997), and laser light scattering (Ram and Koenig, 1997). Tephra used to identify Okmok II as the source eruption were filtered from an ice sample extending from 481.06 to $481.16 \mathrm{~m}$ depth (vertical shaded bar) from the GISP2 core. 


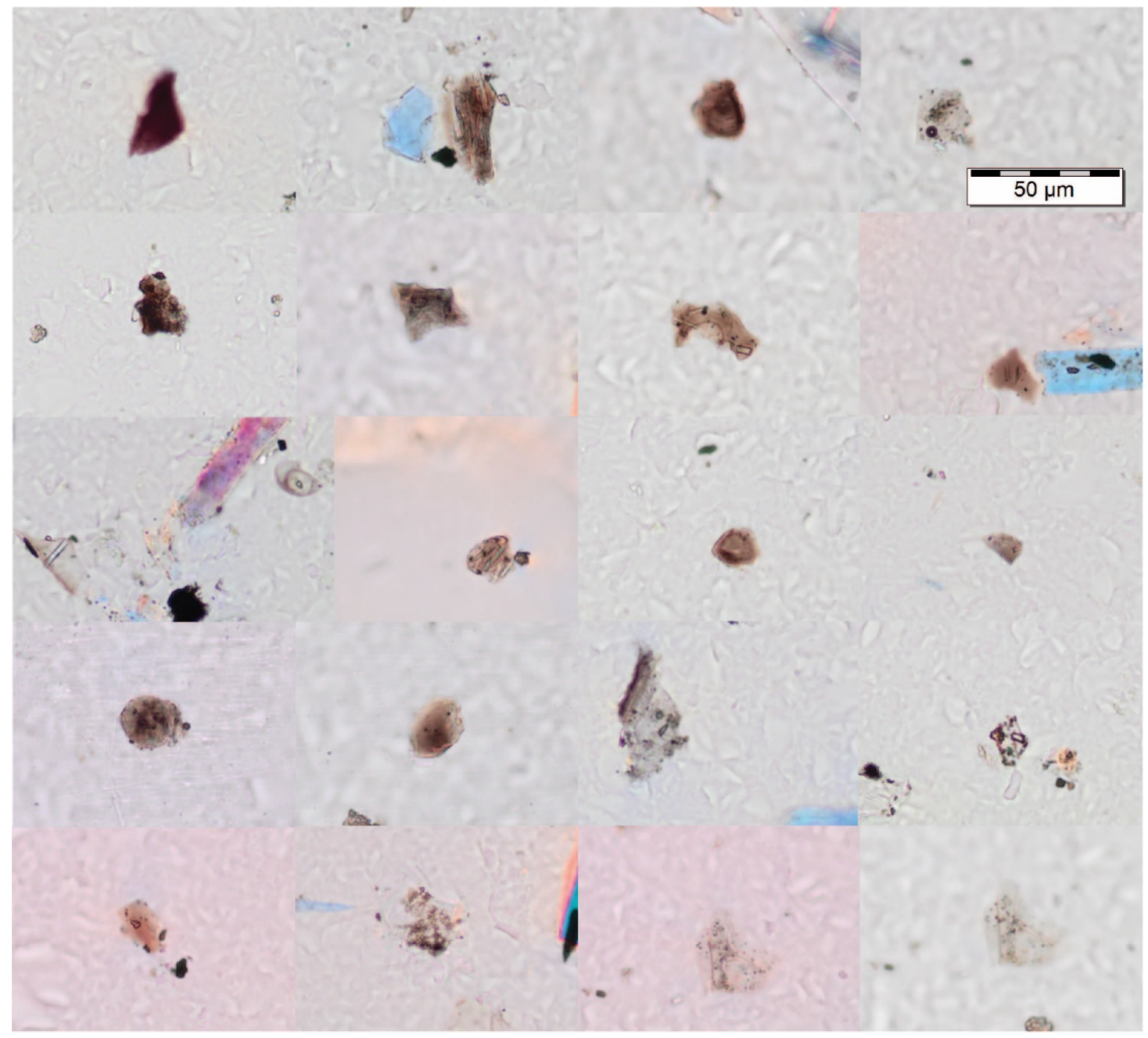

Figure 4.8 - Images of selected tephra shards extracted from GISP2 ice ( 481.06 to $481.16 \mathrm{~m}$ ) and geochemically tied to the Okmok II eruption that started in early $43 \mathrm{BCE}$. 

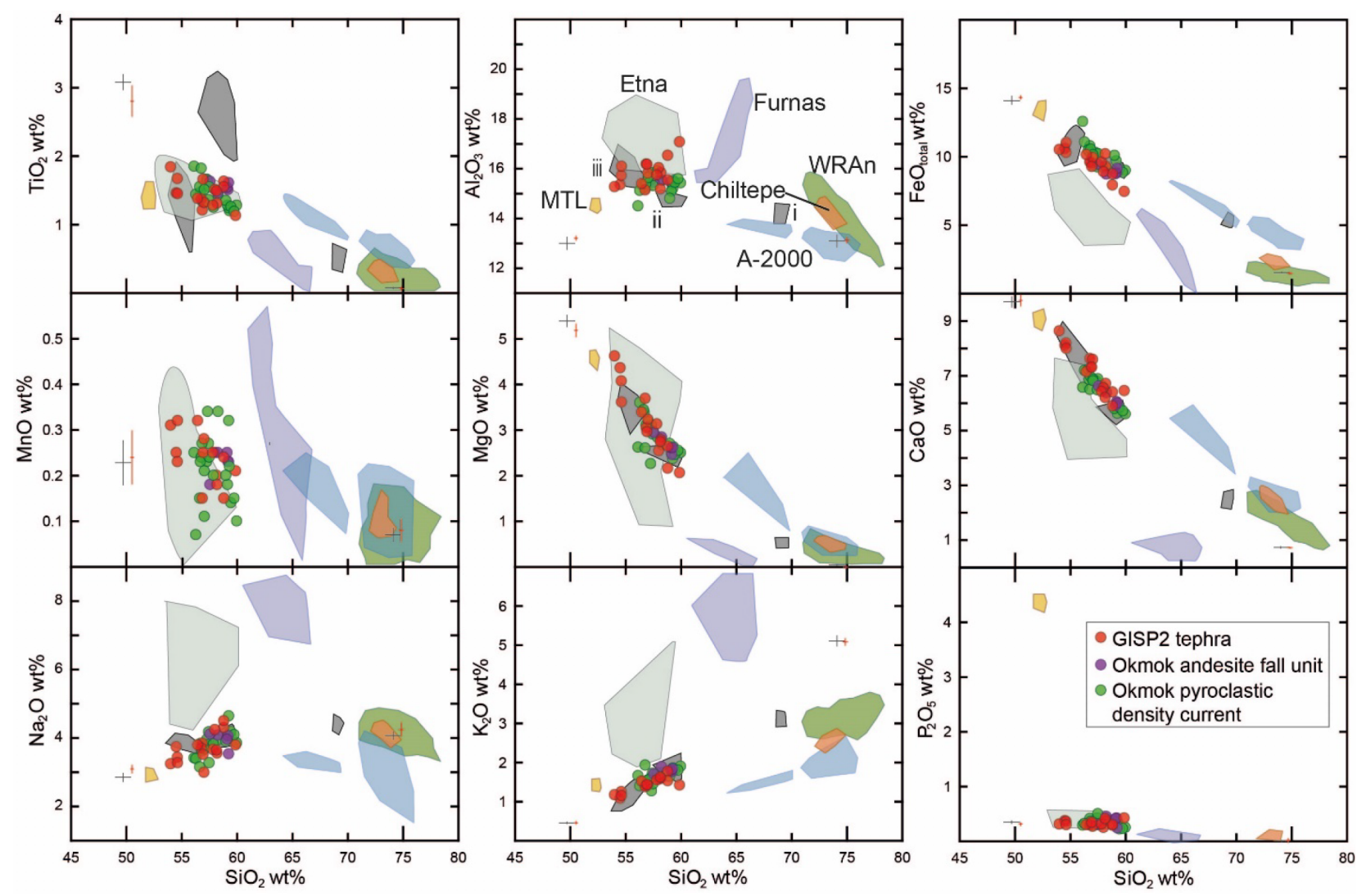

Figure 4.9- Tephra geochemistry comparisons between shards extracted from GISP2 ice (481.06 to $481.16 \mathrm{~m}$ ) and potential $\mathrm{NH}$ source eruptions including Etna, as well as large eruptions thought within dating uncertainties to have occurred in the $1^{\text {st }} 1$ st century BCE. Filled circles show measurements (this study) of GISP2 and Okmok reference tephra (Materials and Methods; Dataset S02). Shaded regions show tephra reference measurements from other potential source volcanoes: Etna, Italy (Sadori and Narcisi, 2001; Vogel et al., 2010); Chiltepe from Apoyeque, Nicaragua (Kutterolf et al., 2008, 2011); Masaya Triple Tuff (MTL), Nicaragua (Kutterolf et al., 2008); A-2000, Askja, Iceland (Barber et al., 2008); White River Ash northern lobe (WRAn), Churchill, Canada (Preece et al., 2014); Furnas, Azores (Wastegård et al., 2020). Gray shading shows prior measurements of tephra samples from the first (i.), second (ii.) and third (iii.) eruption phases of Okmok II (Larsen et al., 2007). Analytical precision for the GISP2/Okmok measurements is illustrated by the red crosses representing $2 \sigma$ of repeated analyses of the secondary glass standards (high Si - Lipari, low Si - Laki); for comparison, accepted values for Lipari and Laki $(2 \sigma)$ (Kuehn et al., 2011) are shown by the grey crosses. 
A. Annual

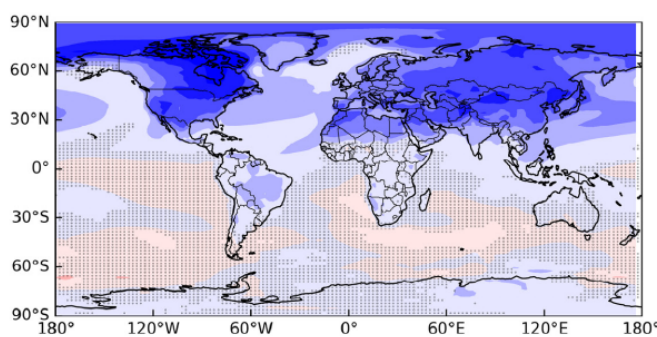

\section{B. Winter (DJF)}

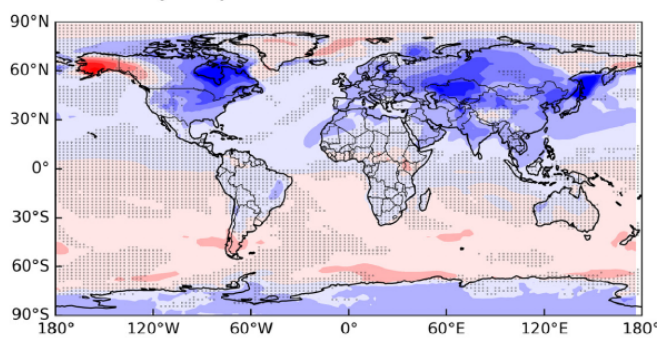

C. Spring (MAM)

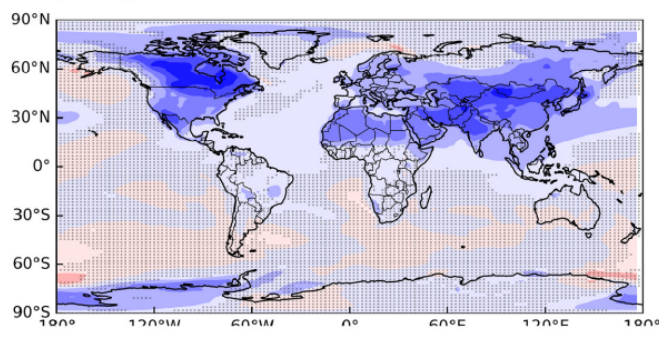

D. Summer (JJA)

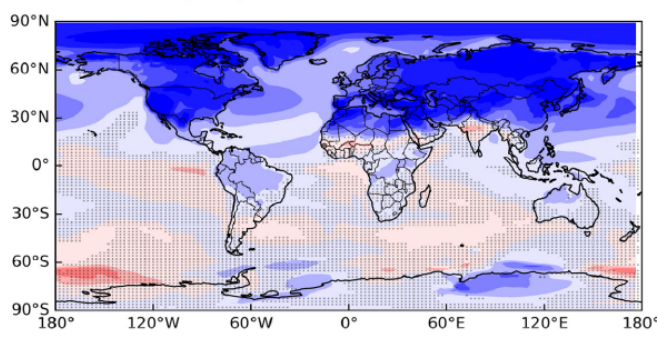

E. Autumn (SON)

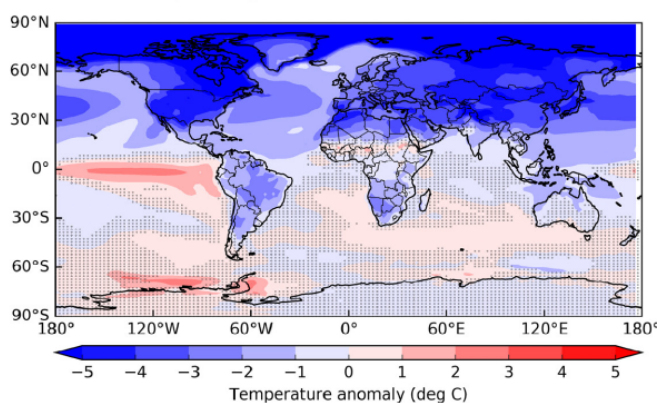

\section{Precipitation anomaly (43 BCE)}
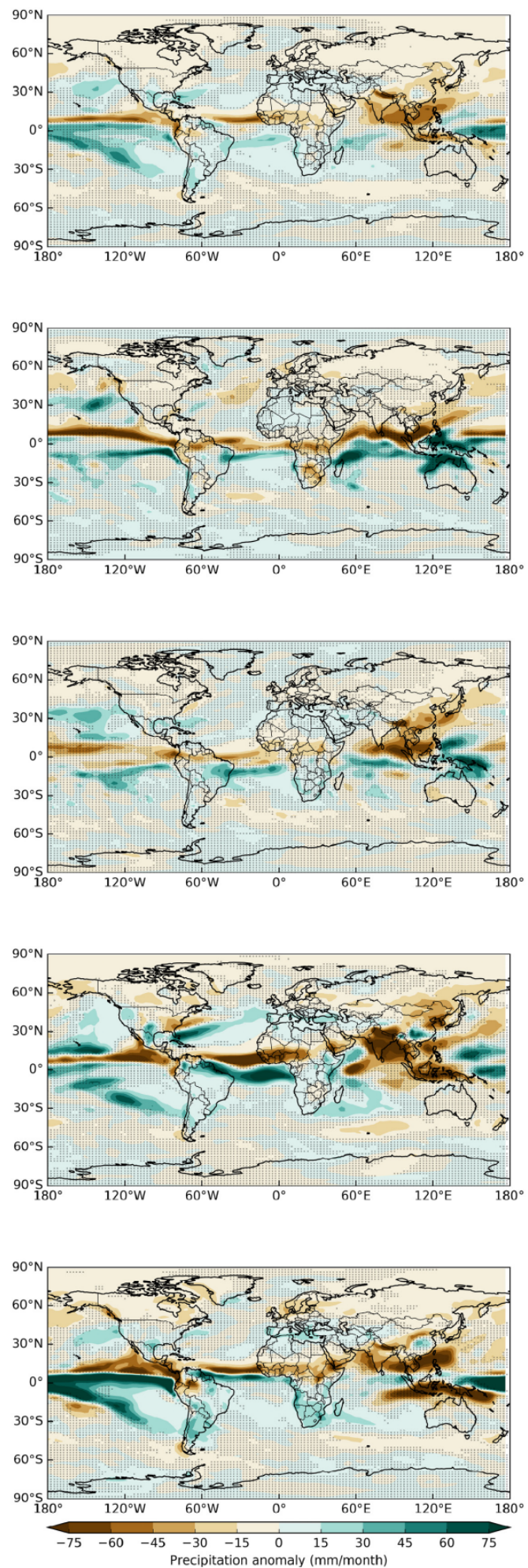

Figure 4.10 - Annual and seasonal 43 BCE CESM-modeled (Materials and Methods) temperature and precipitation anomalies relative to the 60 to $46 \mathrm{BCE}$ reference period with no volcanic forcing. Dots show areas where the anomalies are not significant $(2 \sigma)$ relative to the background variability. 
Chapter 4. Extreme climate after massive eruption of Alaska's Okmok volcano in 43 BCE and effects on

\section{A. Annual}

Temperature anomaly (42 BCE)

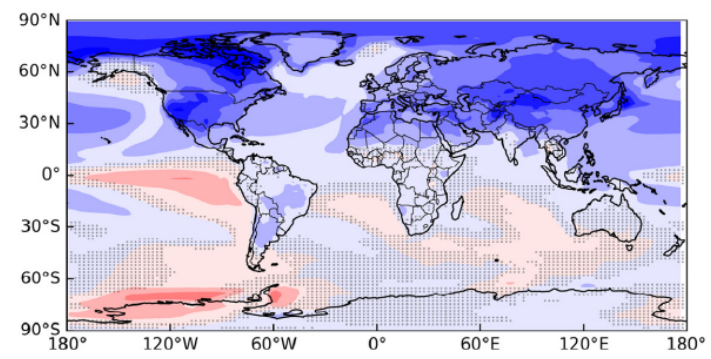

B. Winter (DJF)

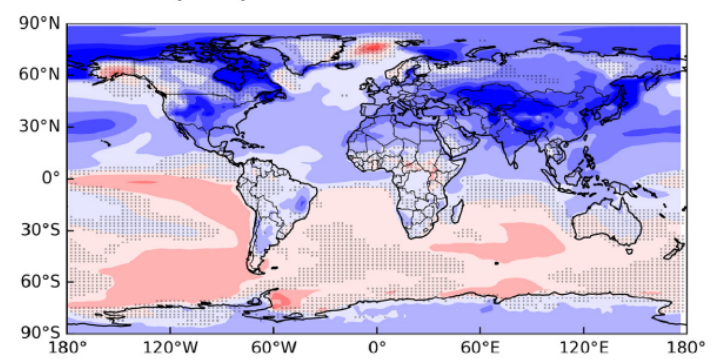

C. Spring (MAM)

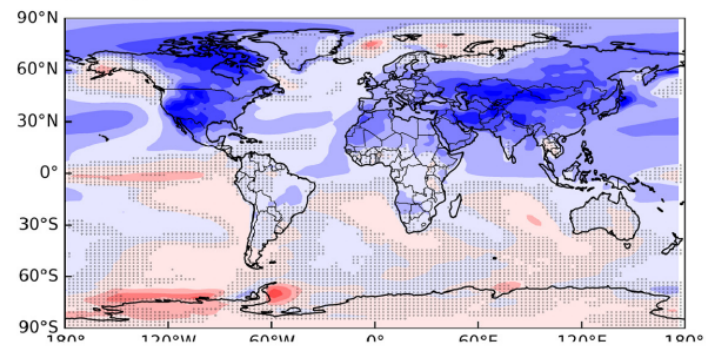

D. Summer (JJA)

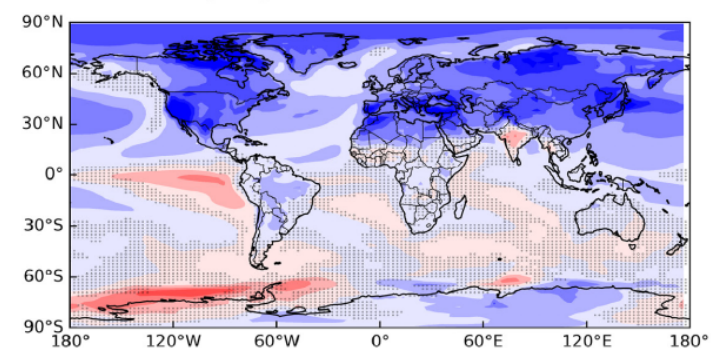

E. Autumn (SON)

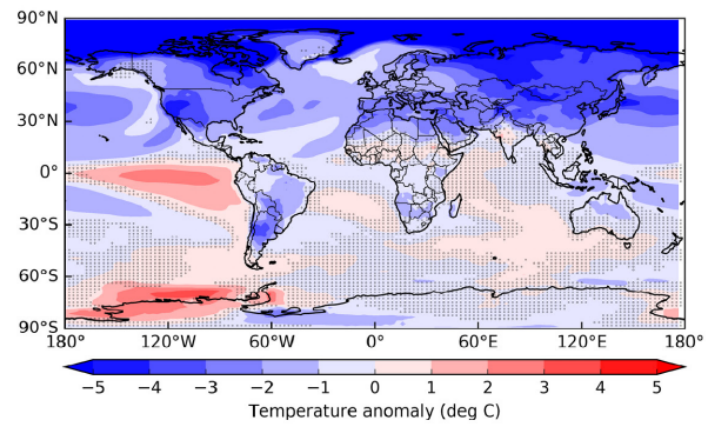

Precipitation anomaly (42 BCE)
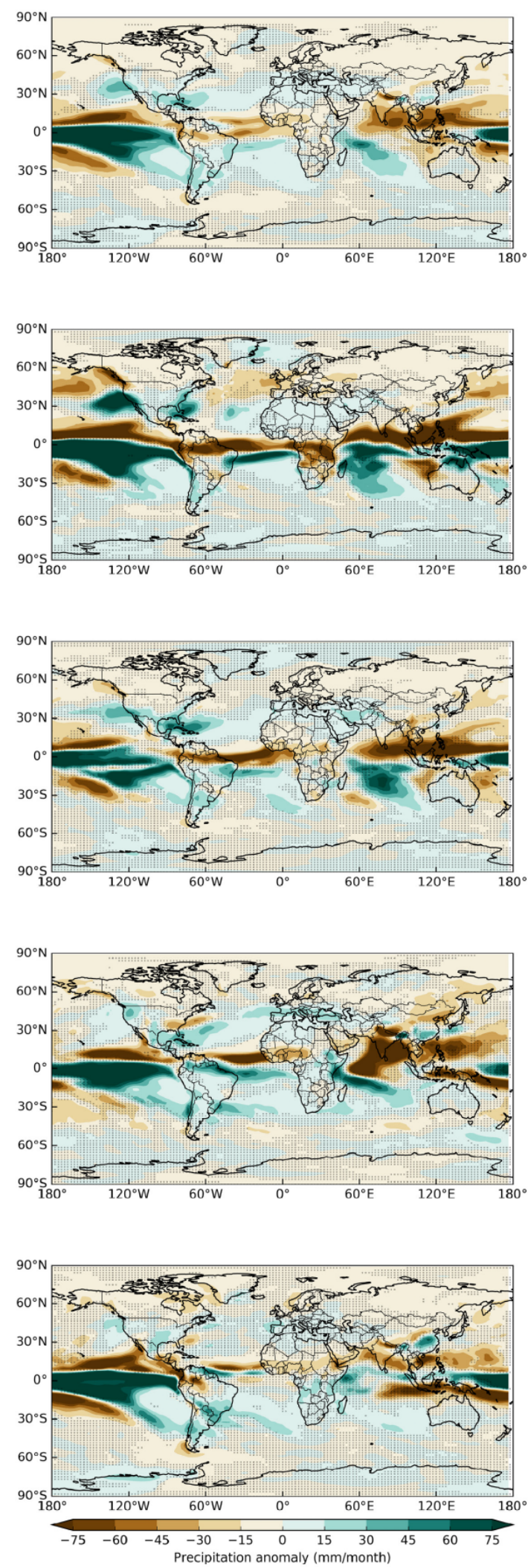

Figure 4.11 - As in SI Appendix, Fig. 4.10 but for 42 BCE. 

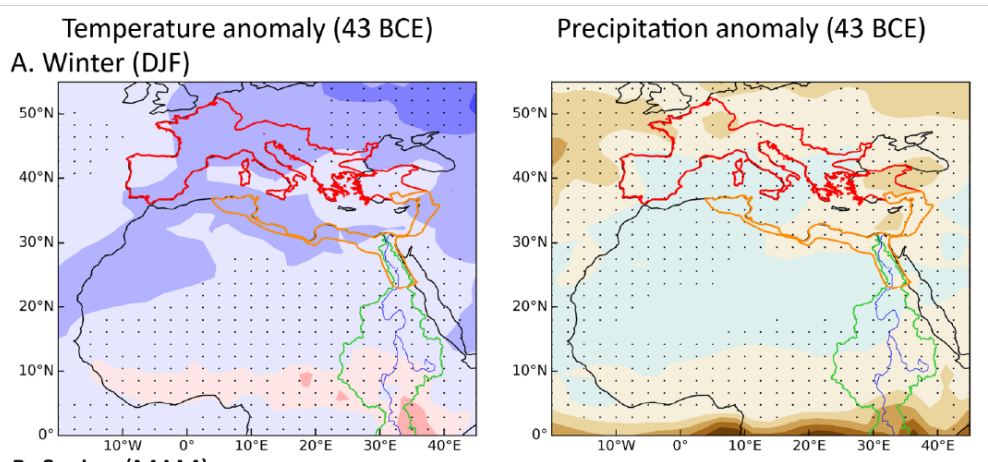

Precipitation \% change (43 BCE)

B. Spring (MAM)
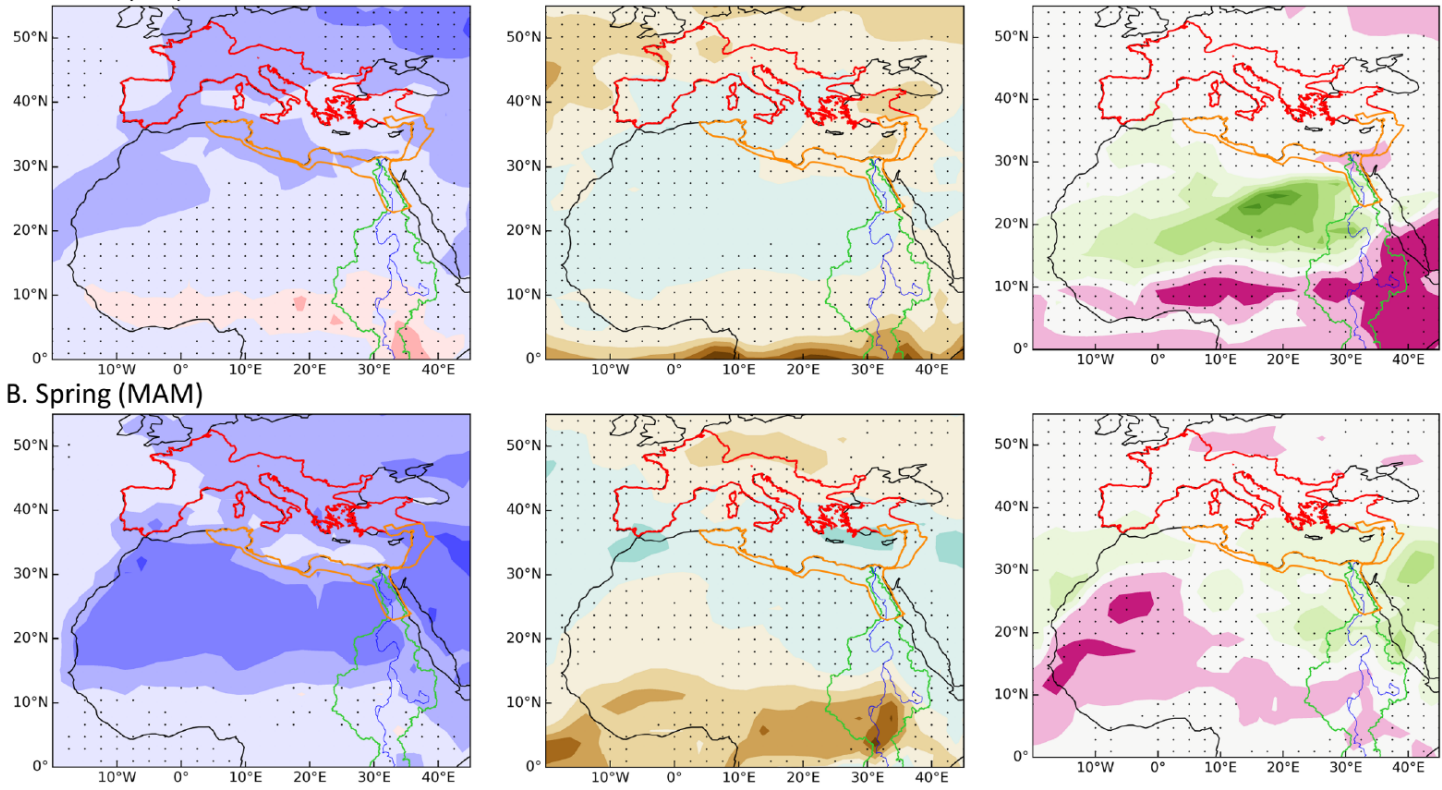

C. Summer (JJA)
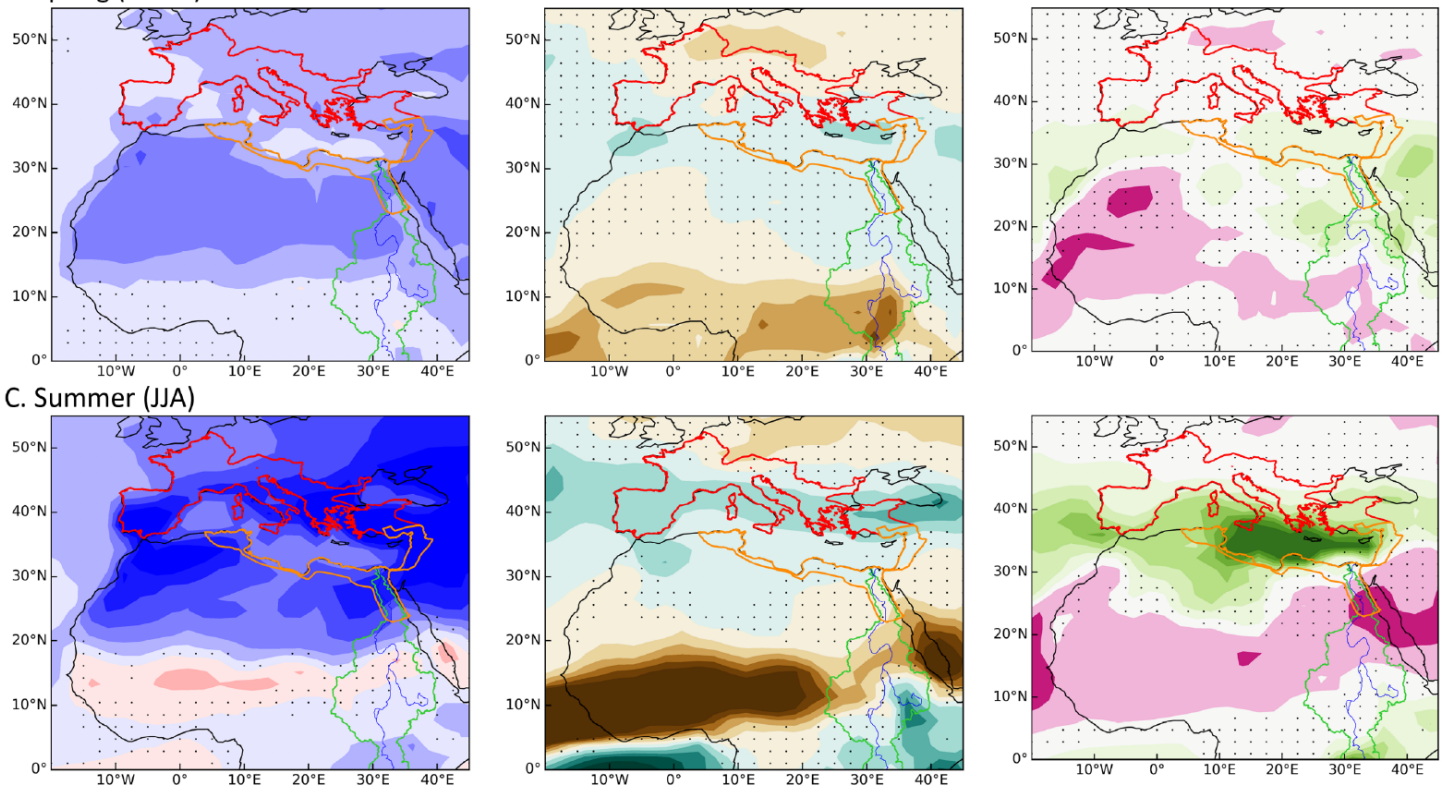

D. Autumn (SON)
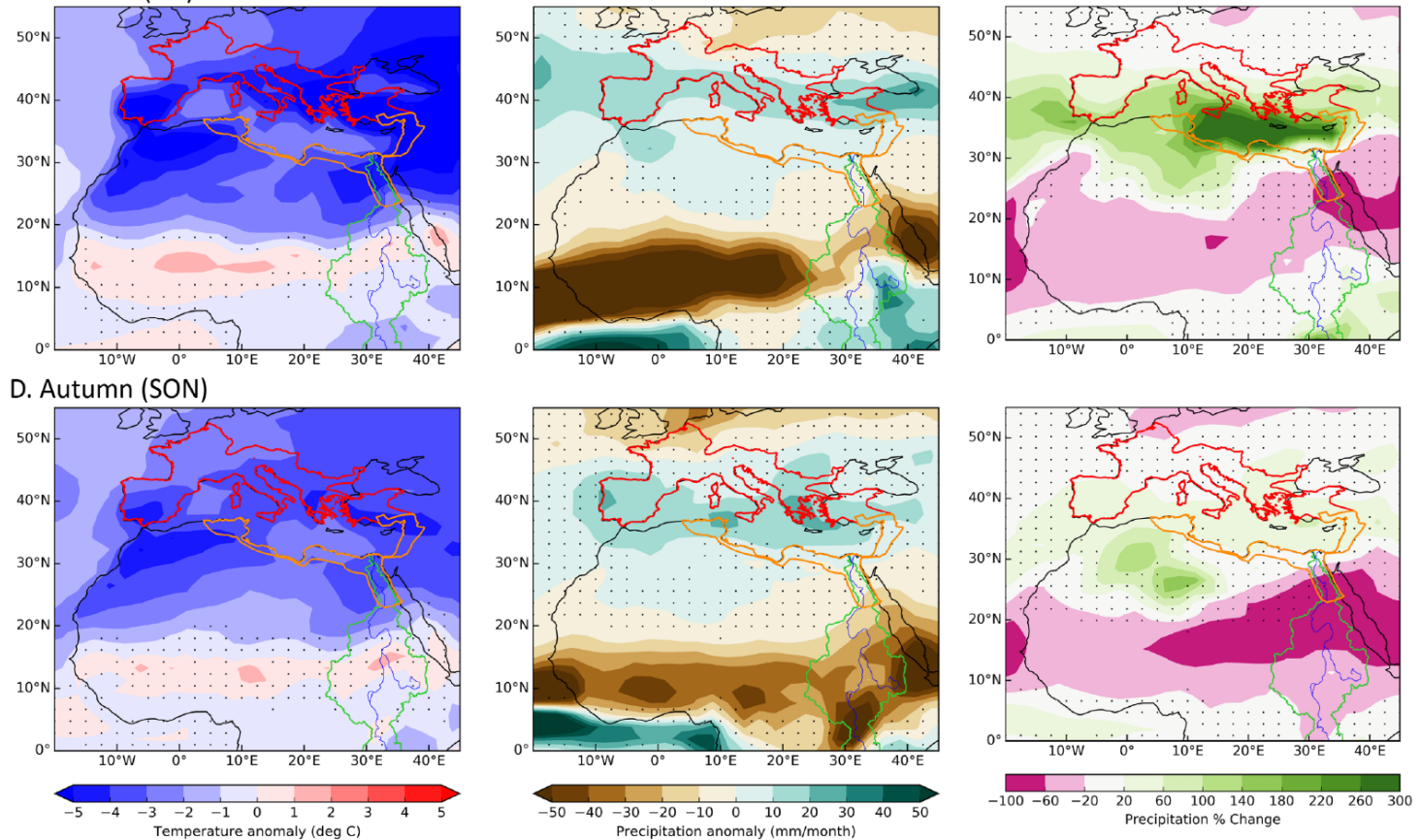

Figure 4.12 - Seasonal 43 BCE CESM-modeled (Materials and Methods) temperature and precipitation anomalies in response to radiative forcing from the early $43 \mathrm{BCE}$ Okmok II eruption. Outlines show (red) Roman provinces north of the Mediterranean, (orange) Ptolemaic Kingdom and Roman provinces south of the Mediterranean, and (green) the Nile River drainage. Anomalies and precipitation change are relative to the 60 to $46 \mathrm{BCE}$ reference period with no volcanic forcing. Dots show areas where the anomalies are not significant $(2 \sigma)$ relative to the background variability. 
Chapter 4. Extreme climate after massive eruption of Alaska's Okmok volcano in 43 BCE and effects on

Temperature anomaly (42 BCE) A. Winter (DJF)

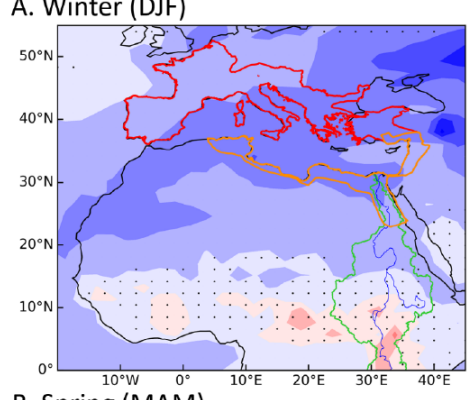

B. Spring (MAM)

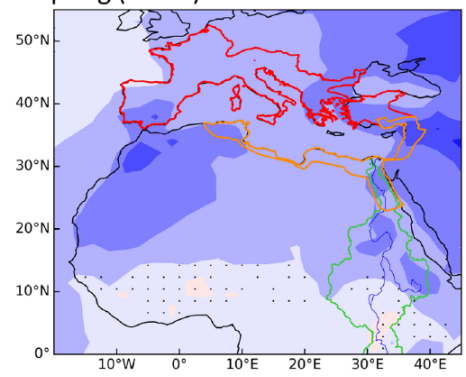

C. Summer (JJA)

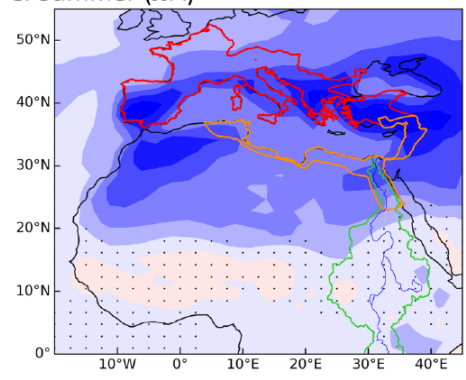

D. Autumn (SON)

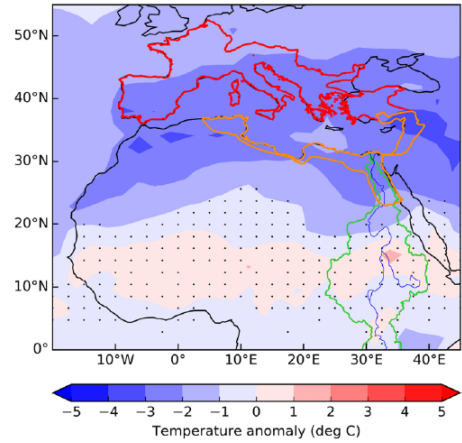

Precipitation anomaly (42 BCE)
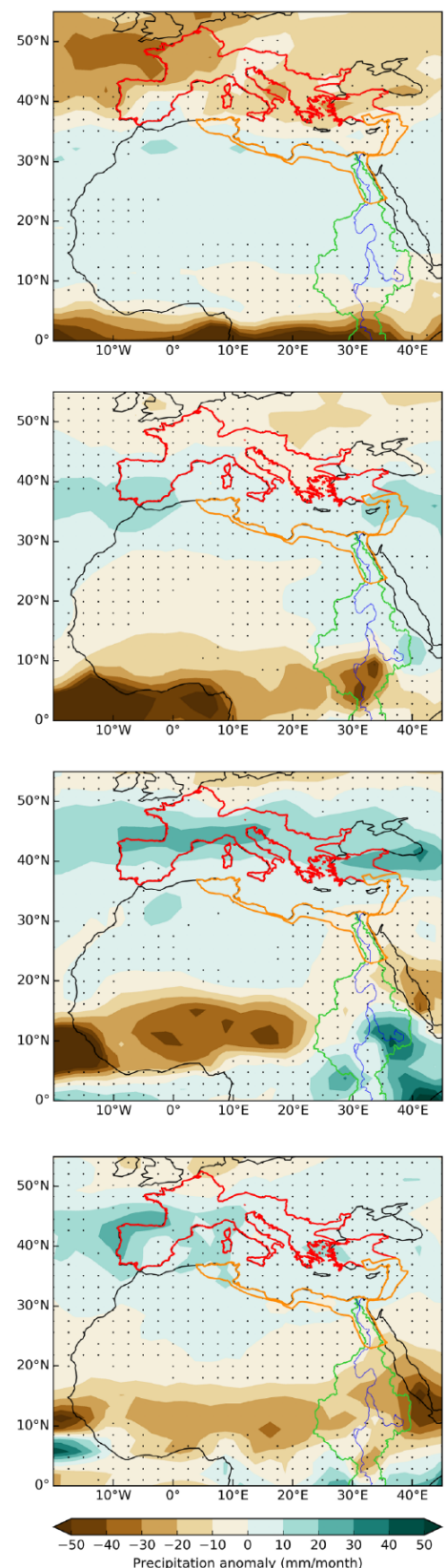

Precipitation \% change (42 BCE)
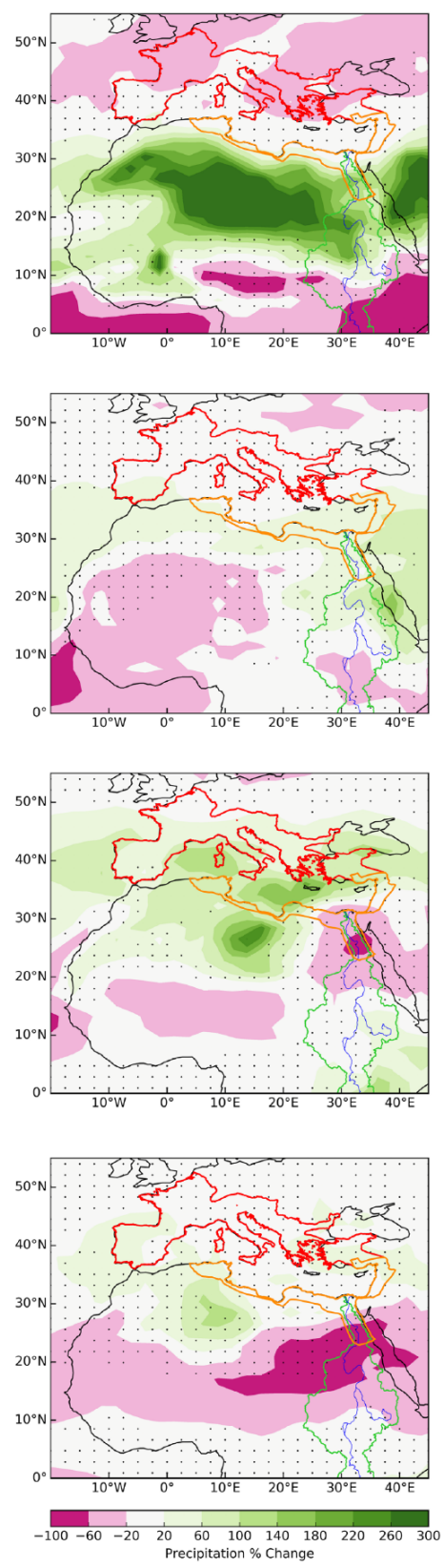

Figure 4.13- As in SI Appendix, Fig. 4.12 but for 42 BCE. 
Chapter 5

\section{Conclusion and Summary}

The aim of this dissertation was to process and interpret the new dielectric profiling (DEP) data set of several ice cores from polar regions. The polar ice sheets contain a lot of information about past climate conditions, which can be investigated employing different methods. One of these methods is recorded dielectric profiling (DEP) (Wilhelms et al., 1998) of ice cores, which is mainly related to the concentration of acidity, salt and ammonia along the ice (Moore et al., 1992; Moore et al., 1994). DEP data can be used in various concepts of glaciology and paleoclimatology. Examples are the detection of volcanic eruptions and the synchronization between different ice cores by means of volcanic chronologies (e.g., Mojtabavi et al., 2020b; McConnell et al., 2020), and geophysical mapping of their vicinities by a synthetic radargram modelling approach. In the first study, the EGRIP ice core from the Greenland ice sheet was measured and processed and the first chronology for the EGRIP ice core was establishedby synchronizing between the EGRIP, NEEM and NGRIP ice cores based on DEP, ECM and tephra layers. In the second study, a forward numerical modelling was applied using new DEP data from the EGRIP, NEEM and NGRIP2 ice cores in Greenland and linking the model results to the airborne radar measurements. In this way, the internal Greenland ice sheet layers were investigated both to understand the physical processes that cause the reflections, and also, to identify ages for the isochrone layers. In the third study, the DEP data of NEEM and NGRIP2 were used to synchronize between the ice cores. To identify the Okmok volcano and understand its impact on the Earth's climate change as well as historical human crises, this eruption was evaluated with various data sets such as DEP, ECM, tephra layers, climate proxy records and climate model simulations. The following conclusions and summaries can be drawn from these studies:

1. First dating was established for the EGRIP ice core over the Holocene and last glacial termination. The EGRIP drill site is located above the NEGIS ice stream, which is presently draining about $12 \%$ of the Greenland ice sheet. In this study, the data were measured and processed in Greenland during the 2017, 2018 and 2019 field seasons, including DEP, ECM and tephra data sets. Volcanic events and synchronous patterns of further events in the DEP and ECM data were matched between NGRIP, NEEM and EGRIP ice cores. Some volcanic tephra layers were used to validate the synchronization of the ice cores. The annuallayer-counted Greenland Ice Core Chronology 2005 (GICC05) was used to transfer timescale (depth-age relation) from the NGRIP to the EGRIP ice cores by interpolation between 381 match points. The uncertainty related to timescale is less than $0.5 \mathrm{yr}$ for the peak assignment and slightly more than $1 \mathrm{yr}$ for the timescale transfer uncertainty over the entire record of the core based on statistical analysis. Also, the EGRIP 
timescale inherits the maximum counting error (MCE) of the GICC05 timescale. In this study, the EGRIP timescale goes back to $14967 \mathrm{yr}$ b2k and an associated MCE of $196 \mathrm{yr}$. This EGRIP timescale is the basis for future studies and interpretation of another EGRIP high-resolution data set.

2. To understand the dynamic behaviour of the Greenland ice sheets, it is essential to investigate internal layers of the ice sheet. Numerical forward modelling was linked to the multichannel ultra-wide-band radar from the airborne measurements, which were produced by AWI UWB for the EGRIP camp and CReSIS data around the NEEM and NGRIP2 camps (Centre for Remote Sensing of Ice Sheets, University of Kansas). For the first time, the three latest Northern Greenland deep ice cores were investigated using this approach;

- DEP data from NGRIP, the oldest undisturbed record in Greenland;

- NEEM, the oldest reconstructed record from a folded core;

- EGRIP, the first ice core from the upper region of the NEGIS ice stream.

The 1D-FD numerical model (Eisen et al., 2004) was used to calculate the synthetic radar based on conductivity and permittivity of DEP data. Excellent agreement between the model results and radio-echo sounding data indicate that mainly conductivity changes caused internal reflection and also the comparison of along and across flow wave propagation speeds suggests the across-flow concentrated fabric in the EGRIP drill site. Additionally, a better assessment of age accuracy was provided for some isochrone layers in the Greenland Ice Sheet.

3. Past massive volcanic eruptions caused a significant effect on the Earth's climate such as global cooling, and they also could have led to human crises. As conductivity peaks of DEP and ECM records along the ice core is mainly related to the volcanic eruptions, the Okmok volcano in Alaska, (early $43 \mathrm{BC}$ ) can be determined using DEP and ECM electrical measurements. The Okmok volcano was evaluated based on several ice cores with high-resolution data such as DEP from the NEEM and NGRIP2 ice cores, ECM, tephra layers, climate proxy records and climate model simulations. The ECM and DEP peaks were investigated to see if the tephra layers have associated with DEP/ECM peaks. The temperature impact of this eruption was investigated by the Earth System Model (ESM). ESM simulations indicate the average temperature was $7^{\circ} \mathrm{C}$ below normal during the two-year period following the eruption. This eruption influenced crop failures, famine, and disease in the Mediterranean region. The fall of the Roman Republic and Ptolemaic Kingdom occurred during this massive eruption. 


\section{References}

Adolphi, F. and Muscheler, R.: Synchronizing the Greenland ice core and radiocarbon timescales over the Holocene-Bayesian wiggle-matching of cosmogenic radionuclide records, Climate of the Past, 12, 15-30, 2016.

Adolphi, F., Bronk Ramsey, C., Erhardt, T., Edwards, R. L., Cheng, H., Turney, C. S. M., Cooper, A., Svensson, A., Rasmussen, S. O., Fischer, H., and Muscheler, R.: Connecting the Greenland ice-core and U/Th timescales via cosmogenic radionuclides: testing the synchroneity of Dansgaard-Oeschger events, Climate of the Past, 14, 1755-1781, doi: 10.5194/ cp-14-1755-2018, URL https://cp.copernicus.org/articles/14/ 1755/2018/, 2018.

Andersen, K. K., Svensson, A., Johnsen, S. J., Rasmussen, S. O., Bigler, M., Röthlisberger, R., Ruth, U., Siggaard-Andersen, M.-L., Steffensen, J. P., Dahl-Jensen, D., Vinther, B. M., and Clausen, H. B.: The Greenland Ice Core Chronology 2005, 15-42ka. Part 1: constructing the time scale, Quaternary Science Reviews, 25, 3246 - 3257, doi: https://doi.org/10. 1016/j.quascirev.2006.08.002, URL http://www.sciencedirect. com/science/article/pii/S0277379106002587, critical Quaternary Stratigraphy, 2006.

Arcone, S. A., Spikes, V. B., Hamilton, G. S., and Mayewski, P. A.: Stratigraphic continuity in $400 \mathrm{MHz}$ short-pulse radar profiles of firn in West Antarctica, Annals of Glaciology, 39, 195-200, doi: 10.3189/172756404781813925, 2004.

Arnold, E., Leuschen, C., Rodriguez-Morales, F., Li, J., Paden, J., Hale, R., and Keshmiri, S.: CReSIS airborne radars and platforms for ice and snow sounding, Annals of Glaciology, p. 1-10, doi: 10.1017/aog.2019.37, 2019.

Augustin, L., Barbante, C., Barnes, P. R. F., Marc Barnola, J., Bigler, M., Castellano, E., Cattani, O., Chappellaz, J., Dahl-Jensen, D., Delmonte, B., Dreyfus, G., Durand, G., Falourd, S., Fischer, H., Flückiger, J., Hansson, M. E., Huybrechts, P., Jugie, G., Johnsen, S. J., Jouzel, J., Kaufmann, P., Kipfstuhl, J., Lambert, F., Lipenkov, V. Y., Littot, G. C., Longinelli, A., Lorrain, R., Maggi, V., Masson-Delmotte, V., Miller, H., Mulvaney, R., Oerlemans, J., Oerter, H., Orombelli, G., Parrenin, F., Peel, D. A., Petit, J.-R., Raynaud, D., Ritz, C., Ruth, U., Schwander, J., Siegenthaler, U., Souchez, R., Stauffer, B., Peder Steffensen, J., Stenni, B., Stocker, T. F., Tabacco, I. E., Udisti, R., van de Wal, R. S. W., van den Broeke, M., Weiss, J., Wilhelms, F., Winther, J.-G., Wolff, E. W., Zucchelli, M., community members, E., and community members (participants are listed alphabetically), E.: Eight glacial cycles from an Antarctic ice core, Nature, 429, 623628, doi: 10.1038/nature02599, URL https://doi.org/10.1038/ nature $02599,2004$.

Barber, K., Langdon, P., and Blundell, A.: Dating the Glen Garry tephra: a widespread late-Holocene marker horizon in the peatlands of northern Britain, The Holocene, 18, 31-43, 2008.
Bingham, R. G. and Siegert, M. J.: Quantifying subglacial bed roughness in Antarctica: implications for ice-sheet dynamics and history, Quaternary Science Reviews, 28, 223 236, doi: https://doi.org/10.1016/j.quascirev.2008.10.014, URL http://www.sciencedirect.com/science/article/pii/ S0277379108003016, special Theme: Modern Analogues in Quaternary Palaeoglaciological Reconstruction (pp. 181-260), 2009.

Borchardt, G. A., Aruscavage, . J., and Millard, H. T.: Correlation of the Bishop Ash, a Pleistocene marker bed, using instrumental neutron activation analysis, Journal of Sedimentary Research, 42, 301-306, doi: 10.1306/74D72527-2B21-11D7-8648000102C1865D, 1972.

Burke, A., Moore, K. A., Sigl, M., Nita, D. C., McConnell, J. R., and Adkins, J. F.: Stratospheric eruptions from tropical and extratropical volcanoes constrained using high-resolution sulfur isotopes in ice cores, Earth and planetary science letters, 521, 113119, 2019.

Cavitte, M. G., Blankenship, D. D., Young, D. A., Schroeder, D. M., Parrenin, F., Lemeur, E., Macgregor, J. A., and Siegert, M. J.: Deep radiostratigraphy of the East Antarctic plateau: connecting the Dome $\mathrm{C}$ and Vostok ice core sites, Journal of Glaciology, 62, 323-334, doi: 10.1017/jog.2016.11, 2016.

Chaney, E.: Revolt on the Nile: Economic shocks, religion, and political power, Econometrica, 81, 2033-2053, 2013.

Clausen, H. B., Hammer, C. U., Hvidberg, C. S., Dahl-Jensen, D., Steffensen, J. P., Kipfstuhl, J., and Legrand, M.: A comparison of the volcanic records over the past 4000 years from the Greenland Ice Core Project and Dye 3 Greenland ice cores, Journal of Geophysical Research: Oceans, 102, 26707-26723, 1997.

Collins, M., Knutti, R., Arblaster, J., Dufresne, J.-L., Fichefet, T., Friedlingstein, P., Gao, X., Gutowski, W. J., Johns, T., Krinner, G., et al.: Long-term climate change: projections, commitments and irreversibility, in: Climate Change 2013-The Physical Science Basis: Contribution of Working Group I to the Fifth Assessment Report of the Intergovernmental Panel on Climate Change, pp. 1029-1136, Cambridge University Press, 2013.

Colose, C. M., LeGrande, A. N., and Vuille, M.: Hemispherically asymmetric volcanic forcing of tropical hydroclimate during the last millennium, Earth System Dynamics, 7, 681-696, 2016.

Cook, E., Davies, S. M., Guðmundsdóttir, E. R., Abbott, P. M., and Pearce, N. J. G.: First identification and characterization of Borrobol-type tephra in the Greenland ice cores: new deposits and improved age estimates, Journal of Quaternary Science, 33, 212-224, doi: 10.1002/jqs.3016, URL https://onlinelibrary. wiley.com/doi/abs/10.1002/jqs.3016, 2018.

Coulter, S. E., Pilcher, J. R., Plunkett, G., Baillie, M., Hall, V. A., Steffensen, J. P., Vinther, B. M., Clausen, H. B., and Johnsen, S. J.: Holocene tephras highlight complexity of volcanic signals 
in Greenland ice cores, Journal of Geophysical Research: Atmospheres, 117, 2012.

Dahl-Jensen, D., Gundestrup, N. S., Miller, H., Watanabe, O., Johnsen, S. J., Steffensen, J. P., Clausen, H. B., Svensson, A., and Larsen, L. B.: The NorthGRIP deep drilling programme, Annals of Glaciology, 35, 1-4, doi: 10.3189/172756402781817275, 2002.

Dahl-Jensen, D., Albert, M. R., Aldahan, A., Azuma, N., BalslevClausen, D., Baumgartner, M., Berggren, A. M., Bigler, M., Binder, T., Blunier, T., Bourgeois, J. C., Brook, E. J., Buchardt, S. L., Buizert, C., Capron, E., Chappellaz, J., Chung, J., Clausen, H. B., Cvijanovic, I., Davies, S. M., Ditlevsen, P., Eicher, O., Fischer, H., Fisher, D. A., Fleet, L. G., Gfeller, G., Gkinis, V., Gogineni, S., Goto-Azuma, K., Grinsted, A., Gudlaugsdottir, H., Guillevic, M., Hansen, S. B., Hansson, M., Hirabayashi, M., Hong, S., Hur, S. D., Huybrechts, P., Hvidberg, C. S., Iizuka, Y., Jenk, T., Johnsen, S. J., Jones, T. R., Jouzel, J., Karlsson, N. B., Kawamura, K., Keegan, K., Kettner, E., Kipfstuhl, S., Kjær, H. A., Koutnik, M., Kuramoto, T., Köhler, P., Laepple, T., Landais, A., Langen, P. L., Larsen, L. B., Leuenberger, D., Leuenberger, M., Leuschen, C., Li, J., Lipenkov, V., Martinerie, P., Maselli, O. J., Masson-Delmotte, V., McConnell, J. R., Miller, H., Mini, O., Miyamoto, A., Montagnat-Rentier, M., Mulvaney, R., Muscheler, R., Orsi, A. J., Paden, J., Panton, C., Pattyn, F., Petit, J. R., Pol, K., Popp, T., Possnert, G., Prié, F., Prokopiou, M., Quiquet, A., Rasmussen, S. O., Raynaud, D., Ren, J., Reutenauer, C., Ritz, C., Röckmann, T., Rosen, J. L., Rubino, M., Rybak, O., Samyn, D., Sapart, C. J., Schilt, A., Schmidt, A. M. Z., Schwander, J., Schüpbach, S., Seierstad, I., Severinghaus, J. P., Sheldon, S., Simonsen, S. B., Sjolte, J., Solgaard, A. M., Sowers, T., Sperlich, P., Steen-Larsen, H. C., Steffen, K., Steffensen, J. P., Steinhage, D., Stocker, T. F., Stowasser, C., Sturevik, A. S., Sturges, W. T., Sveinbjörnsdottir, A., Svensson, A., Tison, J. L., Uetake, J., Vallelonga, P., van de Wal, R. S. W., van der Wel, G., Vaughn, B. H., Vinther, B., Waddington, E., Wegner, A., Weikusat, I., White, J. W. C., Wilhelms, F., Winstrup, M., Witrant, E., Wolff, E. W., Xiao, C., and Zheng, $\mathrm{J}$.: Eemian interglacial reconstructed from a Greenland folded ice core, Nature, 493, 489 EP -, URL https://doi.org/10.1038/ nature11789, 2013.

Dahl-Jensen, D., Kirk, M., Koldtoft, I., Popp, T., and P, S. J.: Field season 2019 East GReenland Ice core Project (EGRIP) 2015-2020: Third year of EGRIP deep drilling, URL https://eastgrip.nbi.ku.dk/documentation/2019/ EGRIP2019FieldPlan_1stVersion.pdf, 2019.

Davies, S. M.: Cryptotephras: the revolution in correlation and precision dating, Journal of Quaternary Science, 30, 114-130, doi: 10.1002/jqs.2766, URL https://onlinelibrary.wiley.com/ doi/abs/10.1002/jqs.2766, 2015.

De'er, Z.: A Compendium of Chinese Meteorological Records of the Last 3,000 Years, Nanjing: Phoenix Publishing House, Jiangsu Education Publishing House, 2004.
Dove, M. R.: Anthropology of Climate Change: An Historical Reader, Wiley Sons, Chichester, UK, 2014.

Drews, R.: Imprints of ice dynamics and atmospheric signals on the internal structure of Antarctic ice as seen via radar, Ph.D. thesis, University Bremen, 2011.

Drews, R., Eisen, O., Weikusat, I., Kipfstuhl, S., Lambrecht, A., Steinhage, D., Wilhelms, F., and Miller, H.: Layer disturbances and the radio-echo free zone in ice sheets, The Cryosphere, 3, 195-203, doi: 10.5194/tc-3-195-2009, URL https://www. the-cryosphere.net/3/195/2009/, 2009.

Dunbar, N. W., Iverson, N. A., Van Eaton, A. R., Sigl, M., Alloway, B. V., Kurbatov, A. V., Mastin, L. G., McConnell, J. R., and Wilson, C. J.: New Zealand supereruption provides time marker for the Last Glacial Maximum in Antarctica, Scientific reports, 7, 18, 2017.

Eichler, J., Weikusat, I., and Kipfstuhl, S.: (Fig. 21) Orientationtensor eigenvalues along the NEEM ice core, PANGAEA, doi: 10.1594/PANGAEA.838059, URL https://doi.org/10.1594/ PANGAEA.838059, in supplement to: Eichler, Jan (2013): Caxis analysis of the NEEM ice core - An approach based on Digital Image Processing. Diploma Thesis, Fachbereich Physik, Freie Universität Berlin, 73 pp, hdl:10013/epic.41621.d001, 2013.

Eisen, O.: Inference of velocity pattern from isochronous layers in firn, using an inverse method, Journal of Glaciology, 54, 613-630, doi: 10.3189/002214308786570818, 2008.

Eisen, O., Nixdorf, U., Wilhelms, F., and Miller, H.: Age estimates of isochronous reflection horizons by combining ice core, survey, and synthetic radar data, Journal of Geophysical Research: Solid Earth (1978-2012), 109, doi: 10.1029/2003JB002858, URL https://doi.org/10.1029/2003JB002858, 2004.

Eisen, O., Wilhelms, F., Steinhage, D., and Schwander, J.: Improved method to determine radio-echo sounding reflector depths from ice-core profiles of permittivity and conductivity, Journal of Glaciology, 52, 299-310, doi: 10.3189/172756506781828674, 2006.

Eisen, O., Hamann, I., Kipfstuhl, S., Steinhage, D., and Wilhelms, F.: Direct evidence for continuous radar reflector originating from changes in crystal-orientation fabric, The Cryosphere, 1, 1-10, doi: 10.5194/tc-1-1-2007, URL https:// www.the-cryosphere.net/1/1/2007/, 2007.

Erdkamp, P.: The grain market in the Roman Empire: a social, political and economic study, Cambridge University Press, 2005.

Esper, J., Düthorn, E., Krusic, P. J., Timonen, M., and Buentgen, U.: Northern European summer temperature variations over the Common Era from integrated tree-ring density records, Journal of Quaternary Science, 29, 487-494, 2014. 
Fahnestock, M., Bindschadler, R., Kwok, R., and Jezek, K.: Greenland Ice Sheet Surface Properties and Ice Dynamics from ERS1 SAR Imagery, Science, 262, 1530-1534, doi: 10.1126/science. 262.5139.1530, URL https://science.sciencemag.org/content/ 262/5139/1530, 1993.

Fahnestock, M. A., Joughin, I., Scambos, T. A., Kwok, R., Krabill, W. B., and Gogineni, S.: Ice-stream-related patterns of ice flow in the interior of northeast Greenland, Journal of Geophysical Research: Atmospheres, 106, 34 035-34 045, doi: 10.1029/2001JD900194, URL https://agupubs.onlinelibrary. wiley.com/doi/abs/10.1029/2001JD900194, 2001.

Fischer, H., Severinghaus, J., Brook, E., Wolff, E., Albert, M., Alemany, O., Arthern, R., Bentley, C., Blankenship, D., Chappellaz, J., Creyts, T., Dahl-Jensen, D., Dinn, M., Frezzotti, M., Fujita, S., Gallee, H., Hindmarsh, R., Hudspeth, D., Jugie, G., Kawamura, K., Lipenkov, V., Miller, H., Mulvaney, R., Parrenin, F., Pattyn, F., Ritz, C., Schwander, J., Steinhage, D., van Ommen, T., and Wilhelms, F.: Where to find 1.5 million yr old ice for the IPICS "Oldest-Ice" ice core, Climate of the Past, 9, 2489-2505, doi: 10.5194/cp-9-2489-2013, URL https://www. clim-past.net/9/2489/2013/, 2013.

Forsyth, P.: In the wake of Etna, 44 BC, Classical Antiquity, 7, 49$57,1988$.

Franke, S., Jansen, D., Binder, T., Dörr, N., Helm, V., Paden, J., Steinhage, D., and Eisen, O.: Bed topography and subglacial landforms in the onset region of the Northeast Greenland Ice Stream, Annals of Glaciology, 61, 143-153, doi: 10.1017/aog. 2020.12, 2020.

Fujita, S. and Mae, S.: Causes and nature of ice-sheet radioecho internal reflections estimated from the dielectric properties of ice, Annals of Glaciology, 20, 80-86, doi: 10.3189/ 1994AoG20-1-80-86, 1994.

Fujita, S., Mae, S., and Matsuoka, T.: Dielectric anisotropy in ice Ih at $9.7 \mathrm{GHz}$, Annals of Glaciology, 17, 276-280, doi: 10.3189/ S0260305500012969, 1993.

Fujita, S., Maeno, H., Uratsuka, S., Furukawa, T., Mae, S., Fujii, Y., and Watanabe, O.: Nature of radio echo layering in the Antarctic Ice Sheet detected by a two-frequency experiment, Journal of Geophysical Research: Solid Earth, 104, 13 01313 024, doi: 10.1029/1999JB900034, URL https://agupubs. onlinelibrary.wiley.com/doi/abs/10.1029/1999JB900034, 1999.

Fujita, S., Matsuoka, T., Ishida, T., Matsuoka, K., and Mae, S.: A summary of the complex dielectric permittivity of ice in the megahertz range and its applications for radar sounding of polar ice sheets, in: Physics of Ice Core Records, pp. 185-212, Hokkaido University Press, URL http://hdl.handle.net/2115/ $32469,2000$.

Fyfe, J. C., von Salzen, K., Gillett, N. P., Arora, V. K., Flato, G. M., and McConnell, J. R.: One hundred years of Arctic surface temperature variation due to anthropogenic influence, Scientific Reports, 3, 2645, doi: 10.1038/srep02645, URL https:// doi.org/10.1038/srep02645, 2013.

Gao, C., Robock, A., and Ammann, C.: Volcanic forcing of climate over the past 1500 years: An improved ice core-based index for climate models, Journal of Geophysical Research: Atmospheres, 113, 2008.

Garnsey, P.: Famine and food supply in the Graeco-Roman world: responses to risk and crisis, Cambridge University Press, 1989.

GEBCO: General Bathymetric Chart of the Oceans (GEBCO), URL https://www.gebco.net/data_and_products/gridded_ bathymetry_data/version_20141103/, 2014.

Gfeller, G., Fischer, H., Bigler, M., Schüpbach, S., Leuenberger, D., and Mini, O.: Representativeness and seasonality of major ion records derived from NEEM firn cores, The Cryosphere, 8, 1855-1870, doi: 10.5194/tc-8-1855-2014, URL https://www. the-cryosphere.net/8/1855/2014/, 2014.

Goosse, H., Kay, J. E., Armour, K. C., Bodas-Salcedo, A., Chepfer, H., Docquier, D., Jonko, A., Kushner, P. J., Lecomte, O., Massonnet, F., Park, H.-S., Pithan, F., Svensson, G., and Vancoppenolle, M.: Quantifying climate feedbacks in polar regions, Nature Communications, 9, 1919, doi: 10.1038/s41467-018-04173-0, URL https://doi.org/10. 1038/s41467-018-04173-0, 2018.

Hale, R., Miller, H., Gogineni, S., Yan, J. B., Leuschen, C., Paden, J., and Li, J.: MULTI-CHANNEL ULTRA-WIDEBAND RADAR SOUNDER AND IMAGER Center for Remote Sensing of Ice Sheets , University of Kansas Alfred Wegener Institute, Germany, 2016 IEEE International Geoscience and Remote Sensing Symposium (IGARSS), 2016.

Hammer, C. U.: Acidity of Polar Ice Cores in Relation to Absolute Dating, Past Volcanism, and Radio-Echoes, Journal of Glaciology, 25, 359-372, doi: 10.3189/S0022143000015227, 1980.

Harper, K.: In the shadow of Caesar, Lapham's Q, 12, 210-217, 2019.

Hayward, C.: High spatial resolution electron probe microanalysis of tephras and melt inclusions without beam-induced chemical modification, The Holocene, 22, 119-125, doi: 10.1177/0959683611409777, URL https://doi.org/10.1177/0959683611409777, 2012.

Hempel, L., Thyssen, F., Gundestrup, N., Clausen, H. B., and Miller, H.: A comparison of radio-echo sounding data and electrical conductivity of the GRIP ice core, Journal of Glaciology, 46, 369-374, doi: 10.3189/172756500781833070, 2000.

Hurrell, J. W., Holland, M. M., Gent, P. R., Ghan, S., Kay, J. E., Kushner, P. J., Lamarque, J.-F., Large, W. G., Lawrence, D., Lindsay, K., et al.: The community earth system model: a framework for collaborative research, Bulletin of the American Meteorological Society, 94, 1339-1360, 2013. 
Jensen, B. J. L., Beaudoin, A. B., Clynne, M. A., Harvey, J., and Vallance, J. W.: A re-examination of the three most prominent Holocene tephra deposits in western Canada: Bridge River, Mount St. Helens Yn and Mazama, Quaternary International, 500, 83 - 95, doi: https://doi.org/10.1016/j.quaint.2019.03. 017, URL http://www.sciencedirect.com/science/article/pii/ S1040618218311911, 2019.

Jones, J. M., Gille, S. T., Goosse, H., Abram, N. J., Canziani, P. O., Charman, D. J., Clem, K. R., Crosta, X., de Lavergne, C., Eisenman, I., England, M. H., Fogt, R. L., Frankcombe, L. M., Marshall, G. J., Masson-Delmotte, V., Morrison, A. K., Orsi, A. J., Raphael, M. N., Renwick, J. A., Schneider, D. P., Simpkins, G. R., Steig, E. J., Stenni, B., Swingedouw, D., and Vance, T. R.: Assessing recent trends in high-latitude Southern Hemisphere surface climate, Nature Climate Change, 6, 917926, doi: 10.1038/nclimate3103, URL https://doi.org/10.1038/ nclimate3103, 2016.

Joos, F. and Spahni, R.: Rates of change in natural and anthropogenic radiative forcing over the past 20,000 years, Proceedings of the National Academy of Sciences, 105, 1425-1430, 2008.

Jordan, R., Picardi, G., Plaut, J., Wheeler, K., Kirchner, D., Safaeinili, A., Johnson, W., Seu, R., Calabrese, D., Zampolini, E., Cicchetti, A., Huff, R., Gurnett, D., Ivanov, A., Kofman, W., Orosei, R., Thompson, T., Edenhofer, P., and Bombaci, O.: The Mars express MARSIS sounder instrument, Planetary and Space Science, 57, 1975 - 1986, doi: https://doi.org/10.1016/j. pss.2009.09.016, URL http://www.sciencedirect.com/science/ article/pii/S0032063309002803, 2009.

Joughin, I., Smith, B. E., Howat, I. M., Scambos, T., and Moon, T.: Greenland flow variability from ice-sheet-wide velocity mapping, Journal of Glaciology, 56, 415-430, doi: 10.3189/ 002214310792447734, 2010.

Joughin, I., Smith, B. E., and Howat, I. M.: A complete map of Greenland ice velocity derived from satellite data collected over 20 years, Journal of Glaciology, 64, 1-11, doi: 10.1017/jog.2017. 73, 2018.

Karlsson, N. B., Eisen, O., Dahl-Jensen, D., Freitag, J., Kipfstuhl, S., Lewis, C., Nielsen, L. T., Paden, J. D., Winter, A., and Wilhelms, F.: Accumulation Rates during 1311-2011 CE in North-Central Greenland Derived from Air-Borne Radar Data, Frontiers in Earth Science, 4, 97, doi: 10.3389/feart.2016.00097, URL https: //www.frontiersin.org/article/10.3389/feart.2016.00097, 2016.

Karlsson, N. B., Razik, S., Hörhold, M., Winter, A., Steinhage, D., Binder, T., and Eisen, O.: Surface accumulation in Northern Central Greenland during the last 300 years, Annals of Glaciology, p. 1-11, doi: 10.1017/aog.2020.30, 2020.

Kjær, K. H., Larsen, N. K., Binder, T., Bjørk, A. A., Eisen, O., Fahnestock, M. A., Funder, S., Garde, A. A., Haack, H., Helm, V., Houmark-Nielsen, M., Kjeldsen, K. K., Khan, S. A., Machguth, H., McDonald, I., Morlighem, M., Mouginot, J.,
Paden, J. D., Waight, T. E., Weikusat, C., Willerslev, E., and MacGregor, J. A.: A large impact crater beneath Hiawatha Glacier in northwest Greenland, Science Advances, 4, doi: 10.1126/sciadv. aar8173, URL https://advances.sciencemag.org/content/4/11/ eaar8173, 2018

Kuehn, S. C., Froese, D. G., Shane, P. A., and Participants, I. I.: The INTAV intercomparison of electron-beam microanalysis of glass by tephrochronology laboratories: results and recommendations, Quaternary International, 246, 19-47, 2011.

Kutterolf, S., Freundt, A., Perez, W., Mörz, T., Schacht, U., Wehrmann, H., and Schmincke, H.-U.: Pacific offshore record of plinian arc volcanism in Central America: 1. Along-arc correlations, Geochemistry, Geophysics, Geosystems, 9, 2008.

Kutterolf, S., Freundt, A., and Burkert, C.: Eruptive history and magmatic evolution of the $1.9 \mathrm{kyr}$ Plinian dacitic Chiltepe Tephra from Apoyeque volcano in west-central Nicaragua, Bulletin of Volcanology, 73, 811-831, 2011.

LaMarche, V. C. and Hirschboeck, K. K.: Frost rings in trees as records of major volcanic eruptions, Nature, 307, 121-126, 1984.

Larsen, J. F., Neal, C., Schaefer, J., Beget, J., and Nye, C.: Late Pleistocene and Holocene caldera-forming eruptions of Okmok caldera, Aleutian islands, Alaska, GMS, 172, 343-364, 2007.

Larsen, N. K., Levy, L. B., Carlson, A. E., Buizert, C., Olsen, J., Strunk, A., Bjørk, A. A., and Skov, D. S.: Instability of the Northeast Greenland Ice Stream over the last 45,000 years, Nature Communications, 9, 1872, doi: 10.1038/s41467-018-04312-7, URL https://doi.org/10.1038/s41467-018-04312-7, 2018.

Li, J., Vélez González, J. A., Leuschen, C., Harish, A., Gogineni, P., Montagnat, M., Weikusat, I., Rodriguez-Morales, F., and Paden, J.: Multi-channel and multi-polarization radar measurements around the NEEM site, The Cryosphere, 12, 2689-2705, doi: 10.5194/tc-12-2689-2018, URL https://www. the-cryosphere.net/12/2689/2018/, 2018.

Luterbacher, J., Werner, J. P., Smerdon, J. E., Fernández-Donado, L., González-Rouco, F. J., Barriopedro, D., Ljungqvist, F. C., Büntgen, U., Zorita, E., Wagner, S., et al.: European summer temperatures since Roman times, Environmental research letters, 11, 024 001, 2016.

MacGregor, J. A., Fahnestock, M. A., Catania, G. A., Paden, J. D., Prasad Gogineni, S., Young, S. K., Rybarski, S. C., Mabrey, A. N., Wagman, B. M., and Morlighem, M.: Radiostratigraphy and age structure of the Greenland Ice Sheet, Journal of Geophysical Research: Earth Surface, 120, 212-241, doi: 10.1002/ 2014JF003215, URL https://agupubs.onlinelibrary.wiley.com/ doi/abs/10.1002/2014JF003215, 2015.

McConnell, J. R., Lamorey, G. W., Lambert, S. W., and Taylor, K. C.: Continuous ice-core chemical analyses using inductively coupled plasma mass spectrometry, Environmental science \& technology, 36, 7-11, 2002. 
McConnell, J. R., Burke, A., Dunbar, N. W., Köhler, P., Thomas, J. L., Arienzo, M. M., Chellman, N. J., Maselli, O. J., Sigl, M., Adkins, J. F., et al.: Synchronous volcanic eruptions and abrupt climate change $17.7 \mathrm{ka}$ plausibly linked by stratospheric ozone depletion, Proceedings of the National Academy of Sciences, 114, $10035-10040,2017$.

McConnell, J. R., Wilson, A. I., Stohl, A., Arienzo, M. M., Chellman, N. J., Eckhardt, S., Thompson, E. M., Pollard, A. M., and Steffensen, J. P.: Lead pollution recorded in Greenland ice indicates European emissions tracked plagues, wars, and imperial expansion during antiquity, Proceedings of the National Academy of Sciences, 115, 5726-5731, 2018.

McConnell, J. R., Chellman, N. J., Wilson, A. I., Stohl, A., Arienzo, M. M., Eckhardt, S., Fritzsche, D., Kipfstuhl, S., Opel, T., Place, P. F., et al.: Pervasive Arctic lead pollution suggests substantial growth in medieval silver production modulated by plague, climate, and conflict, Proceedings of the National Academy of Sciences, 116, 14910-14 915, 2019.

McConnell, J. R., Sigl, M., Plunkett, G., Burke, A., Kim, W. M., Raible, C. C., Wilson, A. I., Manning, J. G., Ludlow, F., Chellman, N. J., Innes, H. M., Yang, Z., Larsen, J. F., Schaefer, J. R., Kipfstuhl, S., Mojtabavi, S., Wilhelms, F., Opel, T., Meyer, H., and Steffensen, J. P.: Extreme climate after massive eruption of Alaska's Okmok volcano in $43 \mathrm{BCE}$ and effects on the late Roman Republic and Ptolemaic Kingdom, Proceedings of the National Academy of Sciences, 117, 15 443-15 449, doi: 10. 1073/pnas.2002722117, URL https://www.pnas.org/content/ 117/27/15443, 2020.

Melesse, A., Awulachew, S. B., and McCornick, P. G.: Introduction: hydrology of the Niles in the face of climate and land-use dynamics, 2011.

Meredith, M., Sommerkorn, M., Cassotta, S., Derksen, C., Ekaykin, A., Hollowed, A., Kofinas, G., Mackintosh, A., MelbournThomas, J., Muelbert, M., et al.: Polar Regions. In: IPCC Special Report on the Ocean and Cryosphere in a Changing Climate [H.-O. Portner, D.C. Roberts, V. Masson-Delmotte, P. Zhai, M. Tignor, E. Poloczanska, K. Mintenbeck, A. Alegria, M. Nicolai, A. Okem, J. Petzold, B. Rama, N.M. Weyer (eds.)]. In press., 2019.

Milillo, P., Rignot, E., Rizzoli, P., Scheuchl, B., Mouginot, J., Bueso-Bello, J., and Prats-Iraola, P.: Heterogeneous retreat and ice melt of Thwaites Glacier, West Antarctica, Science Advances, 5, doi: 10.1126/sciadv.aau3433, URL https://advances. sciencemag.org/content/5/1/eaau3433, 2019.

Millar, D. H. M.: Acidity Levels in Ice Sheets from Radio EchoSounding, Annals of Glaciology, 3, 199-203, doi: 10.3189/ S0260305500002779, 1982.

Miners, W. D., Wolff, E. W., Moore, J. C., Jacobel, R., and Hempel, L.: Modeling the radio echo reflections inside the ice sheet at Summit, Greenland, Journal of Geophysical Research: Solid Earth, 107, EPM 6-1-EPM 6-11, doi:
10.1029/2001JB000535, URL https://agupubs.onlinelibrary. wiley.com/doi/abs/10.1029/2001JB000535, 2002.

Mojtabavi, S. and Wilhelms, F.: Specific conductivity measured with the dielectric profiling (DEP) technique on the EGRIP ice core, 1383.84-2122.445 m depth, PANGAEA, doi: 10.1594/PANGAEA.922285, URL https://doi.pangaea.de/10. 1594/PANGAEA.922285, in supplement to: Mojtabavi, Seyedhamidreza; Eisen, Olaf; Franke, Steven; Jansen, Daniela; Steinhage, Daniel; Paden, John D; Dahl-Jensen, Dorthe; Wilhelms, Frank(in prep.): Deep insights to the Greenland ice sheet by linking multichannel ultra-wide-band radar surveys to the latest deep ice cores by synthetic radar modelling., 2020a.

Mojtabavi, S. and Wilhelms, F.: Permittivity measured with the dielectric profiling (DEP) technique on the EGRIP ice core, 1383.84-2122.445 $\mathrm{m}$ depth, PANGAEA, doi: 10.1594/PANGAEA.922299, URL https://doi.pangaea.de/10.1594/PANGAEA.922299, in supplement to: Mojtabavi, Seyedhamidreza; Eisen, Olaf; Franke, Steven; Jansen, Daniela; Steinhage, Daniel; Paden, John D; Dahl-Jensen, Dorthe; Wilhelms, Frank(in prep.): Deep insights to the Greenland ice sheet by linking multichannel ultra-wide-band radar surveys to the latest deep ice cores by synthetic radar modelling., $2020 \mathrm{~b}$.

Mojtabavi, S. and Wilhelms, F.: Specific conductivity measured with the dielectric profiling (DEP) technique on the NEEM ice core (1493.30- 1757.310 m depth), PANGAEA, doi: 10.1594/PANGAEA.922303, URL https://doi.pangaea.de/10. 1594/PANGAEA.922303, in supplement to: Mojtabavi, Seyedhamidreza; Eisen, Olaf; Franke, Steven; Jansen, Daniela; Steinhage, Daniel; Paden, John D; Dahl-Jensen, Dorthe; Wilhelms, Frank(in prep.): Deep insights to the Greenland ice sheet by linking multichannel ultra-wide-band radar surveys to the latest deep ice cores by synthetic radar modelling., 2020c.

Mojtabavi, S. and Wilhelms, F.: Permittivity measured with the dielectric profiling (DEP) technique on the NEEM ice core (1493.30- $1757.310 \mathrm{~m}$ depth), PANGAEA, doi: 10.1594/PANGAEA.922305, URL https://doi.pangaea.de/10.1594/PANGAEA.922305, in supplement to: Mojtabavi, Seyedhamidreza; Eisen, Olaf; Franke, Steven; Jansen, Daniela; Steinhage, Daniel; Paden, John D; Dahl-Jensen, Dorthe; Wilhelms, Frank(in prep.): Deep insights to the Greenland ice sheet by linking multichannel ultra-wide-band radar surveys to the latest deep ice cores by synthetic radar modelling., 2020d.

Mojtabavi, S. and Wilhelms, F.: Specific conductivity measured with the dielectric profiling (DEP) technique on the NGRIP2 ice core (down to $1298.525 \mathrm{~m}$ depth), PANGAEA, doi: 10.1594/PANGAEA.922306, URL https://doi.pangaea.de/10. 1594/PANGAEA.922306, in supplement to: Mojtabavi, Seyedhamidreza; Eisen, Olaf; Franke, Steven; Jansen, Daniela; Steinhage, Daniel; Paden, John D; Dahl-Jensen, Dorthe; Wilhelms, Frank(in prep.): Deep insights to the Greenland ice sheet by linking multichannel ultra-wide-band radar surveys to the latest deep ice cores by synthetic radar modelling., 2020e. 
Mojtabavi, S. and Wilhelms, F.: Permittivity measured with the dielectric profiling (DEP) technique on the NGRIP2 ice core (down to $1298.525 \mathrm{~m}$ depth), PANGAEA, doi: 10.1594/PANGAEA.922308, URL https://doi.pangaea.de/10. 1594/PANGAEA.922308, in supplement to: Mojtabavi, Seyedhamidreza; Eisen, Olaf; Franke, Steven; Jansen, Daniela; Steinhage, Daniel; Paden, John D; Dahl-Jensen, Dorthe; Wilhelms, Frank(in prep.): Deep insights to the Greenland ice sheet by linking multichannel ultra-wide-band radar surveys to the latest deep ice cores by synthetic radar modelling., $2020 \mathrm{f}$.

Mojtabavi, S. and Wilhelms, F.: Specific conductivity and permittivity of the Greenland ice sheet, PANGAEA, doi: 10.1594/PANGAEA.922310, URL https://doi.pangaea.de/10. 1594/PANGAEA.922310, in supplement to: Mojtabavi, Seyedhamidreza; Eisen, Olaf; Franke, Steven; Jansen, Daniela; Steinhage, Daniel; Paden, John D; Dahl-Jensen, Dorthe; Wilhelms, Frank(in prep.): Deep insights to the Greenland ice sheet by linking multichannel ultra-wide-band radar surveys to the latest deep ice cores by synthetic radar modelling., 2020g.

Mojtabavi, S. and Wilhelms, F.: Specific conductivity measured with the dielectric profiling (DEP) technique on the Talos Dome ice core, Antarctica, PANGAEA, doi: 10.1594/PANGAEA.922320, URL https://doi.pangaea.de/10.1594/PANGAEA.922320, 2020h.

Mojtabavi, S. and Wilhelms, F.: Permittivity measured with the dielectric profiling (DEP) technique on the Talos Dome ice core, Antarctica, PANGAEA, doi: 10.1594/PANGAEA.922322, URL https://doi.pangaea.de/10.1594/PANGAEA.922322, 2020i.

Mojtabavi, S., Eisen, O., Franke, S., Jansen, D., Steinhage, D., Paden, J., Dahl-Jensen, D., and Wilhelms, F.: Deep insights to the Greenland ice sheet by linking multichannel ultra-wideband radar surveys to the latest deep ice cores by synthetic radar modelling. (manuscript in preparation), 2020a.

Mojtabavi, S., Wilhelms, F., Cook, E., Davies, S., Sinnl, G., Skov Jensen, M., Dahl-Jensen, D., Svensson, A., Vinther, B., Kipfstuhl, S., Jones, G., Karlsson, N. B., Faria, S. H., Gkinis, V., Kjær, H., Erhardt, T., Berben, S. M. P., Nisancioglu, K. H., Koldtoft, I., and Rasmussen, S. O.: A first chronology for the East GReenland Ice-core Project (EGRIP) over the Holocene and last glacial termination, Climate of the Past (paper has been accepted), 2020, 1-22, doi: 10.5194/cp-2019-143, URL https: //www.clim-past-discuss.net/cp-2019-143/, 2020b.

Mojtabavi, S., Wilhelms, F., Cook, E., Davies, S., Sinnl, G., Skov Jensen, M., Dahl-Jensen, D., Svensson, A., Vinther, B., Kipfstuhl, S., Jones, G., Karlsson, N. B., Faria, S. H., Gkinis, V., Kjær, H., Erhardt, T., Berben, S. M. P., Nisancioglu, K. H., Koldtoft, I., and Rasmussen, S. O.: Interpolated time scale for the ice with GICC05 ages for each bag depth $(0.55 \mathrm{~m} \mathrm{seg-}$ ments) of the EGRIP core in the $13.7-1383.8 \mathrm{~m}$ depth interval, PANGAEA, doi: 10.1594/PANGAEA.922393, URL https: //doi.pangaea.de/10.1594/PANGAEA.922393, in supplement to: Mojtabavi, S. and Wilhelms, F. and Cook, E. and Davies, S. and Sinnl, G. and Skov Jensen, M. and Dahl-Jensen, D. and Svensson, A. and Vinther, B. and Kipfstuhl, S. and Jones, G. and Karlsson, N. B. and Faria, S. H. and Gkinis, V. and Kjær, H. and Erhardt, T. and Berben, S. M. P. and Nisancioglu, K. H. and Koldtoft, I. and Rasmussen, S. O.: A first chronology for the East GReenland Ice-core Project (EGRIP) over the Holocene and last glacial termination, Clim. Past Discuss., https://doi.org/10.5194/cp-2019-143, 2020c.

Mojtabavi, S., Wilhelms, F., Cook, E., Davies, S., Sinnl, G., Skov Jensen, M., Dahl-Jensen, D., Svensson, A., Vinther, B., Kipfstuhl, S., Jones, G., Karlsson, N. B., Faria, S. H., Gkinis, V., Kjær, H., Erhardt, T., Berben, S. M. P., Nisancioglu, K. H., Koldtoft, I., and Rasmussen, S. O.: Match points between the EGRIP core and the NGRIP2 core and corresponding GICC05 ages, PANGAEA, doi: 10.1594/PANGAEA.922350, URL https://doi.pangaea.de/10.1594/PANGAEA.922350, in supplement to: Mojtabavi, S. and Wilhelms, F. and Cook, E. and Davies, S. and Sinnl, G. and Skov Jensen, M. and DahlJensen, D. and Svensson, A. and Vinther, B. and Kipfstuhl, S. and Jones, G. and Karlsson, N. B. and Faria, S. H. and Gkinis, V. and Kjær, H. and Erhardt, T. and Berben, S. M. P. and Nisancioglu, K. H. and Koldtoft, I. and Rasmussen, S. O.: A first chronology for the East GReenland Ice-core Project (EGRIP) over the Holocene and last glacial termination, Clim. Past Discuss., https://doi.org/10.5194/cp-2019-143, 2020d.

Mojtabavi, S., Wilhelms, F., Cook, E., Davies, S., Sinnl, G., Skov Jensen, M., Dahl-Jensen, D., Svensson, A., Vinther, B., Kipfstuhl, S., Jones, G., Karlsson, N. B., Faria, S. H., Gkinis, V., Kjær, H., Erhardt, T., Berben, S. M. P., Nisancioglu, K. H., Koldtoft, I., and Rasmussen, S. O.: Match points between the EGRIP core and the NGRIP1 core and corresponding GICC05 ages, PANGAEA, doi: 10.1594/PANGAEA.922348, URL https://doi.pangaea.de/10.1594/PANGAEA.922348, in supplement to: Mojtabavi, S. and Wilhelms, F. and Cook, E. and Davies, S. and Sinnl, G. and Skov Jensen, M. and DahlJensen, D. and Svensson, A. and Vinther, B. and Kipfstuhl, S. and Jones, G. and Karlsson, N. B. and Faria, S. H. and Gkinis, V. and Kjær, H. and Erhardt, T. and Berben, S. M. P. and Nisancioglu, K. H. and Koldtoft, I. and Rasmussen, S. O.: A first chronology for the East GReenland Ice-core Project (EGRIP) over the Holocene and last glacial termination, Clim. Past Discuss., https://doi.org/10.5194/cp-2019-143, 2020e.

Mojtabavi, S., Wilhelms, F., Cook, E., Davies, S., Sinnl, G., Skov Jensen, M., Dahl-Jensen, D., Svensson, A., Vinther, B., Kipfstuhl, S., Jones, G., Karlsson, N. B., Faria, S. H., Gkinis, V., Kjær, H., Erhardt, T., Berben, S. M. P., Nisancioglu, K. H., Koldtoft, I., and Rasmussen, S. O.: Acidity measured with the Electrical Conductivity Method (ECM) on the EGRIP ice core (down to $1383.84 \mathrm{~m}$ depth), converted to hydrogen ion concentration, PANGAEA, doi: 10.1594/PANGAEA.922199, URL https://doi.pangaea.de/10.1594/PANGAEA.922199, in supplement to: Mojtabavi, S. and Wilhelms, F. and Cook, E. and Davies, S. and Sinnl, G. and Skov Jensen, M. and DahlJensen, D. and Svensson, A. and Vinther, B. and Kipfstuhl, S. 
and Jones, G. and Karlsson, N. B. and Faria, S. H. and Gkinis, V. and Kjær, H. and Erhardt, T. and Berben, S. M. P. and Nisancioglu, K. H. and Koldtoft, I. and Rasmussen, S. O.: A first chronology for the East GReenland Ice-core Project (EGRIP) over the Holocene and last glacial termination, Clim. Past Discuss., https://doi.org/10.5194/cp-2019-143, $2020 \mathrm{f}$.

Mojtabavi, S., Wilhelms, F., Cook, E., Davies, S., Sinnl, G., Skov Jensen, M., Dahl-Jensen, D., Svensson, A., Vinther, B., Kipfstuhl, S., Jones, G., Karlsson, N. B., Faria, S. H., Gkinis, V., Kjær, H., Erhardt, T., Berben, S. M. P., Nisancioglu, K. H., Koldtoft, I., and Rasmussen, S. O.: Permittivity measured with the dielectric profiling (DEP) technique on the NEEM ice core (down to $1493.295 \mathrm{~m}$ depth), PANGAEA, doi: 10.1594/PANGAEA.922195, URL https://doi.pangaea.de/10. 1594/PANGAEA.922195, in supplement to: Mojtabavi, S. and Wilhelms, F. and Cook, E. and Davies, S. and Sinnl, G. and Skov Jensen, M. and Dahl-Jensen, D. and Svensson, A. and Vinther, B. and Kipfstuhl, S. and Jones, G. and Karlsson, N. B. and Faria, S. H. and Gkinis, V. and Kjær, H. and Erhardt, T. and Berben, S. M. P. and Nisancioglu, K. H. and Koldtoft, I. and Rasmussen, S. O.: A first chronology for the East GReenland Ice-core Project (EGRIP) over the Holocene and last glacial termination, Clim. Past Discuss., https://doi.org/10.5194/cp-2019-143, 2020g.

Mojtabavi, S., Wilhelms, F., Cook, E., Davies, S., Sinnl, G., Skov Jensen, M., Dahl-Jensen, D., Svensson, A., Vinther, B., Kipfstuhl, S., Jones, G., Karlsson, N. B., Faria, S. H., Gkinis, V., Kjær, H., Erhardt, T., Berben, S. M. P., Nisancioglu, K. H., Koldtoft, I., and Rasmussen, S. O.: Specific conductivity measured with the dielectric profiling (DEP) technique on the NEEM ice core (down to $1493.295 \mathrm{~m}$ depth)), PANGAEA, doi: 10.1594/PANGAEA.922193, URL https://doi.pangaea.de/10. 1594/PANGAEA.922193, in supplement to: Mojtabavi, S. and Wilhelms, F. and Cook, E. and Davies, S. and Sinnl, G. and Skov Jensen, M. and Dahl-Jensen, D. and Svensson, A. and Vinther, B. and Kipfstuhl, S. and Jones, G. and Karlsson, N. B. and Faria, S. H. and Gkinis, V. and Kjær, H. and Erhardt, T. and Berben, S. M. P. and Nisancioglu, K. H. and Koldtoft, I. and Rasmussen, S. O.: A first chronology for the East GReenland Ice-core Project (EGRIP) over the Holocene and last glacial termination, Clim. Past Discuss., https://doi.org/10.5194/cp-2019-143, 2020h.

Mojtabavi, S., Wilhelms, F., Cook, E., Davies, S., Sinnl, G., Skov Jensen, M., Dahl-Jensen, D., Svensson, A., Vinther, B., Kipfstuhl, S., Jones, G., Karlsson, N. B., Faria, S. H., Gkinis, V., Kjær, H., Erhardt, T., Berben, S. M. P., Nisancioglu, K. H., Koldtoft, I., and Rasmussen, S. O.: Permittivity measured with the dielectric profiling (DEP) technique on the NGRIP1 ice core (down to $1371.69 \mathrm{~m}$ depth), PANGAEA, doi: 10.1594/PANGAEA.922192, URL https://doi.pangaea.de/10. 1594/PANGAEA.922192, in supplement to: Mojtabavi, S. and Wilhelms, F. and Cook, E. and Davies, S. and Sinnl, G. and Skov Jensen, M. and Dahl-Jensen, D. and Svensson, A. and Vinther, B. and Kipfstuhl, S. and Jones, G. and Karlsson, N. B. and Faria, S. H. and Gkinis, V. and Kjær, H. and Erhardt, T. and Berben, S. M. P. and Nisancioglu, K. H. and Koldtoft, I. and Rasmussen, S. O.: A first chronology for the East GReenland Ice-core Project
(EGRIP) over the Holocene and last glacial termination, Clim. Past Discuss., https://doi.org/10.5194/cp-2019-143, 2020i.

Mojtabavi, S., Wilhelms, F., Cook, E., Davies, S., Sinnl, G., Skov Jensen, M., Dahl-Jensen, D., Svensson, A., Vinther, B., Kipfstuhl, S., Jones, G., Karlsson, N. B., Faria, S. H., Gkinis, V., Kjær, H., Erhardt, T., Berben, S. M. P., Nisancioglu, K. H., Koldtoft, I., and Rasmussen, S. O.: Specific conductivity measured with the dielectric profiling (DEP) technique on the NGRIP1 ice core (down to $1371.69 \mathrm{~m}$ depth), PANGAEA, doi: 10.1594/PANGAEA.922191, URL https://doi.pangaea.de/10. 1594/PANGAEA.922191, in supplement to: Mojtabavi, S. and Wilhelms, F. and Cook, E. and Davies, S. and Sinnl, G. and Skov Jensen, $M$. and Dahl-Jensen, D. and Svensson, A. and Vinther, B. and Kipfstuhl, S. and Jones, G. and Karlsson, N. B. and Faria, S. H. and Gkinis, V. and Kjær, H. and Erhardt, T. and Berben, S. M. P. and Nisancioglu, K. H. and Koldtoft, I. and Rasmussen, S. O.: A first chronology for the East GReenland Ice-core Project (EGRIP) over the Holocene and last glacial termination, Clim. Past Discuss., https://doi.org/10.5194/cp-2019-143, 2020j.

Mojtabavi, S., Wilhelms, F., Cook, E., Davies, S., Sinnl, G., Skov Jensen, M., Dahl-Jensen, D., Svensson, A., Vinther, B., Kipfstuhl, S., Jones, G., Karlsson, N. B., Faria, S. H., Gkinis, V., Kjær, H., Erhardt, T., Berben, S. M. P., Nisancioglu, K. H., Koldtoft, I., and Rasmussen, S. O.: Chronology for the East GReenland Ice-core Project (EGRIP), PANGAEA, doi: 10.1594/PANGAEA.922139, URL https://doi.pangaea.de/10. 1594/PANGAEA.922139, in supplement to: Mojtabavi, S. and Wilhelms, F. and Cook, E. and Davies, S. and Sinnl, G. and Skov Jensen, M. and Dahl-Jensen, D. and Svensson, A. and Vinther, B. and Kipfstuhl, S. and Jones, G. and Karlsson, N. B. and Faria, S. H. and Gkinis, V. and Kjær, H. and Erhardt, T. and Berben, S. M. P. and Nisancioglu, K. H. and Koldtoft, I. and Rasmussen, S. O.: A first chronology for the East GReenland Ice-core Project (EGRIP) over the Holocene and last glacial termination, Clim. Past Discuss., https://doi.org/10.5194/cp-2019-143, 2020k.

Mojtabavi, S., Wilhelms, F., Cook, E., Davies, S., Sinnl, G., Skov Jensen, M., Dahl-Jensen, D., Svensson, A., Vinther, B., Kipfstuhl, S., Jones, G., Karlsson, N. B., Faria, S. H., Gkinis, V., Kjær, H., Erhardt, T., Berben, S. M. P., Nisancioglu, K. H., Koldtoft, I., and Rasmussen, S. O.: Permittivity measured with the dielectric profiling (DEP) technique on the EGRIP ice core, 13.77-1383.84 m depth), PANGAEA, doi: 10.1594/PANGAEA.922138, URL https://doi.pangaea.de/10. 1594/PANGAEA.922138, in supplement to: Mojtabavi, S. and Wilhelms, F. and Cook, E. and Davies, S. and Sinnl, G. and Skov Jensen, $M$. and Dahl-Jensen, D. and Svensson, A. and Vinther, B. and Kipfstuhl, S. and Jones, G. and Karlsson, N. B. and Faria, S. H. and Gkinis, V. and Kjær, H. and Erhardt, T. and Berben, S. M. P. and Nisancioglu, K. H. and Koldtoft, I. and Rasmussen, S. O.: A first chronology for the East GReenland Ice-core Project (EGRIP) over the Holocene and last glacial termination, Clim. Past Discuss., https://doi.org/10.5194/cp-2019-143, 20201.

Mojtabavi, S., Wilhelms, F., Cook, E., Davies, S., Sinnl, G., Skov Jensen, M., Dahl-Jensen, D., Svensson, A., Vinther, B., 
Kipfstuhl, S., Jones, G., Karlsson, N. B., Faria, S. H., Gkinis, V., Kjær, H., Erhardt, T., Berben, S. M. P., Nisancioglu, K. H., Koldtoft, I., and Rasmussen, S. O.: Specific conductivity measured with the dielectric profiling (DEP) technique on the EGRIP ice core, 13.77-1383.84 m depth, PANGAEA, doi: 10.1594/PANGAEA.919313, URL https://doi.pangaea.de/10. 1594/PANGAEA.919313, in supplement to: Mojtabavi, S. and Wilhelms, F. and Cook, E. and Davies, S. and Sinnl, G. and Skov Jensen, M. and Dahl-Jensen, D. and Svensson, A. and Vinther, B. and Kipfstuhl, S. and Jones, G. and Karlsson, N. B. and Faria, S. H. and Gkinis, V. and Kjær, H. and Erhardt, T. and Berben, S. M. P. and Nisancioglu, K. H. and Koldtoft, I. and Rasmussen, S. O.: A first chronology for the East GReenland Ice-core Project (EGRIP) over the Holocene and last glacial termination, Clim. Past Discuss., https://doi.org/10.5194/cp-2019-143, 2020m.

Montagnat, M., Azuma, N., Dahl-Jensen, D., Eichler, J., Fujita, S., Gillet-Chaulet, F., Kipfstuhl, S., Samyn, D., Svensson, A., and Weikusat, I.: Fabric along the NEEM ice core, Greenland, and its comparison with GRIP and NGRIP ice cores, The Cryosphere, 8, 1129-1138, doi: 10.5194/tc-8-1129-2014, URL https://www. the-cryosphere.net/8/1129/2014/, 2014.

Moore, J. and Paren, J.: A new technique for dielectric logging of Antarctic ice cores, Journal de Physique Colloques, 48, C1155-C1-160, doi: 10.1051/jphyscol:1987123, URL https://hal. archives-ouvertes.fr/jpa-00226268, 1987.

Moore, J. C., Wolff, E. W., Clausen, H. B., and Hammer, C. U.: The chemical basis for the electrical stratigraphy of ice, Journal of Geophysical Research: Solid Earth, 97, 1887-1896, doi: 10.1029/91JB02750, URL https://agupubs.onlinelibrary.wiley. com/doi/abs/10.1029/91JB02750, 1992.

Moore, J. C., Wolff, E. W., Clausen, H. B., Hammer, C. U., Legrand, M. R., and Fuhrer, K.: Electrical response of the Summit-Greenland ice core to ammonium, sulphuric acid, and hydrochloric acid, grl, 21, 565-568, doi: 10.1029/94GL00542, 1994.

Mortensen, A. K., Bigler, M., Grönvold, K., Steffensen, J. P., and Johnsen, S. J.: Volcanic ash layers from the Last Glacial Termination in the NGRIP ice core, Journal of Quaternary Science, 20, 209-219, doi: 10.1002/jqs.908, URL https://onlinelibrary. wiley.com/doi/abs/10.1002/jqs.908, 2005.

Najafi, M. R., Zwiers, F. W., and Gillett, N. P.: Attribution of Arctic temperature change to greenhouse-gas and aerosol influences, Nature Climate Change, 5, 246-249, doi: 10.1038/nclimate2524, URL https://doi.org/10.1038/ nclimate2524, 2015.

Navarro, F. and Eisen, O.: 11. Ground-penetrating radar in glaciological applications, 2009.

Neff, P. D.: A review of the brittle ice zone in polar ice cores, Annals of Glaciology, 55, 72-82, 2014.
Nicolas, J. P. and Bromwich, D. H.: New Reconstruction of Antarctic Near-Surface Temperatures: Multidecadal Trends and Reliability of Global Reanalyses, Journal of Climate, 27, 80708093, doi: 10.1175/JCLI-D-13-00733.1, URL https://doi.org/ 10.1175/JCLI-D-13-00733.1, 2014.

Notz, D. and Stroeve, J.: Observed Arctic sea-ice loss directly follows anthropogenic CO2 emission, Science, 354, 747-750, doi: 10.1126/science.aag2345, URL https://science.sciencemag.org/ content/354/6313/747, 2016.

Oerter, H.: Klimaschwankungen: Daten aus Eisbohrkernen in der Antarktis und ihre Interpretation, 2009.

Oman, L., Robock, A., Stenchikov, G. L., and Thordarson, T.: High-latitude eruptions cast shadow over the African monsoon and the flow of the Nile, Geophysical Research Letters, 33, 2006.

Opel, T., Fritzsche, D., and Meyer, H.: Eurasian Arctic climate over the past millennium as recorded in the Akademii Nauk ice core (Severnaya Zemlya), Climate of the Past, 9, 2379-2389, 2013.

O’hare, P., Mekhaldi, F., Adolphi, F., Raisbeck, G., Aldahan, A., Anderberg, E., Beer, J., Christl, M., Fahrni, S., Synal, H.-A., et al.: Multiradionuclide evidence for an extreme solar proton event around 2,610 BP ( $660 \mathrm{BC}$ ), Proceedings of the National Academy of Sciences, 116, 5961-5966, 2019.

Paren, J. G. and Robin, G. d. Q.: Internal Reflections in Polar Ice Sheets, Journal of Glaciology, 14, 251-259, doi: 10.3189/ S0022143000021730, 1975.

Perkins, M. E., Nash, W. P., Brown, F. H., and Fleck, R. J.: Fallout tuffs of Trapper Creek, Idaho-A record of Miocene explosive volcanism in the Snake River Plain volcanic province, Bulletin of the Geological Society of America, 107, 1484-1506, doi: 10.1130/0016-7606(1995)107<1484:FTOTCI>2.3.CO;2, 1995.

Perkins, M. E., Brown, F. H., Nash, W. P., Williams, S. K., and Mclntosh, W.: Sequence, age, and source of silicic fallout tuffs in middle to late Miocene basins of the northern Basin and Range province, Bulletin of the Geological Society of America, 110, 344-360, doi: 10.1130/0016-7606(1998)110<0344:SAASOS> 2.3.CO;2, 1998.

Pithan, F. and Mauritsen, T.: Arctic amplification dominated by temperature feedbacks in contemporary climate models, Nature Geoscience, 7, 181-184, doi: 10.1038/ngeo2071, URL https: //doi.org/10.1038/ngeo2071, 2014.

Plummer, C. T., Curran, M. A., van Ommen, T. D., Rasmussen, S. O., Moy, A. D., Vance, T. R., Clausen, H. B., Vinther, B. M., and Mayewski, P. A.: An independently dated 2000-yr volcanic record from Law Dome, East Antarctica, including a new perspective on the dating of the 1450 s CE eruption of Kuwae, Vanuatu, Climate of the Past, 8, 1929, 2012. 
Pörtner, H., Roberts, D., Masson-Delmotte, V., Zhai, P., Tignor, M., Poloczanska, E., Mintenbeck, K., Nicolai, M., Okem, A., Petzold, J., et al.: IPCC, 2019: Summary for Policymakers, IPCC Special Report on the Ocean and Cryosphere in a Changing Climate, 2019.

Preece, S., McGimsey, R. G., Westgate, J., Pearce, N., Hart, W., and Perkins, W.: Chemical complexity and source of the White River Ash, Alaska and Yukon, Geosphere, 10, 1020-1042, 2014.

Press, W. H., Teukolsky, S. A., Vetterling, W. T., and Flannery, B. P.: Numerical Recipes in C: The Art of Scientific Computing (2d ed.; Cambridge), Cambridge Univ. Press, 1992.

Ram, M. and Koenig, G.: Continuous dust concentration profile of pre-Holocene ice from the Greenland Ice Sheet Project 2 ice core: Dust stadials, interstadials, and the Eemian, Journal of Geophysical Research: Oceans, 102, 26 641-26 648, 1997.

Ramsey, J. T. and Licht, A. L.: The comet of 44 BC and Caesar's funeral games, 39, Oxford University Press on Demand, 1997.

Rasmussen, S. O.: Improvement, dating and analysis of Greenland ice core stratigraphies, Ph.D. thesis, Niels Borh Institute, 2006.

Rasmussen, S. O., Andersen, K. K., Svensson, A. M., Steffensen, J. P., Vinther, B. M., Clausen, H. B., Siggaard-Andersen, M.-L., Johnsen, S. J., Larsen, L. B., Dahl-Jensen, D., Bigler, M., Röthlisberger, R., Fischer, H., Goto-Azuma, K., Hansson, M. E., and Ruth, U.: A new Greenland ice core chronology for the last glacial termination, Journal of Geophysical Research: Atmospheres, 111, doi: 10.1029/2005JD006079, URL https://agupubs.onlinelibrary.wiley.com/doi/abs/10.1029/ 2005JD006079, 2006

Rasmussen, S. O., Abbott, P. M., Blunier, T., Bourne, A. J., Brook, E., Buchardt, S. L., Buizert, C., Chappellaz, J., Clausen, H. B., Cook, E., Dahl-Jensen, D., Davies, S. M., Guillevic, M., Kipfstuhl, S., Laepple, T., Seierstad, I. K., Severinghaus, J. P., Steffensen, J. P., Stowasser, C., Svensson, A., Vallelonga, P., Vinther, B. M., Wilhelms, F., and Winstrup, M.: A first chronology for the North Greenland Eemian Ice Drilling (NEEM) ice core, Climate of the Past, 9, 2713-2730, doi: 10.5194/cp-9-2713-2013, URL https://www.clim-past.net/9/2713/2013/, 2013.

Reimer, P.J., Bard, E., Bayliss, A., Beck, J. W., Blackwell, P. G., Ramsey, C. B., Buck, C. E., Cheng, H., Edwards, R. L., Friedrich, M., and et al.: IntCal13 and Marine13 Radiocarbon Age Calibration Curves 0-50,000 Years cal BP, Radiocarbon, 55, 1869-1887, doi: 10.2458/azu_js_rc.55.16947, 2013.

Richter-Menge, J., Overland, J., Mathis, J., and Osborne, E.: Arctic Report Card 2017 https://arctic. noaa. gov/Report-Card, Report-Card-2017, URL https://arctic.noaa.gov/Report-Card, 2017.

Richter-Menge, J., M. L. D. and M. Jeffries, E.: Arctic Report Card 2019 https://arctic. noaa. gov/Report-Card, ReportCard-2019, URL https://arctic.noaa.gov/Report-Card/ Report-Card-2019, 2019.
Rignot, E. and Mouginot, J.: Ice flow in Greenland for the International Polar Year 2008-2009, Geophysical Research Letters, 39, doi: 10.1029/2012GL051634, URL https://agupubs. onlinelibrary.wiley.com/doi/abs/10.1029/2012GL051634, 2012.

Rippin, D., Bingham, R., Jordan, T., Wright, A., Ross, N., Corr, H., Ferraccioli, F., Brocq, A. L., Rose, K., and Siegert, M.: Basal roughness of the Institute and Möller Ice Streams, West Antarctica: Process determination and landscape interpretation, $\mathrm{Ge}-$ omorphology, 214, 139 - 147, doi: https://doi.org/10.1016/ j.geomorph.2014.01.021, URL http://www.sciencedirect.com/ science/article/pii/S0169555X14000671, 2014.

Riverman, K. L., Alley, R. B., Anandakrishnan, S., Christianson, K., Holschuh, N. D., Medley, B., Muto, A., and Peters, L. E.: Enhanced Firn Densification in High-Accumulation Shear Margins of the NE Greenland Ice Stream, Journal of Geophysical Research: Earth Surface, 124, 365-382, doi: 10.1029/ 2017JF004604, URL https://agupubs.onlinelibrary.wiley.com/ doi/abs/10.1029/2017JF004604, 2019.

Robin, G. d. Q.: Radio-Echo Sounding: Glaciological Interpretations and Applications, Journal of Glaciology, 15, 49-64, doi: 10.3189/S0022143000034262, 1975.

Rodriguez-Morales, F., Gogineni, S., Leuschen, C. J., Paden, J. D., Li, J., Lewis, C. C., Panzer, B., Gomez-Garcia Alvestegui, D., Patel, A., Byers, K., Crowe, R., Player, K., Hale, R. D., Arnold, E. J., Smith, L., Gifford, C. M., Braaten, D., and Panton, C.: Advanced Multifrequency Radar Instrumentation for Polar Research, IEEE Transactions on Geoscience and Remote Sensing, 52, 2824-2842, doi: 10.1109/TGRS.2013.2266415, 2014.

Rodriguez-Morales, F., Braaten, D., Trong Mai, H., Paden, J., Gogineni, P., Yan, J., Abe-Ouchi, A., Fujita, S., Kawamura, K., Tsutaki, S., Van Liefferinge, B., Matsuoka, K., and Steinhage, D.: A Mobile, Multichannel, UWB Radar for Potential Ice Core Drill Site Identification in East Antarctica: Development and First Results, IEEE Journal of Selected Topics in Applied Earth Observations and Remote Sensing, 13, 4836-4847, 2020.

Ruth, U., Wagenbach, D., Steffensen, J. P., and Bigler, M.: Continuous record of microparticle concentration and size distribution in the central Greenland NGRIP ice core during the last glacial period, Journal of Geophysical Research: Atmospheres, 108, doi: 10.1029/2002JD002376, URL https://agupubs. onlinelibrary.wiley.com/doi/abs/10.1029/2002JD002376, 2003.

Sadori, L. and Narcisi, B.: The Postglacial record of environmental history from Lago di Pergusa, Sicily, The Holocene, 11, 655-671, 2001.

Schmidt, G., Jungclaus, J. H., Ammann, C., Bard, E., Braconnot, P., Crowley, T., Delaygue, G., Joos, F., Krivova, N., Muscheler, R., et al.: Climate forcing reconstructions for use in PMIP simulations of the Last Millennium (v1.1), Geoscientific Model Development, pp. 185-191, 2012. 
Schoof, C.: Ice sheet grounding line dynamics: Steady states, stability, and hysteresis, Journal of Geophysical Research: Earth Surface, 112, doi: 10.1029/2006JF000664, URL https://agupubs.onlinelibrary.wiley.com/doi/abs/10.1029/ 2006JF000664, 2007.

Schroeder, D. M., Dowdeswell, J. A., Siegert, M. J., Bingham, R. G., Chu, W., MacKie, E. J., Siegfried, M. R., Vega, K. I., Emmons, J. R., and Winstein, K.: Multidecadal observations of the Antarctic ice sheet from restored analog radar records, Proceedings of the National Academy of Sciences, doi: 10.1073/pnas. 1821646116, URL https://www.pnas.org/content/early/2019/ 08/27/1821646116, 2019.

Schroeder, D. M., Bingham, R. G., Blankenship, D. D., Christianson, K., Eisen, O., Flowers, G. E., Karlsson, N. B., Koutnik, M. R., Paden, J. D., Siegert, M. J., and et al.: Five decades of radioglaciology, Annals of Glaciology, p. 1-13, doi: 10.1017/aog. 2020.11, 2020.

Seierstad, I. K., Abbott, P. M., Bigler, M., Blunier, T., Bourne, A. J., Brook, E., Buchardt, S. L., Buizert, C., Clausen, H. B., Cook, E., Dahl-Jensen, D., Davies, S. M., Guillevic, M., Johnsen, S. J., Pedersen, D. S., Popp, T. J., Rasmussen, S. O., Severinghaus, J. P., Svensson, A., and Vinther, B. M.: Consistently dated records from the Greenland GRIP, GISP2 and NGRIP ice cores for the past $104 \mathrm{ka}$ reveal regional millennial-scale $\delta 18 \mathrm{O}$ gradients with possible Heinrich event imprint, Quaternary Science Reviews, 106, 29 - 46, doi: https://doi.org/10.1016/ j.quascirev.2014.10.032, URL http://www.sciencedirect.com/ science/article/pii/S027737911400434X, dating, Synthesis, and Interpretation of Palaeoclimatic Records and Model-data Integration: Advances of the INTIMATE project(INTegration of Ice core, Marine and TErrestrial records, COST Action ES0907, 2014.

Serreze, M. C., Barrett, A. P., and Stroeve, J.: Recent changes in tropospheric water vapor over the Arctic as assessed from radiosondes and atmospheric reanalyses, Journal of Geophysical Research: Atmospheres, 117, doi: 10.1029/ 2011JD017421, URL https://agupubs.onlinelibrary.wiley.com/ doi/abs/10.1029/2011JD017421, 2012.

Seu, R., Phillips, R. J., Biccari, D., Orosei, R., Masdea, A., Picardi, G., Safaeinili, A., Campbell, B. A., Plaut, J. J., Marinangeli, L., Smrekar, S. E., and Nunes, D. C.: SHARAD sounding radar on the Mars Reconnaissance Orbiter, Journal of Geophysical Research: Planets, 112, doi: 10.1029/2006JE002745, URL https://agupubs.onlinelibrary. wiley.com/doi/abs/10.1029/2006JE002745, 2007.

Shepherd, A., Ivins, E., Rignot, E., Smith, B., van den Broeke, M., Velicogna, I., Whitehouse, P., Briggs, K., Joughin, I., Krinner, G., Nowicki, S., Payne, T., Scambos, T., Schlegel, N., Geruo, A., Agosta, C., Ahlstrøm, A., Babonis, G., Barletta, V. R., Bjørk, A. A., Blazquez, A., Bonin, J., Colgan, W., Csatho, B., Cullather, R., Engdahl, M. E., Felikson, D., Fettweis, X., Forsberg, R., Hogg, A. E., Gallee, H., Gardner, A., Gilbert, L., Gourmelen, N., Groh, A., Gunter, B., Hanna, E., Harig, C., Helm, V.,
Horvath, A., Horwath, M., Khan, S., Kjeldsen, K. K., Konrad, H., Langen, P. L., Lecavalier, B., Loomis, B., Luthcke, S., McMillan, M., Melini, D., Mernild, S., Mohajerani, Y., Moore, P., Mottram, R., Mouginot, J., Moyano, G., Muir, A., Nagler, T., Nield, G., Nilsson, J., Noël, B., Otosaka, I., Pattle, M. E., Peltier, W. R., Pie, N., Rietbroek, R., Rott, H., Sørensen, L. S., Sasgen, I., Save, H., Scheuchl, B., Schrama, E., Schröder, L., Seo, K.-W., Simonsen, S. B., Slater, T., Spada, G., Sutterley, T., Talpe, M., Tarasov, L., Jan van de Berg, W., van der Wal, W., van Wessem, M., Vishwakarma, B. D., Wiese, D., Wilton, D., Wagner, T., Wouters, B., Wuite, J., and Team, T. I.: Mass balance of the Greenland Ice Sheet from 1992 to 2018, Nature, doi: 10.1038/s41586-019-1855-2, URL https://doi.org/10. 1038/s41586-019-1855-2, 2019.

Siegert, M. J., Welch, B., Morse, D., Vieli, A., Blankenship, D. D., Joughin, I., King, E. C., Vieli, G. J.-M. C. L., Payne, A. J., and Jacobel, R.: Ice Flow Direction Change in Interior West Antarctica, Science, 305, 1948-1951, doi: 10.1126/science.1101072, URL https://science.sciencemag.org/content/305/5692/1948, 2004.

Sigl, M., McConnell, J. R., Layman, L., Maselli, O., McGwire, K., Pasteris, D., Dahl-Jensen, D., Steffensen, J. P., Vinther, B., Edwards, R., et al.: A new bipolar ice core record of volcanism from WAIS Divide and NEEM and implications for climate forcing of the last 2000 years, Journal of Geophysical Research: Atmospheres, 118, 1151-1169, 2013.

Sigl, M., Winstrup, M., McConnell, J. R., Welten, K. C., Plunkett, G., Ludlow, F., Büntgen, U., Caffee, M., Chellman, N., DahlJensen, D., et al.: Timing and climate forcing of volcanic eruptions for the past 2,500 years, Nature, 523, 543-549, 2015.

Smith-Johnsen, S., de Fleurian, B., Schlegel, N., Seroussi, H., and Nisancioglu, K.: Exceptionally high heat flux needed to sustain the Northeast Greenland Ice Stream, The Cryosphere, 14, 841854, doi: 10.5194/tc-14-841-2020, URL https://tc.copernicus. org/articles/14/841/2020/, 2020.

Stocker, T., Qin, D., Plattner, G.-K., Alexander, L., Allen, S., Bindoff, N., Breon, F.-M., Church, J., Cubasch, U., Emori, S., Forster, P., Friedlingstein, P., Gillett, N., Gregory, J., Hartmann, D., Jansen, E., Kirtman, B., Knutti, R., Krishna Kumar, K., Lemke, P., Marotzke, J., Masson-Delmotte, V., Meehl, G., Mokhov, I., Piao, S., Ramaswamy, V., Randall, D., Rhein, M., Rojas, M., Sabine, C., Shindell, D., Talley, L., Vaughan, D., and Xie, S.-P.: Technical Summary, book section TS, p. 33-115, Cambridge University Press, Cambridge, United Kingdom and New York, NY, USA, doi: 10.1017/CBO9781107415324.005, URL www.climatechange2013.org, 2013.

Stothers, R. B. and Rampino, M. R.: Volcanic eruptions in the Mediterranean before AD 630 from written and archaeological sources, Journal of Geophysical Research: Solid Earth, 88, 6357-6371, 1983. 
Stuecker, M. F., Bitz, C. M., Armour, K. C., Proistosescu, C., Kang, S. M., Xie, S.-P., Kim, D., McGregor, S., Zhang, W., Zhao, S., Cai, W., Dong, Y., and Jin, F.-F.: Polar amplification dominated by local forcing and feedbacks, Nature Climate Change, 8 , 1076-1081, doi: 10.1038/s41558-018-0339-y, URL https://doi. org/10.1038/s41558-018-0339-y, 2018.

Svensson, A., Andersen, K. K., Bigler, M., Clausen, H. B., DahlJensen, D., Davies, S. M., Johnsen, S. J., Muscheler, R., Rasmussen, S. O., Röthlisberger, R., Steffensen, J. P., and Vinther, B.: The Greenland Ice Core Chronology 2005, 15-42ka. Part 2: comparison to other records, Quaternary Science Reviews, 25, 3258 - 3267, doi: https://doi.org/10.1016/j.quascirev.2006.08. 003, URL http://www.sciencedirect.com/science/article/pii/ S0277379106002599, critical Quaternary Stratigraphy, 2006.

Svensson, A., Andersen, K. K., Bigler, M., Clausen, H. B., DahlJensen, D., Davies, S. M., Johnsen, S. J., Muscheler, R., Parrenin, F., Rasmussen, S. O., Röthlisberger, R., Seierstad, I., Steffensen, J. P., and Vinther, B. M.: A 60000 year Greenland stratigraphic ice core chronology, Climate of the Past, 4, 47-57, doi: 10.5194/cp-4-47-2008, URL https://www.clim-past.net/ 4/47/2008/, 2008.

Tan, M., Liu, T., Hou, J., Qin, X., Zhang, H., and Li, T.: Cyclic rapid warming on centennial-scale revealed by a 2650 -year stalagmite record of warm season temperature, Geophysical Research Letters, 30, 2003.

Tapley, B. D., Watkins, M. M., Flechtner, F., Reigber, C., Bettadpur, S., Rodell, M., Sasgen, I., Famiglietti, J. S., Landerer, F. W., Chambers, D. P., Reager, J. T., Gardner, A. S., Save, H., Ivins, E. R., Swenson, S. C., Boening, C., Dahle, C., Wiese, D. N., Dobslaw, H., Tamisiea, M. E., and Velicogna, I.: Contributions of GRACE to understanding climate change, Nature Climate Change, 9, 358-369, doi: 10.1038/s41558-019-0456-2, URL https://doi.org/10.1038/s41558-019-0456-2, 2019.

Taylor, K. C., Alley, R. B., Lamorey, G. W., and Mayewski, P.: Electrical measurements on the Greenland Ice Sheet Project 2 core, Journal of Geophysical Research: Oceans, 102, 26511-26517, 1997.

Thompson, D.: Cleopatra queen of Egypt, Ancient Hist, 17, 11-15, 2018.

Toohey, M. and Sigl, M.: Volcanic stratospheric sulphur injections and aerosol optical depth from 500 BCE to 1900 CE, Earth System Science Data, 9, 809-831, 2017.

Turner, J., Lu, H., White, I., King, J. C., Phillips, T., Hosking, J. S., Bracegirdle, T. J., Marshall, G. J., Mulvaney, R., and Deb, P.: Absence of 21st century warming on Antarctic Peninsula consistent with natural variability, Nature, 535, 411-415, doi: 10 . 1038/nature18645, URL https://doi.org/10.1038/nature18645, 2016.
Urbini, S., Frezzotti, M., Gandolfi, S., Vincent, C., Scarchilli, C., Vittuari, L., and Fily, M.: Historical behaviour of Dome C and Talos Dome (East Antarctica) as investigated by snow accumulation and ice velocity measurements, Global and Planetary Change, 60, 576 - 588, doi: https://doi.org/10.1016/ j.gloplacha.2007.08.002, URL http://www.sciencedirect.com/ science/article/pii/S0921818107001221, 2008.

Vallelonga, P., Christianson, K., Alley, R. B., Anandakrishnan, S., Christian, J. E. M., Dahl-Jensen, D., Gkinis, V., Holme, C., Jacobel, R. W., Karlsson, N. B., Keisling, B. A., Kipfstuhl, S., Kjær, H. A., Kristensen, M. E. L., Muto, A., Peters, L. E., Popp, T., Riverman, K. L., Svensson, A. M., Tibuleac, C., Vinther, B. M., Weng, Y., and Winstrup, M.: Initial results from geophysical surveys and shallow coring of the Northeast Greenland Ice Stream (NEGIS), The Cryosphere, 8, 1275-1287, doi: 10. 5194/tc-8-1275-2014, URL https://www.the-cryosphere.net/ 8/1275/2014/, 2014.

Veres, D., Bazin, L., Landais, A., Toyé Mahamadou Kele, H., Lemieux-Dudon, B., Parrenin, F., Martinerie, P., Blayo, E., Blunier, T., Capron, E., Chappellaz, J., Rasmussen, S. O., Severi, M., Svensson, A., Vinther, B., and Wolff, E. W.: The Antarctic ice core chronology (AICC2012): an optimized multi-parameter and multi-site dating approach for the last 120 thousand years, Climate of the Past, 9, 1733-1748, doi: 10.5194/cp-9-1733-2013, URL https://www.clim-past.net/9/ 1733/2013/, 2013.

Vinther, B. M., Clausen, H. B., Johnsen, S. J., Rasmussen, S. O., Andersen, K. K., Buchardt, S. L., Dahl-Jensen, D., Seierstad, I. K., Siggaard-Andersen, M.-L., Steffensen, J. P., Svensson, A., Olsen, J., and Heinemeier, J.: A synchronized dating of three Greenland ice cores throughout the Holocene, Journal of Geophysical Research: Atmospheres, 111, doi: 10.1029/2005JD006921, URL https://agupubs.onlinelibrary. wiley.com/doi/abs/10.1029/2005JD006921, 2006.

Vogel, H., Zanchetta, G., Sulpizio, R., Wagner, B., and Nowaczyk, N.: A tephrostratigraphic record for the last glacial-interglacial cycle from Lake Ohrid, Albania and Macedonia, Journal of Quaternary Science: Published for the Quaternary Research Association, 25, 320-338, 2010.

Wang, Z., Gogineni, S., Rodriguez-Morales, F., Yan, J. B., Hale, R., Paden, J., Leuschen, C., Carabajal, C., Gomez-Garcia, D., Townley, B., Willer, R., Stearns, L., Child, S., and Braaten, D.: Wideband imaging radar for cryospheric remote sensing, International Geoscience and Remote Sensing Symposium (IGARSS), pp. 4026-4029, doi: 10.1109/IGARSS.2014.6947369, 2014.

Wastegård, S., Johansson, H., and Pacheco, J. M.: New major element analyses of proximal tephras from the Azores and suggested correlations with cryptotephras in North-West Europe, Journal of Quaternary Science, 35, 114-121, 2020.

Wilhelms, F.: Leitfähigkeits- und Dichtemessung an Eisbohrkernen $=$ Measuring the conductivity and density of ice cores, Berichte 
zur Polarforschung (Reports on Polar Research), Bremerhaven, Alfred Wegener Institute for Polar and Marine Research, 191, 224 p. . doi: 10.2312/BzP_0191_1996, 1996.

Wilhelms, F.: Messung dielektrischer Eigenschaften polarer Eiskerne $=$ Measuring the dielectric properties of polar ice cores , Berichte zur Polarforschung (Reports on Polar Research), Bremerhaven, Alfred Wegener Institute for Polar and Marine Research, 367, 171 p. . doi: 10.2312/BzP_0367_2000, 2000.

Wilhelms, F.: Explaining the dielectric properties of firn as a densityand-conductivity mixed permittivity (DECOMP), Geophysical Research Letters, 32, doi: 10.1029/2005GL022808, URL https://agupubs.onlinelibrary.wiley.com/doi/abs/10.1029/ 2005GL022808, 2005.

Wilhelms, F., Kipfstuhl, J., Miller, H., Heinloth, K., and Firestone, J.: Precise dielectric profiling of ice cores: a new device with improved guarding and its theory, Journal of Glaciology, 44, 171174, doi: 10.3189/S002214300000246X, 1998.

Winski, D. A., Fudge, T. J., Ferris, D. G., Osterberg, E. C., Fegyveresi, J. M., Cole-Dai, J., Thundercloud, Z., Cox, T. S., Kreutz, K. J., Ortman, N., Buizert, C., Epifanio, J., Brook, E. J., Beaudette, R., Severinghaus, J., Sowers, T., Steig, E. J., Kahle, E. C., Jones, T. R., Morris, V., Aydin, M., Nicewonger, M. R., Casey, K. A., Alley, R. B., Waddington, E. D., Iverson, N. A., Dunbar, N. W., Bay, R. C., Souney, J. M., Sigl, M., and McConnell, J. R.: The SP19 chronology for the South Pole Ice Core - Part 1: volcanic matching and annual layer counting, Climate of the Past, 15, 1793-1808, doi: 10.5194/cp-15-1793-2019, URL https://www.clim-past.net/15/1793/2019/, 2019.

Winter, A., Steinhage, D., Arnold, E. J., Blankenship, D. D., Cavitte, M. G. P., Corr, H. F. J., Paden, J. D., Urbini, S., Young, D. A., and Eisen, O.: Comparison of measurements from different radio-echo sounding systems and synchronization with the ice core at Dome C, Antarctica, The Cryosphere, 11, 653-668, doi: 10.5194/tc-11-653-2017, URL https://www. the-cryosphere.net/11/653/2017/, 2017.
Winter, A., Steinhage, D., Creyts, T. T., Kleiner, T., and Eisen, O.: Age stratigraphy in the East Antarctic Ice Sheet inferred from radio-echo sounding horizons, Earth System Science Data, 11, 1069-1081, doi: 10.5194/essd-11-1069-2019, URL https:// www.earth-syst-sci-data.net/11/1069/2019/, 2019.

Wolff, E. W., Moore, J. C., Clausen, H. B., and Hammer, C. U.: Climatic implications of background acidity and other chemistry derived from electrical studies of the Greenland Ice Core Project ice core, Journal of Geophysical Research: Oceans, 102, 26325 $26332,1997$.

Wolff, E. W., Cook, E., Barnes, P. R., and Mulvaney, R.: Signal variability in replicate ice cores, Journal of Glaciology, 51, 462-468, doi: 10.3189/172756505781829197, 2005.

Wolff, E. W., Chappellaz, J., Blunier, T., Rasmussen, S. O., and Svensson, A.: Millennial-scale variability during the last glacial: The ice core record, Quaternary Science Reviews, 29, 2828 - 2838, doi: https://doi.org/10.1016/j.quascirev.2009.10. 013, URL http://www.sciencedirect.com/science/article/pii/ S0277379109003588, vegetation Response to Millennial-scale Variability during the Last Glacial, 2010.

Zhong, Y., Jahn, A., Miller, G., and Geirsdottir, A.: Asymmetric Cooling of the Atlantic and Pacific Arctic During the Past Two Millennia: A Dual Observation-Modeling Study, Geophysical Research Letters, 45, 12-497, 2018.

Zielinski, G. A. and Mershon, G. R.: Paleoenvironmental implications of the insoluble microparticle record in the GISP2 (Greenland) ice core during the rapidly changing climate of the Pleistocene-Holocene transition, Geological Society of America Bulletin, 109, 547-559, 1997.

Zielinski, G. A., Mayewski, P. A., Meeker, L. D., Whitlow, S., Twickler, M. S., Morrison, M., Meese, D. A., Gow, A. J., and Alley, R. B.: Record of volcanism since 7000 BC from the GISP2 Greenland ice core and implications for the volcano-climate system, Science, 264, 948-952, 1994. 